\title{
PACKAGING REVIEW GUIDE FOR REVIEWING \\ SAFETY ANALYSIS REPORTS FOR PACKAGINGS \\ REVISION 1
}

October 1988

Prepared by

L.E. Fischer, C.K. Chou, W.R. Lloyd, M.E. Mount,

T.A. Nelson, M.W. Schwartz, M.C. Witte

Lawrence Livermore National Laboratory

7000 East Avenue

Livermore, California 94550

Prepared for

Office of Security Evaluation U.S. Department of Ener:y Germantown, Maryland

\section{DISCLAIMER}

This report was prepared as an accounl of work spunsorod by an agency of the United States the as an account of work spunsor any of their Government. Neither the United States Government nor any ageney thes liability or respunsiemployees, makes any warranty, express or implied, or ass information, appasatus, product, or bility for the aceurgey. completeness. Or usefulness of any inforiste privately owned nghts. Referprocess disclosed, or represents that its use would not in tringe privalely owned righe trademark. ence herein to any specific commercial product, process, or service by its entorsement, recommanufacturer, or otherwise dies not necessarily constitule or imply its endosement. The views raendation, of favoring by the United States Government or any agency thetcol. The vicws and cpinions of authors expressed. hercin do no United States Government or asy agericy thercof. 


\begin{abstract}
The Department of Energy (DOE) has established procedures for obtaining certification of packagings used hy DOE and its contractors for the transport of radioactive materials. These certification retiew policies and procedures are established to ensure that DOE packaging designs and operations meet safety criteria at least equivalent to the standards prescribed by the Nuclear Regulatory Commission (NRC) certification process for packaging. The Packaging Review Guide (PRG) is not a DOE Order but has been prepared as guidance for the Packaging Certification Staff (PCS) under the Certifying Official, Office of Security Evaluations, or designated representatives. The principal purpose of the PRG is to assure the quality and uniformity of PCS reviews and to present a well-defined base from which to evaluate proposed changes in the scope and requirements of reviews. The PRG also sets forth solutions and approaches determined to be acceptable in the past by the PCS in dealing with a specific safety issue or safetyrelated design area. These solutions and approaches are presented in this form so that reviewers can take consistent and well-understood positions as the same safety issues arise in future cases. An applicant submitting a SARP does not have to follow the solutions or approaches presented in the PRG. However, applicants should recognize that the PCS has spent substantial time and effort in reviewing and developing their positions for the issues. A correspending amount of time and effort will probably be required to review and accept new or different solutions and approaches. Finally, it is alsc a purpose of the PRG to make information about DOE certification policy and procedures widely available to DOE field offices, DOE contractors, federal agencies, and interested members of the public.
\end{abstract}




\section{SUMMARY OF CHANGES}

Summary of Major Changes Made in Revision 1 of the Packaging Review Guide

1. Added draft Section 11.0, "Review of Quality Assurance Requirements. Revised Section 2.0 to make it consistent and compatible.

2. Added draft Appendix A, "Review of Special Form Radioactive Material." Revised Sections 4.0.5.0, and 6.0 to make them consistent and compatible.

3. Added guidance in Section 6.0 for reviewing enclosures for valves and other devices which penetrate the containment boundary. 
Section Title

Abstract.

Summary of Changes

List of Figures

List of Tables

Acknowledgments

1.0 INTRODUCTION

1.1 Purpose

1.2 Scope

1.3 Definitions

1.4 Approach

1.5 Packaging Review Guide (PRG) Sections

1.6 PE kaging Review Guide (PRG) Subsections

1.6.1 General

1.6.2 Areas of Review

1.6.3 Acceptance Criteria

1.6.4 Procedures

1.6.5 Findings

1.6.6 References

1.7 Packaging Review Guide (PRG) Revisions

1.8 References
Page Rev.

No. No.

ii

xy 1

xvi 1

1-2 0

$1-2 \quad 0$

$13 \quad 1$

1.11. 0

1-14 1

1-14 1

1-15 0

1-16 0

1-16 0

1-16 0

1-16 0

1-16 0

1-17 0

1-17 0

20 REVIEW OF GENERAL INFORMATION

21 General

2.1.1 Quality Standards and Assurance

2.1.1.1 Safety Classification

2.1.1.2 Package Categories

2.1.1.3 Quality Standards

$$
\begin{array}{ll}
\text { 2.1.1.3.1 } & \text { Category I } \\
\text { 2.1.1.3.2 } & \text { Category II } \\
\text { 2.1.1.3.3 } & \text { Category III }
\end{array}
$$

2.2 Areas of Review

2.2.1 Use of Packaging

2.2.2 Packaging Description

2.2.3 Operational Features

2.2.4 Contents of Packaging

2.2.5 Package Evaluation

2.2.6 Quality Standards

2.2.7 Supplemental Information

2.3 Acceptance Criteria

2.3.1 Use of Package

2.3.2 Packaging Description

2.3.3 Operational Features

2.3.4 Conienis of Packaging

2.3.5 Pacikage Evaluation

2.3.6 Quality Standards

24 Proceclures

2.4.1 Ise of Packaging

2.4.2 Packaging Description

2.4.2.1 Ceneral

2.4.2.2 Driwings 
2.4.3 Operational Features

2.4.4 Contents of Packaging

2-10

2-10

2.4.5 Packaging Evaluation

2-10

2.4.6 Quality Standards

2-10

2.4.7 Supplemental Information

2.5 Findings

2.6 References

2-10

2-11

2-11

0
0
0
0
0
0
0

3.0 REVIEW OF MATERIAL AND FABRICATION

SPECIFICATIONS

3.1 General

32 Areas of Review

3.2.1 Material Properties

3.2.2 Fracture Resistance

3.2.3 Packaging Fasteners

3.2.4 Fabrication and Processing of Package Components

3.3 Acceptance Criteria

3.3.1 Material Properties

3.3.2 Fracture Resistance

3.3.2.1 Material Selection

Criteria

3.3.2.2 Fracture Resistance by Analysis

3.3.2.3 Fracture Resistance Demonstrated by Prototype Testing

3.3.3 Packaging Fasteners

3.4 Procedures

3.4.1 Material Properties

3.4.1.1 Material Specification

3.4.1.2 Special Processes Used for Manufacture and Fabrication of Components

3.4.1.3 Corrosion Resistance

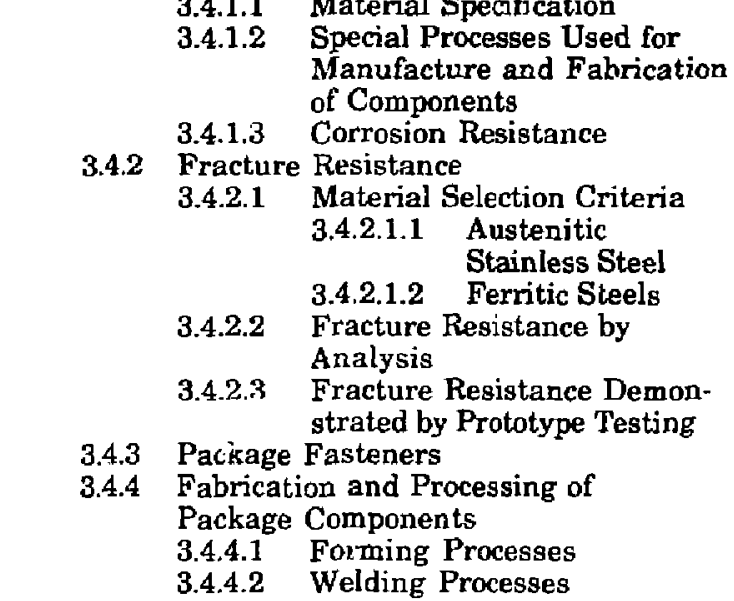

3.5 Eindings

$\begin{array}{ll}\text { 3.4.4.1 } & \text { Forming Processes } \\ \text { 3.4.4.2 } & \text { Welding Processes }\end{array}$

3.6 References

4.0 REVIEW OI STRUCTURAL EVALUATION

4.1 General
4.1.1 Structural Design Criteria
4.1.1.1 Discussion

$\begin{array}{ll}4-1 & 0 \\ 4-2 & 0 \\ 4-2 & 0\end{array}$


4.1.1.2 Stress Intensity

4.1.1.3 Stress Classification

4.1.1.4 Regulatory Guides

4.1.1.5 Design Criteria

4.1.2 Methods of Analysis

4.1.2.1 Penetration and Puncture 4.1.2.2 Impact

4.1.3 Special Form

4.2 Areas of Review

4.2.1 Structural Design

4.2.2 Weights and Centers of Gravity

4.2.3 Mechanical Properties of Materials

4.2.4 General Standards for All Packages

4.2.5 Lifting and Tie-down Standards for all Packages

4.2.6 Normal Conditions of Transport

4.2.7 Hypothetical Accident Conditions

4.2.8 Special Form

4.2.9 Fuel Rods

4.2.10 Appendix

4.3 Acceptance Criteria

4.3.1 Structural Design

4.3.1.1 Discussion

4.3.1.2 Design Criteria

4.3.2 Weights and Centers of Gravity

4.3.3 Mechanical Properties of Materials

4.3.4 General Standards for All Packages

4.3.5 Lifting and Tie-Down Standards for

All Packages

4.3.5.1 Lifting Devices

4.3.5.2 Tie-Down Devices

4.3.6 Normal Conditions of Transport

4.3.6.1 Heat

4.3.6.2 Cold

4.3.6.3 Reduced External Pressure

4,3.6.4 Increased External Pressure

4.3.6.5 Vibration

4.3.6.6 Water Spray

4.3.6.7 Fiee Drop

4.3.6.8 Cozner Irop

4.3.6.9 Compression

4.3.6.10 Penetration

4.3.7 Hypothetical Accident Conditions

4.3.7.1 Free Drop

4.3.7.2 Puncture

4.3.7.5 Thermal

4.3.7.4 Immersion-Fissile

Material

4.3.7.5 Immersion-All Packages

4.3.7.6 Summary of Package

4.3.8 Special Form

4.3.8.1 Contents

4.3.8.2 Packaging

4.3.9 Fue! Rod

4.3.10 Appendices

4-6

4-6

4-6

$4-8$

4-8a

4-8a

4-8a

4-8a

4-9

$4-9$

4-9

4-9

4-9

4-9a

4-10

4-10

4-10

4-10

4-10

4-11

4-11

4-11

4-12

4-12

4-12

4-13

4-14

4-15

4-15

4-15

4-15

4-15

4-15

4-16

4-16

4-16

4-16

4-17

4-17

4-17

4-18

4-18 1

4-18

4-18

4-18

4-18

4-18a

4-18a

Rev. 1, October 1988 
4.4.1 Structural Design

$$
\begin{array}{ll}
\text { 4.4.1.1 } & \text { Discussion } \\
\text { 4.4.1.2 } & \text { Design Criteria }
\end{array}
$$

4.4.2 Weights and Centers of Gravity

4.4.3 Mechanical Properties of Materials

4.4.4 General Standards for All Packages

4.4.5 Lifting and Tie-Down Standards for

All Packages

4.4.5.1 Lifting Devices

4.4.5.2 Tie-Down Devices

$4.4 j$ Normal Conditions of Tran-port

Transport

4.4.6.l Heat

$$
\begin{array}{cl}
\text { 4.4.6.1.1 } & \begin{array}{l}
\text { Summary of } \\
\text { Pressures and } \\
\text { Temperatures } \\
\text { Differential } \\
\text { Thermal Expansion }
\end{array} \\
\text { 4.4.6.1.3 } & \begin{array}{l}
\text { Stress } \\
\text { Calculations } \\
\text { Comparison with } \\
\text { Allowable } \\
\text { Stresses }
\end{array}
\end{array}
$$

4.4.6.2 Cold

4.4.6.3 Reducnd External Pressure

4.4.6.4 Increased External Pressure

4.4.6.5 Vibration

4.4.6.6 Water Spray

4.4.6.7 Free Drop

4.4.6.8 Corner Drop

4.4.6.9 Compression

4.4.6.10 Penetration

4.4.7 Hypothetical Accident Conditions

4.4.7.1 Free Drop

$$
\begin{array}{ll}
\text { 4.4.7.1.1 } & \text { End Drop } \\
\text { 4.4.7.1.2 } & \text { Side Drop } \\
\text { 4.4.7.1.3 } & \text { Corner Drop } \\
\text { 4.4.7.1.4 } & \text { Oblique Drop } \\
\text { 4.4.7.1.5 } & \text { Summary of } \\
& \text { Results }
\end{array}
$$

$4-22 \quad 0$

4-22
4.4.7.3.2 Difierential
Thermal Expansion

\subsection{Stress}

\section{Calculations}

4.4.7.3.4 Comparison with

Allowable Stresses

\subsubsection{4 limmersion$$
\text { Material }
$$

4.4.7.5 Immersion-A]l Packages

$\begin{array}{ll}4-27 & 0 \\ 4-27 & 0 \\ 4-27 & 0 \\ 4-27 & 0 \\ -28 & 0 \\ 4-28 & 0 \\ 4-28 & 0 \\ 4-28 & 0\end{array}$




$\begin{array}{llll} & 4.4 .7 .6 \quad \text { Summary of Damage } & 4-28 & 0 \\ 4.4 .8 & \text { Special Form } & 4-28 & 0 \\ & 4.4 .8 .1 \quad \text { Contents } & 4-29 & 1 \\ & 4.4 .8 .2 \text { Packaging } & 4-29 & 1 \\ 4.4 .9 \text { Fuel Rods } & 4-29 & 1 \\ 4.4 .10 \text { Appendix } & 4-29 \mathrm{a} & 1 \\ 4.5 & \text { Findings } & 4-29 \mathrm{a} & 1 \\ 4.6 & \text { References } & 4-29 \mathrm{a} & 1\end{array}$

5.0 REVIEW OF THERMAL EVALUATION

5.1 General

5.1.1 Methods of Analysis

$\begin{array}{ll}\mathbf{5 - 1} & 0 \\ 5-2 & 0 \\ 5-2 & 0 \\ 5-3 & 0 \\ 5-4 & 1 \\ 5-6 & 1 \\ 5-6 a & 1 \\ 5-7 & 0 \\ 5-7 & 0 \\ 5-7 & 0\end{array}$

5.1.2 Computer Cades

$\begin{array}{ll}\text { 5.1.1.1 } & \text { Scoping Calculations } \\ \text { 5.1.1.2 } & \text { Pressure Calculations }\end{array}$

5.1.3 Special Form

5.2 Areas of Review

5.2.1 Discussion

5.2.2 Thermal Properties of Materials

5.2.3 Thermal Specifications on Packaging Components and Parts

5.2.4 Thermal Evaluation for Normal

$5-7 \quad 0$

5.2.5 Hypothetical Accident Thermal

581

5.2.6 Special Form

$5-8 \quad 1$

5.2.7 Appendix

5.3 Acceptance Criteria

5.3.1 Discussion

5.3.1.1 Thermal Design Featuires

5.3.1.2 Test Standards

5.3.1.3 Maximum Allowable Surface

Temperature

5.3.1.4 Containment Pressure

5.3.1.5 Normal Transport

5.3.1.6 Hypothetical Accident

Conditions

5.3.1.7 Liquid Coolanto

5.3.2 Thermal Properties of Materials

5.3.3 Thermal Specifications on Packaging

Components and Parts

5.3.4 Thermal Evaluation of Normal

Conditions

53.5 Hypothetical Acciden! Thermal Conditions

5.5.6 Sperial Form

5.3.6.1 Contents

5.3.6.2 Packaging

5.3.7 Appendix

5.4 Procedures

5.4.1 Discussion

5.4.2 Thermal Properties of Materials

5.4.3 Thermal Specifications on Packaging

Components and Parts

5.4.4 Thermal Evaluation of Normal Conditions

$5-8$

5-8

5-8

5-8a 1

$5-9 \quad 0$

$5-9 \quad 0$

5-9 0

5-11 0

5-11 0

5-11 0

5-12 0

$5-13 \quad 1$

5-13 1

5-13 1

5-13 1

5-13a 1

5-13a 1

5-14 0

5-14 0

E-14 0

5-14 0

5-15 $\quad 0$ 
5.4.4.1 Thermal Model $\quad 5-15 \quad 0$

5.4.4.2 Test Model

5.4.4.3 Maximum and Minimum

$5-15$

$5-16$

0

Temperature
5.4.4.4 Maximum Internal Pressures

5-16 $\quad 0$

5.4.4.5 Maximum Thermal Stresses

5-16 0

5.4.4.6 Evaluation of Package

$5-16$

Performance

5.4.4.7 Documentation

5-17 $\quad 0$

5.4.5 Hypothetical Accident Thermal Evaluation

$5-17$

5-17

5.4.5.1 Thermal Model

5.4.5.2 Test Model

5.4.5.3 Package Conditions and

5-17 $\quad 0$

5-18 0

5.4.5.4 Package Temperature

5.4.5.5 Maximum Internal Pressures

5-18 $\quad 0$

5.4.5.6 Maximum Thermal Stresses

5.4.5.7 Evaluation of Package

5-18

5-19

5-19

\section{Performance}

5.4.5.8 Documentation

5-19 1

5.4.6 Special Form
5.4.6.1 Contents
5.4.6.2 Packaging

5.4.7 Appendix

5-19a

$5-19 a$

$5-19 a$

$5-20$

$5-20$

$5-20$

5.6 References

6.0 REVJEW OF CONTAINMENT EVALUATION

6.1 General

6.2 Areas of Review

6.2.1 Containment Boundary

6.2.2 Requirements for Normal Conditions of Transport

6.2.3 Requirements for Hypothetical Accident Conditions

6.2.4 Special Requirements for Plutonium Shipments

6.3 Acceptance Criteria

6.3.1 Containment Boundary

6.3.1.1 Containment Vessel

6.3.1.2 Containment Penetrations

6.3.1.3 Seals and Welds

6.3.1.4 Closure

6.3.2 Requirements for Normal Conditions of Transport

6.3.3 Requirements for Hypothe ical Accident Cconditions

6.5.4 Special Requirements for Plutonium Shipments

6.4 Procedures

6.4.1 Containment Boundary

6.4.1.1 Containment Vessel

6.4.1.2 Containment Penetraticns

6.4.1.3 Seals and Welds

6.4.1.4 Closure

$\begin{array}{ll}6-1 & 0 \\ 6-1 & 0 \\ 6-1 & 0 \\ 6-2 & 1 \\ 6-2 & 1 \\ 6-2 & 1 \\ 6-2 & 1 \\ 6-2 & 1 \\ 63 & 1 \\ 63 & 1 \\ 63 & 1 \\ 6-3 a & 1 \\ 6-3 a & 1 \\ 6-3 a & 1 \\ 6-4 & 1 \\ & \\ 6-4 & 1 \\ 6-4 & 1 \\ 64 & 1 \\ 64 & 1 \\ 65 & 1 \\ 65 & 1\end{array}$


6.4.2 Requirements for Normal Conditions of Transport

6.4.2.1 Containment of Radioactiv. Material

6.4.2.2 Pressurization of Containment Vessel

6.4.2.3 Containment Criterion

6.4.3 Requirements for Hypotbetical Accident Condicions

6.4.3.1 Containment of Radioactive Material

6.4.3.2 Fission Gas Products

6.4.3.3 Containment Criterion

6.4.4 Special Requirements for Plutonium Shipments

6.5 Findings

6.4.5 Appendix

6.5.1 Containment Boundary

6.5.2 Requirements for Normal Conditions of Transport

6.5.3 Requirements for Hypothetical Accident Conditions

6.5.4 Special Requirements for Plutonium

6.6 References Shipuents

7.0 REVIEW OF SHIELDING EVALUATION

7.1 General

7.1.1 Methods of Analysis

7.1.2 Computer Codes

72 Areas of Review

7.3 Acceptance Criteria

7.3.1 Normal Conditions of Transport

7.3.1.1 General Package Design

7.3.1.2 Exclusive Use Tranpnort

7.3.2 Hypotheti:al Accident Coubitions

7.4 Procedures

7.4.1 Discussion and Results

7.4.2 Source Specification

7.4.2.1 Gamma Source

7.4.2.2 Nesutron Source

7.4.3 Model Specification

7.4.3.1 Radial and Axial Shielding

Configuration

7.4.3.2 Shield Regional Densities

7.4.4 Shielding Evaluation

7.4.5 Appendix

7.5 Findings

7.6 References

$\begin{array}{ll}6-5 & 1 \\ 6-5 & 1 \\ 6-6 & 0 \\ 6-6 & 0 \\ 66 & 0 \\ 6-6 & 0 \\ 6-7 & 0 \\ 6-7 & 0 \\ 6-7 & 0 \\ 6-7 & 0 \\ 6-8 & 0 \\ 6-8 & 0 \\ 6-8 & 0 \\ 6-9 & 0 \\ 69 & 0 \\ 6-10 & 0\end{array}$

$7-1$

$7-2$

7.2

7.3

74

$\because 4$

74

$1 / 4$

75

75

7.5

76

76

76

$7-7$

$7 \%$

0

0

0

0 0

0

$7-8 \quad 0$

$788 \quad 0$

$7-9 \quad 0$

$7-9 \quad 0$

7-10 0

8.0 REVIEW OF CRITICALITY EVALUATION

8.1 General

8.2 Areas of Review

8.2.1 Discussion and Results

8.2.2 Package Fuel Loading

$\begin{array}{ll}8-1 & 0 \\ 83 & 0 \\ 83 & 0 \\ 83 & 0\end{array}$


8.2.3 Model Specification

8.2.3.1 Description of

Calculational Models

8.2.3.2 Package Regional Densities

8.2.4 Criticality Calculation

8.2.4.1 Calculational or Experimental Method

8.2.4.2 Fuel Loading or Other

Contents loading

Optimization

8.2.4.3 Criticality Results

8.2.5 Critical Benchmark Experiments

8.2.5.1 Benchmark Experiments and Applicability

8.2.5.2 Details of Benchmark Calculations

8.2.5.3 Results of Benchmark Calculations

8.3 Acceptance Criteria

8.3.1 Discussion and Results

8.3.2 Package Fuel Ioading

8.3.3 Model Specification
8.3.3.1
Description of
Calculational Model

8.3.3.2 Package Regional Densities

8.3.4 Criticality Calculation
8.3.4.1
Calculational or
Experimental Method

8.3.4.2 Fuel Loading or Other Cor:tents Loading Optimization

8.3.4.3 Criticality Results

85

85

86

0

87

9.5.5 Critical Benc'smark Experiments

8.4.1 Discussion of Resulto

8.4.2 Package Fuel Loading

8.4.3 Model Specification

8.4.3.1 Description of Calculational Models

8.4.4 Criticality Calculation

\subsubsection{Package Regional Densities}

8-13

$8-13$

8.4.4.1 Calculational or Experimental Method

8.4.4.2 Fuel Loading or Other Con-

8.14

0

8.4.4.3 Criticality Results

8-14

8-15

8-15

0

8.4.5 Critical Benchmark Experiments

8.4.5.1 Benchmark Experiments and Applicability

8.4.5.2 Results of Benchmark

8-15

Calculations

\subsection{Findings}

8.6 References

8-15

8-16 


$\begin{array}{llll}9.2 & \text { Areas of Review } & 9-1 & 0 \\ 9.3 & \text { Acceptance Criteria } & 9-2 & 0 \\ 9.4 & \text { Procedures } & 9-2 & 0 \\ & 9.4 .1 \text { General } & 9-2 & 0 \\ & 9.4 .1 .1 \quad \text { Planning } & 9-2 & 0 \\ & 9.4 .1 .2 \quad \text { Personnel Qualifications } & 9-2 & 0 \\ & 9.4 .1 .3 \quad \text { Equipment } & 9-3 & 0 \\ & 9.4 .1 .4 \quad \text { Records } & 9.3 & 0 \\ & 9.4 .1 .5 \quad \text { Quality Assurance } & 9.3 & 0 \\ 9.4 .2 \quad \text { Summary of Operating Requirements } & 9-3 & 0 \\ & \text { and Restrictions } & 9-4 & 0 \\ 9.4 .3 \text { Package Loading } & 9-5 & 0 \\ 9.4 .4 \quad \text { Shipment Preparation } & 9-5 & 0 \\ 9.4 .5 \text { Package Receipt } & 9-5 & 0 \\ 9.4 .6 \text { Package Unloading } & 9-6 & 0 \\ 9.5 & \text { Findings } & 9-6 & 0\end{array}$

10.0 REVIEW OF ACCEPTANCE TESTS AND MAINTENANCE

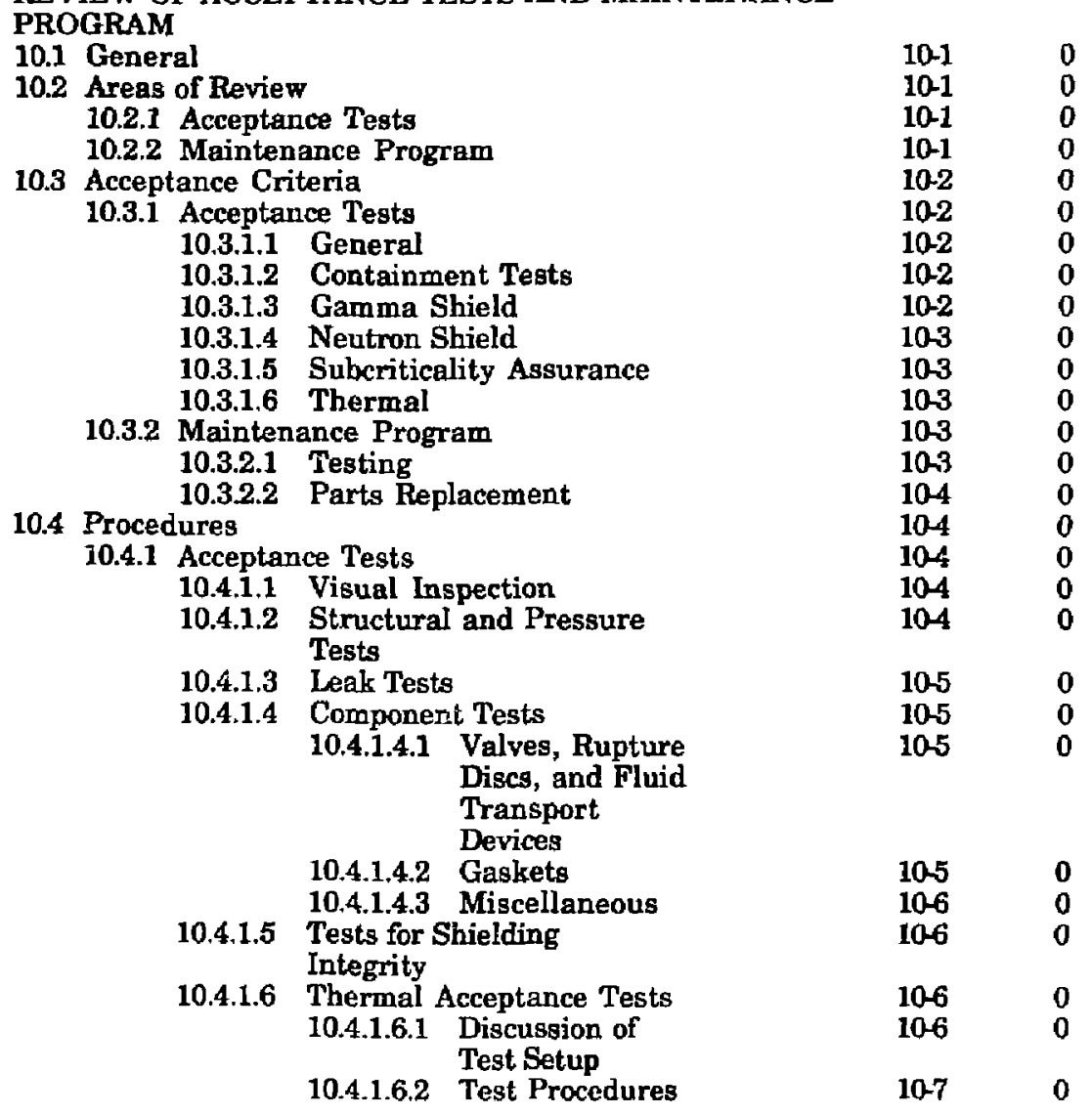


10.4.1.6.3 Acceptance

$$
\text { Criteria }
$$

10.4.2 Maintenance Program

10.4.2.1 Structural and Pressure

Tests

10.4.2.2 Leak Tests

10.4.2.3 Subsystem Maintenance

10.4.2.4 Valves, Rupture Discs, and

Gaskets on Containment.

Vessel

10.4.2.5 Shie]ding

10.4.2.6 Thermal

10.4.2.7 Miscellaneous

10.5 Findings

$$
\text { ings }
$$

10.6 References

11.0 REVIEW OF QUALITY ASSURANCE REQUIREMENTS

11.1 General

11.1.1 Objects and Authorization

11.1.2 Safety Focus-Package Object

11.1.3 Q-List and QA Categories

11.2 Areas of Review

11.2.1 Management Organization

11.2.2 Quality Assurance Program

11.2.3 Q-List Preparation

11.2.4 Quality Assurance Categories

11.2.5 Control Activities

11.2.6 Essential QA Elements

11.2.7 Documentation

11.2.8 Personnel Qualifications

11.2.9 Appropriate Effort

11.3 Acceptance Criteria

11.3.1 Management Organization

11.3.2 Quality Assurance Program

11.3.3 Q-List Preparation

11.3.4 Quality Assurance Categories

11.3.5 Control Activities

11.3.6 Essential QA Elements

11.3.7 Documentation

11.3.8 Personnel Qualifications

11.3.9 Appropriate Effort

11.4 Procedures

11.4.1 Management Organization

11.4.2 Quality Assurance Program

11.4.3 Q-List Preparation

11.4.4 Quality Assurance Categories

11.4.5 Control Activities

11.4.6 Essential QA Elements

11.4.7 Documentation

11.4.8 Personnel Qualifications

11.4.9 Appropriate Effort

11.5 Findings

11.6 References
10-7

0

10.7

10-7

10-7

10.7

$10-8$

$10-8$

$10-8$

$10-8$

10-8

10-9

0

0

0

0

0

0
0
0
0
0

11-1

11-1

11-2

11-2

$11-3$

113

113

11-3

11-3

113

113

11-4

11-4

114

114

114

$11-5$

11-5

11-5

116

116

11-7

11-7

11-7

11-8

11-8

11-8

$11-8$

11-9

$11-9$

11-9

11-9

11-10

11-10

11-10

11-11

1

1

1

1

1

1

1

1

1

1

1

1

1

1

1

1

1

1

1

1

1

1

1

1

1

1

1

1

1

1

1

1

1

1

1

1

APPENDIX A 


\section{LIST OF FIGURES}

Figure No. Title

1-1

2-1

$2-2$

4-1

42

43

44

5-1 Input and output information for the thermal review process

5-2 Heat balance across component boundaries

6-1 Input and output information for the containment review process

7-1 Input and output information for the shielding review process

8-1 Input and output information for the criticality review process

9-1 Input information for the review of operating procedures

10-1 Input and output information for the review of the acceptance tests and maintenance program

11-1 Regulatory documents with QA provisions

11-2 Guidelines for determining category of Graded QA planning
Page No. Rev. No.

1-19

0

2-13

0

2-14

0

$4-32$

0

433

0

4-34

0

4-35

0

5-23

0

5-24

0

6-12

0

7-12

0

8-18

0

98

0

10-10

0

11-16

1

11-17

1 


\section{LIST OF TABEDS}

Table No. Tile

2.1 Design, Manufacture, Use, and Maintenance Criteria

4.1

Around Rods

Input for KENO Va
Structural Design Criteria

Maximum Insolation Data

Summary of Load Combinations for Normal and Hypothetical Accident Conditions of Transport

Criteria for Free Drop Test

Maxionum Insolation Data

Summary of Load Combinations for Normal and Hypothetical Accident Conditions of Transport

Summary of Maximum Dose Rates, Normal Conditions of Transport, General Package Design

Summary of Maximum Dose Rates, Normal Conditions of Transport, Exclusive Use Transport

Summary of Maximum Dase Rates, Hypothetical Accident Conditions

Required Number of Packages to be Demonstrated as Subcritical under Specific Moderation and Reflection Conditions as per Sections 71.55, 71.57, 71.59, and 71.61 of 10 CFR Part 71
Page No Rey. No.

2-15

0

$4-36$

0

4-37 $\quad 0$

$4-38 \quad 0$

$4-39$

0

5-25

0

5-26

0

7-13

0

7-14

0

$7-16 \quad 0$

B-19

0

8-20

0

8221

Uranium/U02 Rods in Water, Aluminum Clad

823

1

11-12

1 


\title{
ACKNOWLEDGMENTS
}

The authors wish to acknowledge the technical contributions made to this report by G.L. Johnson and T.Y. Lo of the Lawrence Livermore National Laboratory. The authors wish to thank C.J. Mauck of Packaging Certification in the Office of Security Evaluations for his support and comments during the research and preparation of this guide. Many thanks to E.A. Sturmer for word processing and D. Bowden for editing.

In addition, the authors would like to thank the following organizations for providing review and comment on the draft versions of this guide.

\author{
Albuquerque Operations Office, DOE \\ Argonne National Laboratory \\ Sandia National Laboratory \\ Transportation and Waste Systems Division, OCRWM, DOE
}




\subsection{INTRODUCTION}

The Department of Energy (DOE) has established procedures for obtaining certification of packagings used by DOE and its contractors for the transport of radioactive materials. ${ }^{1}$ These certification review policies and procedures have been established to ensure that DOE packaging designs and operations protect the public health and safety, and meet safety criteria at least equivalent to the standards prescribed by the Nuclear Regulatory Commission (NRC) certification process for packaging (10 CFR 71, "Packaging and Transportation of Radioactive Materials"2). DOE 1540.2 specifies administrative procedures to use when applying for the certification and use of packaging. To obtain a Certificate of Compliance for packaging, Chapter II.2 of DOE 1540.2 requires that a Safety Analysis Report for Packaging (SARP) be prepared to demonstrate that the packaging design, manufacture, operations, and quality assurance meet DOE safety criteria. ${ }^{3}$ The SARP must then be submitted to the Certifying Official, Office of Security Evaluations (OSE), for review and approval. This Packaging Review Guide (PRG) has been prepared as guidance for the Packaging Certification Staff (PCS) under the Certifying Official or designated representatives when reviewing SARPs.

The authority for DOE to certify packagings is established by the Department of Transportation (DOT) in 49 CFR 173.7 (d) ". . p packagings made by or under the directi in of the U.S. DOE may be used for the transportation of radioactive materials when evaluated, approved and certified by the DOE against packaging standards equivalent to those specified in 10 CFR 71."

The DOT recognition of DOE's authority is based on the premise that the DOE evaluation and approval process will provide an assurance of safety equivalent to that renuired by the NRC. Such an assurance can be nrovided tay:

(1) Requiring that DOE package designs meet the standards of 1.0 CFR 71 or their equivalent, and

(2) Ensuring that the evaluation methods used to demonstrate compliance with standards are equivalent to those used by the NRC in their evaluation of commercial packaging designs. 
Therefore, ihis PRG makes extensive use of 10 CFR 71 regulations, NRC Regulatory Guides, and NUREGs for esłablishing acceptance criteria and review procedures.

\subsection{Purpose}

The principal purpose of the Packaging Review Guide (PRG) is to establish and maintain the quality and uniformity of reviews of Safety Analysis Reports for Packagings (SARPs) which are submitted to the DOE Certifying Official for approval. The PRG provides a well-defined base from which to evaluate proposed changes in the scope and requirements of SARP reviews. The PRG also provides information about the DOE certification policy and procedures to DOE field offices, DOE contractors, federal agencies, and interested members of the ge neral public. The PRG is not a DOE Order on packaging requirements but has been prepared for the guidance of the Packaging Certification Staff (PCS) in reviewing SARPs. An applicant submitting a SARP does not have to follow the guidelines in the PRG.

\section{Scope}

This PRG covers a variety of transport packaging designs. Most guidance is for reviewing new designs for compliance with the regulations. General advice is also provided to assist in evaluating older packaging designs.

DOE operations offices and contractors may use any packaging whose design has been certified by the Certifying Official provided the user meets the requirements specified in DOE 1540.2. This general applination of a packaging to many potential users through the certification process requires the SARP review to cover every aspect of the packaging design, manufacture, use, maintenance, and quality assurance.

Although each section of the PRG provides the complete prucedure and all acceptance criteria for all areas of review pertinent to that section, information must at times be obtained frum other reviewers. Also, for any given application, the reviewer may appropriately emphasize particular aspects of each PRG section as appropriate. In some cases, the major portion of the review of a packaging feature may be done generically for a family of transport packagings such as an impact limiter design. In other cases, a packaging feature may be sufficiently similar to that of a previous packaging so that a detailed review of the feature is not needed. For these and other reasons, the reviewer 
may not carry out in detail all of the review steps listed in each PRG section during the review of every application. The riviewer, through the Certifying Official, may at any time require additional information to be submitted for review in order to assure public sifety and compliance with the regulations.

\subsection{Definitions}

The following terins are taken from 10 CFR 71.4, DOE 1540.2 and 5480.3, and from NUREG-0544, or are defined here by the staff for the purpose of this guide. ${ }^{1-4}$ Standards are expressed in metric units. The approximate English equivalents presented in parentheses are for information only.

$A_{1}$ means the maximum activity of special form radioactive material permitted in a Type A package [1].

$\mathrm{A}_{2}$ means the maximum activity of radioactive material, other than special form radioactive material, permitted in a Type A package [1].

ALARA means as low as reasonably achievable [4].

Carrier means a person engaged in the transportation of passengers or property by land or water as a common, cuntract, cr private carrier, or by civil aircraft [1].

Cask is a large type of packaging, heavily shielded ag, inst gamma radiation [5].

Centralized Technical Review_office is a corp of specialists in the necessary engineering disciplines reporting to the DOE Headquarters Certifying Official (hereafter called the Certifying Official) who perform technical reviews of DOE Safety Analysis Reports for Packaging (SARPs) [2].

[1] 10 CFR 71.4

[2] DOE order 1540.2

[3] DOE order 5480.3

[4] NUREG-0544

[5] Defined by staff 
Certifying Official is the designated Headquarters official responsible for administering the DOE program for the design review of DOE packagings and issuance of a certificate of comphance upon approval [2].

CFR is the Code of Federal Regulations [5].

Containment System means the components of the packaging intended to retain the radioactive material during transport [1].

Conveyance means any vehicle, aircraft, vessel, freight container, or hold, compartment, or defined deck area of an inland waterway craft or seagoing vessel [1].

DOE is the Department of Energy [5].

DOE and NRC Certificate of Compliance is a certificate issued by DOE or NRC, as appropriate, approving for use with specified limitations a specific packaging for quantities of radioactive materials exceeding $A_{1} / A_{2}$ quantities as defined in DOE and NRC regulations [3,5].

DOE Alternative is an administrative relief from DOE regulations that meets and provides equivalent health and safety protection [2].

DOE Contractor is a contractor managing or operating a Government-owned or leased facility on behalf of the Department of Energy [2].

DOT Specification Packaging is general packaging designed to meet requirements established by the Department of Transportation for hazardous materials [2].

Enclosure is a space barrier surrounding a packaging containment component which protects the component from unauthorized operation and retains any leakage from the component [5]. 
Equivalent Protection means alternative measures which will achieve a levei of safety at least equal to that specified in the regulations from which the aitcrnative is sought, which will be consistent with the public intent, and will provide adequate protection against risks to life and property [2].

Exclusive Use (also referred to in other regulations as "sole use" or "full load") means the sole use of a conveyance by a single consignor and for which all initial, intermediate, and final loading and unloading are carried out in accordance with the direction of the consignor or consignee [1].

Fissile Classification means the categorization of fissile maturial packages into one of the following three classes according to the controls neec $:$ to provide nuclear criticality safety during transportation:

(1) Fissile Class I: A package which may be transported in unlimited numbers and in any arrangement, and which requires no nuclear criticality safety controls during transportation. A transport index is not assigned for purposes of nuclear criticality safety but may be required because of external radiation levels.

(2) Fissile Class II: A package which may be transported together with other packages in any arrangement but, for criticality control, in numbers which do not exceed an aggregate transport index of 50 . These shipments require no other nuclear criticality safety control during transportation. Individual packages may have a transport index not less than 0.1 and not more than 10 .

(3) Eissile Class III: A shipment of packages which is controlled in transportation by specific arrangements between the shipper and the carrier to provide nuclear criticality safety [1].

Fissile Material and Fissile Radionuclides: "Fissile material" means any material consisting of or containing one or more fissile radionuclides. Fissile radionuclides with odd numbers of neutrons, including uranium 233, 235; plutonium 239, 241; 
Americium 242m; curium 243, 245, 247; and Californium 249, 251, can have critical masses in aqueous solutions that are less than $1 \mathrm{Kg}$. Fissile radionuclides witl even numbers of neutrons including Neptunium 237; plutonium 238, 240, 242, Americium 241, 243; and curium 244 may in many cases be made critical, but the mass required is greater than a $1 \mathrm{Kg}$. Other fissile isotopes exist but require large masses to become critical, and in most cases are available in only extremely small quan'ities. Neither natural nor depleted uranium is fissile material $[1,3,5]$.

Hazardous Materials means a substance or material that has been determined by the Secretary of Transportation to be capable of posing an unreasonable risk to bealth, safety, and property when transported in commerce, and has been so designated. These materials are listed in the Hazardous Materials Table, 49 CFR $172.101[2]$.

Hazardous Substance is a maverial, and its mixtures or solutions, that is identified by the letter " $\mathrm{E}$ " in column 1 of the Table to 49 CFR 172.101 when offered for iransportation in one package, or in one transport vehicle if not packaged, and when the quantity of the material therein equals or exceeds the reportable quantity (RQ) [2].

Hazardons Waste is any material that is subject to the hazardous waste manifest requirements of the Environmental Protection Agency (EPA) as specified in 40 CFR 262 [2].

Low Specific Activity Material means any of the following:

(1) Uranium or thorium ores and physical or chemical concentrates of those ores;

(2) Unirradiated natural or depleted uranium or unirradiated natural thorium;

(3) Tritium oxide in aqueous solutions, provided the concentration does not exceed 5.0 millicuries per milliliter; 
(4) Material in which the radioactivity is essentially uniformly distributed and in which the estimated average concentration per gram of contents does not exceed:

(i) 0.0001 millicurie of radionuclides for which the $A_{2}$ quantity in Appendix A of 10 CFR 71 is not more then 0.05 curie;

(ii) 0.005 millicurie of radionuclides for which the $A_{2}$ quantity is more than 0.05 curie, but not more than 1 curie; or

(iii) 0.3 millicurie of radionuclides for which the $A_{2}$ qunntity in Appendix $A$ of 10 CFR 71 is more than 1 curie.

(5) Objects of nonradioactive material externally contaminated with radioactive material, provided that the radioactive material is not readily dispersible and the surface contamination, when averaged over an area of 1 square meter, does not exceed 0.0001 millicurie (220,000 disintegrations per minute) per square centimeter of radionuclides for which the A2 quantity in Appendix A of 10 CFR 71 is not more than 0.05 curie, or 0.001 millicurie $(2,200,000$ disintegrations per minute) per square centimeter for other radionuclides [1].

Maximum Normal Operating Pressure meaus the naximum gauge pressure that would develop in the containment system in a period of one year under the heat test specified in $10 \mathrm{CFR} 71.71$ (c)(1), in the absence of venting, external cooling by an ancillary system, or operational controls during transport [1].

Natural Thorium means thorium with the naturally occurring distribution of thorium isotopes (essentially 100 weight percent thorium-232) [1].

Neutron Poisons are materials other than fissile material which will absorb neutrons, especially materials such as boron [5]. 
Normal Form Radioactive Material means radioactive material which has not been demonstrated to $\xi_{2}+$ alify as "special form radioactive material" [1].

NRC is the Nuclear Regulatory Cur.mission [5].

Ootimum Interspersed Hydrogenous Moderation means the presence of hydrogenous material between packages to such an extent that the maximum nuclear reactivity results $[1]$.

QSE is the DOE Office of Security Evaluation [5].

Package means the packaging together with its radioactive contents as presented for transport.

(1) Fissile_material package means a fissile material packaging together with its fissile contents.

(2) Type B package means \& Type B package together with its radioactive contents. On approval, Type B package design is designated by NRC or DOE as $B(U)$ unless the package has a maximum normal operating pressure of more than 700 kilopascal $\left(100 \mathrm{lb} / \mathrm{in}^{2}\right)$ gauge or a pressure relief device which would allow the release of radioactive material to the environment under the tests specified in 10 CFR 71.73 (hypothetical accident conJitions), in which case it will receive a designation $B(M)$. $B(U)$ refers to the need for unilateral approval of international shipments; $B(M)$ refers to the need for multilateral approval. There is no distinction made in how packages with these designations may be used in domestic transportation. To determine their distinction for international transportation, see DOT regulations in 49 CFR 173 . A Type B package approved prior to September 6, 1983, was designated only as Type B. Limitations on its use are specified in 10 CFR 71.13 [1].

Packaging means the assembly of components necessary to ensure compliance with the packaging requirements of $10 \mathrm{CFR} 71$. It may consist of one or more receptacles, 
absorbent materials, spacing structures, therma! insulation, radiation shielding, and devices for cooling or jsorbing mechanical shocks. The vehicle, tie-down system, and auxiliary equipment may be designated as part of the packaging [1].

PCS is the Packaging Certification Staff within the DOE Office of Security Evaluation [5].

PRG is this Packaging Review Guide [5].

Quality is a generalized value characteristic of a thing, component, or system [5].

Quality Assurance is planned and systematic action necessary to provide adequate confidence that a facility, structure, system, or component will perform satisfactorily and safely $i$ service. The goal of quality assurance is to ensure: that research, dcrelopment, demonstration, scientific investigations, and production activities are performesi in a controlled manner; that components, systems, and processes are designed, develaped, constructed, tested, operated, and maintained according to engineering standards, quality practices, and Technical Specifications/ Operational Safety Requirements; and that resulting technology data are valid and retrievable. Quality assurance includes quality control, which comprises all those actions necessary to control and verify the features and cbaracteristics of a material, process, product, or service to specified requirements [5].

Quality Assurance Plan is a document that contains or references the quality assurance elements established for an activity, group of activities, a scientific investigation, or a project. It describes how conformance with such requirements is to be assured fo: structures, systems, computer software, components, and their operation commensurate with (1) the scope, complexity, duration, and importance to satisfactory performance, (2) the potential impact on environment, safety, and health, and (3) requirements for reliability and continuity of operation [5].

Quality Assurance Prorram is a systematic program of controls and inspections applied by any organization or body involved in the transport of radioactive material to provide adequate confidence that the standard of safety prescribed in Regulations is achieved in practice [5]. 
Radioactive Material is any material having a specific activity greater than 0.002 microcuries per gram (Ci/g) [2].

$\mathrm{RQ}$ means reportable quantity (as of a hazardous substance) [2].

Safety Analysis Report for Packaging (SARP) is a document that provides a comprehensive technical evaluation and review of the design, testing, operational procedures, maintenance procedures, and quality assurance program. The purpose of the SARP is to demonstrate compliance with the DOE Regulatory safety standards equivalent to those established by the NRC for approving packagings and issuing certificates of compliance [2].

SAR is a Safety Analysis Report [2].

SER is a Safety Evaluation Report [3].

Special Form Radioactive Material means radioactive material which satisfies the following conditions:

(1) It is either a single solid piece or is contained in a sealed capsule that can be opened only by destroying the capsule; 
(2) The piece or capsule has , least one dimension not less than 5 millimeters (0.i97 inch); and

(3) It satisfies the test requirements of 10 CFR 71.75 .

A special form encapsulation designed in accordance with the requirements of 10 CFR 71.4(o) of this part in effect on June 30, 1983, and constructed prior to July 1, 1985, may continue to be used. A special form encapsulation either designed or constructed after June 30, 1985, must meet requirements of 10 CFR 71 applicable at the time of its design or construction [1].

Specific_Activity of a radionuclide means the radioactivity of the radionuclide per unit mass of that nuclide. The specific activity of a material in which the radionuclide is essentially uniformly distributed is the radioactivity per unit mass of the material [1].

Subcriticality is the condition of a nuclear system in which the rate of production of fission neutrons is lower than in the previous generation due to neutron leakage and poisons, thus a self-supporting chain reaction cannot be maintained [5].

Transport Iradex means the dimensionless number (rounded up to the first decimal place) placed on the label of a package to designate the degree of control to be exercised by the carrier during transportation. The transport index is determined as follows:

(1) The number expressing the maximum radiation level in millirem per hour at 1 meter from the external surface of the package; or

(2) For Fissile Class II packages, the number expressing the maximum radiation level in millirem per hour at 1 meter from the external surface of the package, or the number obtained by dividing 50 by the allowable number of the packages which may be transported together as determined under $10 \mathrm{CFR}$ 71.59, whichever number is larger [1]. 
Type_A Quantity means a quantity of rudioactive material, the aggregatc radioactivity of which does not exceed $A_{1}$ for special form radioactive material or $A_{2}$ for normal form radioactive material, where $A_{1}$ and $A_{2}$ are given in Appendix $A$ of 10 CFR 71 or may be determined by procedures described in Appendix A of 10 CFR 71 [1].

Trpe B Quantity means a quantity of radioactive material greater than a Type A quantity [1].

\section{Uranium--Natural. Depleted. Enriched}

(1) Natural uranium means uranium with a naturally occurring distribution of uranium isotopes (approximately 0.711 weight percent of uranium-235, and the remainder essentially uranium-238).

(2) Depleted uranium means uranium containing less uranium-235 than the naturally occurring distribution of uranium isotopes.

(3) Enriched uranium means uranium containing more uranium-235 than the naturally occurring distribution of uranium isotopes [1].

\subsection{Approach}

The overall safety of a packaging is the responsibility of the applicant. The applicant is responsible for meeting the regulations in the design, development, use, and maintenance of the packaging. The SARP must be sufficiently detailed to permit the reviewer both to determine whether the transport package has been designed and analyzed in sufficient detail and to conclude that it can be built and operated without undue risk to the health and safety of the public. The SARP is the principal document in which the applicant provides the information needed for the reviewer to understand the basis upon which this conclusion has been reached. The reviewer is to verify that the applicant has properly documented in the SARP the adequacy of the packaging with respect to regulations. The reviewer should not perform design analysis or modify the 
design for the applicant. The reviewer should perform only confirmatory analysis and such other techniques as those provided in this guide to verify the adequacy of the design. The review should emphasize those components of the packaging that are most important to safety.

The regulations are intended to assure that the public will be protected during normal transportation or in the event that a package is involved in a transportation accident. Basically, the regulations state that a package must meet certain containment, radiation control, and subcriticality assurance requirements when it is subjected to specified normal transport conditions and also hypothetical accident conditions. The hypothetical accident conditions are specified in terms of regulation-defined test conditions which include a free drop ( 9.0 meters [ $30 \mathrm{ft}$ ] onto a flat unyielding surface), a puncture (1-meter drop onto a vertical 6-inch-diameter mild steel bar), thermal exposure (30 minutes to a defined $800^{\circ} \mathrm{C}$ environment), and immersion under specified depths of water. The test conditions must be sequentially imposed on all packages in a manner that would cause maximum damage. The resulting package response must then be determined by test or analysis.

The regulations do not define the allowable structural or thermal damage a packaging may sustain, but instead use radiological criteria, i.e., radioactivity release (leakage) and radiation levels external to the packaging as a measure of the acceptability of the design. Therefore, the package response must be such that the packaging can ( 1 ) meet containment requirements (any radioactive material release must be restricted within stated limits), (2) keep external radiation levels within stated limits, and (3) ensure that a criticality event cannot occur.

Normally packages are designed to meet the test conditions and radiation ha: ard limits in the regulations by using established codes and standards.

Both DOE Order 5480.3, Section 9 and 10 CFR 71.37 require: "The applicant shall identify any established codes and standards proposed for use in the package design, fabrication assembly, testing, maintenance, and use. In the absence of any codes and standards, the applicant shall describe the basis and rationale used to formulate the package quality assurance program."

At a minimum, codes and standards provide quality assurance criteria, acceptance criteria, and margins of safety. In general, margins of safety are included in established 
codes and standards such as the ASME code and the ANSI Standards and Regulatory Guides.

These margins of safety ensure that the package not only will meet the Regulatory conditions and limits but also will survive under extreme loading conditions without causing unacceptable radiological risks.

To develop a measurement of the risk to the public from all shipments of radioactive material, the NRC in 1977 published an environmental impact statement, NUREG-0170, entitled, "Transportation of Radioactive Material by Air and Other Modes." 5 The analysis performed in this document presumed that, in certain classes of accidents, transportation accident loads could exceed those implied by the hypothetical accident conditions specified in the regulations. The analysis further presumed that for these classes of accident, releases of radioactive material could occur. Even under these presumptions, the analysis indicated that the potential radiological consequences from real transportation accident loadings on a package were most often very small (e.g., limited to minor property contamination which required only cleanup actions). Even though NUREG-0170 presumed the release of radioactive material under certain severe accident circumstances, the overall resulting risk from transporting radioactive material under current regulations was calculated to be acceptable. The results of NUREG-0170 rely in part on the presumption that Type $\mathbf{B}$ packagings have sufficient margins designed into them that a major radioactive material release would not occur even at loading conditions which exceed those specified in regulations.

In performing a SARP review, a reviewer should have an open mind toward evaluating new technology and methods. However, in evaluating new materials, technologies, and methods, a reviewer must consider the intent of the regulations not to expose the public to undue risk as assessed in NUREG-0170. For example, if a packaging structural design uses ASME code material shown as "Cask 1 " in Fig. 1-1, the design limits usually have sufficient margins embedded in them to protect the public from undue risk for impact conditions exceeding the hypothetical accident conditions. 5 If a new material not specified in the ASME code is used for structural design shown as "Cask 2" in Fig. 1-1, the embedded margin is likely unknown, and may be insufficient. If unknown, the margin would have to be determined and, perhaps, a risk assessment would have to be performed. The risk assessment would have to include not only the 
material properties at or below the Regulatory conditions but must cover all possible conditions to assess the total risk.

\subsection{Packaging Review Guide (PRG) Sections}

The review is primarily based on the information provided by an applicant in a SARP. Section II.2 of DOE 1540.2 requires that SARPs shall be prepared in the format described in NRC Regulatory Guide (R.G.) 7.9, "Standard Format and Content of Part 71 Applications for Approval of Packaging of Type B, Large Quantity, and Fissile Radioactive Material."7

While not specifically addressed in R.G. 7.9, DOE 1540.2 requires the SARP to include a description of the quality assurance program for the design, fabrication, assembly, testing, maintenance, repair, modification, and use of the proposed packaging.

The sections of this PRG parallel the standard format for each of the sections given in R.G. 7.9. A review section addressing Quality Assurance Plans (Section 11.0) has been added to provide guidance for complying with DOE 5700.6B. ${ }^{8}$ Also, this PRG contains an additional review section, Materials and Fabrication Specifications (Section 3.0) to provide expanded guidance in reviewing the structural adequacy of materials.

\subsection{Packaging Review Guide (PRG) Subeections}

The individual PRG sections address in detail the objectives and methods of the review, the areas that are reviewed, the acceptance criteria for the review, how $t$. review is accomplished, and the types of conclusions that are sought. One of the objectives of the PRG is to identify the disciplines required to perform the review and to define the sometimes complex interfaces between them. Each PRG section identifies the primary discipline required to review that section. In some review areas the primary discipline may require support. Each PRG section also identifies the other disciplines that are required to perform these supplemental reviews. Each PRG is organized according to the following six subsections:

\section{X.1 General \\ X2 Areas of Review \\ X.3 Acceptance Criteria}




\section{X.4 Procedures \\ X.5 Findings \\ X.6 References}

A description of each of the PRG subsections is given below.

\subsubsection{General}

This subsection discusses the overall objectives, approach, and methods of the review. The information required to complete the review is identified. Acceptable methods of analysis and computer codes for performing analyses are identified and discussed. Acceptable testing methods are also discussed. The guidance provided assists the reviewer to estimate the depth and complexity required to accomplish specific reviews.

This subsection typically sets forth the solutions and approaches determined to be acceptable in the past by the PCS in dealing with a specific safety issue or safety-related design area. These solutions and approaches are presented in this form so that reviewers can take consistent and well-understood positions as the same safety issues arise in future cases. This review subsection and the review references represent solutions and approaches that are acceptable to the PCS, but they are not required as the only possible solutions and approaches. However, applicants should recognize that the PCS has apent substantial time and effort in reviewing and developing their positions for the issues. A corresponding amount of time and effort will probably be required to review and accept new or different solutions and approaches. Thus, applicants proposing solutions and approaches to safety issues or safety-related design areas other than those described in the PRG sections must expect longer review times and more extensive questioning in these areas. The PCS is, however, willing to consider proposals for generic solutions and approaches, apart from a specific license application, to avoid the additional review time on individual cases. 


\subsubsection{Areas of Review}

This subsection describes the specific areas to be reviewed in parallel with R.G. 7.9. This subsection identifies the systems, components, analyses, data, or other information that is reviewed as part of the particular PRG section in question.

\subsubsection{Acceptance Criteria}

This subsection identifies which Regulatory safety requirements apply and the criteria for determining the acceptability of a design within the area of review of the PRG section. The acceptance criteria are from DOE Orders, NRC Regulations, DOT Regulation, IAEA Regulations, NRC Regulatory Guides, codes and standards, NUREGs, and any resolutions of safety issues which are documented in the "General" subsection.

\subsubsection{Procedures}

This subsection discusses how to review a SARP. The subsection generally follows R.G. 7.9 and is a step-by-step procedure that the reviewer goes through to provide reasonable verification that the applicable safety criteria have been met.

\subsubsection{Findings}

This subsection presents the type of conclusion that is sought for each review area. For each section, a conclusion of this type is included in the Safety Evaluation Report $(G \mathrm{R})$ in which the review results are documented. The SER also contains a description of the review including such subjects as which aspects of the review were selected or emphasized, where the packaging design or the applicant's programs deviate from the criteria stated in the PRG, and the basis for any deviations from the PRG or exemptions from the regulations.

\subsubsection{References}

This subsection lists the references used in the review process. 


\subsection{Packaging Review Guide (PRG) Revisions}

The PRG not only documents current methods of review but also provides the base for orderly modifications of the review process in the future. The PRG will be revised and updated as the need arises to clarify the content, to correct errors, or to incorporate modifications approved by the DOE Certifying Official.

The revision number and publication date are printed at a lower corner of each page of each PRG section. Since individual sections have been, and will continue to be, revised as needed, the revision numbers and dates will not be the same for all sections. The Table of Contents indicates the revision numbers of the currently effective sections. Comments and suggestions for improvement will be considered and should be sent to the Director, Office of Security Evaluations, DP-4, U.S. Department of Energy, Washington, DC 20545. Notices of errors or omissions should also be sent to the same address.

\section{References}

1. U.S. Department of Energy, DOE 1540.2: Hazardous Material Packaging for Transport-Administrative Procedures, U.S. Department of Energy, Washington, DC, September 30, 1986.

2. Office of the Federal Register, Title 10. Code of Federal Regulations, Part 71, Office of the Federal Register, Washington, DC, January 1984.

3. U.S. Department of Energy, DOE 5480.3: Safety Requirements for the Packsging and Transportation of Hazardous Materials. Hazardous Substance. and Hazardous Wastes, U.S. Department of Energy, Washington, DC, August 9, 1985.

4. U.S. Nuclear Regulatory Commission, A Handbook of Acronvms and Initicalisms, U.S. Nuclear Regulatory Commission, Washington, DC, NUREG-0544, Rev. 2, April 1981.

5. U.S. Nuclear Regulatory Commission, Final Environmental Statement on the Transpertation of Radioactive Material by Air and Other Medes, U.S. Nuclear Regulatory Commission, Washington, DC, NUREG-0170, December 1977. 
6. American Society of Mechanical Engineers, ASME Boiler and Pressure Vessel Code 1983 edition, the American Society of Mechanical Engineers, United Engineering Center, 345 East 47th Street, New York, NY 10017.

7. U.S. Nuclear Regulatory Commission, Regulatory Guide 7.9: Standard Format and Content of Part 71 Applications for Approval of Packaging of Type B, Large Quantity. and Fissile Radioactive Material, U.S. Nuclear Regulatory Commission, Office of Standards Development, Washington, DC, January 1980, Rev. 1.

8. U.S. Department of Energy, DOE 5700.6B: Quality Assurance, U.S. Department of Energy, Washington, DC, September 23, 1986. 


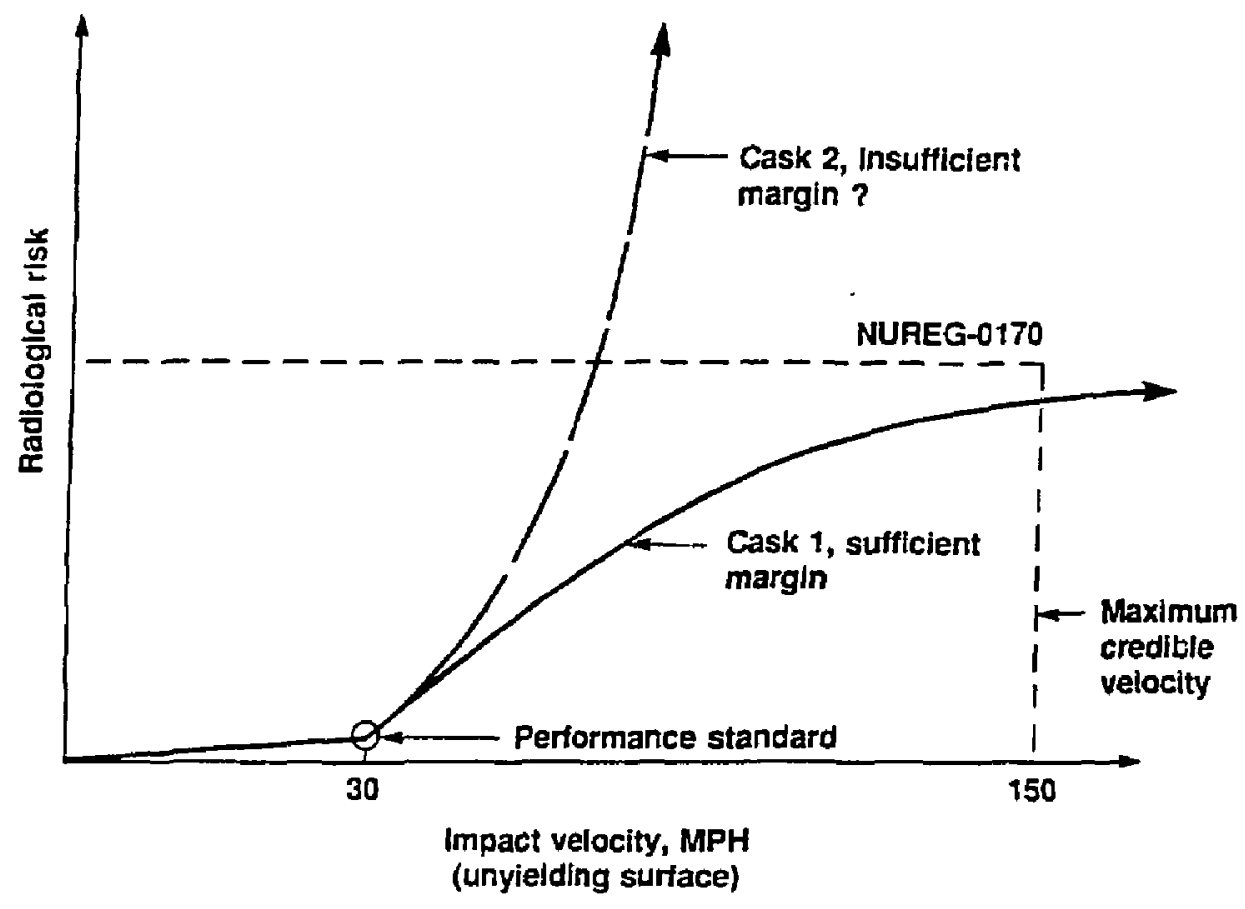

Figure 1-1 Effects of design margins on radiological risk. 


\subsection{REVIEW OF GENERAL INFORMATION}

\subsection{General}

The objective of this portion of the review is to ensure that the applicant has included at least the general information required by DOE 5480.3, Section 8.1 The general information is required to permit an orderly review of an application for a Certificate of Compliance. The information must be adequate to permit the reviewer to determine whether the transport package has been designed and analyzed in sufficient detail to conclude that it can be built and operated without undue risk to the public health and safety.

\subsubsection{Quality Standards and Assurance}

The applicant must have a quality assurance (QA) program that conforms to the requirements of DOE $5700.6 \mathrm{~B}$ and Subpart $\mathrm{H}$ of $10 \mathrm{CFR} 71,2,3$ The applicant may choose to use a "graded" approach in the quality assurance programs for designing, manufacturing, using, and maintaining the packaging.4,5 To develop a quality assurance program in which the application of QA requirements is commensurate with their safety significance, it is essential that the SARP document a systematic evaluation of each component and system to assess its safety function and potential radiological hazard to the public. After each component has been assessed, quality standards and QA requirements can be identified for designing, manufacturing, using, and maintaining each component. The quality standards and QA requirements are usually contained in National Codes and Standards and are consistent with the safety level of importance of the component. This portion of the review covers the review of the overall quality standards and $Q A$ requirements specified for designing, manufacturing, using, and maintaining the packaging. The review in Section 11.0 covers the specific QA requirements for the packaging and components with an associated Q-List and should be coordinated with this review.

A logical sequence leading to identifying realistic quality standards and QA requirements would be by (1) classifying each component and system as important to safety or not important to safety, (2) designating items classified as important to safety into safety groups by their function, (3) categorizing the packaging with respect to the type and amount of the contents, and (4) specifying quality standards applicable to each safety group. The following discussion of safety classification, package categories, and quality 
standards for designing, manufacturing, using, and maintaining packaging components is provided to give a better understanding of the process.

\subsubsection{Safety Classification}

To protect the public health and safety, shipments of radioactive materials are required to be made in packagings that are designed, manufactured, used, and maintained in accordance with provisions of DOE 5480.3, 10 CFR 71, and 49 CFR 173.6 
Three basic safety requirements addressed by the regulations must be ruet when transporting radioactive materials:

1. Adequate containment of radioactive material.

2. Assurance of nuclear subcriticality.

3. Adequate shielding of the radiation emitted by the radioactive contents.

Containment is the retention of radioactive material within a closed vessel. Containment is provided to preclude contact between radionctive material and people or the environment. The regulations seek absolute retention, but specify practical limits which allow quantitative analysis and requirements. Typically, containment is provided by the integrity of a steel vessel (Fig. 2-1). The vessel is provided with a bolted end closure to accommodate the loading and unloading of contents. The closure contains a seal to minimize leakage between the cask containment and the environment. Piping penetrations of this containment are needed for operating purposes, and the associated closure valves are considered a part of the containment system. These penetrations are in the containment vessel for draining, filling, testing, etc. The cavity of a containment system may be filled with a coolant such as water or helium during transportation.

Criticality is a self-sustained nuclear chain reaction which might result in high energy production and a radiation burst before self-termination. Packages carrying fissile materials are designed to maintain a condition of subcriticality. The subcriticality assurance function, if not assured by the physical limitation on the amount of fissile material being shipped, is achieved by maintaining geometric control of the fissile materi.l during shipment and by using "neutron poisons" in appropriate materials. Neutron interactions with fissile materials must attain a prescribed level before criticality can occur. The poisons, which are typically included in the solid structure or basket retaining the fissile material, absorb emitted neutron particles sufficiently to limit this neutron interaction and thus assure subcriticality.

A radiation shield is a harrier which atsorbs ionizing energy or subatomic particles emanating from a radioactive source. Shielding against both gamma and neutron radiation may be needed in packaging design. Shielding against the highly penetrating gamma radiation is achieved through the use of heavy materials such as lead, uranium, or steel. These materials surround the containment vessel (Fig. 2-1) and are, in turn, enclosed within an outer steel shell. If steel is the shield inaterial, this shield can be an 
integral part of the containment vessel. The neutron shielding mitigates radiation caused by emission of neutrons from radioactive materials such as curium. Normally hydrogenous materials provide shielding against neutrons. The neutron shield typically surrounds the packaging on its exterior surfaces.

These safety requirements (10 CFR 71) are important in classifying packaging components because they determine the safety classification of packaging components. Transport packages can be functionally subdivided into three component safety groups to provide a "graded" approach in selecting quality standards for packaging components. The first group, containment components, incluries all components used to retain the radioactive contents in the packaging during transport. Containment components include the containment vessel, closure, seals, piping, and bolts. The second group, subcriticality components, includes all components used to control nuclear criticality during the transport of fissile materials in the packaging. The subcriticality components include neutron absorber materials such as boron carbide and the associated structures that retain the relative positions of the fissile and neutron absorber materials during transport. The third group, shielding and other safety components, includes all of the remaining safety-related components. In this group are gamma and neutron shielding; secondary containment seals, bolts, and closures; impact limiters; and lifting lugs and tie-down devices.

\subsubsection{Package Categoriea}

The requirements for transport packagings increase with the activity of their contents as shown in Fig. 2-2. Type B packagings are defined as containing radioactive materials either of special forms with activities greater than $A_{1}$ or of normal formB with activities greater than $A_{2}$. The requirements for Type $B$ packaging are given in DOE 5480.3 and 10 CFR 71 and require the submittal and approval of a SARP. For specific isotopes, the margins of safety that should be provided in Type B packagings increase with the activity of the contents. Three packaging categories and their associated types and levels of contents are defined in Ref. 8 and are shown in Fig. 2-2.

For a specific radioactive isotope, Category I includes the highest levels of activity to be transported and requires the highest margin of safety, whereas, Categories II and III include the medium- and low-activity levels, respectively. Category I applies when the 
content activity exceeds either 30,000 curies, $3000 A_{1}$, or $3000 A_{2}$ whichever is less. Category IT applies when the content activity exceeds either $30 \mathrm{~A}_{1}$ or $30 \mathrm{~A}_{2}$ but is less than Category I content activity. Category III applies when the content activity exceeds either $A_{1}$ or $A_{2}$ but is less than Category II contents.

\subsubsection{Quality Standards}

The quality standards for the design, manufacture, use, and maintenance of components of packagings used for transporting radioactive materials are based on the ASME Code as summarized in Table 2.1 for the three packaging categories. These standards are discussed in the following subsections. ${ }^{B}$

\subsection{Category I}

Acceptable quality standards for the design, manufacture, use, and maintenance of components for transport packagings are given in the ASME Code Section III, Subsection NB for containment components; Subsection NG for subcriticality components; and Section VIII, Division I or Section III, Subsection NF for shielding and other safety components. An acceptable specification for drums and pails used in any of the component safety groups is DOT Specification $17 \mathrm{C}$ or better.

\subsection{Category II}

Acceptable quality standards for the design, manufacture, use, and maintenance of components for transport packagings are given in the ASME Code Section III, Subsection ND for containment components; Subsection NG for suberiticality components; and Section VIII, Division I or Section III, Subsection NF for shielding and other safety components. An acceptable specification for drums and pails used in any of the component safety groups is DOT Specification $17 \mathrm{H}$ or better.

\subsubsection{Category III}

Acceptable quality standards for the design, manufacture, use, and maintenance of components for transport packagings are given in the ASME Code Section VII, Division I for containmen: components; Subsection NG for subcriticality components; and Section VII, Division I or Section III, Subsection NF for shielding and other safety components. 
An acceptable specification for drums and pails used in any of the component safety groups is DOT Specification $17 \mathrm{H}$ or better.

\subsection{Areas of Review}

DOE 1540.2 and Subpart D of 10 CFR Part 71 defines the rules governing the preparation of an application for package approval. These rules give the minimum general infr. $z$ : $n$ required for an orderly review of an application for a certificate of complius. is: form a comprehensive review, a modification of the R.G. 7.9 format will be us a eviewing SARPs to assure that component classification and general information are adequately addressed as follows:

\subsubsection{Use of Packaging}

The prcposed use of the packaging, the model number, and other information such as fissile class and transport index should be reviewed as appropriate.

\subsection{Packaging Description}

The description of the package in the SARP, including drawings, should be reviewed. The review should emphasize those design features that are essential to nuclear safety.

\subsubsection{Operational Features}

The operation of any complex package system should be reviewed.

\subsection{Contents of Packaging}

The contents of the packaging, including radioactive materials, dunnage, other materials, and any coolants, should be reviewed.

\subsection{Package Evaluation}

The summaries of the package evaluations contained in the other SARP sections should be reviewed for compliance with regulations. 


\subsubsection{Quality Standards}

The overall quality standards and QA requirements for the packaging, including the component safety classifications, should be reviewed.

\subsection{Supplemental Information}

Supplemental information which may include drawings, operational schematics, and loading configurations should be reviewed.

\subsection{Acceptance Criteria}

\subsubsection{Use of Packroge}

Sufficient information must be provided that the use of the packaging is clearly identified. The transport index and fissile classification should be documented according to Parts 71.4, 71.55, 71.57, 71.59, and 71.61 of $10 \mathrm{CFR} 71$. Any special controls required for loading the packaging should be identified.

\subsubsection{Packaging Description}

Per 10 CFR 71.33, the description of the packaging must include:

1. Classification as type $B(U), B(M)$, or fissile material packaging.

2. Gross weight.

3. Model number.

4. Identification of the containment system.

5. Specific materials of construction, weight, dimensions, and fabrication methods of:

a. receptacles

b. internal and external structures supporting or protecting receptacles

c. neutron absorbers

d. valves, sampling ports, lifting devices, and tie-down devices

e. structural and mechanical means for the transfer and dissipation of heat

f. identification and volumes of any receptacles containing coolant.

\subsection{Operational Features}

Sufficient information must be provided so that the reviewer can understand all operations and conclude that the packaging system can be operated without undue risk to the public and within ALARA guidelines for nuclear workers. 


\subsection{A Contents of Packaging}

Per 10 CFR 71.33, the description of the packaging contents must include:

1. Identification and maxim $1 \mathrm{~m}$ radioactivity of radioactive constituents.

2. Identification and maximum quantities of fissile constituents.

3. Chemical and physical form.

4. Extent of reflection, amount and identity of non-fissile materials used as neutron absorbers or moderators, and the atom ratio of moderator-to-fissile constituents.

5. Maximum normal operating pressure.

6. Maximum weight.

7. Maximum amount of decay heat.

8. Identification and volume of any coolants.

\subsubsection{Package Evaluation}

An evaluation must be presented that shows the effect on the package of tests specified in Paragraph 71.71 (Normal Conditions of Transport) and Paragraph 71.73 (Hypothetical Accident Conditions) of 10 CFR 71 Subpart F. Other sections of this PRG cover demonstration with respect to structural adequacy, shielding, containment, thermal behavior, and criticality. The results of the evaluations should be summarized in sufficient detail and referenced to the appropriate SARP section such that the reviewer can determine if the package design complies with regulations.

Per 10 CFR 71.43, the following general standards must be met:

1. The smallest overall dimension of a package is not less than $10 \mathrm{~cm}$ (4 inches).

2. The outside of a package incorporates a feature, such as a seal, which is not readily breakable and which, while intact, would be evidence that the package has not been opened by an unauthorized person.

3. The package includes a containment system securely closed by a positive fastening device that cannot be opened unintentionally.

4. For the materials or construction specified, there will be no significant chemical, galvanic, or other reaction among the packaging components or between the packaging components and the packaging contents, including possible reaction resulting from in-leakage of water, to the maximum credible extent. 
5. A package valve, or other device whose failure would allow radioactive materials to escape, is protected against unauthorized operation. In the case of a pressure relief valve, assure that an enclosure is provided to retain any leakage.

6. The application contains conclusions to the effect that under the methods chosen to demonstrate compliance, there would be no loss or dispersal of radioactive contents, no significant increase in external radiation levels, and no substantial reduction in the effectiveness of the packaging.

7. The package application contains as a design criterion the requirement that in still air at $38^{\circ} \mathrm{C}\left(100^{\circ} \mathrm{F}\right)$ and in the shade, no accessible surface of a package would have a temperature exceeding $50^{\circ} \mathrm{C}\left(122^{\circ} \mathrm{F}\right)$ in a non-exclusive shipment or $82^{\circ} \mathrm{C}\left(180^{\circ} \mathrm{F}\right)$ in an exclusive use shipment.

8. The packaging does not incorporate a feature that is intended to allow continuous venting during transport.

\subsubsection{Qualicy Standards}

Per DOE Orders and 10 CFR 71.37, quality standards and QA requirements must be specified:

1. The applicant has provided a quality assurance program that conforms to the requirements of DOE Order 5700.6B and Subpart H of 10 CFR 71.

2. The applicant identifies established codes and standards used in package design, fabrication, assembly, testing, maintenance, and use. In the absence of any codes or standards, the applicant must describe the basis and rationale used to formulate the package quality assurance program. When established codes and standards are not available, detailed guidance with respect to assessing compliance is provided in subsequent sections of this PRG dealing in specialized areas.

If the applicant uses a graded approach, then all components essential to safety shall be clearly identified, classified according to their importance, and related to quality standards such as those contained in codes and standards. The quality standards specified must be consistent with the QA requirements given in Section 11.0 of the SARP. 


\section{$2 A$ Procedures}

In general, verify that all the information specified in Section 2.3, Acceptance Criteria, is provided in the SARP.

\subsubsection{Uee of Packaging}

The description of the use of the packaging must be sufficient so that the reviewer can understand exactly how the packaging is to be used. Confirm the assignment of the fissile class and transport index of the packaging for the specified contents.

\subsection{Packaging Description}

Verify the items listed in the following subsections.

\subsubsection{General}

Verify that the packaging description includes the gross weight, materials of construction, materials used as neutron absorbers or moderators, external dimensions and cavity size, internal and external structures, receptacles, valves, sampling ports, means of heat dissipation, volumes and types of coolant, outer and inner protrusions, lifting and tie-down devices, amount of shielding, pressure relief systems, closures, and means of containment. Verify that the containment vessel is clearly identified, and that overall and cutaway sketches ( $8-1 / 2 \times 11$ inches) of the packaging are included as part of the description.

\subsubsection{Drawings}

Verify that drawings which clearly detail the safety features considered in the analysis are included; e.g., material lists, dimensions, valves, fasteners, and welder and welding procedure qualification requirements. The drawings should specify, by appropriate weld symbol, the requirements for all packaging weld joints, including the method of nondestructive examination and the acceptance standard. Gasketed joints in the containment system should be sufficiently detailed to show at least the surface finish and flatness requirements of the closure surfaces, the gasket specification, and, if appropriate, the method of gasket retention. All dimensions on the drawings must be consistent and complete. 


\subsubsection{Operational Features}

For complex packages, verify that all operational features and functions are discussed. A schematic diagram should be included in the SARP showing all valves, connections, piping, openings, seals, and containment boundaries. Evaluate the operational features for their operability and safety.

\subsection{A Contents of Packaging}

Verify that the applicant has stated the quantity of radionuclides (in the case of spent fuel shipments, and has estimated the quantity of radionuclides available for immediate release within the void space of the fuel rods), chemical and physical form, material density, moderator ratios, configurations as required for nuclear safety evaluation, the maximum amount of decay heat, maximum pressure buildup in the inner container, and any other loading restrictions.

Evaluate the information for consistency, e.g., for a specified reactor type, U-235 enrichment, burnup, operating history, and cooling period, spent fuel specific fission decay products, decay heat, gamma and neutron spectrum.

\subsubsection{Packaging Evahuation}

Verify that the summaries of the evaluations are correctly taken from their various sections. Evaluate the summary results to determine if the packaging complies with regulations.

\subsubsection{Quality Standards}

Verify that all safety components have been properly identified and classified such that appropriate quality standards are applied during the design, manufacture, and use of the packaging. Verify that the quality standards and QA requirements are consistent with the level of safety provided for each component (see Section 11.0).

\subsection{Supplemental Information}

Verify that all of the supplemental information such as drawings, operational schematics, loading configurations, and radionuclide listing (such as ORIGEN output) are consistent with the packaging and content descriptions. 


\subsection{Findings}

Verify that sufficient information has been provided to satisfy the requirements of this review guide section and that the evaluation supports conclusions of the following type, to be included in the safety evaluation report.

The staff concludes that the application for package approval has been prepared so that:

1. "The packaging and its contents have been described in sufficient detail to identify the package accurately and provide a sufficient basis for evaluation of the package."

2. "The application contains all the information required to demonstrate compliance with DOE 1540.2, Chapter 11 and the Subparts E and F of 10 CFR Part 71. Where alternative methods have been proposed to demonstrate compliance, sufficient information has been provided to perform an orderly review."

3. "The application provides sufficient information and does in fact assure compliance with the requirements relating to general otandards for all packages."

4. "The spplication contains a quality assurance program that conforms io DOE 5700.6B and Subpart H of 10 CFR Part 71."

\subsection{Peferences}

1. U.S. Department of Energy, DOE 5480.3: Safety Requirements for the Packaging and Transportation of Hazardous Materials. Hazardous Substance, and Hazardous Wastes, U.S. Department of Energy, Washington, DC, August 9, 1985.

2. U.S. Department of Energy, DOE 5700.6B: Quality Assurance, U.S. Department of Energy, Washington, DC, September 23, 1986.

3. Office of the Federal Register, Title 10. Code of Federal Regulations. Part 71 Office of the Federal Register, Washington, DC, 1984.

4. U.S. Nuclear Regulatory Commission, Regulatory Guide 7.10: Establishing Quality Assurance Programs for Packaging Used in the Transport of Radioactive Material, U.S. Nuclear Regulatory Commission, Washington, DC, January 1983. 
5. American National Standards Institute, QA Program Requirements for Nuclear Facilities, American National Standards Inst., New York, NY, ANSUASME-NQA-1.

6. Office of the Federal Register, Title 49, Code of Federal Regulations, Part 173, Office of the Federal Register, Washington, DC, November 1, 1984.

7. U.S. Nuclear Regulatory Commission, Eracture Toughness Criteria for Ferritic Steel Shipning Cask Containment Yesgels with a Maximum Wall Thickness_of Four Inches $(0.1 \mathrm{~m})$. Draft Regulatory Guide MS 144.4. Single copies are available from the USNRC Division of Technical Information and Document Control, Washington, DC 20555.

8. American Society of Mechanical Engineers, ASME Boiler ind Pressure Vessel Code, 1983 edition, the American Society of Mechanical Engineers, United Engineering Center, 345 East 47th Street, New York, NY 10017.

9. U.S. Departmeint of Energy, DOE 1540.2: Hazardous Material Packaging for Transport - Administrative Procedures, U.S. Department of Energy, Washington, DC, September 30, 1986.

10. U.S. Nuclear Regulatory Commission, Regulatory Guide 79: Standard Format and Content of Part 71 Applications for Aporoval of Packaging of Troe B. Large Quantity and Fissile Radioactive Material, U.S. Nuclear Regulatory Commission, Office of Standards Development, Washington, DC, January 1980, Rev. 1. 

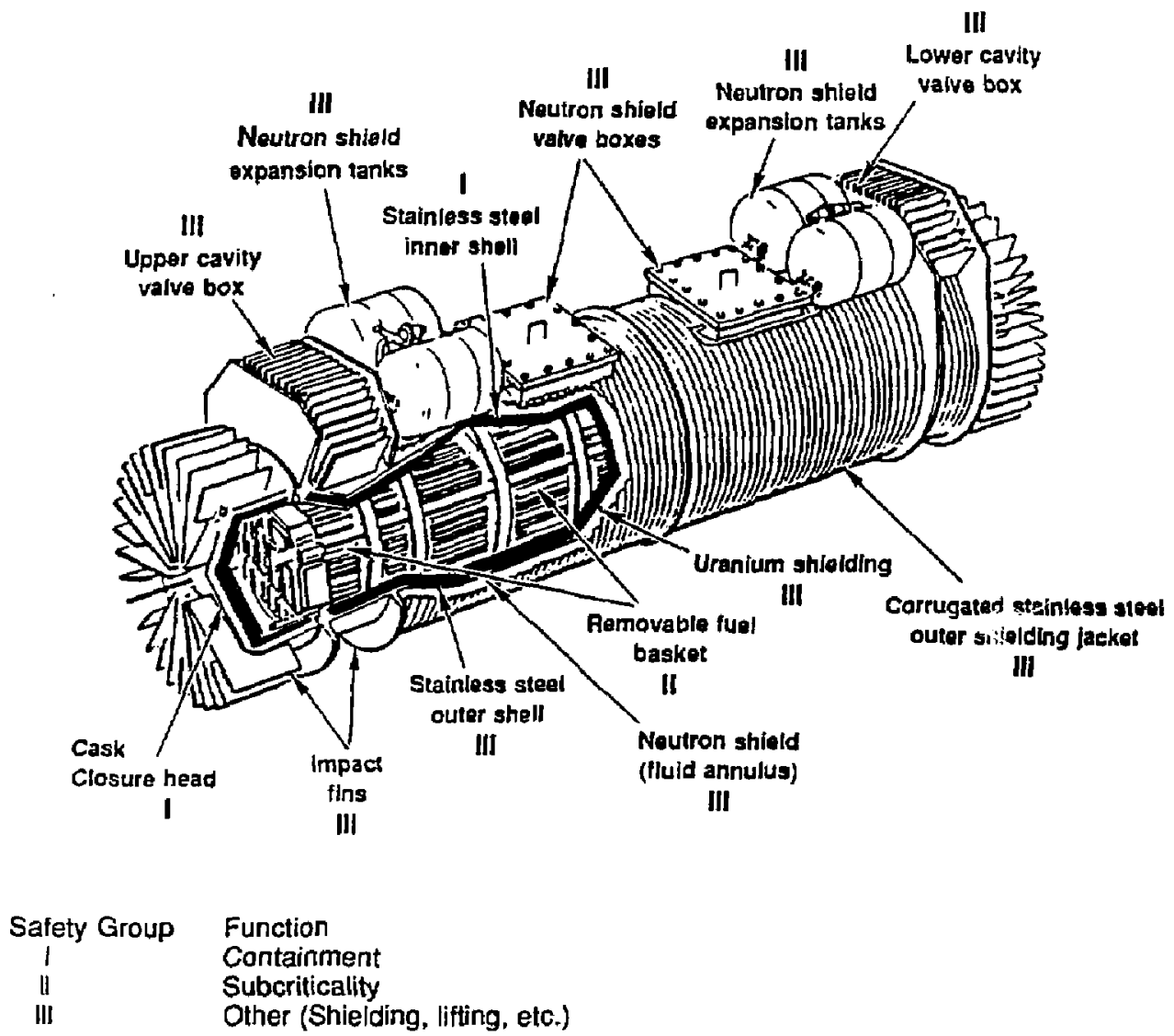

Figure 2-1 Packaging features important to safety for a spent fuel cask. 


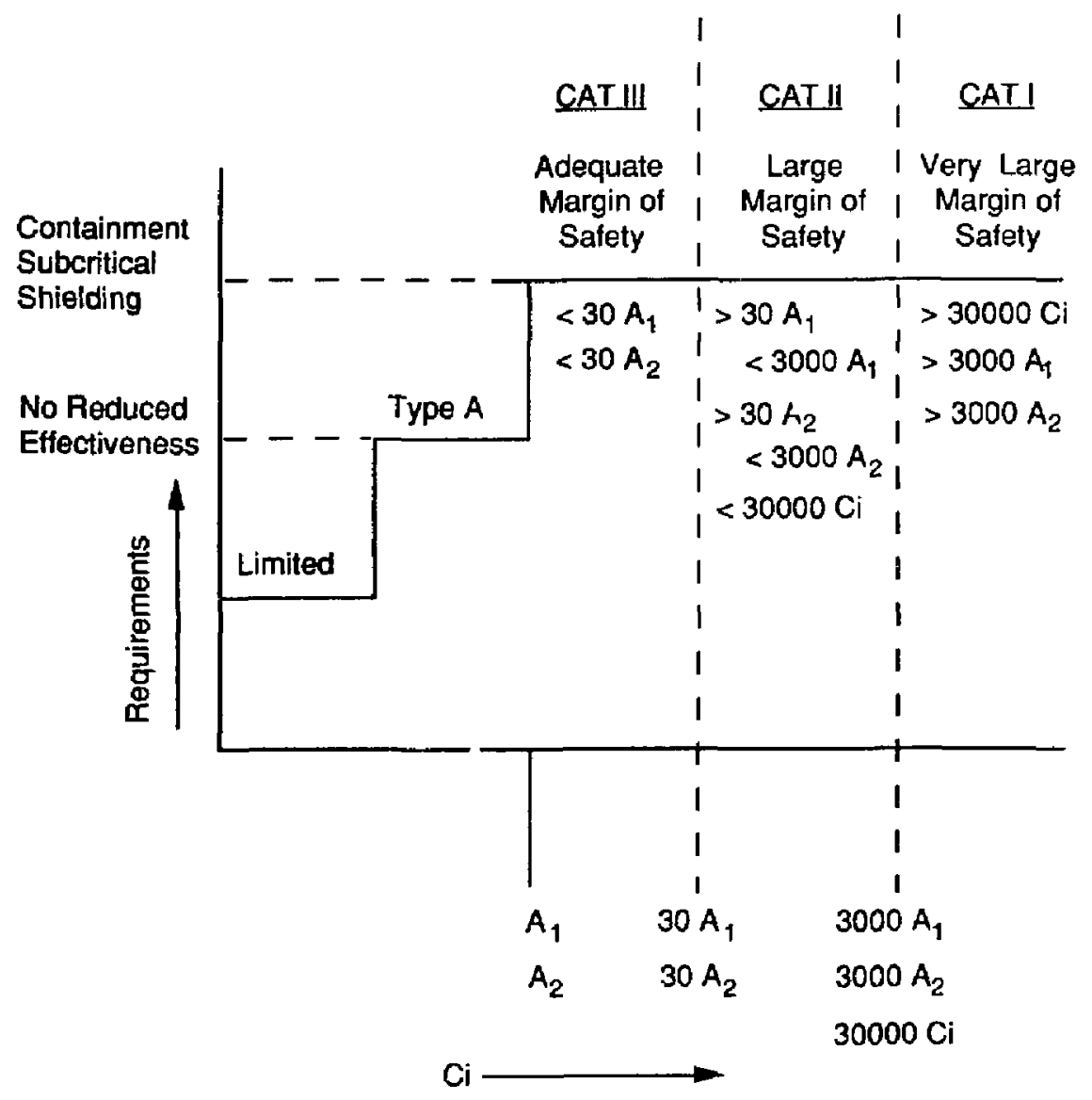

Figure 2-2 Packaging requirements and activity levels of $+\mathrm{w}_{4}$.ts. 
Table 2.1

Design, Manufacture, Use, and Maintenance Criteria (Based on ASME Code)

\begin{tabular}{|c|l|l|l|}
\hline \multirow{2}{*}{ Component Safeiy Group } & \multicolumn{3}{|c|}{ Container Contents } \\
\cline { 2 - 4 } & Category I & Category II & Category III \\
\hline Containment & $\begin{array}{l}\text { Section III } \\
\text { Subsection NB }\end{array}$ & $\begin{array}{l}\text { Section III } \\
\text { Subsection ND }\end{array}$ & $\begin{array}{l}\text { Section VIII } \\
\text { Division ! }\end{array}$ \\
\hline Subcriticality & \multicolumn{3}{|c|}{ Section III, Subsection NG } \\
\hline Shielding and Other & \multicolumn{3}{|c|}{$\begin{array}{c}\text { Section VIII, Division 1 or } \\
\text { Section III, Subsection NF }\end{array}$} \\
\hline
\end{tabular}




\subsection{REVIEW OF MATERIAL AND FABRICATION SPECIFICATIONS}

\subsection{General}

DOE 5480.3, Section 9 and Paragraph 71.33(a)(5) of 10 CFR Part 71 requires that information relative to materials of construction be furnished in sufficient detail to provide a basis for evaluation of the packaging. 1,2 Furthermore, Paragraph 71.37(b) requires, in part, that the applicant identify any established codes and standards proposed for use in package design. These regulatory requirements compel the applicant to provide materials property data that is thorough and of high quality. If possible, only materials that are described by standard specifications should be used. This assures that the material properties which serve as a basis for the various safety analyses will be uriform. The applicant must adequately characterize any specified materials that are not described by authoritative standards. Not only should the material be characterized with respect to the values of its mechanical and physical properties but, in addition, the means by which quality is assured and the effect of fabrication processes should be addressed.

In general, materials adopted by the ASME and listed in the appendices of the boiler and pressure vessel code may be selected for package components important to sefety. 3 Besides the advantage of being supplied the primary membrane stress intensity limit, $S_{\mathbf{m}}$, for the listed materials, there is an implied assurance that the materials are sufficiently ductile to allow yielding at structural discontinuities with a large margin of safety against failure. Such materials may be used with confidence for package components for normal design conditions. Under accident conditions, however, the package is assumed to be subjected to severe loads where ductility and toughness of the material must be adequate to prevent brittle fracture.

Similar requirements exist for pressure vessels that may be subjected to thermal shock. While fracture may be initiated in the wall of the pressure vessel, the rapidly decreasing stress gradient combined with an increasing temperature gradient arrests cracking. No such mitigating factors may be assumed for the package containment envelope under impact loads bccause the stresses are assumed to be primary and the temperaiure uniform throughout the wall at $-29^{\circ} \mathrm{C}\left(20^{\circ} \mathrm{F}\right)$. Consequently, except for austenitic stainless steel, the ability of packaging materials to resist fracture under accident conditions must be convincingly demonstrated. 


\section{Areas of Review}

The following areas which relate to materials used for constructing radioactive material packages for transportation are reviewed:

\subsubsection{Material Properties}

Review the material specifications used for packaging and applicable appurtenances and their adequacy for use in the construction of such components. Assess adequacy on the basis of the material mechanical and physical properties, their corrosion resistance, and fabricability. Review information submitted by the applicant for any special process used in the manufacture of th $\approx$ packaging or any of its appurtenances. Assess the capability of these processes io provide components with suitable mechanical and physical properties.

\subsection{Fracture Resistance}

Review the fracture resistance of materials used for the packaging containment to assure that the containment will not fracture in a brittle manner under operating, maintenance, testing, and postulated accident conditions. This review guide describes in 3.3 various acceptance criteria that assure fracture resistance.

\subsubsection{Packaging Fasteners}

Review the materials selected for the stud bolts, washers, and nuts, or other fasteners used to secure the closures to ensure that they will provide their function under normal accident conditions. Check mechanical properties to ensure that all requirements are met. Review lubricants or surface treatments to assure that studs will be resistant to stress-corrosion cracking under the environmental conditions during service and shutdowns. Review the adequacy of the destructive and nondestructive testing procedures used to ensure initial integrity, along with the applicable acceptance criteria.

\subsection{Fabrication and Processing of Package Components}

a) Review the influence of fairication and processing upon the structural adequacy of materials used for components important to safety. This review is particularly relevant to containments constructed of ferritic steels and ductile cast irons, and baskets 
constructed of borated austenitic stainless steels, ferritic stainless stets, and aluminum alloys.

b) Review the effect of special processes on the fracture toughness and stress corrosion characteristics of the material.

c) Review special methods for nondestructive examination. Nondestructive examination methods differing from those described in the ASME Boiler and Pressure Vessel Code (hereafter, the Code), Section III, are reviewed. Attention is directed towards calibration methods, instrumentation, methods of application, sensitivity, reliability, and standards use.

\subsection{Acceptance Criteria}

The acceptance criteria for the areas of review described in Section 3.2 are as follows:

\subsubsection{Material Properties}

a) Acceptable material specifications are those listed in the Code, Section III, Appendix I, and are presented in detail in Section II, Parts A, B, and C.

The acceptability of materials not specified in the Code is considered on an individual basis. Suitability is evaluated on the basis of data submitted in accordance with the requirements of Code Section III, Appendix IV-1400. These data must include not only information on mechanical properties but also a description of any physical or mechanical changes of the material that might be caused by fabrication and processing.

b) All material properties required for the analysis of components important to safety must be described, and all the material mechanical properties used in the structural evaluation must be listed. If impact limiters are used, a compression stressstrain curve for the material or the force-deformation relationship for the limiter, as appropriate, should be included at the relevant high and low temperatures. For materials that a $:$ subjected to dynamic loadings or elevated temperatures, the appropriate mechanical properties under these conditions should be specified to the extent needed for the structural evaluation. The source of all material properties information should be clearly and specifically referenced as to publication and page 
number. Where material properties are determined by testing, the test procedure, conditions, and measurements should be described in sufficient detail to conclude that the results are valid.

\subsubsection{Fracture Resistance}

Packages must meet the following requirements for fracture resistance during system hydrostatic tests, normal operating conditions, and accident conditions:

\subsubsection{Material Selection Criteria}

The fracture resistance of a material refers to its ability to resist brittle fracture. This resistance is demonstrated by materials of sufficient toughness that fracture is not initiated before the yield strength is exceeded. Austenitic steels meet this requirement provided that neither fabrication processes nor environment significantly degrades their properties. Consequently, austenitic stainless steels qualify as fracture-resistant materials if the applicant demonstrates that processes such as forming or welding, or the materials in contact with them, do not significantly reduce toughness.

For materials such as ferritic steels which exhibit a transition with temperature from ductile to brittle behavior, the nil ductility transition temperature shall be such that, at the lowest $\left(-40^{\circ} \mathrm{F}\right)$ service temperature, catastrophic crack propagation cannot occur even if a crack begins.

\subsubsection{Fracture Resistance hy Analysis}

Where formal methods for computing fracture resistance such as linear elastic fracture mechanics are used, resistance to fracture initiation must be demonstrated at yield strength levels of stress, with the critical flaw size at least twice the maximum allowable flaw size specified.

\subsubsection{Fracture Resistance Demongtrated by Prototype Testing}

A full-scale drop test to demonatrate resistance to fracture under accident conditions will have been performed with an artificially flawed container. 


\subsubsection{Packaging Fasteners}

a) Packaging fasteners used for closures, lifting lugs, and tie-down devices are considered components important to safety. The ASME Code, Section III, defines acceptance criteria for closure bolts, studs, and fasteners applicable to Category I and II packages. Studs and bolts used for lifting lugs and tie-down devices are required to meet similar acceptance criteria.

b) The material for studs, bolts, nuts, and other types of fasteners should be selected from those that are listed in the material specifications of the Code. In addition, the material for the package fasteners important to safety should conform to the requirements of sub-article $\mathrm{NB} \cdot 2580$ of Section III of the Code.

c) Surface treatments, plating, or thread lubricants used must be shown to be compatible with the materials and stable at operating temperatures.

\subsection{Procedures}

The reviewer will select and emphasize material from the procedures described below, as appropriate for a particular case. Review as follows for each area specified in Section 1.0 of this plan.

\subsubsection{Material Properties}

\subsubsection{Material Specification}

a) Verify that the material specifications for the packaging components conform to the acceptable specifications listed in the ASME Code, Section III, Appendix I, and Section II, Parts A, B, and C.

b) Identify any materials not listed in the Code, or any deviations in a listed specification, and evaluate the basis for deviation or nonconformance. A study of the suitability of the material and comparisons with precedents set in earlier cases enable the reviewer to determine the acceptability of the proposed exception. In those instances where the reviewer has taken exception to the use of a specific material, or questions certain aspects of a specification, advise the applicant which material is not acceptable and the reason for disapproval. 
c) Verify that for materials not specified in any authorized code, the applicant has provided sufficient information to support the structural analysis that demonstrates safety of the package under the design loading conditions. Properties marked with an asterisk(*) in the list below should be specified over a range of operating temperatures:

1. minimum yield strength *

2. minimum tensile strength *

3. percentage elongation *

4. percentage reduction of area

5. Young's modulus *

6. Poisson's ratio

7. fatigue curves

8. creep threshold temperature corresponding to $10^{6}$ hours creep rupture life

9. fracture toughness *

10. coefficient of thermal expansion *

11. chemical composition ranges

12. heat treatment

13. density

14. chemical composition

15. heat capacity *

16. thermal conductivity *

17. melting temperature

18. emissivity *

d) Verify that the source of the above material properties are clearly and specifically referenced. If the materials properties are determined by testing, verify that the test procedures, conditions, and measurements are described in sufficient detail to conclude that the results are valid.

\subsubsection{Special Proceses Used for Manufacture and Fabrication of Components}

Review information on special processes used for manufacture and fabrication of the packaging components.

a) Identify each special process. 
b) Determine whether there are any code restrictions on use.

c) Establish the adequacy of the process in providing components with suitable mechanical and physical properties. Since there are no specific code requirements on the use of special processes, the suitability of a process is assessed on the basis of service experience with similar parts fabricated by the process being reviewed.

d) Establish the effects of such processes on the stress-corrosion characteristics of the material.

e) Identify whether special requirements for nondestructive exemination are needed if a special process is used.

\subsubsection{Corrosion Resistance}

Verify that the following information is provided:

a) A list of the construction materials of packaging components that are exposed to corrosive or other aggressive environments.

b) A description of material compatibility with the containment or radiolytic products to which the materials may be exposed.

c) An assessment of the degree to which the material or structural properties of the material are affected by exposure to the corrodants. This may be reflected by reductions in design stress intensity, fatigue limits, or fracture toughness.

\subsubsection{Fracture Pesistance}

\subsubsection{Material Selection Criteria}

\subsection{Austenitic Stainless Steel}

Austenitic stainless steels do not exhibit a transition from ductile to brittle behavior with temperature. They normally retain their ductility and toughness at extremely low temperatures. However, austenitic stainless steels are subject to stress corrosion cracking and intergranular corrosion and must be protected from contaminants and environments that promote cracking and corrosion. Test data and service experience indicate that sensitized stainless steel is significantly more susceptible to stress corrosion cracking. Sensitization is caused by intergranular precipitation of chromium carbide in austenitic stainless steels that are exposed to temperatures in the appropriate range 
$427^{\circ} \mathrm{C}\left(800^{\circ} \mathrm{F}\right)$ to $870^{\circ} \mathrm{C}\left(1599^{\circ} \mathrm{F}\right)$. Precipitation increases with increasing carbon content and exposure time. Because excessive cold working in austenitic stainless steels can render this material more susceptible to stress corrosion cracking, the cracking must be controlled by placing an upper limit on the yield strength. Review the following items:

a) Plans to avoid sensitization during welding. Reference to Regulatory Guide (R.G.) 1.44, "Control of the Use of Sensitized Stainless Steel" is acceptable. ${ }^{4}$

b) Plans for isolation of austenitic stainless steel from halogens or halogen-bearing compounds (e.g., die lubricants, marking compounds, and masking tape) and other environments that may promote stress corrosion cracking.

c) For cold worked stainless steels, the upper limit on yield strength, as indicated by tests and experience, does not exceed $90,000 \mathrm{psi}$.

\subsection{Ferritic Steels}

Ferritic steels exhibit a transition with temperature from ductile to brittle behavior. It is essential that the steel at the lowest service temperature exhibit a toughness well beyond its nil ductility transition temperature (NDTT). The required margin between the lowest service temperature and the maximum allowable NDTT depends upon the thickness of the material. Methods for establishing the required NDTT are currently being developed based upon the research described in References 5 and 6. Pending release of an R.G., use these references to review the adequacy of ferritic steels specified by the applicant for the primary containment structure.

\subsubsection{Fracture Resistance by Anglysig}

Fracture resistance by analysis implies the use of the linear elastic and elastic plastic fracture mechanics to assess the likelihood of catastrophic brittle fracture given the presence of a flaw. Stress levels, critical stress intensity, flaw size, and flaw geometry are essential parameters for evaluating fracture resistance by this method. This methodology to qualify a component for resistance to brittle fracture has its inherent uncertainties. Verify that the margins of safety against fracture conservatively reflect the uncertainties in the data. Furthermore, since allowable stresses under accident conditions could exceed the elastic limit and, in fact, could result in a small amount of 
plastic deformation, insist that flaws do not exceed sizes that would cause catastrophic crack propagation even at yield strength levels of stress. Appliceble techniques of nondestructive examination (NDE) must be capable of reliably detecting flaws apparentiy smaller than the maximum allowable flaw size.

\subsubsection{Fracture Resistance Demonstrated by Prototype Testing}

Where the material specified for the construction of the primary containment of the package cannot be qualified for resistance to brittle fracture either by an acceptable materials selection criterion or by a classical fracture mechanics type of analysis, acceptance may be based upon an appropriate drop test. The severity of the test must be great enough to envelop the loadings that would be developed in a credible transportation accident of sufficiently low probability of occurrence. The establishment of a "sufficiently low probability of occurrence" is related to the issue of what constitutes an acceptable level of risk and, in the end, can only be resolved by invoking subjective perceptions of safety. Guidance in this regard is provided by the drop test specifications of 10 CFR 71.71 and 75 . While the test specification ensures universal acceptance as an adequate simulation for real world accidents, consider the margins of safety against more serious consequences should an accident occur that causes loads in excess of those developed during the test.

Verify that the test plan is adequate to demonstrate that brittle fracture will not occur under accident conditions if the condition of the package following the test meets the specified acceptance criteria. Reference 7 gives guidance with respect to the test conditions and acceptance criteria.

\subsection{Package Fasteners}

a) Verify that materials for all package fasteners important to safety are listed in the material specification of the ASME Code.

b) Verify that the special requirements relating to bolting material for nuclear applications are specified in the SARP. Specifically verify that provisions of the joint ASME/ASTM specification SA-614 are included.

c) Review the SARP for information relating to the application of surface treatments, plating, or thread lubricants. Verify that if such are applied, they are 
compatible with package fastener materials and remain stable at operating temperatures.

\subsection{A Fabrication and Processing of Package Components}

Verify that the SARP considers the effect of fabrication processes upon the mechanical or structural properties of the materials. Some fabrication processes that may affect these properties are identified in 3.4.4.1 and 3.4.4.2.

\section{A.4.1 Forming Proceses}

The fracture toughness properties of materials can be reduced during fabrication by forming or bending. The magnitude of the reduction is usually determined by test and should be considered when establishing fracture toughness limits. Reference 8 contains guidance relating to recommended fabrication criteria for shipping containers.

\subsubsection{Welding Processes}

The mechanical and structural properties of a material are significantly affected at the heat effect zone adjacent to a weld. In addition, the welding process may introduce stresses, cracks, or other imperfectio. s that compromise the base materials properties. Ascertain that the SARP considers the effect of welds upon the assumed design stress intensity, fatigue, limits, or fracture toughness limits. Reference 9 contains guidance relating to welding criteria applicable to shipping containers.

\subsection{Findings}

Verify that sufficient information has been provided to satisfy the regulatory requirements and that this evaluation supports conclusions of the following type, to be included in the safety evaluation report.

The siaff concludes that the materials selected for the packaging are adequate for use in construction of its components. This conclusion is based on the following items:

1. "The applicant has provided sufficient information to show that all materials are identified by authoritative material specifications. For those materials that are not so identified, sufficient information has been provided, in an acceptable format, that justifies the allowable limits estimated for the safety analysis." 
2. "The applicant has demonstrated that the material selected for the package containment has a nil ductility tranf tion temperature sufficiently below the lowest service temperature to assure that brittle fracture will not occur under postulated accident conditions."

3. "The applicant has demonstrated for conservatively established values of stress, critical stress intensity, flaw size, and flaw configuration, that brittle fracture will not occur under pastulated accident conditions. The use of Appendix $G$ of the ASME Code as a guide in establishing stress intensity factors, and use of the results of the fracture toughness tests performed in accordance with the ASME Code and ASTM, will provide adequate safety margins during operating, testing, and postulated accident conditions. Compliance with these Codes and standards constitutes an acceptance basis for satisfying the fracture toughness requirements,"

4. "The applicant has furnished sufficient information with respect to a drop test plan to assure that brittle fracture will not occur under postulated accident conditions if the conditions of the package following the test meet the specified acceptance criteria."

5. "The materials of construction of the packaging components exposed to aggressive environment have been identified, and all of the materials are compatible with the expected environment, as proven by extensive testing and satisfactory performance. General corrosion of all materials is negligible. Where it is not, conservative corrosion allowances have been provided for all surfaces in accordance with the requirements of the Code, Section III."

6. "The applicant has identified special processes used for the fabrication of the packaging components and has submitted appropriate data reports on each process as required by Section III of the Code. Since certification has been made by the applicant that the materials and fabrication requirements of Section IX of the Code have been complied with, the special processes used are considered acceptable." 


\subsection{References}

1. U.S. Department of Energy, DOE 5480.3: Safety Requirements for the Packaging and Transportation of Hazardous Materials. Hazardous Substances, and Hazardous Wasteg, U.S. Department of Energy, Washington, DC, August 9, 1985.

2. Office of the Federal Register, Title 10. Code of Federal Regulations, Part 71, Office of the Federal Register, Washington, DC, January 1984.

3. American Society of Mechanical Engineers, ASME Boiler and Pressure Vessel Code, 1983 edition, the American Society of Mechanical Engineers, United Engineering Center, 345 East 47th Street, New York, NY 10017.

4. U.S. Nuclear Regulatory Commission, Regulatory Guide 1.44. "Control of the Use of Sensitized Stainless Steel," U.S. Nuclear Regulatory Commission, Washington, DC.

5. Holman, W.R., and Langland,W.R., Recommendations for Protecting Agaisst Failure by Brittle Fracture in Ferritic Steel Shipping Containers Up to Four Inches Thick, Lawrence Livermore National Laboratory, Livermore, CA, NUREG/CR-1815, UCRL-53013, June 1981.

6. Schwartz, M.W., Recommendations for Protecting Against Brittle Fractures in Eerritic Steel Shipping Containers Greater Than Four Inches Thick, Lawrence Livermore National Laboratory, Livermore, CA, NJREG/CR-3826, UCRL-53538, April 1984.

7. Schwartz, M.W., A.Study on Ductile and Brittle Failure Desipi Criteria for Ductile Cast Iron Snent-Fuel Shipping Containers, Lawrence Livermore National Laboratory, Livermore, CA, NUREG/CR-3760, UCRL-53532, Rev. 1, August 1985.

8. Fischer, L.E., and Lai, W., Eabrication for Shipping Containers, Lawrence Livermore National Laboratory, Livermore, CA, NUREG/CR-3854, UCRL-53544, March 1985.

9. Monroe, R.E.; Woo, H.H.; and Sears, R.G., Recommended Weiding Criteria for Use in the Fabrication of Shipping Containers for Radioactive Materials, Lawrence Livermore National Laboratory, Livermore, CA, NUREG/CR-3019, UCRL-53044, March 1984. 


\subsection{REVIEW OF STRUCTURAL EVALUATION}

\subsection{General}

The objectives of the review are to confirm that the structural design of the transport packaging uses acceptable analytical and/or test methods and complies with DOE 5480.3 and 10 CFR 71 regulations.1,2 This section gives guidance for review of the structural design of a packaging submitted in a SARP for DOE certification.

The types of information required from other sections of the SARP to perform the structural review are shown in Fig. 4-1. General information is required on the packaging dimensions, component materials, and component classification. Each component needs to be specifically defined for its functionality and classification. Structure reviewers need to review the definition carefully and understand how the designated function can be achieved through structural design. The packaging temperature distributions for normal and hypothetical accident conditions are taken from the thermal section. Information on materials in the SARP should include structural design properties and descriptions of the fabrication processes. Reviewers responsible for these other sections should assist in verifying that the information required for the structural reviews is adequate and usable for the review.

The structural loads applied to the package are reviewed. The structural loads can include impact, temperature gradients, puncture, pressure, and vibration. Fabrication processes can also affect the load on the package. In most cases, various loading combinations for several loading conditions have to be reviewed. The specific areas for review which address these loads are given in Subsection 4.2.

The structural review requires an in-depth assessment of the structural mechanics aspects of the packaging design. The reviewer must evaluate structural models and their assumptions. Special structural features and operating modes that can significkutly affect mechanical loads must be recognized, understood, and evaluated. The reviewer should have a general knowledge of materials, their structural properties, and how the structural properties may change under environmental conditions, such as temperature and cycling. The reviewer should be aware of structural dynamic behavior under impact loading and the methods available for calculating impact responses.

The structural review should assess the adequacy of the structural design of each component for all loading conditions. The review evaluation of the structural results 
should be provided to other disciplines which include thermal, subcriticality, shielding, containment, operations, and acceptance testing. The distortions determined by the structural analyses from the SARP are used in other areas to evaluate heat transfer; reduction in the subcriticality margin, containment or shielding capabilities and establishing cycling or temperature limits on certain operations.

General guidance is given in the following subsections to assist in the structural review of transport packagings. The general guidance addresses the structural design criteria and methods of analysis.

\subsubsection{Structural Design Criteria}

\subsubsection{Discussion}

A survey was performed to identify industry codes, standards, and practices which could apply to the structural design of packagings. The most important code and standards identified in the survey were the ASME and AISC Codes and the ASTM and ANSI Standards. The ASME Code was selected as the primary source for structural design criteria because it is the basis for designing components for nuclear reactors. ${ }^{3}$ In addition, the ASME Code provides design criteria to ensure various levels of safety. Although there is no specific section in the ASME Code dedicated to transport packaging, the shipping industry has used the ASME Code extensively for designing packagings over the past 20 years.

The general philosophy of the ASME Code is applicable to almost any loading and structural condition. It is clear that the margin of safety concept used in developing the ASME Code should still be the fundamental principle for transport packaging design. But the design criteria provided in the ASME Code for nuclear reactor design may not be directly applicable to packaging design due to the differences in loading (impact vs. pressure) and environmental conditions (temperature range). It may be necessary that a new set of criteria be developed by the ASME in the future to safeguard packaging design. In the absence of such a complete set of design criteria, the NRC has established a set of regulations to safeguard portions of structural design. The following sections discuss ASME stress allowable philosophy and stress classification, as well as available regulatory guides. It should be understood that in most cases the acceptance criteria are closely related to the method of analysis used in the design. In both ASME Code and 
NRC Regulatory Guides, the method of analysis used in design is an integral part of acceptance criteria. Therefore, the method of analysis for certain loading conditions is also described.

\subsubsection{Stress Intensity}

The basic philosophy of the ASME Code was founded upon elastic models of structural and material behavior for ductile shell structures. 4 The maximum shear stress theory of failure is used as a basis for allowable stresses. A stress intensity defined, as twice the maximum skear stress, is used as the measume of stress. The stress intensity is required to be less than or equal to the stress intensity linit specified for a given or combined loading condition. The stress intensity limit depends upon either a design intensity value, $S_{\mathfrak{m}}$, or a tensile strength value, $S_{u}$, for each material of construction at the specified temperature. Failure modes addressed by the stress acceptance criteria are gross rupture, progressive deformation, and fatigue. Reference 44 provides the basic code philosophy for the establishment of stress acceptance criteria for the specified categories of stress intensity.

General guidance and stress definitions are provided in the ASME Code, Section III, Subsection NB, for classification of stresses in Class 1 pressure vessels. The stress classifications are:

$$
\begin{aligned}
& P_{m} \text { - General Primary Membrane } \\
& P_{L} \text { - Local Primary Membrane } \\
& P_{b} \text { - Primary Bendin } \\
& \mathbf{Q} \text { - Secondary } \\
& \text { F - Peak }
\end{aligned}
$$

\subsubsection{Strese Classification}

The stress classification depends, in part, on whether the loading event is load controlled or deformation controlled. A siress resulting from a load controlled event, such as impact, may be in any of the above categories, but a stress resulting from a deformation controlled event may only be secondary or peak. For instance, internal pressure results in a load controlled condition, and thermal stress normally is a deformation controlled stress. An exception is : chermal stress in the closure system. 
This stress is primary, because the function of the closure system is controlled by controlling the deformations. The general membrane stress that results from that pressure is primary in that deformation of the vessel will not relieve the general membrane load. At the junction of the vessel head to the cylindrical shell, there is both membrane and bending stress. In curved shells, the primary load resistance path is membrane loading. Bending caused by incompatible rotations of adjacent shell segments is generally considered a secondary stress only in those cases where a small amount of inelastic deformation satisfies the rotation incompatibility and relieves the applied moment in the joint. Peak stress may result at a local discontinuity (notch). Any local yielding relieves the localized loading without altering the general equilibrium of the structure.

\subsubsection{Regulatory Guides}

Regulatory Guide (R.G.) 7.6 adapts portions of the ASME Code, Section III, Subsection NB, to form acceptable structural design criteria for spent fuel cask containment vessels. 5 Design criteria for Level A Service Limits and Level D Service Limits from the ASME Code are adopted in R.G. 7.6 for normal and accident conditions, respectively, for application to spent fuel casks. However, R.G. 7.6 states that linear elastic analysis can be applied for designing spent fuel containment vessels. The assumption of using linear elastic analysis for design is compatible with the basic philosophy of the ASME Code, allows the principle of superposition to be used for load combinations, and ensures that appropriate margins of safety are designed into spent fuel casks. In recommending linear elastic analysis, R.G. 7.6 does not preclude appropriate nonlinear treatment of other cask components such as lead shielding and impact limiters.

Figure 4-2 outlines a procedure for identifying and combining loads, classifying stresses, and comparing the stress results with the acceptance criteria specified in R.G. 7.6 for spent fuel casks. First of all, individual loading conditions are identified for normal and accident conditions. Individual loading conditions and initial environmental conditions are specified in R.G. 7.8. ${ }^{6}$ Some of the load conditions specified have both positive and negative directions of loading depending on environmental conditions. As such, each specified load combination may result in several sets of resultant stresses. Stresses caused by fabrication processes such as pouring lead and shrink fitting are assessed for inclusion in any detailed analysis. Loads such as internal pressure caused 
by cask operations may have to be included in the analysis. Cursory analyses may be performed to determine which loads should be calculated in detail and combined with the impact loads.

\subsubsection{Design Criteria}

In the early 80 's, brittle fracture criteria for ferritic steels were developed for the NRC by LLNL for Type B packagings.7-9 It was recognized that most Type B packagings were not as potentially hazardous as spent fuel casks and therefore could be constructed to less atringent standards than those required for spent fuel casks. Three packaging categories were defined according to their type and level of contents as shown in Figure 4 3. For a specific radioisotope, Category I includes the highest levels of activity to be transported, such as spent fuel, and requires the highest margins of safety, whereas, Categories II and III include the medium and low activity levels and therefore require lower margins of safety. The margins of safety, acceptance criteria, and quality assurance requirements for each category were developed under an extensive NRC research program. Fabrication and welding criteria were then adapted from the ASME code for the three package categories and three component safety groups.10,11 The first designated safety group, containment components, includes all components used to retain the radioactive contents in the packaging during transport. Containment components include the containment vessel, closure, seals, piping, and bolts. The second group, subcriticality components, includes all components used to control nuclear criticality during the transport of fissile materials in the packaging. The subcriticality components include neutron absorber materials such as boron carbide and the associated structures that retain the relative positions of the fissile and neutron absorber materials during transport. The third group, shielding and other safety components, includes all of the remaining safety-related components. In this group are gamma and neutron shielding; secondary containment seals, bolts, and closures; impact limiters; and lifting lugs and tie-down devices. The ASME code criteria that was selected for welding and fabrication are identified in Table 4.1 for the designated package categories and component safety groups.

Currently there is no specific national code or standard for constructing and using Type B packagings. Until applicable codes and standards are develeped, it is recommended to use the applicable ASME code structural design criteria identified in Table 4.1 or equivalent for reviewing the structural evaluation of Type $B$ packages. 


\subsubsection{Methods of Analysis}

\subsubsection{Penetration and Puncture}

Two puncture type loads are required by 10 CFR 71. First, a penetration evaluation, is a normal load requirement. It is the drop of the hemispherical end of a vertical steel cylinder of $3.2 \mathrm{~cm}(1-1 / 4)$ inch diameter and $6 \mathrm{~kg}$ (13-lb.) weight, from a height of $1 \mathrm{~m}$ (40 inches) onto the exposed surface of the packaging that is expected to be the most vulnerable to puncture. The second, a puncture test, represents a hypothetical accident condition and consists of the free drop of the package through a height of $1 \mathrm{~m}$ (40 inches) onto the end of a specified solid, vertical steel bar, $15 \mathrm{~cm}$ ( 6 inches) in diameter, mounted on an unyielding horizontal surface. Because the normal and accident conditions have different stress allowables, these two cases are considered independent of each other. However, the same analytical methods can be used to evaluate the loading effects. These loads will affect primarily the packaging body and closure system. For flexible packagings, the internals and radiogctive contents may also be affected.

One approach to the puncture problem is to use the method described by P.P. Bijlaard in Ref. 4-12. This technique may be used as an approximate method for radial loads which may be idealized as uniformly distributed over a rectangular region.

A second approach is to run dynamic finite element analyses of various loading conditions. This is the method that can offer the greatest degree of accuracy, especially if local deformation of a region of complex geometry is needed.

In addition to the localized effect of the puncture load, the accident conditions may result in bending the package as a whole over the puncture bar. For a long, narrow package, this response may be roughly approximated by an equivalent beam model with the inertial load applied as a uniformly distributed load along the cask with the puncture bar acting as a fulcrum.

\section{1,2.2 Impact}

The most severe loading condition that the cask must survive is caused by the impact imparted by the specified free-drop tests. In addition, evaluation of stresses as a result of impact is one of the most difficult of the structural evaluations. Impact evaluation requires a method which can analyze the impact at any angle and which includes primary impact, with consideration of nonlinear, inelastic response of impact limiters, 
primary impact, with consideration of nonlinear, inelastic response of impact limiters, rigid body rotation, and secondary impact.

Three analysis methods have been used for impact evaluations: quasi-static, dynamic lumped-parameter, and dynamic finite element. Each method can be used to predict the response of a package to an impact load under certain conditions. The dynamic analysis method can more accurately predict package response under impact loading since this loading produces dynamic response of the package.

The quasi-static method is based on D'Alembert's principle for substituting equivalent static forces for inertial forces created by impact. This method assumes constant, homogeneous deceleration and cannot capture dynamic package response. Also, restrictive assumptions must be applied to eapture secondary impact. It is not recommended for analyzing oblique impact cases. In applying this method, a deceleration force is calculated by assuming that all of the kinetic energy of the falling package is absorbed by impact limiters and that the deceleration is constant. The acceptability of this method is predicated on several factors. First, the limiter must be relatively soft compared to the packaging body so that the load rate is slow enough to reduce the probability of dynamic amplification. Second, since even for a soft limiter there may exist a stiff initial modulus, a dynamic amplification factor should be applied to the results. Third, since there are many uncertainties in this method, there should be a large margin of safety in the final st=esses if this method is used.

The specific dynaxic lumped parameter method combines simplicity in modeling with the ability to analyze the dynamic response of the package as a result of a rapid impact load. In addition, the method can be formulated to analyze the rigid-body rotation which can occur as a result of oblique impact. Overall package response can be determined as well as the resulting major stresses. Stress recovery assumptions can become restrictive if calculation of detailed stress states is attempted. The most straightforward application of this method is for packagings with solid shells or with lead shielding that is assumed to be bonded to the steel shells. Simple methods are being developed to account for lead slump using this method. The dynamic lumped parameter method is recommended for confirmatory analyses for impact loading. It is simple to use and is not as complex as 3-D dynamic analysis. However, due to the simplicity of the model, it cannot accurately predict local stresses. 
In order to obtain detailed stress recovery or accurately model nonlinear behavior, such as lead slump or buckling, a dynamic finite element analysis should be performed. In this method, each component can be modeled separately, and stresses in each element can be calculated directly during the analysis. While they can be expensive and time consuming, dynamic finite element analysis methods can provide the most accurate and detailed estimates of package response to impact loads. The dynamic finite element method should be used for reviewing of packaging components that have predicted stresses close to allowables, complex geometry, or complex loading conditions.

A summary of the impact analysis methods is shown in Fig. 4.4, and a more detailed discussion of each can be found in Ref. 4-13.

\subsubsection{Special Form}

Two aspects of special form radioactive material must be taken into consideration: the qualification of a radioactive material as a special form radioactive material, and the implication that the containment requirements of a Type B package are met with qualified special form radioactive material.

A radioactive material can be qualified as a special form radioactive material if it can satisfy the requirements of $10 \mathrm{CFR} 71.75$. Guidelines for reviewing the qualification of special form radioactive material is given in Appendix $\mathbf{A}$.

The current 10 CFR 71 and IAEA \#6 standards for Type B quantities of radioactive material do not address the use of special form radioactive material to meet the containment requirements of Type B packagings. Thus, as current regulations stand, there is no differentiation between the containment requirements for a package containing a Type $B$ quantity of a normal radioactive material and the containment requirements for a package containing the same quantity of a special form radioactive material. However, a special form radioactive material can satisfy the containment requirements for a Type $B$ package if it can be demonstrated that its properties will satisfy the test requirements specified in $10 \mathrm{CFR} 71.71$ and $10 \mathrm{CFR} 71.73$ at temperatures as low as $-29^{\circ} \mathrm{C}$, with the activity release rate less than that specified in $10 \mathrm{CFR} 71.53$. 


\subsection{Areas of Review}

The following areas identified in R.G. 7.9 per DOE 1540.2 are reviewed for compliance with regulations and DOE Orders. 14,15

\subsubsection{Structural Design}

The significant structural design features of the package are identified and reviewed for their adequacy to provide their intended safety functions. Structural design criteria are reviewed.

\subsubsection{Weights and Centers of Gravity}

The package weights and centers of gravity are reviewed for major individual subassemblies of the package. The center of gravity of the package should be located, along with any ather center of gravity referenced in the application.

\subsubsection{Mechanical Properties of Materials}

The structural properties of the materials used in the packaging design are reviewed for completeness and accuracy for the packaging application and the related structural evaluation. This review is coordinated with the review described in Section 3.0 of this guide. 


\subsection{A General Standards for all Packages}

The general standards for the packages, as specified in 10 CFR 71.43, are reviewed. This review is coordinated with the review described in Section 2.0 of this guide.

\subsubsection{Lifting and Tie-Down Standards for All Packages}

All devices and attachments that can be used to lift or to tie down the package should be reviewed for compliance with 10 CFR 71.45.

\subsubsection{Normal Conditions of Transport}

The structural evaluation of the packaging is reviewed to determine if the packaging meets the standards specified in 10 CFR 71.43 and 71.51 under the normal test conditions specified in 10 CFR 71.71. The normal test conditions include heating, cooling, external pressure changes, vibration, water spray, free drops, compression, and penetration resistance of the packaging.

\subsubsection{Hypothetical Accident Conditions}

The structural evaluation of the packaging is reviewed to determine if the packaging meets the standards specified in 10 CFR 71.51 under the bypothetical accident conditions specified in 10 CFR 71.73. The hypothetical accident conditions are considered in sequence and include free drop, puncture, fire, and immersion in water of the packaging.

\subsubsection{Special Form}

If the contents of a package are a special form radioactive material, the applicant may take credit for the containment requirements of a Type $B$ package if certain conditions are met. The contents of the package are reviewed for conformance with the applicable regulatory definition of and requirements for a special form radioactive 
material. The static and dynamic structural loads on the special form contents of a package that is subject to the normal and hypothetical accident conditions are reviewed. The static and Iynamic structural response of the special form contents to the normal and hypothetical accident condition loads applied to the package are reviewed.

\subsection{Fuel Rods}

When fuel rods are considered to provide containment of radioactive material, the containment of contents is reviewed for normal and accident conditions. 


\subsubsection{Appendix}

Supplemental information that may include test data, computer program input/output, and analytical procedures are reviewed.

\subsection{Axceptance Criteria}

The following subsections provide the specific criteria for judging the acceptability of the structural eveluation contained in the SARP.

\subsubsection{Saructural Design}

The description of the structural design features and criteria must include the following:

\subsubsection{Discussion}

Per 10 CFR 71.33, the package must be described in sufficient detail to identify the package accurately and provide a sufficient basis for evaluation of the package. The description should include appropriate drawings and should identify those components to be evaluated.

\subsubsection{Design Criteria}

Per 10 CFR 71.37, the applicant must describe the quality assurance program for the design, fabrication, assembly, testing, maintenance, repair, modification, and use of the package. R.G. 7.10 provides guidance for establishing a Quality Assurance Program which meets 10 CFR 71.37.16 Also R.G. 7.10 provides guidance for establishing a "graded" approach in which the QA requiremente are commensurate with the safety significance of the packaging components. In addition, the applicant must identify any codes and standards used for the packaging.

For spent fuel casks R.G. 7.6 adapts portions of the ASME code, Section III, Subsection NB, to form acceptable structural design criteria for spent fuel cask containment vessels. Design criteria for Level A Service Limits and Level D Service Limits from the ASME code are adopted in R.G. 7.6 for normal and accident conditions, respectively, for application to spent fuel casks. R.G. 7.6 also states that linear elastic 
analysis can be applied for designing spent fuel containment vessels. Figure 4-2 identifies an acceptable method for identifying and combining loads, classifying stresses and comparing the stress results with the acceptance criteria specified in R.G. 7.6 for spent fuel casks.

Individual loading conditions and initial environmental conditions are specified in R.G. 7.8 for spent fuel casks. Some of the load conditions specified have both positive and negative directions of loading. As such, each specified load combination may result in several sets of resultant stresses. Each significant set of loading combinations must be evaluated.

As discussed in 4.1.1.5 of this guide, there are no specific national codes for the construction and use of Type B packages. In the absence of such codes and standards it is acceptable to use the applicable ASME code structural design criteria identified in Table 4.1 for reviewing the structural evaluation of Type B packagings. For spent fuel casks which are Category I packages, these criteria are consistent with those specified in R.G. 7.6. Also for all Type B packages the individual loading conditions and initial environmental conditions specified in R.G. 7.8 should be considered in this structural evaluation. Acceptable meihods for reviewing and analyzing impact loads are discussed in 4.1,2.2.

\subsubsection{Weights and Centers of Gravity}

Per 10 CFR 71.33, the total weights of the packaging and contents must be listed. The weights of major subassemblies should be tabulated such that the sum of the parts equals the package total.

\subsubsection{Mechanical Properties of Materials}

For acceptance criteria, see Subsection 3.3 of this guide.

\subsubsection{General Standards for All Packages}

For acceptance criteria, see Subsection 2.3 .5 of this guide. 


\subsubsection{Lifting and Tie-Down Standards for All Packages}

\subsubsection{Lifting Devices}

Lifting devices must meet the requirements of $10 \mathrm{CFR} 71.45(\mathrm{a})$, and the requirements of ANSI Ni4.6.17 Normal load requirements are as follows: the load bearing members shall be capable of lifting three times the combined weight of the shipping container without generating a combined shear stress or maximum tensile stress at any point in excess of their minimum yield strength. They shall also be capable of lifting five times that weight without exceeding the ultimate strength of the materials. In addition, if the package to be lifted constitutes a critical load, then either a dual load path system must be designed, or the stress design must be twice as strong as stated above. A critical load is any lifted load whose uncontrolled movement or release could adversely affect any safety-related system when such system is required for unit safety, or which could result in potential off-site exposures.

Per 10 CFR 71.45, lifting attachments must be designed so that failure of any lifting device under excessive load would not impair the ability of the package to meet other requirements of Subpart $E$ of 10 CFR 71. A further requirement is that any other part of the package which could be used to lift the package must be capable of being rendered inoperable for lifting during transport, or must be designed as a lifting device.

There is no separate requirement for lifting devices under accident loads, other than if the cask is in a drop accident, the lifting device may not cause failure of the cask body by puncture or other means. This must be addressed and analyzed in the SARP, as appropriate.

\subsubsection{Tie-Down Devices}

The acceptance criteria for tie-down components are listed in Paragraph 71.45(b) of 10 CFR. For normal leads, they are the following: the system must be capable of withstanding, without generating stress in any material of the packaging in excess of its yield strength, a static force applied to the center of gravity of the package that has a vertical component of two times the weight of the package, a horizontal component along the direction in which the vehicle travels of 10 times the weight of the package, and a horizontal component in the transverse direction of five times the weight of the package. An additional requirement for tie-down devices is that they must be designed so that 
failure of any device under normal or accident loads would not impair the ability of the package to meet other requirements of 10 CFR 71 Subpart E.

\subsubsection{Normal Conditions of Transport}

Per 10 CFR 71.71, the packaging design must be evaluated for normal transport conditions. R.G. 7.8 provides supplemental information concerning normal transport conditions that should be evaluated for nuclear spent fuel transport. The information in R.G. 7.8 can be generalized for all Type B packages to provide guidance in performing reviews of structural evaluations of Type $B$ packages for normal transport conditions. The following criteria should be used in reviewing the structural evaluation for packages under normal transport conditions.

a. Initial ambient temperature at $-20^{\circ} \mathrm{C}\left(-20^{\circ} \mathrm{F}\right)$ with insolation and of ambient temperature at $38^{\prime} \mathrm{C}\left(100^{\prime} \mathrm{F}\right)$ with the maximum insolation data given in Ta' le 4.2. Exceptions to the above are made for the hot environment and cold environment normal conditions (which use other steady state values) and for the thermal accident condition (which considers the higher thermal initial condition but not the lower one).

b. The decay heat of the contents must be considered as part of the therasal load. Generally, the maximum amount of decay heat should be considered in com ination with the thermal environmental conditions in 4.3.6.a. Table 4.3 summarizes thermal loads and boundary conditions for the cases which can be thermally and struct cally evaluated by the applicant and reviewed for completeness and correctness.

c. The internal pressure in the packaging cavity that is used in evaluating normal conditions should be consistent with the other conditions that are being considered.

d. The release of all pressurized gases inside the packaging contents should be considered in determining the maximum contain lent vessel $p$ essure. The release could involve gases from spent fuel rods, outgassing of resin bee is from reactor cleanup systems, etc. In addition, gas pressure buildup from any deionization of the coolant caused by radiation or from vaporization of the coolant carsed by heating must be included in the pressure calculation. The reviewer is to assc ss whether all phenomena that could effect the pressure have been properly considered in the pressure calculation. 
e. Intermediate temperature conditions should also be evaluated by the applicant if they can cause a more severe structural response than the extreme conditions given in Table 4.3.

f. For packaging designs that involve fabrication processes (such as lead pouring or the shrink fitting assembly of parts) where the structural response can be significantly affected, the apmropriate initial conditions are determined to be at the point where the parts involved in the process are free of any significant stresses. In these cases the applicant is to perform a structural evaluation to determine the thermal stresses.

g. Factors that can cause thermal fatigue should be evaluated by the applicant to show that they do not cause any significant deterioration or damage to the packaging even when they are combined with other loads. These factors can include thermal cycling of high decay heat load packagings due to the loading and unloading of the contents or extreme weather variations during transport over the life of the packaging. The reviewer is to assess that all phenomena that could affect fatigue have been properly considered in the structural evaluation.

h. To assess the response of the package to a hot environment, the applicant should structurally evaluate the packaging for a temperature of $38^{\circ} \mathrm{C}\left(100^{\circ} \mathrm{F}\right)$ in still air and with maximum insolation. If the packaging has a non-safety grade conling system, it should be assumed that the system is inoperable during the hot environment condition.

i. To assess the response of the package to a cold environment, the applicant should structurally evaluate the packaging for a temperature of $-40^{\circ} \mathrm{C}\left(-40^{\circ} \mathrm{F}\right)$ in still air and no insolation. The case of maximum decay heat load and maximum internal pressure should be considered in addition to the case of no internal heat load. The possibility and consequences of coolant freezing should also be considered.

\subsubsection{Feat}

Per 10 CFR 71.71(i), the package must be evaluated for heat conditions with an ambient temperature of $38^{\circ} \mathrm{C}\left(100^{\circ} \mathrm{F}\right)$ in still air, decay heat and solar insolation. See 4.3.1 above. 


\subsubsection{Cold}

Per 10 CFR 71.71(c), the package must be evaluated for cold conditions with an ambient temperature of $-40^{\circ} \mathrm{C}\left(-40^{\circ} \mathrm{F}\right)$ in still air in the shade. See 4.3 .1 above.

\subsubsection{Reduced External Pressure}

Per 10 CFR 71.71(c), the package must be evaluated for reduced external pressure of 24.5 kilopascal (3.5 psi) absolute.

\subsubsection{Increased Futernal Pressure}

Per 10 CFR 71.71(c), the package must be evaluated for increased external pressure of 140 kilopascal ( 20 psi) absolute.

\subsubsection{Vibration}

Per 10 CFR 71.71(c), the package must be evaluated for vibration normally incident to transport. A fatigue analysis per R.G. 7.6 should be performed, as applicable.

\subsubsection{Water Spray}

Per 10 CFR 71.71(c), the package must be evaluated for a water spray that simulates exposure to rainfall of approximately $5 \mathrm{~cm}$ ( $2 \mathrm{in}$ ) per hour for at least one hour.

\subsubsection{Free Drop}

Between $11 / 2$ and $21 / 2$ after the conclusion of the water spray test, the package must be subjected to a free drop through the distance specified in Table 4.4 onto a flat, essentially unyielding, horizontal surface, striking the surface in a position for which maximum damage is expected. For Fissile Class II packages, this free drop must be preceded by a free drop from a height of $0.3 \mathrm{~m}(1 \mathrm{ft})$ on each corner or, in the case of a cylindrical Fissile Class II package, onto each of the quarters of each rim. 


\subsubsection{Cornex Drop}

Per 10 CFR 71.71(c), the package must be evaluated for a free drop onto each corner of the package in succession, or in the case of a cylindrical package onto each quarter of

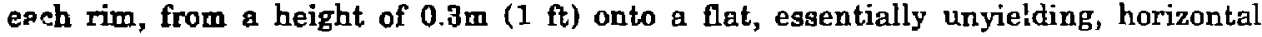
surface. This test applies only to fiberboard or wood rectangular packages not exceeding $50 \mathrm{~kg}$ (110 pounds) and fiberboard or wood sylindrical packages not exceeding $100 \mathrm{~kg}$ (220 pounds).

\subsubsection{Compression}

Per 10 CFR 71.71(c), for packages weighing up to $5000 \mathrm{~kg}$, the package must bo subjected, for a period of 24 hours, to a compressive load applied uniformly to the top and bottom of the package in the position in which the package would normally be transported. The compressive load must be the greater of the following: (i) The equivalent of five times the weight of the package; or (ii) the equivalent of 12.75 kilopascal $\left(1.85 \mathrm{lb} / \mathrm{in}^{2}\right)$ multiplied by the vertically projected area of the package.

\subsubsection{Penetration}

Per 10 CFR 71.71(c), the package must be evaluated for impact on the hemispherical end of a vertical steel cylinder of $3.2 \mathrm{~cm}(1-1 / 4 \mathrm{in})$ diameter and $6 \mathrm{~kg}$ (13 lb) mass dropped from a height of one $\mathrm{m}$ ( $40 \mathrm{in}$ ) onto the exposed surface of the package which is expected to be most vulnerable to puncture. The long axis of the cylinder must be perpendicular to the package surface.

\subsection{Hypothetical Accident Conditions}

Per 10 CFR 71.73, the package design must be evaluated for hypothetical accident conditions. R.G. 7.8 provides supplemental information concerning hypothetical accident conditions that should be evaluated for nuclear spent fuel transport. The information in R.G. 7.8 can be generalized for all Type B packages to provide guidance in performing reviews of structural evaluations of Type B packages for hypothetical accident conditions. Per 10 CFR 71.73 the evaluation for hypothetical accident conditions is to be based on sequential application of the tests specified in this section, in the order indicated, to determine their cumulative effect on a package or array of packages. With respect to the 
initial conditions for the tests except for the water immersion tests, to demongtrate compliance with the requirements during testing, the ambient air temperature before and after the tests must remain constant at that value between $-29^{\circ} \mathrm{C}\left(-20^{\circ} \mathrm{F}\right)$ and $+38^{\circ} \mathrm{C}$ $\left(100^{*} \mathrm{~F}\right)$ which is most unfavorable for the feature under consideration. The initial internal pressure within the containment system must be the maximum normal operating pressure unless a lower internal pressure consistent with the ambient temperature assumed to precede and follow the tests is more unfavorable. Tests for hypothetical accident conditions must be conducted as follows:

\subsubsection{Free Drop}

A free drop of the specimen through a distance of $9 \mathrm{~m}(30 \mathrm{ft}$ ) onto a flat, essentially unyielding, horizontal surface, striking the surface in a position for which maximum damage is expecied.

\subsubsection{Puncture}

A free drop of the specimen through a distance of $1 \mathrm{~m}$ (40 in) in a position for which maximum damage is expected, onto the upper end of a solid, vertical, cylindrical, mild steel bar mounted on an essentially unyielding, horizontal surface. The bar must be 15 $\mathrm{cm}(6 \mathrm{in})$ in diameter, with the top horizontal and its edge rounded to a radius of not more than $6 \mathrm{~m}$ ( $1 / 4 \mathrm{in})$ and of a length as to cause maximum damage to the package, but not less than $20 \mathrm{~cm}$ ( $8 \mathrm{in}$ ) long. The long axis of the bar must be vertical.

\subsubsection{Thermal}

Exposure of the whole specimen for not less than 30 minutes to a heat flux. not less than that of a radiation environment of $800^{\circ} \mathrm{C}\left(1475^{\circ} \mathrm{F}\right)$ with an emissivity coefficient of at least 0.9 . For purposes of calculation, the surface absorptivity must be either that value which the package may be expected to possess if exposed to a fire or 0.8 , whichever is greater. In addition, when significant, convective heat input must be included on the basis of still, ambient air at $800^{\circ} \mathrm{C}\left(1475^{\circ} \mathrm{F}\right)$. Artificial cooling must not be applied after cessation of external heat input and any combustion of materials of construction must be allowed to proceed until it terminates naturally. The effects of solar radiation may be neglected prior to, during, and following the test. 


\subsubsection{Immersion-Fissile Matericl}

For fissile material, in those cases where water inleakage has not been assumed for criticality analysis, an undamaged specimen must be immersed under a head of water of

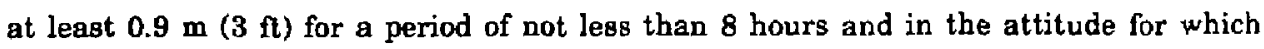
maximum leakage is expected.

\subsubsection{Immergion-All Packages}

A separate undamaged specimen must be subjected to water pressure equivalent to immersion under a head of water of at least $15 \mathrm{~m}(50 \mathrm{ft}$ ) for a period of not less than 8 hours. For test purposes, an external pressure of water of 147 kilopascal (21 psi) gauge is considered to meet these conditions.

\subsubsection{Summary of Package}

After each of the accident tests, the condition of the package must be discussed. The condition of the package must be summarized and compared with the acceptance criteria such as those specified in 4.3 .1 .

\section{3 .8 Special Form}

The acceptance criteria for a package containing a special form radioactive material include the application of the loads prescribed for both normal and accident conditions of transport. The acceptance criteria for the contents and the package are described below.

\subsubsection{Contents}

The special form radioantive material contents of the package must meet the requirements for a special form radioactive material as given in 10 CFR 71.75.

\subsubsection{Packaging}

A packaging with special form radioactive material contents must undergo the tests for normal conditions (10 CFR 71.71) and bypothetical accident conditions (10 CFR 71.73). For credit to be given to the containment structural requirements for a Type $B$ package with special form radioactive material contents, the following acceptance criteria are necessary, but not necessarily sufficient. 


\section{a. Loads on Package Contents}

The tests on the package specified in 10 CFR 71.71 and 10 CFR 71.73 shall not produce static or dynamic structural loads, or cause such loads to be produced in the special form radioactive material, greater than those specified in 10 CFR 71.77.

\section{b. Response of the Contents to Packace Loading}

The static and dynamic structural response of the special form radioactive material to the loads applied to the special form by the package response to the loads of $10 \mathrm{CFR} 71.71$ and $10 \mathrm{CFR} 71.73$ must not exceed the yield strength of the special form material, or cause brittle fracture.

\subsection{Fuel Rod}

When fuel rod cladding is considered to provide containment of radioactive material under normal and accident conditions, then test and analysis must demonstrate that the fuel cladding has adequate structural integrity.

\subsubsection{Appendices}

The information contained in the appendices should be complete and provide adequate support to the struciural evaluation. 


\section{A Procedures}

The section of structural evaluation should identify, describe, discuss, and analyze the principal structural engineering design of the packaging, components, and systems important to safety and necessary to compliance with the performance requirements specified in Paragraphs 71.41 through 71.51 and 71.73 through 71.77 in 10 CFR 71.

\section{A.1 Structural Design}

Verify that the principal structural components have been identified and appropriate design criteria for each of them have been specified and discussed.

\subsubsection{Discussion}

Verify that the principal structural members and systems such as the containment vessel, impact limiters, closure devices, and valves that are vital to safe operation of the package have been identified. The location of these items on drawings should be referenced and their structural design and performance discussed.

\subsubsection{Design Criteria}

Verify that the load combinations and factors that serve as design criteria are described. Design criteria in 4.3 .1 or their equivalent are acceptable for various safety group components and the three packaging categories. For each criteria identified, verify that the maximum allowable stresses and strains (as a percentage of the yield or ultimate values) for ductile failure are stated. Review how the other structural failure modes (e.g., brittle fracture, fatigue, buckling) are considered. When different design criteria are used in various parts of the packaging or for different conditions, the appropriate values for each case should have been indicated. Verify that the criteria used in the impact evaluation has been discussed. Verify that all codes and standards that are used to determine material properties, design limits, or methods of combining loads and stresses have been identified. In cases of deviation from standard codes, or if certain components are not covered by such codes, detailed description of the design criteria used as substitutes should have been provided. 


\subsubsection{Weights and Centers of Gravity}

Verify that the total weight of the packaging and contents is listed. The weights of major individual subassemblies should be tabulated such that the sum of the parts equals the total of the package. Verify that the center of gravity of the package and any other centers of gravity have been located. Calculations do not need to be included, but a sketch or drawing that clearly shows the individual subassembly referred to and the reference point for locating its center of gravity should be included.

\subsection{Mechanical Propertieg of Materials}

Verify that the material mechanical properties used in the structural evaluation are listed. The review of material properties is discussed in Section $\mathbf{3 . 0}$ of this guide. The mechanical properties may include yield stress, ultimate stress, modulus of elasticity, ultimate strain, Poisson's ratio, density, and coefficient of thermal expansion. If impact limiters are used, either a compression stress- ain curve for the material or the forcedeformation relationship for the limiter, as appropriate, should be included. For materials subjected to elevated temperatures, the appropriate mechanical properties under these conditions should be specified. The source of all information on material properties should be clearly and specifically referenced as to publication and page number. Where material properties are determined by testing, the test procedure, conditions, and measurements should be described in sufficient detail that the review can be performed satisfactorily.

\subsubsection{General Standards for All Packages}

Verify that the general standards for all packaging, specified in Section 71.43 , are complied with, as discussed in 2.3 .5 and 2.4 .5 of this guide.

\section{A.5 Yifting an: i Tio-Down Standards for All Packages}

\section{A.5.1 Lifting Devices}

Verify that all devices and attachments that can be used to lift the package or its lid have been identified. Review all testing and analysis which show that these devices comply with the requirements of Paragraph 71.45(a) of 10 CFR 71. Drawings or sketches should be included that show the location and construction of the 
effects of the forces imposed by lifting on vital package components, the interfaces between the lifting device and ather packaging surfaces, have been determined. Verify that the acceptance criteria in 4.3.5.1 or equivalent have been met.

\subsubsection{Tie-Down Devices}

Verify that all devices that are a structural part of the package and can be used as tiedowns have been identified. Review the discussion of the overall tiedown system. Review all testing and analysis which show that these devices comply with the requirements of Paragraph 71.45(b) of 10 CFR 71. Drawings and sketches should be included that show the location and construction of these devices and the overall tiedown system. Verify that the effect of the imposed forces on vital package components, including the interfaces between the tiedown devices and other package surfaces, has been included. Verify that the acceptance criteria in 4.3.5.2 or equivalent have been met.

\subsubsection{Normal Conditions of Transport}

Verify that the package, when subjected to the conditions and test (normal conditions of transport) specified in Section 71.71 of 10 CFR 71, meets the standards specified in Sections 71.43 and 71.51 of 10 CFR 71, as demonstrated in the following paragraphs. The package should be assessed against each condition separately and a determination made that the applicable performance requirements specified in the regulations have been satisfied.

\subsubsection{Heat}

Verify that the thermal evaluation for the heat test is reported in Section 3.4 of the SARP and is being reviewed for adequacy.

\section{A.6.1.1 Summary of Pregsures and Temperatures}

Verify that all pressures and temperatures, determined in the thermal evaluation, bave been summarized to perwit the performance of reviewing thermal sxpansion and thermal stress as effects on the package. 


\subsection{Differential Thermal Expansion}

Review the calculations of the circumferential and axial deformations and stresses (if any) that result from differential thermal expansion. Both steady-state and transient conditions should have been considered. These calculations must be sufficiently comprehensive to demonstrate package integrity under normal transport conditions.

\subsection{Stres Calculations}

Review the calculated stresses due to the combined effects on thermal gradients, pressure, and mechanical loads (including fabrication stresses from lead pour and lead cooldown). Review the sketches that show the configuration and dimensions of the members or systems being analyzed. These sketches should consider whether repeated cycles of thermal loadings, together with other loadings, will cause fatigue failure or extensive accumulations of deformation.

\subsection{Comparison with Allowable Streseses}

Review the stress combinations, and the resulting stress comparisons with the design criteria. All the performance requirements specified in the regulations must be shown to have been satisfied.

\subsubsection{Cold}

Review the package for the effects of a steady-state ambient temperature of $-40^{\circ} \mathrm{F}$ ($40^{\circ} \mathrm{C}$ ). Review both material properties and possible freezing of liquids and lead shrinkage under this condition. Review, for vital components of the package, the resulting temperatures and their effect on operation of the package. Brittle fracture should have been considered. (Note: For the sequential hypothetical accident test series, $-20^{\circ} \mathrm{F}\left(-29^{\circ} \mathrm{C}\right)$ is the lowest service temperature that need be considered. See Paragraph 71.73(b).)

\subsubsection{Reduced External Pressure}

Review the package for the effects of external pressure equal to 3.5 psia. 


\subsubsection{Increased External Pressure}

Review the package for the effects of external pressure equal to 20 psia.

\subsubsection{Vibration}

Review the package for the effects of vibrations normally incident to transport.

\subsubsection{Water Spray}

Review the package for the effects of water spray test.

\subsubsection{Free Drop}

Review the package for the effects of the free drop test. The seneral comments in Section 4.4.7.1 of this guide also apply to this conditiou. (Note that the free drop test follows the water spray test.)

\subsubsection{Corner Drop}

If applicable, verify that the package has been assessed for the effects of corner drops and meets the acceptance criteria in 4.3 .1 or equivalent.

\section{A.6.9 Compression}

If applicable, verify that the package has been assessed for the effects of compression and meets the acceptance criteria in $\mathbf{4 . 3 . 1}$ or equivalent.

\subsubsection{Penetration}

Verify that the package has been assessed for the effects of penetration and meets the acceptance criteria in 4.3 .1 or equivalent. (Note that the point of impact could be at any location on the exterior surface of the package.)

\section{A.7 Hypothetical Accident Conditions}

Verify that the package, when subjected to the tests (hypothetical accident conditions) as specified in Section 71.73 of $10 \mathrm{CFR} 71$, meets the standards specified in Section 71.51 of 10 CFR 71 . 
The hypothetical accident conditions are to be considered in the sequence specified by the regulatior.s. Damage caused by each test is cumulative, and the evaluation of the ability of a package to withstand any one test must consider the damage that resulted from the previous tests. It should be noted that a determination must have been made that the effectiveness of the package has not been reduced as a result of the normal conditions of transport. Brittle fracture should be considered.

\subsubsection{Free Drop}

Verify that the performance and structural integrity of a package has been evaluated for the drop orientation that causes the most severe damage. An orientation that results in the most damage to one system or component may not be the most damaging for other systems and components. For this reason, it is usually necessary to consider several drop orientations. The minimum requirement is that orientations for which the center of gravity is directly over the point of impact must be considered.

The assessment of the package may be by analysis, prototype testing, model testing, or comparison with a similar package.

\section{a. Analysis}

Review the drop and structural calculations. Acceptable impact analysis methods are described in 4.3.1. The calculations should be presented in sufficient detail to allow the results to be verified. Adequate narration and use of sketches and free body force diagrams should be included. For equations used in the analysis, either the source should be referenced or the derivation should be included.

The analysis should show how all the kinetic energy will be dissipated and which local deformation and dynamic forces occur during impact. The response of the package in terms of stress and strain to components and structural members should be shown. The structural stability of individual members, as applicable, should be investigated as well as stress due to impact combined with those stresses caused by temperature gradients, differential thermal expansions, pressure, and other loads. Verify that the performance requirements of $10 \mathrm{CFR} 71$ are met. 


\section{b. Prototype Testing}

Review the test method, procedures, and target that were used. Review the package orientation at time of impact. If the package tested is not identical in all respects to the package described in the application, the differences should be explained to show that these differences would not affect the test results. Review all analyses performed to establish the package configuration and orientation for the testing.

Review in detail materials used as substitutes for the radioactive contents during the tests. Verify that this substitution would not affect the test results. The effects of internal decay heat and pressure buildup must be considered if these effects had arisen with the actual loading.

Review the damage caused by the impact and the results of any quantitative measurements that were made. Both interior and exterior damage shall be included. Review photographs of the damaged packaging. Review analyses performed to demonstrate that adequate margins of safety have been included in structural design.

Verify or deny that the performance requirements of 10 CFR 71 have been met for the damaged package.

\section{c. Medel Testing}

Review the model description and the detailed drawings that show its dimensions anc saterials of construction. Review the dimensional tolerances to which the model was fabricated, and the comparison of these to the tolerances that are used for the prototype. Review all analyses performed which relate the scale model to the prototype for the regulatory test conditions.

For the actual model tests, review all the information required for item $b$ above.

Review the correlation method used and the amount of damage done to the model with damage to a prototype. Model testing should be performed primarily to benchmark computer codes used to an-yze the prototype. Review the discussion which demonstrates that the prototype would be adequate to meet all the performance requirements of $10 \mathrm{CFR}$ 71. 


\section{d. Comparisor with Similar_Eackages}

Review the comparison with similar packages. The comparison must demonstrate that the proposed package is, in all respects, better than or equal to the package previously approved and that the proposed package can meet all the regulatory performance requirements. The following information should be included for your review:

(1) The dimensions, materials, and configurations of both packages,

(2) The overall weight of both packages, and

(3) The weight and form of the contents of both pactrages.

The comparison should demonstrate:

(1) That the paclages will have a similar response to the specified tests,

(2) That the forces acting on all vital safety systems and components of the proposed package are less than the tested package or that all vital safety systems and components of the proposed package have sufficient structural integrity, and

(3) That the proposed package will meet all the regulatory performance requirements.

\subsection{Find Drop}

Review the package for the effects of the end drop test.

\section{A.7.12 Side Drop}

Review the package for the effer . : the side drop test.

\subsection{Corner Drop}

Review the package for the effects of the corner drop test. 


\subsubsection{A Oblique Drop}

Review the package for the effects of oblique drops. Review information that shows that the end, side, and corner drops are more damaging to all systems and components vital to safely.

\subsection{Summary of Results}

Review the discussion of the condition of the package after each drop test. The extent to which the packaging would be damaged in each orientation should have been summarized for your review.

\subsubsection{Puncture}

Review the effects of the puncture tests. Verify that both local damage near the point of impact and the overall effect on the package have been evaluated. The point of impact could be at any location on the exterior surface of the package. Review how the point of impact was selected. It is particularly important that all valveg and fittings necessary for containment be considered. Most of the general comments provided in Section 4.4.7.1 also apply to this test condition.

\subsubsection{Thermal}

The thermal test should follow the free drop and puncture tests and should be reported in Section $\mathbf{3 . 5}$.

\subsection{Summary of Prescures and Temperatures}

Review all the temperatures and pressures, as determined in the thermal evaluation (Chapter 3 ) of the application.

\subsection{Differential Thermal Expansion}

Review the calculations of the circumferential and axial deformations and stresses (if any) that result from differential thermal expansion. Peak conditions, post-fire steadystate conditions, and all transient conditions should have been considered. 


\subsection{Stress Calculations}

Review the calculations of the stresses due to thermal gradients, differential expansion, pressure, and other mechanical loads. Review the sketches showing configuration and dimensions of the members of systems under investigation, and the locations of the points at which the stresses have been calculated.

\subsection{7-3.4 Comparison with Allowable Stresses}

Review the appropriate stress combinations, and the resulting stresses comparison with the design criteria in Section 2.1.2 of the application. Review how all the performance requirements specified in the regulations have been satisfied.

\subsubsection{Immersion-Fissile Material}

Review the effects and consequences of the water immersion test condition for fisf le packages.

\subsubsection{Immersion--All Packages}

Review the immersion of the package under $50 \mathrm{ft}(15 \mathrm{~m})$ of water for 8 hours. For test purposes, an external gauge pressure of water of $21 \mathrm{psi}(145 \mathrm{kPa})$ is considered to meet these conditions.

\subsubsection{Summary of Damage}

Review the discussion of the condition of the package after the accident test sequences. Review the extent to which vital safety systems and components have been damaged, and related to the acceptance standards.

\section{AB Special Form}

As applicable, when special form is claimed, review the contents that are stated to meet special form requirements given in Section 71.75 when subjected to the applicable test conditions of Section 71.77 of 10 CFR 71. Review the chemical and physical form. A detailed drawing of the special form radioactive material should be included for review 
showing the dimensions, materials, manner of construction, and method of nondestructive examination.

\subsubsection{Contents}

Verify that the contents meet the special form requirements specified in $10 \mathrm{CFR}$ 71.75. Guidelines for reviewing the qualification of special form radioactive material are given in Appendix A.

\subsubsection{Packaging}

Verify that the packaging with the special form radioactive material contents meet the test requirements for normal conditions (10 CFR 71.71) and for hypothetical accident conditions (10 CFR 71.73). Verify that the static and dynamic response of the special form radioactive material to the structural loads from the package response to the tests of 10 CFR 71.71 and 10 CFR 71.73 do not exceed the yield strength of the special form materiai, or cause brittle fracture.

Verify that the structural response, determined either by test measurement or $\lrcorner y$ analysis, is appropriate for the maximum force and impulse transmitted in the special form radioactive material. Verify that the yield strength associated with the special form material is consistent with that used in the special form radioactive material given in Appendix A.

Verify that for the state of radiation damage, if any, and for a temperature of $-29^{\circ} \mathrm{C}$ that the special form radioactive material will not propagate cracks for flaw sizes that are detectable at stresses less than the yield strength of the material.

\subsubsection{Fuel Rods}

When fuel rod cladding is considered to provide containment of radioactive materisl under normal or accident test conditions, review the analysis or test results showing that the cladding will $x$ :aintain sufficient mechanical integrity to provide the degree of containment claimed. 


\subsubsection{Appendix}

Review supporting information such as justification of assumptions or analytical procedures, test results, photographs, computer program descriptions and input/output, reference lists, and applicable pages from referenced documents.

\subsection{Findings}

In the Safety Evaluation Report (SER), briefly discuss the process that i is carried out (list confirmatory analyses, other pertinent information), and discuss conclusions for each structural component reviewed. If the reviewer does not agree with the asign or the structural analysis method described in the SARP for a particular component, but nonetheless agrees with the conclusion that the component meets the regulations based on confirmatory analyses, clearly state this in the Evaluation Findings. Maintrin for each SARP a separate file or document which contains detailed engineering discus sions on all confirmatory analyses.

\subsection{References}

1. U.S. Department of Energy, DOE 5480.3: Safety Requirements for the Packaging and Teansportation of Hazardous Materials. Hazardous Substances, and Hazardous Waates, U.S. Department of Energy, Washington, DC, August 9, 1985.

2. Office of the Federal Register, Title 10. Code of Federal Regulations, Part 71, Office of the Federal Register, Washington, DC, 1984. 
3. American Society of Mecbanical Engineers, ASME_Boiler_and Pressure Yessel Code, 1983 edition, American Society of Mechanical Engineers, United Engineering Center, 345 East 47th Street, New York, NY 10017.

4. American Society of Mechanical Engineers, Criteria of the ASME Boiler and Pressure Code for Desion by Analysis in Sections III and TV. Division.2 American Society of Mechanical Engineers, United Engineering Center, 345 East 47th Street, New York, NY 10017.

5. U.S. Nuclear Regulatory Commission, Regulatory Guide 7.6: Degign Criteria for the Structural Analysis of Shipping Cagk Containment Vessels, U.S. Nuclear Regulatory Commission, Washington, DC, January 1980, Rev. 1.

6. U.S. Nuclear Regulatory Commission, Regulatory Guide 7.8: Joad Combinations for the Structural Analysis of Shipoing CaskB, U.S. Nuclear Regulatory Commission, Washington, DC, May 1977.

7. U.S. Nuclear Regulatory Commission, (Draft) Regulatorg Guide. Eracture Tourghness Criteria for Ferritic Steel Shipping Cask Containment Vessels_with a Maximum Wall Thicknegs of Four Inches $(0.1 \mathrm{~m}$, U.S. Nuclear Regulatory Commission, Office of Nuclear Regulatory Research, Washington, DC, June 1986.

8. Holman, W.R., and Langland, R.T., Recommendations for Protecting against Failure by Brittle Fracture in Ferritic Steel Shipnine Containers up to Four Inches Thick, Lawrence Livermore National Laboratory, Livermore, CA, UCRL-53013, NUREG/CR-1815, June 1981.

9. Schwartz, M.W., Recommendations for Protecting Arginst_Brittle Fractures in Ferritic Steel Shippine Containers Greater Than Four Inches Thick, Lawrence Livermore National Laboratory. Livermore, CA, UCRL-53538, NUREG/CR-3826, April 1984.

10. Fischer, L.E., and Lai, W., Eabrication for Shipping Containers, Lawrence Livermore National Laboratory, Livermore, CA, UCRL-53544, NUREG/CR-3854, March 1985. 
11. Monroe, R.E.; Woo, H.H.; and Sears, R. G., Recommended Weldinc Criteria for Use in the Eabrication of Shipping Containers for Radioactive Materials, Lawrence Livermore National Laboratory, Livermore, CA, UCRL-53044, NUREG/CR-3019, March 1984.

12. Bijlaard, P.P., "Stresses from Radial Loads in Cylindrical Pressure Vessels," Weldine Research Joumal Supplement, December 1954.

13. Nelson, T.A., and Chun, R.C., Methode for Impact Anglysis of Shinting Containers, Lawrence Livermore National Laboratory, Livermore, CA, NUREG/CR-3966 (Draft).

14. U.S. Nuclear Regulatory Commission, Regulatory Guide 79: Standard Format and Content of Part 71 Applications for Approval of Packaging of Type B. Large Quantity, gnd Fisgile Radiogctive Matarial, U.S. Nuclear Regulatory Commission, Office of Standards Development, Washington, DC, January 1980, Rev 1.

15. U.S. Department of Energy, DOE 1540.2: Hazardous Maierial_Packaging for Transport-Administretive Procedures, U.S. Department of Energy, Washington, DC, September 30, 1986.

16. U.S. Nuclear Regulatory Commission, Regulatory Guide 7.10; Establishing_Quality Assurance Prosrams for Packaging Used in the Transport of Radioactive Material, U.S. Nuclear Regulatory Commisaion, Waghington, DC, January 1983.

17. ANSI N14.6, American National Standard for Special Iifting Device for Shipping Containers Weighing 10.000 lho ge More for Nuclear Materials. 


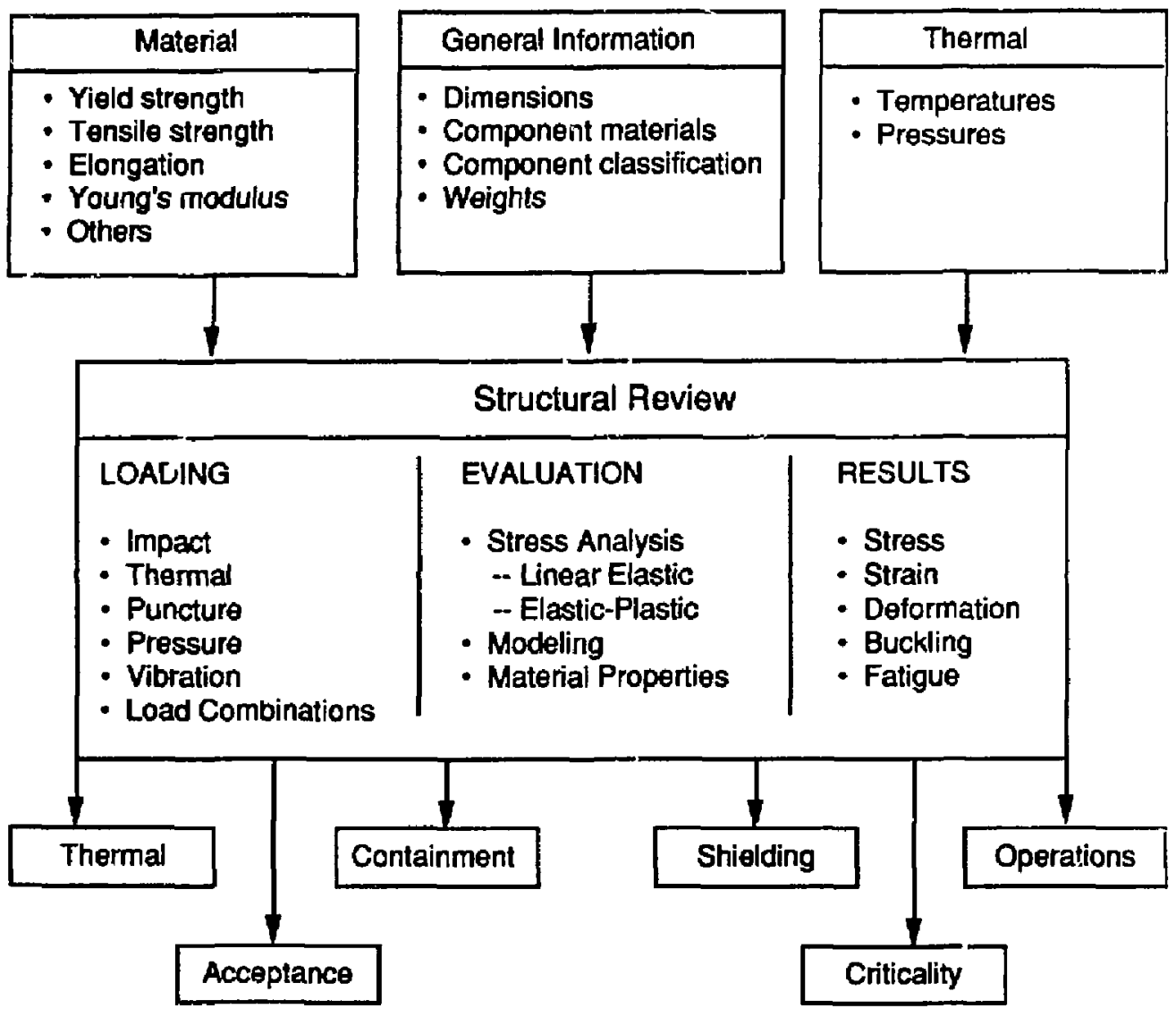

Figure 4-1 Input and output information for the structural review process. 


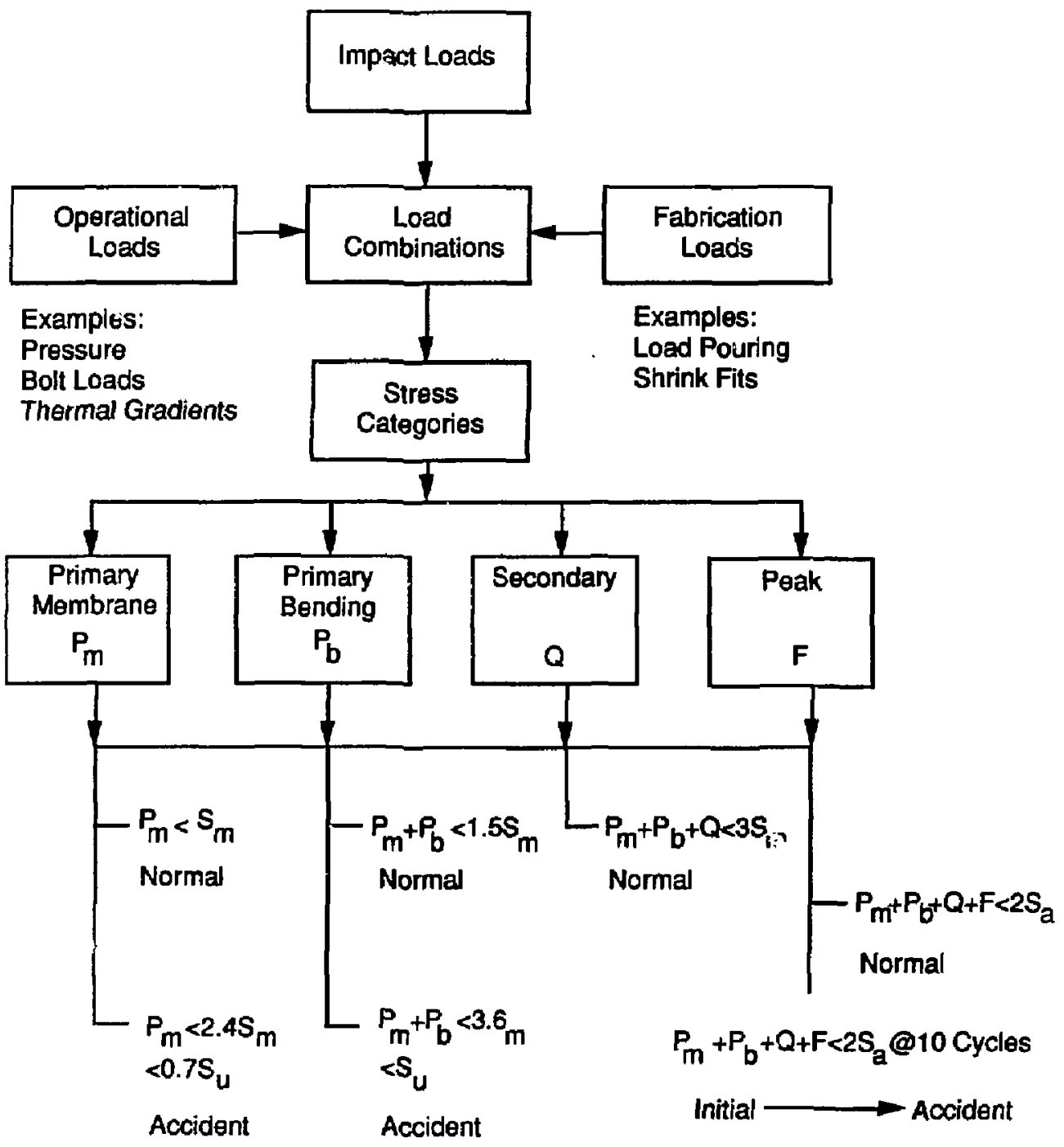

Figure 4-2 Load combinations and stress intensity limits. 


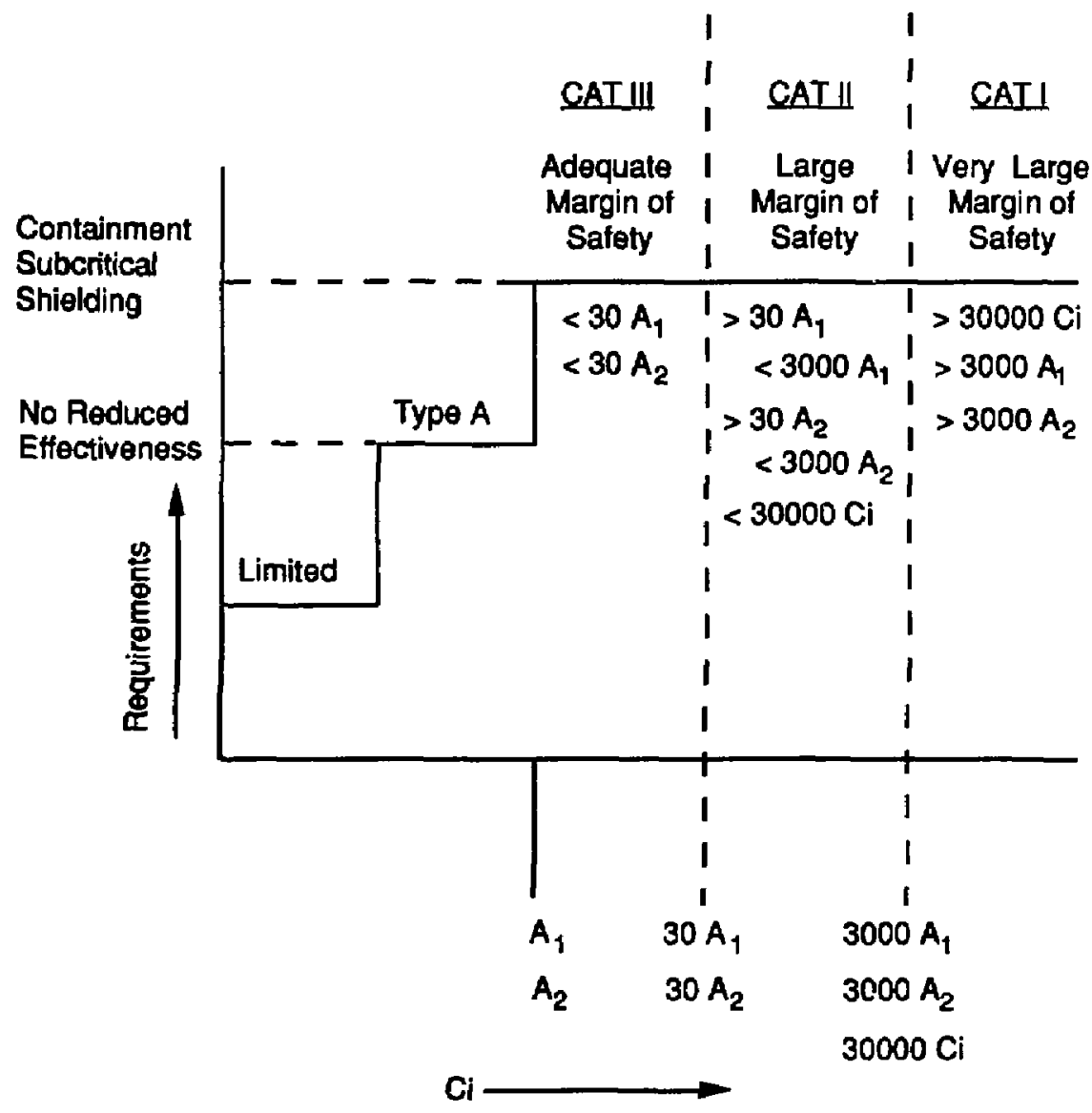

Figure 4-3 Packaging requirements and activity levels of contents. 


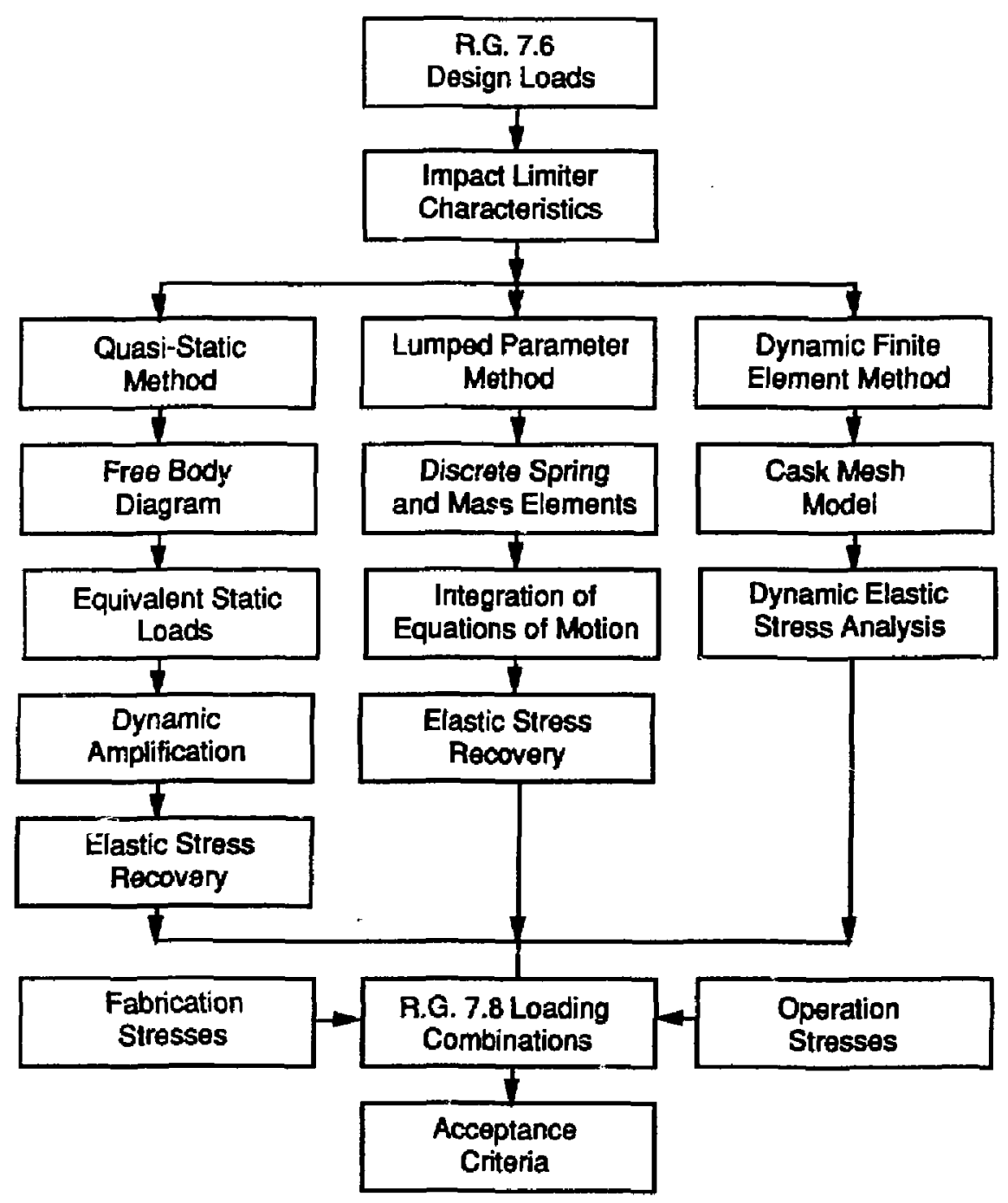

Figure 4-4 Impact analysis methods flow chart. 
Table 4.1

Structural Design Criteria (Based on ASME Code)

\begin{tabular}{|l|l|l|l|}
\hline \multirow{2}{*}{ Component Safety Group } & \multicolumn{3}{|c|}{ Container Contents } \\
\cline { 2 - 4 } & Category I & Category II & Category III \\
\hline Containment & $\begin{array}{l}\text { Section III } \\
\text { Subsection NB }\end{array}$ & $\begin{array}{l}\text { Section III } \\
\text { Subsection ND }\end{array}$ & $\begin{array}{l}\text { Section VIII } \\
\text { Division 1 }\end{array}$ \\
\hline Subcriticality & \multicolumn{3}{|c|}{ Section III, Subsection NG } \\
\hline Shielding and Other & \multicolumn{3}{|c|}{$\begin{array}{l}\text { Section VIII, Division 1 or } \\
\text { Section III, Subsection NF }\end{array}$} \\
\hline
\end{tabular}


Table49

Maximum Insolation Data

Form and location

of surface
Insolation for 12 hours per day

Flat surfaces transporied

horizontally:

Base

Other surfaces
None

$800 \mathrm{gcal} / \mathrm{cm}^{2}\left(2,950 \mathrm{Btu} / \mathrm{ft}^{2}\right)$

Flat surfaces not transported horizontally:

Each surface

$200 \mathrm{gcal} / \mathrm{cm}^{2}\left(75 \overline{\mathrm{B}} \overline{\mathrm{tu}}_{\mathrm{ft}}{ }^{2}\right)$

Curved surfaces 
Table 43

Summary of Load Comingations for Normal and

Hypothetical Accident Conditions of Traisport

\begin{tabular}{|c|c|c|c|c|c|c|c|c|}
\hline \multirow{3}{*}{$\begin{array}{l}\text { Normal or } \\
\text { Acoldent } \\
\text { Condition }\end{array}$} & \multicolumn{8}{|c|}{ Appllcable Initial Condition } \\
\hline & \multicolumn{2}{|c|}{$\begin{array}{c}\text { Ambient } \\
\text { Tamperature }\end{array}$} & \multicolumn{2}{|c|}{ Insolation } & \multicolumn{2}{|c|}{ Decay Heal } & \multirow{2}{*}{ 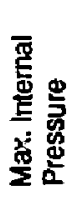 } & \multirow{2}{*}{ 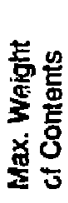 } \\
\hline & $\frac{4}{8}$ & $\stackrel{4}{\circ}$ & 曽 & 0 & 杀 & 0 & & \\
\hline \multicolumn{9}{|l|}{ Normal Conditions } \\
\hline $\begin{array}{l}\text { Hot environment- } \\
100^{\circ} \mathrm{F} \text { ambient ::mp. }\end{array}$ & & & $x$ & & $x$ & & $x$ & \\
\hline \multirow{2}{*}{$\begin{array}{l}\text { Cold enviroment- } \\
-40^{\circ} \mathrm{F} \text { amblent temp. }\end{array}$} & & & & $x$ & $x$ & & $x$ & \\
\hline & & & & $x$ & & $x$ & $\mathbf{x}$ & \\
\hline \multirow{2}{*}{$\begin{array}{l}\text { Minimum external } \\
\text { pressure }\end{array}$} & $x$ & & $\mathbf{x}$ & & $x$ & & $x$ & \\
\hline & & $x$ & & $x$ & $x$ & & $x$ & \\
\hline \multirow{3}{*}{$\begin{array}{l}\text { Vibration \& shock- } \\
\text { Normally incident to } \\
\text { the mode of transport }\end{array}$} & $x$ & & $\bar{x}$ & & $x$ & & $x$ & \\
\hline & & $\bar{x}$ & & $x$ & $x$ & & $x$ & \\
\hline & & $\bar{x}$ & & $x$ & & $x$ & $\bar{x}$ & \\
\hline \multirow{3}{*}{$\begin{array}{l}\text { Froe drop- } \\
1 \text { loot drop }\end{array}$} & $x$ & & $x$ & & $x$ & & $x$ & $x$ \\
\hline & & $\bar{x}$ & & $x$ & $x$ & & $x$ & $\bar{x}$ \\
\hline & & $x$ & & $x$ & & $x$ & $x$ & 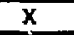 \\
\hline \multicolumn{9}{|l|}{ Accident Condittons } \\
\hline \multirow{3}{*}{$\begin{array}{l}\text { Froe drop- } \\
30 \text { foot drop }\end{array}$} & $x$ & & $x$ & & $\mathbf{x}$ & & $x$ & $x$ \\
\hline & & $x$ & & $x$ & $x$ & & $x$ & $x$ \\
\hline & & $x$ & & $x$ & & $x$ & $x$ & $x$ \\
\hline \multirow{2}{*}{$\begin{array}{l}\text { Punclure- } \\
\text { drop onto bar }\end{array}$} & $x$ & & $x$ & & $x$ & & $x$ & $\bar{x}$ \\
\hline & & $\mathbf{x}$ & & $\mathbf{x}$ & $x$ & & $x$ & $x$ \\
\hline $\begin{array}{l}\text { Thermal- } \\
\text { fire accident }\end{array}$ & $x$ & & $x$ & & $x$ & & $x$ & \\
\hline
\end{tabular}




\section{Twble 4 A}

Criteria for Free Drop Test

(Wesght/Distance)

\begin{tabular}{llll}
\hline \multicolumn{2}{c}{ Package Weight } & & \multicolumn{2}{c}{ Free Drop Distance } \\
\hline Kilograms & \multicolumn{1}{c}{ Pounds } & Meters & Feet \\
\hline & & & 1.2 \\
5,000 or less & $(11,000)$ & 0.9 & $(4)$ \\
5,000 to 10,000 & $(11,00$ to 22,000$)$ & 0.6 & $(3)$ \\
10,000 to 15,000 & $(22,000$ to 33,000$)$ & 0.3 & $(1)$ \\
More than 15,000 & $(M 0 x e$ than 33,000$)$ & & \\
\hline
\end{tabular}




\subsection{REVEW OF THERMAL EVALUATION}

\subsection{General}

This eection of the review confirms that the thermal design of a transport packaging submitted in a SARP for DOE certification uses acceptable analytical and/or test methods and complies with DOE 5480.3 and 10 CFR 71 regulations. $1,2,3$

Figure 5-1 shows the types of information required from other sections of the SARP to perform the thermal review. General information is required on the packaging dimensions, component materials, componen classification, and decay heat values. If the package undergoes any deformation under accident conditions, information on structures is required. Information on materials in the SARP should include thermal design properties and descriptions of the fabrication processes. Reviewers should verify that this information is adequate and usable.

The therroal loads applied to the packaging are to be reviewed. Thermal loads can include radioactive decay heat from the contents, heat from the hypothetical accident fire, and heat from the sun. The environment can also affect the load on the packaging. In most cases, various loading combinations for several environmental conditions have to be reviewed. Subsection 5.2 gives the specific areas for review which address these loads.

The thermal review requires an in-depth knowledge of the three heat transfer modes: conduction, convection, and radiation. Special thermal features that can significantly affect heat transfer have to be recognized, understood, and evaluated. The reviewer should have a general knowledge of materials, their thermal properties, and how the thermal properties may change, especially with temperature. The reviewer should be knowledgeable of possible sources of pressure that can be caused by gases or vapors and how to calculate them.

The thexmal review should assess the results of component temperatures, cavity pressure for varie!s conditions, and any phase changes or thermal degradation that could occur. The therral results from the SARP are used in other areas to evaluate thermal stresses, temperature effects on material properties, and reduction in containment or shielding capabilities caused by material phase changes or degradation. Thermal results are also used in performing leak testing and establishing temperature limits. The thermal review evaluation should be provided to other disciplines that review structures, shielding, containment, operations, and acceptance testing. 
The following subsections contain guidance to assist in the thermal review of transport packagings. This guidance addresses scoping calculations, pressure analysis, and computer codes.

\subsubsection{Methods of Analysis}

\subsubsection{Scoping Calculations}

When sufficient information is available in the SARP, scoping calculations are performed during the initial review to provide an overview of the thermal design and to identify the critical areas for concentrating the review efforts. One-dimensional steadystate heat balances are performed at major boundaries such as component interfaces to determine the primary heat flow paths, the primary modes of heat transfer, and the sensitivity of the heat flow to any changes in the controlling heat transfer parameters.

Several references discuss heat transfer by conduction, convection, and radiation.412 They also give engineering formulas which can be used for scoping calculations. For these scoping calculations, most packaging components and assemblies or portions of them can be approximately represented by plane walled rectangles, annular walled cylinders, or solid cylinders.

By using simple representations and appropriate engineering formulas for each made of heat transfer, the reviewer can make a heat balance between defined boundaries as shown in Fig. 5-2. The temperatures $T_{1}$ and $T_{2}$ at the boundaries are values taken from the SARP, which are used to estimate the total heat flow that could occur. By considering that the scoping calculation is an approximation, the calculated heat flow is then compared with the appropriate decay heat values documented in the SARP.

Next, the maximum permissible temperature gradient across the boundaries is determined from the structural evaluation of maximum allowable stresses from thermal gradients or is calculated by using the maximum permissible qualification temperature for the component for $T_{1}$. The reviewer can calculate the maximum allowable heat flow by comparing the maximum permissible temperature gradient to the decay heat value. The difference beiween the maximum permissible heat flow and the decay heat is the thermal margin. Components that have large positive thermal margins may not require additional evaluation. Components with small or negative margins require detailed verification analyses. 


\subsubsection{Prewore Calculations}

The pressure in the cavity of a packaging can vary from the initial value when the packaging is filled, sealed shut, and leak checked. The pressure depends primarily on the contents and the temperature of the contents. Changes in pressure can be particularly significant in packaginge containing heat sources. The pressure increases as the package heats up from the decay heat source. The environment can also affect the cavity pressure, particularly for the hypothetical fire accident conditions.

The pressure in a cask containing only solids and liquids is the sum of the vapor pressures for both the solid and the liquid. For example, if a packaging contains only spent fuel and water coolant, the pressure in the packaging will be the water vapor pressure, because the vapor pressure of the solid fuel rods is negligible at transport temperatures. The water vapor pressure increases with the water bulk temperature which can increase from the decay heat or the hypothetical fire. The vapor pressure as a function of temperature can be found for most liquids involved in the transport of radioactive materials. 4 When the radioactive material is a liquid, its vapor pressure must also be included in calculating the total pressure.

For all practical purposes, the pressure in a cask containing only solids and gases is the gas pressure. The gas pressure follows the perfect gas low and varies with bulk gas temperature and the initial fill pressure by

$$
P=\frac{P_{i} T}{T_{i}}
$$

where $P_{i}=$ initial pressure, $T_{i}=$ initial bulk temperature, and $T=$ buik temperature at conditions for which the pressure is being calculated such as equilibrium transport conditions or accident conditions. The bulk temperature can be conservatively assumed to be the maximum temperature of the gas.

Packagings which contain a liquid coolant may have residual air or gas in the volume. In this case the total pressure in the cavity is the sum of the liquid gas vapor pressure and the air pressure at their appropriate bulk temperatures.

Packagings which contain a gaseous coolant may have residual liquid such as water that did not drain from the package. In the case where the residual liquid does not totally vaporize, the total cavity pressure is the sum of the gaseous coolant pressure and the 
vapor pressure of the liquid at their appropriate bulk temperatures. In the case where the residual liquid totally vaporizes, the total pressure in the cavity is the sum of the gaseous coolant pressure and the vaporized liquid pressure at the appropriate bulk temperature for the mixed gases. The reviewer can calculate the vaporized liquid pressure by using the perfect gas low and the mass of the liquid from

$$
P_{v}=\frac{m R T}{V}
$$

where $m=$ the mass of the liquid, $R$ is the gas constant of the vaporized liquid, $T$ is the bulk temperature, and $\mathrm{V}$ is the free cavity volume available for the vaporized liquid.

Pressure increases can also be caused by gas releases from the radioactive material contents. As examples, off-gassing of radwaste resin beads can occur in the cavity, chemical dissociation of liquids can occur in the presence of ionization radiation from radioactive materials, and spent fuel rods can rupture and vent high pressure fission products and other gases into the cavity. In all cases the pressures created by these sources have to be added to pressures from the other sources previously discussed.

The pressure caused by spent fuel venting can be calculated from

$$
P_{s}=P_{R}\left(\frac{X V_{R}}{V_{s}+X V_{R}}\right)\left(\frac{T}{T_{R}}\right)=\frac{X N_{R}}{\left(V+X V_{R}\right)} R T
$$

where $X=$ number of rods failed, $V=$ volume in the cavity, $T=$ bulk temperature of gases in the cavity, $P_{R}=$ rod pressure before venting, $V_{R}=$ gas volume in the rod, $T_{R}=$ gas temperature in the rod, $R$ is the universal gas constant, and $N_{R}=$ moles of gases in the rod. Typically the number of gas moles in a spent fuel (BWR/PWR) rod is less than 2.5 $\times 10^{-4}$.

\subsection{Computer Codes}

Many codes are available for performing the various calculations to verify the thermal evaluation. It is important to select a thermal code that has been well benchmarked and that interfaces with a structural code in order to perform thermal stress analysis. The capabilities of the publicly available thermal codes vary significantly. Reference 5-13 evaluates tive thermal codes using test problems. The five codes described 
in the following paragraphs, izclude two codes recently developed and benchmarked at LLNL.

HEATING-5 is a large, general-purpose conduction computer code originally developed at Oak Ridge National Laboratory. It can handle steady state and transient leat transfer in one, two, or three dimensions, and with all types of boundary conditions. It has been used for many applications in heat transfer. HEATING-5 is a Finite Difference Method (FDM) code. HEATING-5 cannot compute naturally driven convection, and it allows radiation only straight across a gap with an assumed shape factor of 1 . It does allow ratiation and convection gaps in the interior of a model as well as on a boundary. It is not built to handle grids other than triangles, but it is very easy to set up and use.

NACHOS also is a large, general-purpose code with rigorous conduction and convection capabilities. The code was developed by and is in primary use at Sandia National Laboratory. NACHOS is a Finite Element Method (FEM) code, so supplying the structural design team with convenient thermal data may be easier when using this type of code. Handling an irregular grid with the FEM is also easier. It can handle more of the important physics than any other code in this report. However, it has two drawbacks: it is only two-dimensional, and it allowe radiation boundary conditions only on the exterior of the model.

TEMPEST is a large, general-purpose conduction/convection code developed at Pacific Northwest Laboratory. The advantage of TEMPEST is that it solves computed convection, like NACHOS, but is also three-dimensional. Unlike NACHOS it cannot do phase changes with or without convection. Its conduction and radiation capabilities are similar to HEATING-5; thus it too has only a gap radiation model. Like HEATING-5, it is easy to set up and use, and the documentation and verification are excellent. It comes with a user's manual as well as a verification manual. Approximately twelve sample problems containing sample input and output are provided.

CINDA-3G is a large, general-purpose conduction code developed by Chrysler. CINDA-3G can do everything HEATING-5 can do, and its convection and radiation capabilities are more general. The user's manual covers a multitude of capabilities including user written subroutines, but it is more difficult to learn than HEATING-5. CINDA-3G can handle any number of radiation connections (generalized gray body 
enclosure radiation), which makes it superior to the analogous capabilities of HEATING5, NACHOS, and TEMPEST.

TRUMP is a large, general-purpose FDM conduction code originally developed at the Lawrence Livermore National Laboratory. It can handle irregular geometries. TRUMP seems more versatile that CINDA-3G because it has a more general treatment of convection (except not computed convection) and radiation. Like CINDA-3G, TRUMP can handle any number of radiation connections. It is a vintage code (1966), and so the verification state of TRUMP can be considered excellent. Because of its very general geometry capability, more input specification is required. It is harder to set up than HEATING-5 or TEMPEST.

TOPAZ is a two-dimensional or three-dimensional FEM computer code for heat conduction analysis. 14 It presents sample problems with analytical solutions. TOPAZ has been implemented on the CRAY, VAX, and IBM PC computers. TOPAZ can be used to solve for the steady state or transient temperature field on two-dimensional planar or axisymmetric geometries. Material properties may be temperature- or time-dependent and either isctropic or orthotropic. A variety of temperature- and time-dependent boundary conditions can be specified including temperature, flux, convection, and radiation. By implementing the user-defined subroutine feature, users can model chemical reaction kinetics and allow for any type of functional representation of boundary conditions and internal heat generation. TOPAZ can solve problems of diffuse band radiation in an enclosure coupled with conduction in the material surrounding the enclosure. Additional features include thermal contact resistance across an intsrface, bulk fluids, phase change, and energy balances. Mainframe versions of TOPAZ interface with the structural codes DYNA, NIKE, and GEX̂HNI anú the pre- anù püst-processor codes MAZE and ORION.

\subsection{Special Form}

Two aspects of special form radioactive material: the qualification of a radioactive material as a special form radioactive material; and the implication that the containment requirements of a Type B package are met with qualified special form radioactive material. 
A radioactive material can be qualified as a special form radioactive material, if it can satisfy the requirements of $10 \mathrm{CFR} 71.75$. Guidelines for reviewing the qualification of special form radioactive material are given in Appendix A.

The current 10 CFR 71 and IAEA \#6 standards for Type B quantities of radioactive material do not address the use of special form radioactive material to meet the containment requirements of Type B packagings. Thus, as current regulations stand, there is no differentiation between the containment requirements for a package containing a Type $B$ quantity of a normal radioactive material and the containment requirements for a package containing the same quantity of a special form radioactive material. However, a special form radioactive material can satisfy the containment requirements for a Type $B$ package if it can be demonatrated that its properties will satisfy the test requirements specified in 10 CFR 71.71 and 10 CFR 71.73 at temperatures as low as $-29^{\circ} \mathrm{C}$, with the activity release rate less than that specified in $10 \mathrm{CFR} 71.53$.

\subsection{Arees of Review}

The following areas, identified in Regulatory Guide (R.G.) 7.9, are reviewed for compliance with regulations and DOE orders. 15 


\subsubsection{Discusgion}

The significant thermal design features and operating characteristics of the package are identified and reviewed for adequacy to provide their intended safety functions. Thermal criteria are identified.

\section{Thermal Properties of Materials}

The thermal properties of the materials used in the packaging design are reviewed for completeness and accuracy for the packaging application and the rolated thermal evaluation. The reviewer coordinates this effort with the person performing the materials review using the complete specifications for each material to assure that the material thermal properties are compatible with the structural properties used.

\subsubsection{Thermal Specifications on Packaging Components and Parts}

The thermal specifications and supporting qualification test documentation for safety-related components are reviewed with respect to their safety functions and the thermal evaluation results.

\subsubsection{Thermal Evaluation for Normal Conditions}

The thermal evaluation of the packaging and contents is reviewed for engineering soundness and correctness for normal transport conditions. The thermal model is checked to determine its adequacy in representing the packaging and contents. The evaluation is reviewed to determine if all thermal loading combinations for normal conditions in R.G. 7.8 are addressed. 16 The review includes the description of the thermal models, thermal analysis methods, and the detailed calculations for normal transport conditions. The results of the thermal calculations are reviewed with respect to the acceptance criteria which include the thermal specifications for components important to safety. For most packagings, especially large complex ones, thermal verification calculations should be performed using well-established, benchmarked analytical methods and computer codes whenever possible. The thermal modeling should be done as exact as possible or approximated in a conservative manner that can be reasonably justified. All references and computer codes used should be documented in the review. 


\subsection{Hypothetical Accident Thermal Fvaluation}

The thermal evaluation of the packaging and contents for accident conditions is reviewed. The review addresses the same items identified in 5.2.4, except the review is performed for accident conditions.

\subsubsection{Special Form}

If the contents of a package are a special form radioactive material, the applicant may take credit for the containment requirements of a Type B package if certain conditions are met. The contents of the package are reviewed for conformance with the applicable regulation definition and requirements for a special form radioactive material. The thermal loads on the special form contents of a package that is subject to the normal and hypothetical conditions must be reviewed. The thermal response of the special form contents to the normal and hypothetical accident condition thermal loads applied to the package must be reviewed.

\subsubsection{Appendix}

All supplemental information provided in the SARP which supports the thermal evaluation for the packaging anci contents is reviewed.

\subsection{Acceptance Criteria}

The following subsections provide the specific criteria for judging the acceptability of the thermal evaluation contained in the SARP.

\subsubsection{Discugsion}

The description of the thermal design features and the thermal design criteria must include the following. 


\subsubsection{Thermal Design Features}

Per 10 CFR 71.33, all of the thermal design features, particularly valves, sampling ports, and any structural and mechanical means for the transfer of heat must be identified and described. Tho maximum operating pressure and the maximum radioactive decay heat must be specified for the package. The types of volumes of any coolants used in the packaging must also be identified and evaluated for their effects on the packaging performance.

\subsubsection{Teat Standards}

Per 10 CFR 71.35, the package must satisfy the test standards specified in Subparts $\mathbf{E}$ and $F$ of 10 CFR 71. Results from the thermal evaluation which affect other evaluations must be identified for inclusion in the other evaluations. In addition, any results from other areas that could effect the thermal evaluation must be identified and included in the thermal evaluation. 


\subsubsection{Maximum Allowable Surface Temperature}

Per $10 \mathrm{CFR} 71.43$, the applicant must show that in still air at $38^{\circ} \mathrm{C}$ and in the shade, no accessible surface of a package would have a temperature exceeding $50^{\circ} \mathrm{C}$ in a nonexclusive use shipment or $82^{\circ} \mathrm{C}$ in an exclusive use shipment.

\subsubsection{Contrinment Presaure}

Per 10 CFR 71.51, the applicant must show that specified containment requirements must be satisfied under the test specified in $10 \mathrm{CFR} 71.71$ and 71.73. Sufficient information resulting from thermal calculations such as containment pressure shall be included in the SARP so that an appropriate containment evaluation can be performed.

\subsubsection{Normal Transport}

Per 10 CFR 71.71, the package design must be evaluated for normal transport conditions. R.G. 7.8 provides supplemental information concerning normal transport conditions that should be evaluated for nuclear spent fuel transport. The information in R.G. 7.8 can be generalized for all Type B packages to provide guidance in performing reviews of thermal evaluations of Type B packages for normal transport conditions. The following criteria should be used in reviewing the thermal evaluation for packages under normal transport conditions.

a. Initial ambient temperature at $-29^{\circ} \mathrm{C}\left(-20^{\circ} \mathrm{F}\right)$ with no insolation and of ambient temperature at $38^{\circ} \mathrm{C}\left(100^{\circ} \mathrm{F}\right)$ with the maximum insolation data given in Table 5.1 . Exceptions to the atrove are made for the hot environment and cold environment normal conditions (which use other steady state values) and for the thermal accident condition (which considers the higher thermal initial condition but not the lower one).

b. The decay heat of the contents must be considered as part of the thermal load. Generally, the maximum amount of decay heat should be considered in combination with the thermal environmental conditions in 5.3.1.7.a. Table 5.2 summarizes thermal loads and boundary conditions for the cases which can be thermally and scructurally evaluated by the applicant and reviewed for completeness and correctness. 
c. The internal pressure in the packaging cavity that is used in evaluating normal conditions should be consistent with the other conditions that are being considered.

d. The release of all pressurized gases inside the packaging centents should be considered in determining the maximum containment vessel pressure. The release could involve gases from spent fuel rods, outgassing of resin beads from reactor cleanup systems, etc. In addition, gas pressure buildup from any deionization of the coolant caused by radiation or from vaporization of the coolant caused by heating must be included in the pressure calculation. The reviewer is to assess whether all phenomena that could affect the pressure have been properly considered in the pressure calculation.

e. Intermediate temperature conditions should also be evaluated by the applicant if they can cause a more severe structural response than the extreme conditions given in Table 5.2.

f. For packaging designs that involve fabrication processes (such as lead pouring or the shrink fitting assembly of parts) where the structural response can be significantly affected, the appropriate initial conditions are determined to be at the point where the parts involved in the process are free of any significant stresses. In these cases the applicant is to perform a thermal evaluation to determine the thermal stresses as jiscussed in PRG Section 4.0.

g. Factors that can cause thermal fatigue should be evaluated by the applicant to show that they do not cause any significant deterioration or damage to the packaging even when they are combined with other loads. These factore can include thermal cycling of high decay heat load packagings due to the loading and unloading of the contents or extreme weather variations during transport over the life of the packaging. The reviewer is to assess that all phenomena that could affect thermal fatigue have been properly considered in the thermal evaluation.

h. To assess the response of the package to a hot environment, the applicant should thermally evaluate the packaging for a temperature of $38^{\circ} \mathrm{C}\left(100^{\circ} \mathrm{F}\right)$ in still air and with maximum insolation. If the packaging has a non-safety grade cooling system, it should be assumed that the system is inoperable during the hot environment condition.

i. To assess the response of the package to a cold environment, the applicant should thermally evaluate the packaging for a temperature of $-40^{\circ} \mathrm{C}\left(-40^{\circ} \mathrm{F}\right)$ in still air and no 
insolation. The case of maximum decay heat load and maximum internal pressure should be considered in addition to the case of no internal heat load. The possib:lity and consequences of coolant freezing should also be considered.

\subsubsection{Hypothetical Aocident Conditions}

Per 10 CFR 71 73, the package design must be evaluated for hypothetical accident conditions. R.G. 7.8 provides supplemental information concerning hypothetical accident conditions that should be evaluated for nuclear spent fuel transport. The information in R.G. 7.8 can be generalized for all Type $B$ packages to provide guidance in performing reviews of thernal evaluations of Typr B packages for hypothetical accidant conditions. In addition to the thermal criteria used in reviewing the $t, 1$, mal evaluation for packagea under normal transport conditions in $5.3 .1 .7 . \mathrm{a} \cdot \mathrm{g}$, the followins thermal criteria should be included:

a. The effects of the free drop and puncture tests specified in $10 \mathrm{CFR} 71.73$ must be assessed prior to the thermal evaluation to determine the condition of the package, particularly the thermal design features. The package configuration resulting from the drop and puncture tests should then be evaluated for a thermal conitition in which the whole package is exposed for not less than 30 minutes to a heat flux not less than that of a radiation environment of $800^{\circ} \mathrm{C}\left(1,475^{\circ} \mathrm{F}\right)$ with an emissivi cy coefficient of ai ieast 0.9 for 30 minutes. For purposes of calculation, the surface absorptivity should be either that value which the package may be expected to possess if expused to a fir or .8, whichever is greaiter. In addition, when significant, convective heat transfer to the package should be included.

\subsubsection{Liquid Coolants}

Per 10 CFR 71.87, if the packaging contains a liquid, there must be adequate space or other specified provision for the expansion of the liquid.

\subsubsection{Thermal Properties of Materials}

Specific criteria for judging the acceptability of the thermal properties of materials used in the package design are as follows: 
a. Criteria for acceptable specifications for structural materials are given in Section 3.0. For non-ctructural materials such as thermal coatings, lead shielding, and neutron shielding, information or references should be included to permit an evaluation of the material properties, makeup, processes, and intended use.

b. All material properties required for thermal analyses of components and parts important to eafety must be described. Verify that all the material properties used in the thermal analyses are listed and cover the ranges of application. These properties may include heat capacity, emissivity, and thermal conductivity. The source of all material jioperties information should be clearly and specifically referenced as to tine publication and page number. Where material properties are determined by testing, the test procedure, conditions, and measurements should be described in sufficient detail to conclude that the resilts are valic.

\subsection{Thermal Specifications on Packaging Components and Parts}

The applicant must include thermal specifications for all safety-related components and parts. In many cases the material specifications required in $\mathbf{3 . 0}$ may be referenced and supplemented with information on the fabrication and assembly processes, particulariy for structural materials. However, for closure systems and valves which include parts such as seals and gaskets, the thermal specification may have to be supported by appropriate qualification testing. All specifications should include information on the component description, safety function, materials of construstion, significant fabrication processes, temperature and pressure ranges of operation, the time period of use before seplacement or maintenance is required, and all limitations that could affect the component's safety function. Periods of replacement and maintenance should be justified through tests and analysis. Supporting qualification tests for valves should be performed in accordance with the appropriate articles of the ASME code Section III, and for burst dise in accordance with the ASME code Section VIII. The component specification should include operation for both normal and hypothetical accident conditions. All testing and analysis must include the effects of normal operation for the maximum time without replacement or maintenance of parts for the component, followed by analysis for the hypothetical accident condition. Any deterioration of the component's safety function should be identified. Evidence should be provided that the qualification test has been successfully performed. 


\subsubsection{Thermal Evaluation of Normal Conditions}

The applicant must include thermal evaluations of the package for normal conditions as specified in $10 \mathrm{CFR}$ 71.71. The evaluations must include thermal models, heat transfer analysis, and temperature distributions for each safety-related component. All modeling and analysis assumptions, including those used in computer codes, must be stated and justified. When the package design includes various operating modes or configurations such as different content loadings and different coolants, each mode and operation must be evaluated to determine the adequacy of the design for all conditions. The results of the thermal evaluation must demonstrate that the thermal component specifications are adequate for the component to provide its safety function under normal conditions. The thermal evaluation must consider any deteriorating effects or damage caused by normal transport.

\subsection{Hypothetical Aocident Thermal Conditions}

The applicant must include thermal evaluations of the package for hypothetical accident conditions as specified in $10 \mathrm{CFR}$ 71.73. The evaluations must include thermal models, heat transfer analysis, and minimum/maximum temperature distributions for each safety-related component. All modeling and analysis assumptions, including various operating modes or configurations such as differert content loadings and different coolants, must be evaluated to determine the adequacy of the design. The results of the thermal evaluation must demonstrate that the thermal component specifications are adequate for the component to provide its safety function under hypothetical accident conditions. The thermal evaluation must consider any deteriorating effects or damage caused by normal transport.

\subsubsection{Special Form}

The acceptance criteria for a package containing a special form radioactive material include the application of the thermal loads prescribed for both normal and accident conditions of transport. The acceptance criteria for the contents and the package are described below.

\subsubsection{Contents}

The special form radioactive material contents of the package must meet the requirements for a special form radioactive material given in 10 CFR 71.75. 


\subsubsection{Packaging}

A packaging with special form radioactive material contents must undergo the thermal tests for normal conditions (10 CFR 71.71 (C1,2)) and hypothetical accident conditions (10 CFR 71.73 (C))). For credit to be given to the containment requirements for a Type $B$ package with special form radioactive material contents, the following acceptance criteria are necessary, but not necessarily sufficient.

\section{a. Loads on Packace Contents}

The thermal tests on the package specified in $10 \mathrm{CFR} 71.71$ and $10 \mathrm{CFR} 71.73$ shall not produce thermal loads, or cause such loads to $b_{2}$ : produced, in the special form radioactive material, greater than those specified in 10 CFR 71.77 (d).

b. Regponse of the Contents to the Package Loading

The static and dynamic response of the special form radioactive material to the thermal loads applied from the package response to the thermal loads of 10 CFR 71.71 and 10 CFR 71.73 must not exceed the temperature that would be produced by the application of the heat test of 10 CFR 71.77 (d) to the unpackaged special form radioactive material.

\subsubsection{Appendix}

All supplemental information to the thermal evaluation should be included as an appendix. This information should include material and component specifications, qualification tests, and computer codes used in the thermal evaluations. 


\subsection{Procedures}

The reviewer will ensure that the information discussed below is provided in appropriate detail considering the package complexity, contents, and size.

\subsubsection{Discussion}

The safety function and classification of all components should be reviewed for their potential impact on the thermal evaluation of the packaging. Verify that all thermal design features have been properly identified and discussed to determine their relationship to the thermal safety function and the overall evaluation. The thermal design features may include items such as cooling fins, thermal barriers that may be activated under accident conditions, contact and clearance regions, and special materials for controlling heat conduction. Verify that all of the acceptance criteria in 5.3.1 have been considered or are irrelevant to the package.

\subsection{Thermal Properties of Material.}

Compare the material specifications for the packaging components with acceptable specifications listed in the ASME Code, Section III, Appendix I, and Section II, Parts A, $B$, and C. Verify that any materials not listed in the code, or any deviations in a listed specification, are clearly identified, and the bases for deviation or nonconformance evaluated. Determine the acceptability of the proposed exception through a study of the suitability of the material and comparison with precedents set in earlier cases. In many cases ASTM specifications with additional controls as required to upgrade them to Code level can be used. In those instances where the reviewer takes exception to the use of a specific material or questions certain aspects of a specification, advise the applicant which material is not acceptable, and the reason for disapproval.

\subsubsection{Thermal Specifications on Packaging Components and Parts}

Verify that thermal specifications are included for all safety-related components, particularly for valves and closures. Verify that each specification is complete and contains the information required in acceptance criteria per 5.3.3. Review in detail the qualification tests and analyses which qualify a component for its use against the thermal specifications to verify that the temperature requirements in the thermal specification 
have been met. In those cases where the reviewer determines that a thermal specification or a qualification test and analysis are not acceptable or questions certain aspects of them, advise the applicant of the determinations and the reasons for any rejection.

\subsection{A Thermal Evaluation of Normal Conditions}

Verify that the following information is included in the thermal evaluation for normal transport conditions. In those instances where the fabrication processes can affect the thermal evaluation, similar types of information should be included.

\subsection{A.1 Thermal Model}

Verify that the thermal model and evaluation are described in detail and are related to the package design. The evaluation should include gaskets, valves, internal supports, contents, coolant thermal barriers, and impact limiters. Critical gaps or clearances should be included. Modeling assumptions should be identified and justified. The model can be 1-, 2-, or 3-dimensional and can be done piecewise as components as long as the modeling is justified and the thermal boundary conditions are compatible at each component interface. All heat sources and sinks should be identified. When contents vary or their heat absorption capability cannot be ensured, they should not be included in the model as a heat sink but included only as a heat source.

\subsection{A.2 Test Model}

Verify that any test performed to support the thermal model or the packaging qualification is clearly described and related to the model. The specific objectives of the test and how they support the thermal model or packaging qualification should be stated. The pracedures used to correlate the test data to the thermal environment specified in 10 CFR 71.71 for normal transport conditions should be describer. Verify that heat flux, heat transfer area, and temperature data are provided for all onmponents being modeled and tested, particularly at the boundaries. 


\subsubsection{Maximum and Minimum Temperatures}

Verify that maximum and minimum temperature distributions for each component are listed for normal transport conditions for the various boundary conditions. The minimum temperature distribution should consider the minimum heat load. When a decay heat load greater than zero is required for safe operation, assurance of that heat must be provided. The shipment of an empty package with no heat load should be addressed.

\subsubsection{Maximum Internal Pressures}

Verify that maximum internal pressures are determined for the packaging for normal transport conditions. The pressures that result in most severe thermal loading in combination with any other structural loads developed should be determined. In addition, the pressure is used in evaluating the containment of radioactive material. Verify that details of the pressure calculation are presented. The details should include temperatures, quantities of fluids and their physical states, and the associated fluid volumes. Where chemical reactions, dissociations, or phase changes occur, the following should be discussed; 1) the reaction or phase change mechanism, 2) the reactants and products involved, 3) estimates of the extent and the rate of reaction or phase change, and 4) the consequences of the reaction or phase change. For spent fuel shipments, the additional pressure that would result from fuel rod failure should be considered. For radiation waste shipment, outgassing of resin beads and filters should be considered.

\subsubsection{Maximum Thermal Stresges}

For packaging designs that involve fabrication processes (such as lead pouring or shrink fitting assembly of parts) where the structural response can be significantly affected, verify that the appropriate initial conditions are determined to be at the point where the parts involved in the process are iree of any significant stresses. In these cases, verify that the applicant performs a thermal evaluation to determine the thermal stresses as discussed in PRG Section 4.0.

\subsubsection{Evahuation of Package Performance}

Evaluate package performance, including system and subsystem operation for normal transport conditions. Compare the temperature calculated in the thermal 
analysis or measured in the thermal test with the allowable temperature and pressure limits for packaging components. Assess fatigue and aging effects on the components. Determine if each component properly provides a specified safety function for normal and accident conditions in accordance with regulations.

\subsubsection{Documentation}

Information to be used in other evaluations should be summarized and supported by comments. Verify that the comments state where the information is to be used and the specific conditions that apply. For example, temperature gradient information may be provided for thermal stress evaluation for normal conditions. Maximum pressure and closure seal temperature information may be provided for containment evaluations.

\subsubsection{Hypothetical Accident Thermal Evahuation}

Verify that the following information is included in the thermal evaluations for hypothetical accident conditions. In those instances where the fabrication processes can affect the thermal evaluation, similar types of information should be included.

\subsubsection{Thermal Model}

Verify that the thermal model and evaluation are described in detail and relate to the package design. The evaluation should include gaskets, valves, internal supports, contents, coolant, thermal barriers, and impact limiters. Critical gaps or clearances should be included. Modeling assumptions should be identified and justified. The model can be 1-, 2-, or 3-dimensional and can be done piecewise as components as long as the modeling is justified and the thermal boundary conditions are compatible at each component interface. All heat sources and sinks should be identified. When contents vary or their heat absorption capability cannot be ensured, they should not be included in the model as a heat sink but included only as a heat source.

\subsubsection{Test Model}

Verify that any test performed to support the thermal model or the packaging qualification is clearly described and related to the model. The specific objectives of the test and how they support the thermal model or packaging qualification should be stated. 
The procedures used to correlate the test data to the thermal environment specified in 10 CFR 71.73 for hypothetical accident conditions should be described. Heat flux, heat transfer area, and temperature data should be provided for all components being modeled and tested, particularly at the boundaries.

\subsubsection{Package Conditions and Environment}

For the hypothetical accident conditions, verify that the thermal model and analysis include the effects of any damage resulting from the free drop and puncture tests. Also any aging or fatiguing effects on the components and parts caused by normal transport conditions must be included.

\subsubsection{Package Temperature}

Verify that the transient temperature distributions for each component are listed for the hypothetical accident conditions as determined by test and analysis. The temperatures listed should be at locations on the components such that the reviewer can assess the ability of the component to provide its safety function or can use the information in other evaluation areas, such as structural, in determining thermal stress levels. Verify that temperatures of items such as contents, internal support structure, valves, closure seals, and shielding are listed. The temperature distributions for all components should extend beyond the one-half hour time period to include the maximum values. In addition, the steady state temperature distributions following the hypothetical fire should be included in the SARP, particularly when a thermal barrier that restricts heat transfer is activated.

\subsubsection{Marimum Internal Pressures}

Verify that the maximum internal pressures are determined for the packaging for hypothetical accident conditions. The pressures that result in the most severe thermal loading in combination with any other structural loads developed should be determined. In addition, the pressure is used in evaluating the containment of radioactive material. Verify that details of the pressure calculation are presented. The details should include temperatures, quantities of fluids and their physical states, and the associated fluid volumes. Where chemical reactions, dissociations, or phase changes occur, the following 
should be discussed: 1) the reaction or phase change mechanism, 2) the reactants aud products involved, 3 ) estimates of the extent and the rate of reaction or phase change, and 4) the consequences of the reaction or phase change. For spent fuel shipments, the additional pressure that would result from fuel rod failure should be considered. For radiation waste shipment, outgassing of resin beads and filters should be considered.

\subsubsection{Maximum Thermal Stresees}

For packaging designs that involve fabrication (processes such as lead pouring or shrink fitting assembly of parts) where the structural response can be significantly effected, verify that the appropriate initial conditions are determined to be at the point where the parts involved in the process are free of any significant stresses. In these cases, the applicant is to perform a thermal evaluation to determine the thermal stresses as discussed in PRG 4.0.

\subsubsection{Evahuation of Package Performance}

Verify that the package performance is evaluated and includes system and subsystem operation for hypothetical accident conditions. Compare the temperature calculated in the thermal analysis measured into the thermal test with the allowable temperature and pressure limits for the packaging components. Fatigue and aging effects on the components are also assessed. Determine if each component properly provides a specified safety function for normal and accident conditions in accordance with regulations.

\subsubsection{Documentation}

Verify that information to be used in other evaluations is summarized and supported by comments. The comments should state where the information is to be used and the specific conditions that apply. For example, temperature gradient information may be provided for thermal stress evaluation for hypothetical accident conditions. Maximum pressure and closure seal temperature information may be provided for containment evaluations. 


\subsection{Special Form}

The procedures for reviewing the contents and package for conformance to the acceptance criteria giver, in Section 5.3.6 are described below.

\subsubsection{Contents}

Verify that the contents of the package meet the special form requirements specified in 10 CFR 71.75. Guidelines for reviewing the qualification of special form radioactive material are given in Appendix A.

\subsubsection{Packaging}

Verify that the packaging with the special form radioactive material contents meet the thermal test requirements for normal conditions (10 CFR 71.71) and hypothetical accident conditions (10 CFR 71.73). Verify that the static and dynamic response of the special form radioactive material to the thermal loads from the package response to the tests of 10 CFR 71.71 and 10 CFR 71.73 and including the energy deposition in the packaging from the contencis do not exceed temperatures that would be produced by the application of the heat test of $10 \mathrm{CFR} 71.77$ (d) to the unpackaged special form radioactive material.

Verify that the thermal response, determined either by test measurement or by analysis, is appropriate for the heat loads transmitted from the package to the contents, and the heat generated in the contents by radioactive decay of the contents. Verify that the thermal properties used are those specified for the special form radioactive material. Verify that the internal energy deposited in the packaging and special form material contents from the radioactive decay of the special form material is appropriate to the radioisotope composition and decay chain of the special form material contents. Verify that the energy attenuation coefficients for the packaging and special form material are appropriate for the type and energy of decay products produced by the disintegration of the radionuclides of the special form radioactive material. 


\subsubsection{Appendix}

Review all supplemental information in the SARP which supports the thermal evaluation for the packaging and contents. This appendix could include information such as justification of assumptions, analytical procedures, test results, computer program descriptions, and computer input'output.

\subsection{Findings}

The reviewer verifies that sufficieat and adequate information has been provided to satisfy the general requirements of the review plan for the package, and that the evaluation supports the following conclusion, to be included in the safety evaluation report:

"This section of the applicant's SAR has been reviewed to determine that the thermal design features have been designed in a manner that will assure compliance with the performance requirements of 10 CFR Part 71, Paragraphs 71.33, 71.35, 7.1.43, 71.51, 71.71, 71.73, and 71.87 for the paskage."

"Basis for acceptance in the review has been conformance with established guidelines and criteria. The evaluation of the thermal design provides reasonable assurance that, from the standpoint of general requirements on the packaging, it will be possible to transport radioactive material safely."

"The staff concludes that the protective features provided in the design of the package conform to applicable Regulations, Regulatory Guides, and industry standards, and are acceptable."

\subsection{References}

1. U.S. Department of Energy, DOE 1540.2: Hazardoug Material Packaging for Transport-Administrative Procedures, U.S. Department of Energy, Washington, DC, September 30, 1986.

2. Office of the Federal Register, Title 10. Code of Federal Regulations, Part 71, Office of the Federal Register, Washington, DC, 1984. 
3. U.S. Department of Energy, DOE 5480.3: Safety Requirements for the Rackagine and Transportation for.Hazardous Materials. Hazardous Substance, and Hazardous Wastes, U.S. Department of Energy, Washington, DC, August 9, 1985.

4. Kreith, Frank, Principles of Heat, Transfer, Second Edition, International Textbook Company, Scranton, PA, July 1968.

5. Eckert, E.R.G., and Drake, Robert M. Jr., Analysis of Heat and Mass Transfer, McGraw-Hill Book Company, New York, NY, 1972.

6. McAdams, William H., Heat Transmission, Third Edition, McGraw-Hill Book Company, New York, NY, 1954.

7. Sparrow, E.M., and Cess, R.D., Radiation_Heat Trangfer Revised Edition, Brooks/Cole Publishing Company, Belmont, CA, 1977.

8. Siegel, Robert, and Howell, John R, Thermal Radiation Heat Transfer, McGrawHill Book Company, New York, NY, 1972.

9. Hottel, Hoyt C., and Sarofim, Adel F., Radiative Tranafer, McGraw-Hill Book Company, New York, NY, 1967.

10. General Electric Company, Heat Transfer Data Book, General Electric Company, Corporate Research and Development, Schenectady, NY, 1977.

11. VanSant, James H., Conduction Heat Transfer Solutions, UCRL-52863, Lawrence Livermore National Laboratory, August 1983, Rev. 1.

12. Wooten, R.O., and Epstein, H.M., "Heat Trangfer from a Parallel Rod Fuel Element in a Shipping Container," Nuclear Science and Enginesring, 1964.

13. Budden, M.J., Comparison and Evaluation of Several_Computer Prosrams for. Use in Design of Spent Euel_Shipping Casks, PNL-5213, UC-71, Prepared for the U.S. Department of Energy by Pacific Northwest Laboratory, Richland, WA, July 1984. 
14. Shapiro, Arthur B., TORAZ - A Finite Element Heat Conduction Code for Analyzing 2.D Solids, Lawrence Livermore National Laboratory, Livermore, CA, UCID-20045, March 1984.

15. U.S. Nuclear Regulatory Commission, Regulatory Guide 7.9: Standard Format and Content of Part 71 Applicgtions for Approval of Packaging of Type B. Large Quantity and Fissile Radioactive Material, U.S. Nuclear Regulatory Commission, Washington, DC, Rev. 1, January 1980.

16. U.S. Nuclear Regulatory Commission, Regulatory Guide 7.8: Load Combinations for the Structural Analysis of Shipping Casks, U.S. Nuclear Regulatory Commission, Washington, DC, May 1977. 


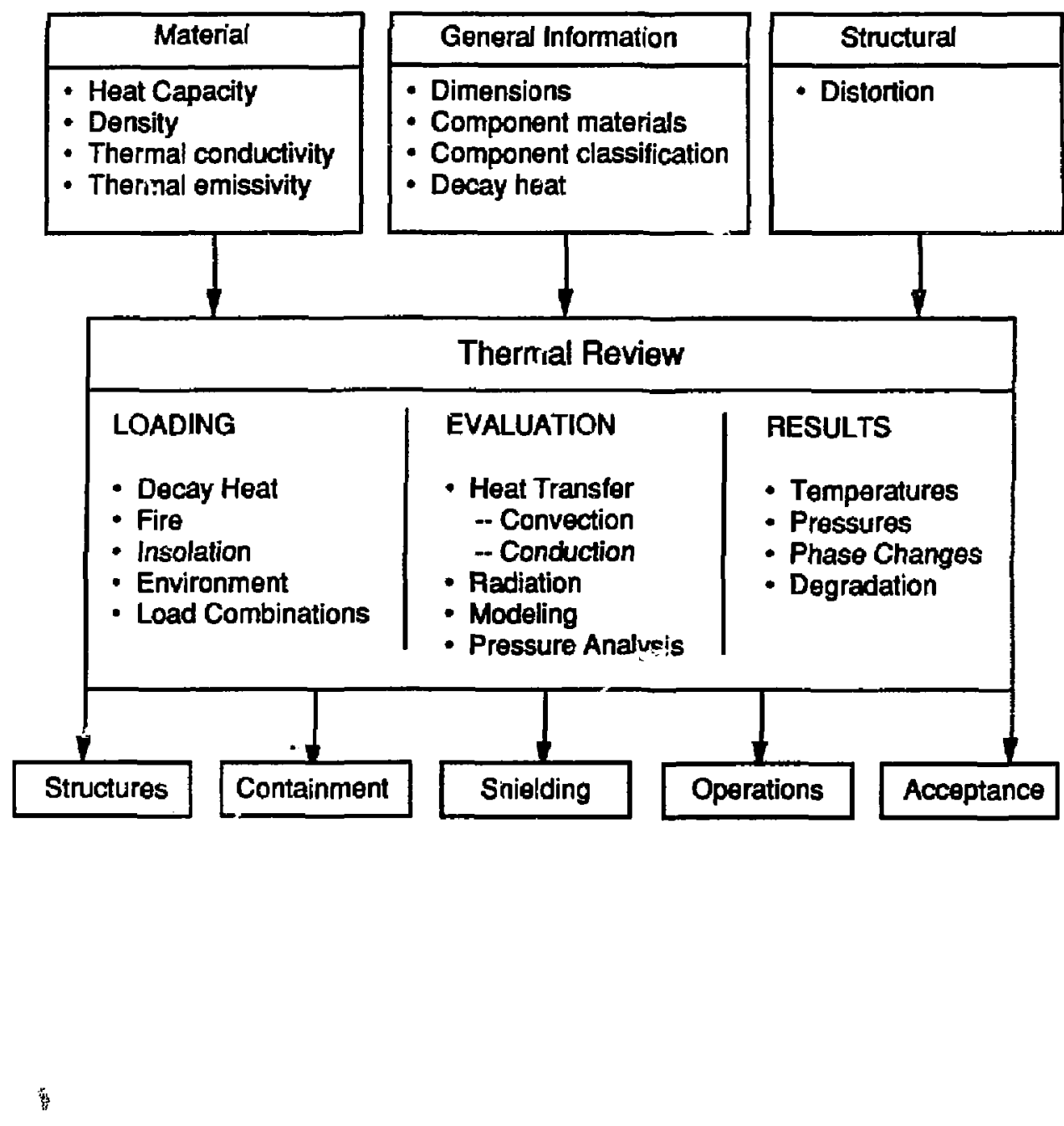

Figure 5-1 Input and output information for the thermal review process. 


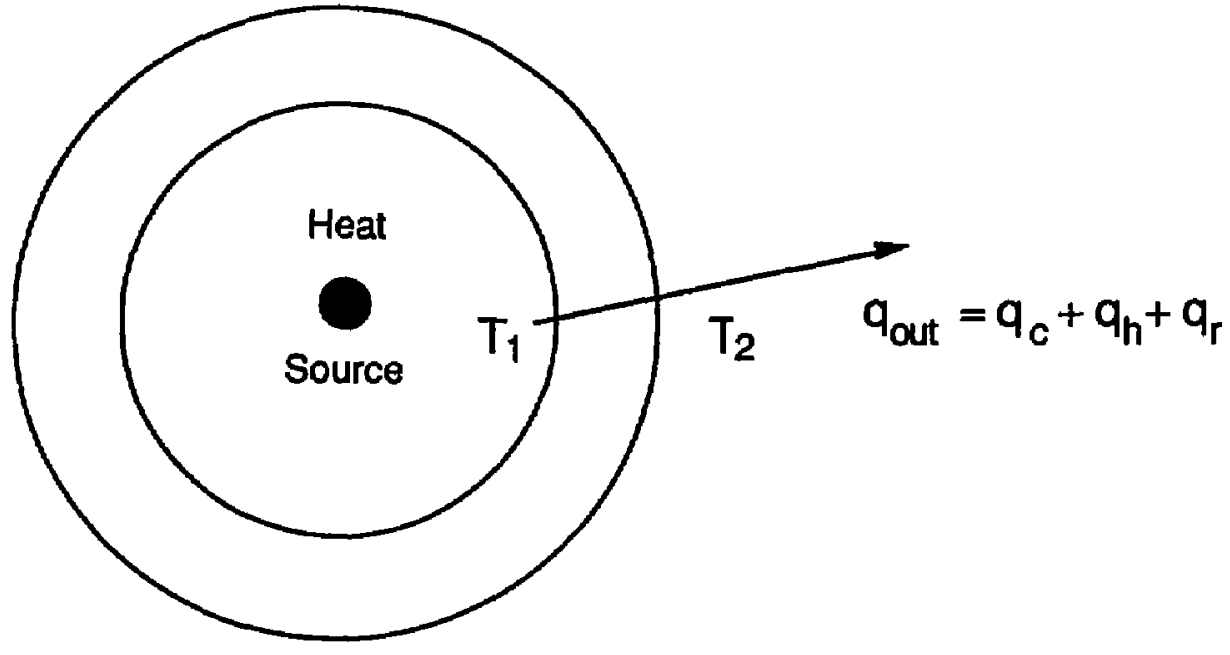

Figure 5-2 Heat balance acroes component boundaries. 
Table 5.1

Maximum Insolation Data

Form and location

Insolation for 12 hours

of surface per day

Flat surfaces transported horizontally:

Base

Other surfaces

Flat surfaces not transported

horizontally:

Each surface

Curved surfaces
None

$800 \mathrm{gcal} / \mathrm{cm}^{2}\left(2,950 \mathrm{Btw} / \mathrm{ft}^{2}\right)$

$200 \mathrm{gcal} / \mathrm{cm}^{2}\left(737 \mathrm{Btw} / \mathrm{ft}^{2}\right)$

$400 \mathrm{gcal} / \mathrm{cm}^{2}\left(1,475 \mathrm{Btw} / \mathrm{ft}^{2}\right)$ 
Table 52

Sammary of Load Combinations for Normal and Hypothetical Accident Conditions of Transport

\begin{tabular}{|c|c|c|c|c|c|c|c|c|}
\hline \multirow{3}{*}{$\begin{array}{l}\text { Normal or } \\
\text { Accident } \\
\text { Conditton }\end{array}$} & \multicolumn{8}{|c|}{ Applicable Initial Condition } \\
\hline & \multicolumn{2}{|c|}{$\begin{array}{c}\text { Ambient } \\
\text { Temperature }\end{array}$} & \multicolumn{2}{|c|}{ Insolation } & \multicolumn{2}{|c|}{ Decay Heat } & \multirow{2}{*}{ 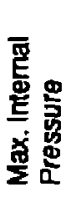 } & \multirow{2}{*}{ 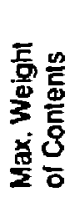 } \\
\hline & 岁 & $\stackrel{4}{\circ}$ & 尊 & 0 & $\stackrel{\check{d}}{2}$ & 0 & & \\
\hline \multicolumn{9}{|l|}{ Nomal CondHions } \\
\hline $\begin{array}{l}\text { Hot environment- } \\
100^{\circ} \mathrm{F} \text { ambient terno. }\end{array}$ & & & $x$ & & $x$ & & $x$ & \\
\hline \multirow{2}{*}{$\begin{array}{l}\text { Cold environment- } \\
-40^{\circ} \mathrm{F} \text { ambiaiti temp. }\end{array}$} & & & & $x$ & $x$ & & $x$ & \\
\hline & & & & $x$ & & $x$ & $x$ & \\
\hline \multirow{2}{*}{$\begin{array}{l}\text { Minimum external } \\
\text { pressure }\end{array}$} & $\mathbf{x}$ & & $x$ & & $x$ & & $x$ & \\
\hline & & $x$ & & $x$ & $x$ & & $x$ & \\
\hline \multirow{3}{*}{$\begin{array}{l}\text { Vibration } 8 \text { shock- } \\
\text { Nomally incident to } \\
\text { the mode of transport }\end{array}$} & $x$ & & $x$ & & $x$ & & $x$ & \\
\hline & & $x$ & & $\mathbf{x}$ & $x$ & & $x$ & \\
\hline & & $x$ & & $x$ & & $x$ & $x$ & \\
\hline \multirow{3}{*}{$\begin{array}{l}\text { Free drop- } \\
1 \text { toot drop }\end{array}$} & $x$ & & $x$ & & $x$ & & $x$ & $x$ \\
\hline & & $x$ & & $x$ & $x$ & & $x$ & $x$ \\
\hline & & $x$ & & $x$ & & $x$ & $x$ & $x$ \\
\hline \multicolumn{9}{|l|}{ Accldent Conditions } \\
\hline \multirow{3}{*}{$\begin{array}{l}\text { Free drop- } \\
30 \text { loot drop }\end{array}$} & $x$ & & $x$ & & $x$ & & $x$ & $x$ \\
\hline & & $x$ & & $x$ & $x$ & & $x$ & $x$ \\
\hline & & $x$ & & $x$ & & $x$ & $x$ & $x$ \\
\hline \multirow{2}{*}{$\begin{array}{l}\text { Puncture- } \\
\text { drop onto bar }\end{array}$} & $x$ & & $x$ & & $x$ & & $x$ & $x$ \\
\hline & & $x$ & & $x$ & $x$ & & $x$ & $x$ \\
\hline $\begin{array}{l}\text { Thermal- } \\
\text { fire accident }\end{array}$ & $x$ & & $x$ & & $x$ & & $x$ & \\
\hline
\end{tabular}




\subsection{General}

This section of the review provides details of the containment analysis. Compliance with the regulatory requirements must be demonstrated, 1,2 The discussions presented must detail the packaging containment during normal conditions of transport (10 CFR Part 71.71) and hypothetical accident conditions (10 CFR Part 71.73).

Figure 6-1 shows the types of information required from other sections of the SARP to perform the containment review. General information is required on the packaging dimensions, component materials, component classification and the radinactive source terms. Information from the structural section should reveal whether any permanent deformation has occurred to the containment eystem. The packaging temperatures and internal pressures should be provided from the thermal section.

The containment evaluation is reviewed to verify that the proper temperatures, pressures, and source terms have been used. The release model is reviewed to verify that all potential leak paths, particularly at flanges and welds, have been identified and properly evaluated.

The results of the containment review should include information on all potential release paths and release values for normal and accident conditions. The containment results are used to set operational limits and to develop acceptance and maintenance testing criteria.

\section{Areag of Review}

The following areas are reviewed for compliance with regulations and DOE Orders as identified in Regulatory Guide (R.G.) 7.9.3,4

\subsubsection{Containment Boundary}

The containment design features of the packaging and the containment evaluation are reviewed. Included in this review are the source description; the containment boundary description, including design and/or performance specifications for the vessel, penetrations, seals and welds, and closure devices including initial bolt torques; and any supportive information. Also included are the general standards for security of the 
packaging against an unauthorized entry which could result in the release or leakage of the radioactive contents.

\subsubsection{Requirements for Normal Conditions of Transport}

The containmen ${ }^{+}$design features of the packaging and the containment evaluation are reviewed. " $\therefore$ : $c i$ in this review are containment criteria for radioactive materials (10 CFR 71.51' $(1)$, he effect of pressurization or explosion within the containment vessel on pack $\%$ fectiveness, verifiable containment criteria, and any supportive information or documentation.

\subsubsection{Requirements for Hypothetical Accident Conditions}

The containment design features of the packaging and the containment evaluation are reviewed. Included in this review are containment criteria for radioactive materials (10 CFR 71.51(a)(2)), the maximum quantity of spent fuel gaseous fission products available for release within the containment vessel, verifiable containment criterion, and any supportive information or 'xcumentation.

\section{Special Requirements for Phutonium Shipments}

The containment design features of the packaging and the containment evaluation are reviewed. Included in the review are the design and/or performance specifications for the separate inner container, its response to the tests specified for both normal conditions of transport and hypothetical accident conditions, and any supportive information or documentation.

\section{Acceptance Criteria}

Packaging containment analyse日 are acceptable if the methods are comparable to commonly acceptable containment calculations and assumptions regarding source terms, leakage rates, upstream and downstream pressures, flow conditions, and temperatures.

\subsubsection{Containment Boundary}

The containment boundary must be identified including the vessel, containment penetration, seal and welds, and closure devices which must be specified. 


\subsubsection{Containment Vessel}

Containment vessel drawings must be provided with a list of the applicable design specifications. If credit is taken for special form radioactive material as part of the containment system, then the special form radioactive material containment requirements in 10 CFR 71.75 must be met in addition to those specified for Type $B$ packagings.

\subsubsection{Contaimment Penetrations}

All vessel penetrations must be identified and specified to authoritative standards. The conditions for which containment is required by them must be clearly specified.

Paragraph 71.43(e) of 10 CFR 71, in part, requires that a package valve or other device, the failure of which would allow radioactive contents to escape, must be protected against unauthorized operation and, except for a pressure relief device, must be provided with an enclosure to retain any leakage. This requirement covers any valve or other device which, by design, penetrates the primary containment boundary. Except for pressure relief devices, the penetration must be enclosed. Category 1 packaging designs must include a pressure tap into the enclosure volume for leak checking of the enclosure at final package assembly. Leak testing of the enclogure must be to the same requirements and standards as the primary containment boundary. After completion of leak testing procedures, the pressure tap must be plugged with a double sealing device. The double sealing device used to plug the pressure tap must be protected against unauthorized removal. Additionally, the enclosure lid must also be protected against unauthorized tampering or removal.

Paragraph 71.43(h) of 10 CFR Part 71, in part, requires that a packaging must not incorporate a feature which is intended to allow continuous venting during transport.

\subsubsection{Seals and Welds}

All seals and welds must be identified and specified to authoritative standards. The conditions for which containment is required by them must be clearly specified. 


\subsubsection{Closure}

All closure devices used for containment must be identified and specified to authoritative standards. The conditions for which containment is required by them must be clearly specified. Paragraph $71.43(\mathrm{c})$ of $10 \mathrm{CFR} 71$, in part, requires that the containment must be securely closed by a positive fastening device which cannot be opened unintentionally.

\subsubsection{Requirements for Normal Conditions of Transport}

Paragraph 71.51(a)(1) of 10 CFR 71, in part, requires that a Type B package be designed, constructed, and prepared for shipment so that under the tests specified in Paragraph 71.71 of 10 CFR 71 (Normal Conditions of Transport), there would be no loss or dispersal of radioactive contents, as demonstrated to a sensitivity of $10^{-6} \mathrm{~A}_{2}$ per hour.

Paragraph 71.51(b) of 10 CFR 71, in part, requires that compliance with the permitted activity release limits of Paragraph 71.51(a)(1) of 10 CFR 71 be achieved without depending upon filters or upon a mechanical cooling system.

Packaging containment is acceptable, in part, if it can be shown that it meets these criteria. Acceptable methods for testing are contained in ANSI N14.5.

\subsection{Requirements for Hypothetical Accident Conditions}

Paragraph 71.51(a)(2) of 10 CFR 71, in part, requires that a Type $B$ package be designed, constructed, and prepared for shipment so that under the tests specified in Paragraph 71.73 of 10 CFR 71 (Hypothetical Accident Conditions), there would be no escape of ${ }^{85} \mathrm{Kr}$ exceeding $10,000 \mathrm{Ci}$ in one week and no escape of other radioactive material exceeding a total amount $A_{2}$ in one week.

Paragraph 71.51(b) of 10 CFR 71, in part, requires that compliance with the permitted activity release limits of Paragraph 71.51(a)(2) of 10 CFR 71 be achieved without depending upon filters or upon a mechanical cooling system. 
Packaging containment is acceptable, in part, if it can be shown that it meets these criteria. Acceptable methods for testing are contained in Ref. 6-5.

\subsubsection{Special Requirements for Plutonium Shipments}

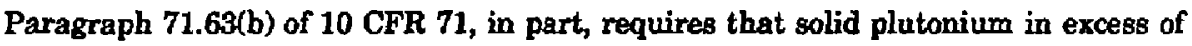
$20 \mathrm{Ci}$ per package be packaged in a separate inner container placed within outer packaging such that the separate inner container will not release plutonium, as demonstrated to a sensitivity of $10^{-6} \mathrm{~A}_{2}$ per hour when ine entire package is subjected to the tests specified in Paragraph 71.71 of 10 CFR 71 (Normal Conditions of Transport), and such that the separate inner container will restrict the loss of plutonium to not more than $A_{2}$ in one week when the entire package is subjected to the tests specified in Paragraph 71.73 of 10 CFR 71 (Hypothetical Accident Conditions).

Packaging containment is acceptable, in part, for solid plutonium shipments in excess of $20 \mathrm{Ci}$ per package if it can be shown that it meets the above criteria.

\subsection{Procedures}

\subsubsection{Containment Boundary}

Verify that the containment boundary for the packaging is identified. This identification is to include, but is not limited to, the containment vessel, the containment penetrations, the seals and welds, and the closure devices. All figures and tables must be sufficiently detailed to stand alone. Verify that the package conforms to 10 CFR 71.43 (a, e and $h$ ). Verify that special form radioactive material contents meet the requirements in 10 CFR 77.75 .

\subsubsection{Containment Vessel}

Verify that a summary of design specifications for the containment vessel is provided. Drawings, to scale, showing dimensions of the containment vessel must be provided.

\section{A.1.2 Containment Penetrations}

Verify that all penetrations into the primary containment are identified. Drawings, to scale, showing dimensions of the containment penetrations must be provided. Verify that a summary of the performance specifications for all components that penetrate the 
containment boundary are provided in tabular form. Verify that each valve or penetration device is protected against unauthorized operation and except for a pressure relief device is provided with an enclosure to retain leakage. Leak testing of the enclosure should be to the same requirements and standards as the primary containment boundary. 


\subsubsection{Seals and Welds}

Verify that all seals and welds that affect the packaging containment are identified. Drawings, to scale, showing dimensions of these seals and welds must be provided. Verify that a summary of the design specifications for these seals and welds is also provided in tabular form.

\subsubsection{Closure}

Verify that the closure devices used for the containment are identified. Drawings, to scale, showing dimensions of the closure devices must be provided. Verify that initial bolt torque required to maintain a positive seal during normal conditions of transport and hypothetical accident conditions is presented in tabular form.

\subsubsection{Requirements for Normal Conditions of Trangport}

Verify that there is a summary of the pertinent results of the analysis or test performed in PRG 4.0, "Review of Structural Evaluation," and PRG No. 5.0, "Review of Thermal Evaluation," to demonstrate that the packaging meets the containment requirements of Paragraphs 71.51(a)(1) and 71.51(b) for normal conditions of transport as defined in Paragraph 71.71 of 10 CFR 71. All figures and tables should be sufficiently detailed to stand alone.

\subsubsection{Containment of Radioactive Material}

Verify that the containment criteria for radioactive materials that satisfy Paragraph 71.51(a)(1) of 10 CFR 71 are determined. Source terms must be specified, all parameters and assumptions pertinent to the calculation of the containment criteria must be presented, and any data used are to be supported by appropriate references. Whether a single radionuclide or mixtures of radionuclides are considered, the method used to compute $\mathrm{A}_{2}$ must be clearly specified. Sample calculations should be presented, where appropriate. 


\subsubsection{Pressurization of Containment Veseel}

Verify that any mixture of vapors of gases that could form in the containment vessel are identified. It must be shown that any increase in pressure or chemical reactions within the containment vessel due to these vapors or gases could not significantly reduce package effectiveness.

Verify that all source terms are specified, all parameters and assumptions pertinent to the calculation of the internal pressure are presented, and any data used is supported by appropriate references. Sample calculations, where appropriate, should be presented.

\subsubsection{Contginment Criterion}

Verify that a verifiable containment criterion (e.g., leak test) is opecified. This criterion is to be used to demonstrate that the containment criteria of Section 6.4.2.1 are satisfied. Any conditions pertinent to achieving the verifiable containment criterion must also be presented.

\subsection{Requirements Lor Hypothetical Accident Conditions}

Verify that there is a summary of the pertinent results of the enalysis or test performed in PRG No. 4.0, "Review of Structural Evaluation," and SRG No. 5.0, "Review of Thermal Evaluation," to demonstrate that the prckage meets the containment requirements of Paragraphs 71.51(a)(2) and 71.51(b) for hypothetical accident conditions as defined in Paragraph 71.73 of $10 \mathrm{CFR} 71$. All figures and tables must be sufficiently detailed to stand alone.

\subsubsection{Containment of Eadioactive Materipl}

Verify that the containment criteria for radioactive materials that satisfy Paragraph 71.51(a)(2) of 10 CFR 71 are determined. Source terms must be specified, all parameters pertinent to the calculation of the containment criteria must be presented, and any data used are to be supported by appropriate references. Whether a single radionuclide or mixtures of radionuclides are considered, the method used to compute $A_{2}$ must be clearly specified. Sample calculations should be presented, where appropriate. 


\subsubsection{Fission Gas Producte}

Verify that the maximum quantity of fission gas products that could be available for release in the containment vessel under the hypothetical accident conditions are identified for spent fuel shipments. Source terms must be specified, all parameters and assumptions pertinent to the calculation of the fission gas products must be presented, and any data used must be supported by appropriate references. Sample calculations should be presented, where appropriate.

\subsubsection{Containment Criterion}

Verify that a verifiable containment criterion (e.g., leak test) is specified. This criterion is to be used to demonstrate that the containment criteria of Section 6.4.3.1 are satisfied. Any conditions pertinent to achieving the verifiable containment criterion must also be presented.

\subsection{Special Requirements for Plutonium Shipments}

Verify that there is adequate discussion of the separate inner container for packaging subject to the special requirements for solid plutonium shipments in excess of $20 \mathrm{Ci}$ per package (Paragraph 71.63(b) of $10 \mathrm{CFR} 71$ ). Drawings, to scale, showing dimensions of the separate inner container must be provided. The response of the inner container when subjected to the tests associated with both normal conditions of transport and hypothetical accident conditions must be detailed. $A_{2}$ must be computed for the plutonium and compared with the permitted activity release limits of Paragraph 71,63(b).

\subsubsection{Appendix}

Verify that all supportive information or documentation is provided for the containment evaluation under both normal conditions of transport and hypothetical accident conditions. This would include, but not be limited to, information such as ustification of assumptions or analytical procedures, package test results and photographs associated with both normal conditions of transport and hypothetical accident conditions, computer program descriptions and input/output, and applicable pages from referenced documents. 


\subsection{Findings}

\subsubsection{Containment Boundary}

The reviewer verifies that sufficient and adequate information has been provided to satisfy the regulatory requirements for the package, and that the evaluation supports the following conclusion, to be included in the safety evaluation report:

"This section of the applicant's SAR has been reviewed to determine that the containment design features have been designed in a manner that will assure compliance with the performanc requirements of 10 CFR 71, Paragraphs 71.43(c), $71.43(e)$, and $71.43(h)$ for the package. The scope of the review ccrers the source descrijition; the containment boundary description, including design and/or performance specifications for the vessel, penetrations, seals and welds, and closure devices; and any supportive information or documentation."

"Basis for acceptance in the review has been conformance with established guidelines and criteria. The evaluation of the containment design provides reasonable assurance that, from the standpoint of general requirements on the packaging, it will be possible to transport radioactive material safety."

"The staff concludes that the protective features provided in the design of the package conform to applicable Regulations, Regulatory Guides, and industry stendards, and are acceptable."

\subsection{Requirements for Normal Conditions of Transpart}

The reviewer yerifies that sufficient and adequate information has been provided to satisfy the regulatory requirements for the package under normal conditions of transport, and that this evaluation supports the following conclusion, to be included in the safety evaluation report:

"This section of the applicant's SAR has been reviewed to determine that the containment design features have been designed in a manner that will assure compliance with the performance requirements of 10 CFR Part 71, Paragraphs 71.51(a)(1) and 71.51 (b) for the package under normal conditions of transport. The scope of the review covers the containment of radioactive materials, pressurization of the containment vessel, verifiable containment criterion, and any supportive information or documentation." 
"Basis for acceptance in the review has been onformance with established guidelines and criteria. The evaluation of the containment design provides reasonable assurance that, under normal conditions of transport, it will be possible to transport radioactive material safely."

"The staff concludes tho. the protective features provided in the design of the package conform to applicabie Regulations, Regulatory Guides, and industry standards, and are acceptable."

\subsection{Requirements for Hypothetical Accident Conditions}

The reviewer verifies that sufficient and adequate information has been provided to satisfy the regulatory requirements for the package under hypothetical accident conditions, and that his ( raluation supports the following conclusion, to be included in the safety evaluation repor:

"This section of the applicant's SAR has been reviewed to determine that the containment design features have been designed in a menner that will assure compliance with the performance requirements of 10 CFR Part 71, Paragraphs 71.51(a)(2) and 71.51 (b) for the pack ge under hypothetical accident conditions. The scope of the review covers the containment of radioactive materials, spent fuel gaseous fission products, verifiable cortainment criterion, and any supportive information or documentation."

"Basis for acceptance in the review has been conformance with established guidelines and criteria. The evaluation of the containment design provides reasonable assurance that, under hy oidietical accident conditions, it will be possible to transport radioactive material safely."

"The staff concludes that the protective features provided in the design of the package conform to applicable Regulations, Regulatory Guides, and industry standards, and are acceptable."

\section{In A Special Requirements for Phutonium Shipments}

The reviewer verifies that sufficient and adequate information has been provided to satisfy the special requir sments of the review plan for solid plutonium shipments in excess of $20 \mathrm{Ci}$ per packafe under both normal conditions of transport and hypothetical 
accident conditions, and that his evaluation supports the following conclusion, to be included in the safety evaluation report:

"This section of the applicant's SAR has been reviewed to determine that the separate inner container and outer packaging containment design features have been designed in a manner that will assure compliance with the performance requirements of 10 CFR 71, Paragraph 71.63(b) for solid plutonium shipments in excess of $20 \mathrm{Ci}$ per package under both normal conditions of transport and bypothetical accident conditions."

"The scope of the review covers the design and/or performance specifications of the separate inner container, its response to the tests specified for both normal conditions of transport and hypothetical accident conditions, and any supportive information or documentation."

"Basis for acceptance in the review has been conformance with established guidelines and criteria. The evaluation of the containment design provides reasonable assurance that, under hypothetical accident conditions, it will be possible to transport solid plutonium in excess of $20 \mathrm{Ci}$ per package safely."

"The staff concludes that the protective features provided in the design of the package conform to applicable Regulations, Regulatory Guides, and industry standards, and are acceptable."

\section{Reierences}

1. U.S. Department of Energy, DOE 5480.3: Safety Requirements for the Packaging and Transportation of Hazardous Materials. Hazardous Substance, and Hazardous Wastes, U.S. Department of Energy, Washington, DC, August 9, 1985.

2. Office of the Federal Register, Title 10. Code of Eederal Regulations, Part 71, Office of the Federal Register, Washington, DC, 1984.

3. U.S. Department of Energy, DOE 1540.2; Hazardous Material Packaging for Transport-Administrative Procedures, U.S. Department of Energy, Washington, DC, September 30, 1986. 
4. U.S. Nuclear Regulatory Commission, Bepulatory Guide 7.9: Standard Format and Content of Part 71 Applications for Approval of Packaping of Type B. Iarge Quantity, and Fissile Radioactive Matecial, U.S. Nuclear Regulatory Commission, Office of Standards Development, Washington, DC, January 1980, Rev. 1.

5. American National Standards Institute, Amecican National Standard for Leakage Tests on Packages for Shinment of Radiogetiye Material. American National Standards Ingtitute, New York, NY, ANSI N14.5-1985, (1985), Rev. 1. 


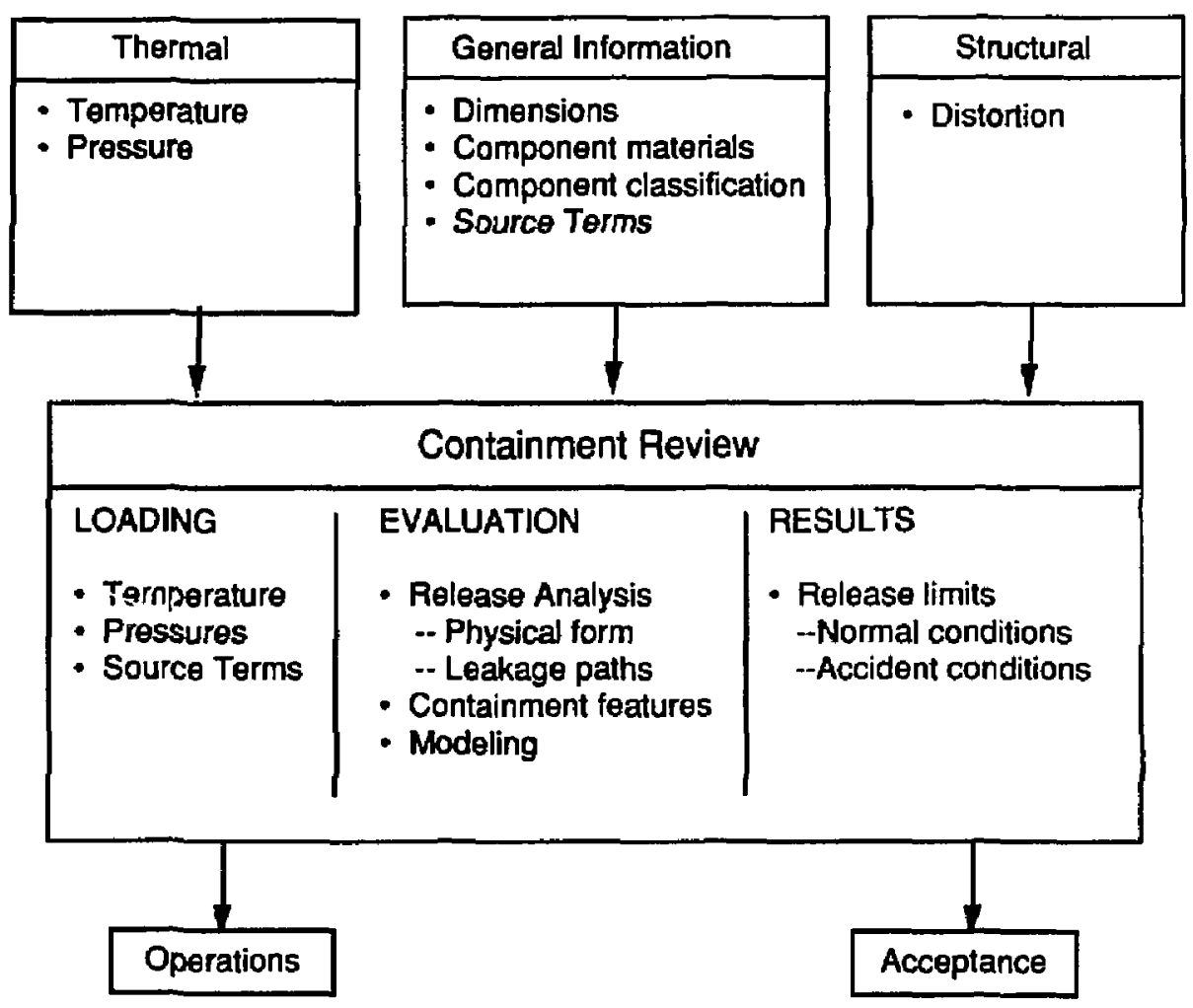

Figure 6-1 Input and output information for the containment review process. 


\subsection{REVIEW OF SHIELDING EVALUATION}

\subsection{General}

This section of the review provides the details of the shielding design analysis. Compliance with DOE orders and regulatory requirements must be demonstrated.1,2,3 The discussions presented must detail the shielding response of the packaging, components, and systems important to safety during normal conditions of transport (10 CFR 71.71) and hypothetical accident conditions (10 CFR 71.73). At the minimum, details of the shielding design analysis for the packaging must be provided. If exclusive use transport is contemplated, then the interaction of the packaging and conveyance must also be included in the analysis and discussion.

The types of information required from other sections of the SARP to perform the shielding review are shown in Fig. 7-1. General information is required on the packaging dimensions, component materials, component classification, and source terms. If the packaging undergoes any deformation under accident conditions, information is required from the structural and thermal sections. Information on materials in the SARP should include shielding properties and descriptions of the fabrication processes. Reviewers responsible for these review sections should assist in verifying that the information required for the shielding reviews is adequate and usable for the review.

The source terms for the package are reviewed. The source terms can include gamma and neutron radiation. The specific areas for review which address these source terms are given in Subsection 7.4.2.

The shielding review requires an in-depth knowledge of shielding analysis for both gamma and neutron radiation. The reviewer must be able to evaluate shielding models and their assumptions. Penetrations, streaming paths, voids, etc., could effect shieiding and have to be recognized, understood, and evaluated. The reviewer should have a general knowledge of materials, their shielding properties, and how these properties depend on the radiation energy levels.

The shielding review should assess the results of the gamma and neutron radiation doses that could occur. The shielding results from the SARP are used in other areas to limit radiation dose exposures during loading and unloading operations and transport of the package. The review evaluation of the shielding results should be provided to other disciplines which include operations and acceptance testing. 
General guidance is given in the following subsections to assist in the shielding review of transport packagings. The general guidance addresses both the methods of analysis and computer codes.

\subsubsection{Method of Analydis}

The ultimate requirement of any shielding design is the attenuation of the neutrons and/or photons emitted by the source to a level that is within regulatory requirements. Care must be taken to ensure that adequate consideration is given to shield penetrations and/or streaming paths which may result in local increases in the radiation field. In addition, accident effects must be closely examined to ensure that all scenarios involving a loss or local reduction in the package shielding are evaluated for their radiation dose consequences. Once the geometries of the source and package shielding are known, it is a relatively easy task to estimate the adequacy of the package shielding using geometry specific formulas and a desk-top calculator for the calculations.

Formulas and their use for a point source and slab shield, line source and slab shield, cylindrical volume source with slab shield at side and end, and a spherical volume source with slab shield a<e discussed in detail in References 7-4 and 7-5. For photons, these works include general discussions of photon attenuation and the concept and application of buildup. For neutrons, there are general discussions of neutron attenuation and the concept and application of removal cross sections. With respect to penetrations, streaming paths, voids, etc., formulas for the estimate of the effects of irregularities in the shield are presented and discussed in both works for neutron and gamma sources.

\subsubsection{Computer Codes}

A number of computer codes are available to perform the various calculations necessary to complete the shielding evaluation. Some are available as part of the SCALE system: ORIGEN for generation of the source terms and MORSE for the shielding analysis. Other acceptable shielding codes include, but are not limited to, ANISN and DOT.

SCALE is a comprehensive computational system that was designed for evaluating nuclear fuel facilities and package designs. ${ }^{6}$ It was developed for the NRC staff by the Oak Ridge National Laboratory to serve as a standard analysis tool. Criticality, shielding, and/or heat transfer calculations may be performed by the automated analytical 
sequences within SCALE. The user may run the computer codes within each analytical sequence in either a stand-alone job or coupled sequence.

ORIGEN is a versatile point-depletion code that calculates the radioactive growth and decay for large numbers of isotopes with arbitrary coupling. 7 The matrix exponential method is used in the solution of coupled, linear, first-order differential equations with constant coefficients. With ORIGEN it is possible to calculate composition and activity of fuel, fission products, and structural materials in light-water reactors (LWR), liquid metal fast breeder reactors (LMFBR), molten salt breeder reactors (MSBR), and hightemperature gas reactors (HTGR). For given decay times, gamma source distributions and neutron emission rates can be calculated.

MORSE is a multigroup Monte Cario radiation transport code with specialized onedimensional and three-dimensional geometries. 8 Time dependence for both shielding and criticality problems is provided. Anisotropic scattering is treated for each group-togroup transfer by utilizing a generalized Gaussian quadrature technique. For shielding purposes, both neutron, photon, and coupled neutron-photon problems may be solved.

ANISN solves the one-dimensional energy-dependent Boltzmann transport equation with high-order anisotropic scattering in slab, cylindrical, and spherical geometries, for neutrons and photons. 9 The method of discrete ordinates is used to solve for the angular dependence of the neutron or photon flux with anisotropic scattering treated as a Legendre expansion of the scattering cross section. For shielding purposes, both neutron, photon, and coupled neutron-photon problems may be solved. DOT ${ }^{10}$ is a twodimensional version of ANISN.

\subsection{Arees of Heview}

The areas of review are those identified in R.G. 7.9.11 The shielding design features of the package and the adequacy of the shielding evaluation are reviewed for a general package and/or a package transported as exclusive use under normal conditions of transport and hypothetical accident conditions. Included in this review are neutron and gamma source specifications; the radial and axial shielding configuration of the package and conveyance, if any; the regional densities of the shield and conveyance, if any; the computational method employed in the shielding evaluation; and any supportive information or documentation. 


\subsection{Acceptance Criteria}

Packaging shielding analyses are acceptable if the methods are comparable to commonly acceptable shielding calculations and assumptions regarding source terms, cross sections, shield and source geometries, and if methods of transport are realistic.

\subsubsection{Normal Conditions of Transport}

\subsubsection{General Paclage Design}

Shielding acceptance criteria for a package transported under normal conditions of transport are found in Paragraph 71.47 (External Radiation Standards for All Packages) and Paragraph 71.51(a)(1) (Additional Requirements for Type B Packages) of 10 CFR 71.

Packaging shielding design is acceptable if it can be shown that the radiation dose rate at any point on the external surface of the package does not exceed 200 mrem per hour under the tests specified in Paragraph 71.71 (Normal Conditions of Transport) of 10 CFR 71.

\subsubsection{Erclusive Use Transport}

Shielding acceptance criteria for a package transported as exclusive use by rail, highway, or water under normal conditions of transport are found in Paragraphs 71.47(a) through (d) (External Radiation Standards for All Packages) and Paragraph 71.51(a)(1) (Additional Requirements for Type B Packages) of 10 CFR 71. Packaging shielding design is acceptable if it can be shown that the radiation dose rate does not exceed any of the following under the tests specified in Paragraph 71.47 (Normal Conditions of Transport) of 10 CFR 71:

(a) 200 mrem per hour on the accessible external surface of the package, unless (1) the shipment is made in a closed transport vehicle, (2) provisions are made to secure the package so that its position within the vehicle remains fixed during transportation, and (3) there are no loading or unloading operations between the beginning and end of transportation, in which case the limit is 1000 mrem per hour on the accessible external surface of the package;

(b) 200 mrem per hour at any point on the outer surface of the vehicle, including the upper and lower surfaces, or in the case of an open vehicle, at any point on the vertical 
planes projected from the outer edges of the vehicle, on the upper surface of the load, and on the lower external surface of the vehicle;

(c) 10 mrem per hour at any point 2 meters from the vertical planes represented by the outer lateral surfaces of the vehicle, or, in the case of an open vehicle, at any point 2 meters from the vertical planes projected from the outer edges of the conveyance; and

(d) 2 mrem per hour in any normally occupied positions of the vehicle, except that this provision does not apply to private motor carriers when persons occupying these positions are provided with special health supervision, personnel radiation exposure monitoring devices, and training in accordance with Paragraph 19.12 of 10 CFR 19.

\subsection{Hypothetical Accident Conditions}

Shielding acceptance criteria for a general package under hypothetical accident conditions or a package transported as exclusive use by rail, highway, o1 water under hypothetical accident conditions are found in Paragraph 71.51(a)(2) (Additional Requirements for Type B Packages) of 10 CFR 71 .

Packaging shielding design is acceptable if it can be shown that the radiation dose rate at any point 1 meter from the external surface of the package does not exceed 1000 mrem per hour under the tests specified in Paragraph 71.73 (Hypothetical Accident Conditions) of 10 CFR 71.

\section{A Procedures}

The reviewer will ensure that the information required in the procedures described below is provided. Any differences in the source, package, or conveyance conditions between normal conditions of transport and hypothetical accident conditions must be clearly indicated.

\subsubsection{Discussion and Fesults}

Verify that the significant shielding design features of the packaging and the adequacy of the shielding evaluation are addressed for a general package and/or a package transported as exclusive use by rail, highway, or water under the tests specified in Paragraph 71.71 (Normal Conditions of Transport) and Paragraph 71.73 (Hypothetical 
Accident Conditions) of 10 CFR 71. Verify that results are presented in a format similar to Table 7.1 for a general package under normal conditions of transport; Table 7.2 for a package transported as exclusive use by rail, highway, or water under normal conditions of transport; and Table 7.3 for a package under hypothetical accident conditions. For packaging designed for spent fuel transport, verify that assumptions for fuel enrichment, fuel burnup, power density, and cooling times are provided.

\section{A.2 Source Specification}

Verify that the contents and the gamma and neutron source strengths used in the shielding analysis are adequately described for a general package and/or a package transported es exclusive use by rail, highway, or water under normal conditions of transport and hypothetical accident conditions. Verify that the condition of the source is as described in Section 4 (Structural Evaluation) and Section 5 (Thermal Evaluation) for normal conditions of transport and hypothetical accident conditions.

\subsubsection{Gamma Source}

Verify that the quantity of radioactive material included as contents is stated, and the gamma decay source strength (photons/sec and/or $\mathrm{MeV} / \mathrm{sec}$ ) are tabulated as a function of both the source photon energy and the photon energy group structure used in the shielding calculations. Verify that the method used to determine the gamma source strength, spectra and spatial distribution, including the computer codes employed, are adequately detailed. For spent fuel sources, ensure that the gamma source strength and diatributions for the active fuel and structural support regions (e.g. the head and foot pieces) are detailed separately. Verify that all figures and tables are sufficiently detailed to stand alone.

\subsubsection{Neutron Source}

Verify that the quantity of radioactive material included as contents is stated, and the neutron source strength (neutrons/sec) is tabulated as a function of both the source neutron energy and the neutron energy group structure used in the shielding calculations. Verify that the method used to determine the neutron source strength, spectral and spatial distribution, ircluding the computer codes employed, are adequately 
detailed. For spent fuel sources, verify that the subcritical multiplication and axial source distribution are tabulated and adequately described. Verify that all figures and tables are sufficiently detailed to stand alone.

\section{A.3 Model Specification}

Verify that the model used in the shielding evaluation is adequately described for a general package and/or a package transported as exclusive use by rail, highway, or water under normal conditions of transport and hypothetical accident conditions. Verify that the composition and condition of the source and shielding is as described in Section 3 (Materials and Fabrication Specifications), Section 4 (Structural Evaluation), and Section 5 (Thermal Evaluation) for normal conditions of transport and hypothetical accident conditions.

\subsubsection{Radial and Axial Shielding Conf guration}

Verify that drawings to scale are provided, showing dimensions of the radial and axial shielding materials under normal conditions of transport and hypothetical accident conditions. If transport as exclusive use is considered and credit is taken for the shielding properties of the conveyance, verify that the shielding configuration of the conveyance is also included in the drawings. For spent fuel sources, a clear distinction must be made between the active fuel and structural support regions (e.g. head and foot pieces). Verify that dose point locations for the various calculations on and off the external surface of the package are shown relative to the source regions in the drawings supplied. In the case of transport under hypothetical accident conditions, the dose point locations are at $1 \mathrm{~m}$ from the exterior surface of the package. For transport as exclusive use inder normal conditions of transport, verify that dose point locations of the following are identified: (a) the accessible external surface of the package; (b) the outer surface of the vehicle, including the upper and lower surfaces, or in the case of an open vehicle, at any point on the vertical planes projected from the outer edges of the vehicle, on the upper surface of the load, and on the lower external surface of the vehicle; (c) any point 2 meters from the vertical planes represented by the outer lateral surfaces of the vehicle, or, in the case of an open vehicle, at any point 2 meters from the vertical planes projected from the outer edges of the conveyance; and (d) any normally occupied positions of the vehicle. Verify that voids or irregularities not taken into account in the model are discussed in 
detail and their effect on the resultant dose rate calculations are shown to be conservative. Ensure that sufficient detail is provided in the drawings and discussion to cover all configurations evaluated by the shielding calculations.

\subsection{Shield Revional Densities}

Verify that material densities $(\mathrm{g} / \mathrm{cm} 3)$ and atomic number densities (atoms/barncm) for constituent nuclides of all materials used in the calculational models are provided in sufficient detail to allow computational verification. If transport as exclusive use is considered and credit is taken for the shielding properties of the conveyance, verify that material and atomic number densities for the constituent nuclides of all materials of the conveyance are also provided. Differences in material and atomic number densities for normal conditions of transport and hypothetical accident conditions must be clearly stated. For uncommon materials, the source of the data must be referenced, and validation must be provided in Section 3 (Materials and Fabrication Specifications).

\section{AA Shielding Evahuation}

Verify that a general description of the basic method used to determine the gamma and neutron dose rates at the selected points on and off the external surface of the package under normal conditions of transport and hypothetical accident conditions is provided. This must include a description of the spatial source distribution and any computer codes used, including their referenced documentation. The basic input parameters should be discussed in detail. Verify that the basis for selecting the various computer codes employed, including any pertinent assumptions and parameters, is provided. Flux-to-dose conversion factors must be tabulated as a function of the group structure energy used in the shielding calculations and must be based upon ANSWANS. 6.1.1-1977.12 For spent fuel sources, neutron dose rates must include the primary neutrons and subcritical multiplication; gamma dose rates must include the primary gamma rays and any secondary gamma rays derived from a coupled neutron-gamma

problem. Verify that all figures and tables are sufficiently detailed to stand alone, and any data used are supported by appropriate references. 


\subsubsection{Appendix}

Ensure that all supportive information or documentation is provided. This would include, but not be limited to, information such as justification of assumptions or analytical procedures; package test results and photographs of a general package and/or a package transported as exclusive use by rail, highway, or water under normal conditions of transport and hypothetical accident conditions; computer program descriptions and input/output; and applicable pages from referenced documents.

\subsection{Findings}

Verify that sufficient and adequate information has been provided to satisfy the requirements of the review plan for a general package and/or a package transported as exclusive use by rail, highway, or water under normal conditions of transport and hypothetical accident conditions, and that this evaluation supports the following conclusion, to be included in the safety evaluation report: 13

"This section of the applicant's SAR has been reviewed to determine that the shielding design features have been designed in a manner that will assure compliance with the performance requirements of 10 CFR Part 71, Paragraphs 71.47 and 71.61 for a general package and/or a package transported as exclusive use by rail, highway, or water under normal conditions of transport and hypothetical accident conditions. The scope of the review covers the shielding design features of the package and conveyance (if considered), the source and model specifications, the shielding evaluation, and supportive information or documentation."

"Basis for acceptance in the review has been conformance with established guidelines and criteria. The evaluation of the shielding design provides reasonable assurance that, under normal conditions of transport and hypothetical accident conditions, it will be possible to transport radioactive material in the package safely."

"The staff concludes that the protective features provided in the design of the package conform to applicable Regulations, Regulatory Guides, and industry standards, and are acceptable." 


\section{References}

1. U.S. Department of Energy, DOE 5480.3: Safety Requirements for the Packagine and Transportation of Hazardous Materials, Hazardous Substance, and Hazardous Wastes, U.S. Department of Energy, Washington, DC, August 9, 1985.

2. Office of the Federal Register, Title 10. Code of Eederal Regulations. Part 71, Office of the Federal Register, Washington, DC, 1984.

3. U.S. Department of Energy, DOE 1540.2: Hazardous Material Packaping for Trangport-Administrative Procedures, U.S. Department of Energy, Washington, DC, September 30, 1986.

4. Rockwell, T. III, ed., Reactor Shielding_Degign_Manual, (D. Van Nostrand Co., Inc., New York, 1956).

5. Blizard, E.P., and Abbott, L.S., Eds., Reactor Handbook; Volume III.Part_B. Shielding, (John Wiley and Sons, New York, NY, 1962).

6. Oak Ridge National Laboratory, Nuclear Engineering Applications Department, SCALE: A Modular Code System for Performing Standardized Computer Analyses for Licensing Evaluations, Vol. 1-3, Oak Ridge National Iaboratory, Oak Ridge, TN, NUREG/CR-0200, ORNL/NUREG/CSD-2/R, January 1982.

7. Bell, M.J., ORIGEN - The ORNL Isotope Generation and Depletion Code, Oak Ridge National Laboratory, Oak Ridge, TN, ORNL-4628, May 1973.

8. Straker, E.A. et al., MORSE Code - A Multigroup Neutron and Gamma-Ray Monte Carlo Transport Code, Oak Ridge National Laboratory, Oak Ridge, TN, ORNL-4585, September 1970.

9. Engle, W.W., Jr., A Users Manual for ANISN - A One Dimensional Discrete Ordinates Transport Cede with Anisotropic Scattering, Oak Ridge National Laboratory, Oak Ridge, TN, K-1693, March 1967. 
10. Rhodes, W.A., a.s Mynat., i.R., DOT-III Two Dimensional Discrete Ordinates Transport Code, Oak Ridge National Laboratory, Oak Ridge, TN, ORNL-TM-4280, September 1973.

11. U.S. Nuclear Regulatory Commission, Regulatory Guide 7.9: Standard Eormat and Content of Part 71 Applications for Approval of Packaping of Type B. Large Quantity and Fissile Radiogctive Material. U.S. Nuclear Regulatory Commisgion, Office of Standards Development, Washington, DC, January 1980, Rev. 1.

12. American Nuclear Society, Neutron and Gamma-Ray Elux-to-Dose Rate Factors, American Nuclear Society, La Grange Park, IL, ANSU/ANS-6.1,1-1977, (1977).

13. U.S. Nuclear Regulatory Commission, "Chapter 12: Radiation Protection," in Siandard Review Plan for the Review of Safety Analysis Reports for Nuclear Power Plants, U.S. Department of Commerce, Washington, DC, NTISUB/B/201-0012, NUREG-75/087, (1975), Rev. 1. 


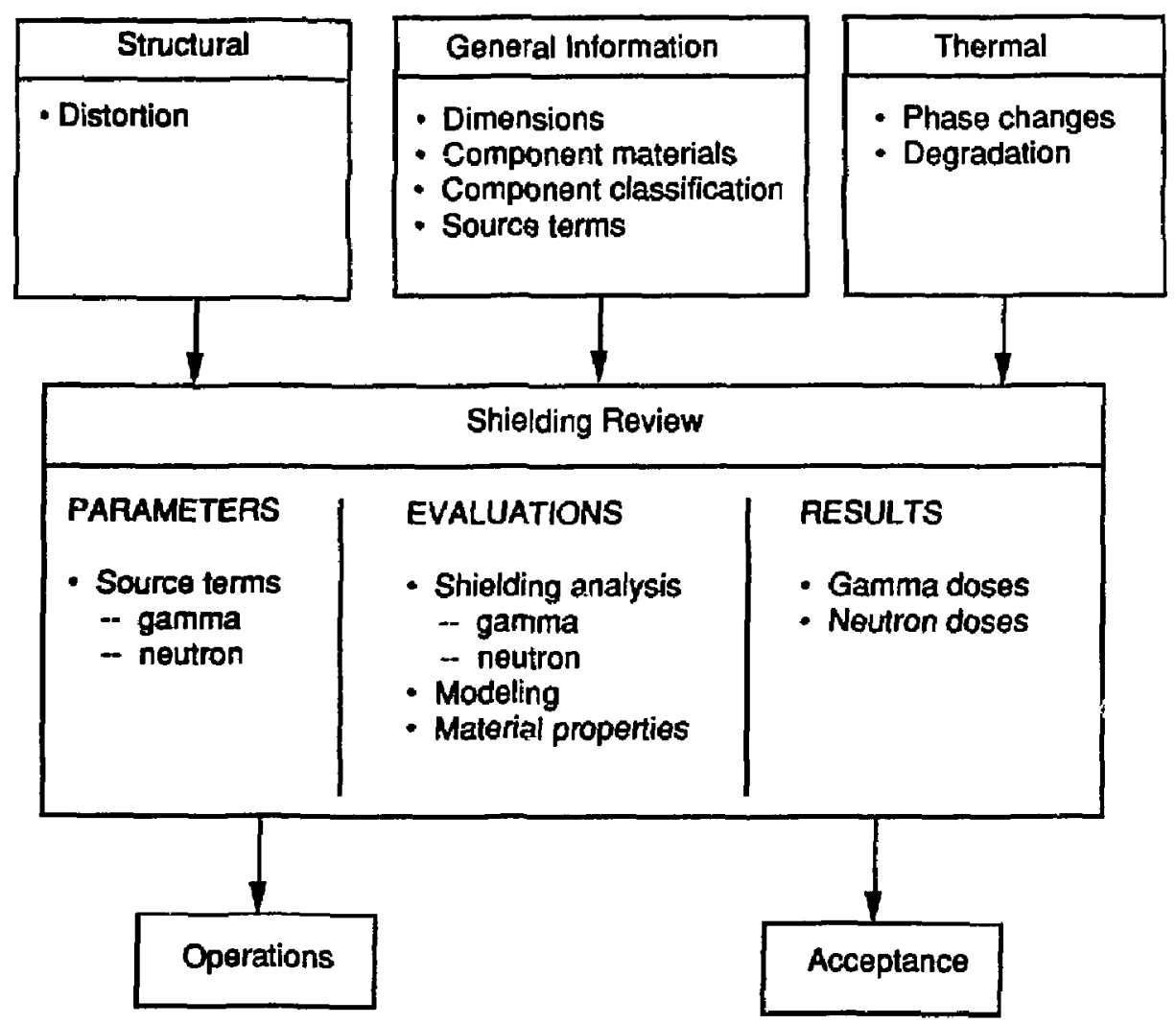

Figure 7-1 Input and output information for the shielding review process. 


\section{Table 7.1}

Summary of Maximum Dose Rates (mrem/hr) Normal Conditions of Transport

General Package Design

\begin{tabular}{llll}
\hline & & Package Surface & \\
& Side & Top & Bottom \\
\hline $\begin{array}{l}\text { Gamma } \\
\text { Neutron } \\
\text { Total }\end{array}$ & & & \\
\hline 10 CFR Part 71 Limit & 200 & 2000 & 200 \\
\hline
\end{tabular}


Summary of Maximum Dose Rates (mrem/hr) Normal Conditions of Transport

Exclusive Use Transport

\begin{tabular}{|c|c|c|c|}
\hline & \multicolumn{3}{|c|}{ Accessible Package Surface a. } \\
\hline & Side & Top & Bottom \\
\hline \multicolumn{4}{|l|}{$\begin{array}{l}\text { Gamma } \\
\text { Neutron } \\
\text { Total }\end{array}$} \\
\hline \multirow[t]{3}{*}{10 CFR Part 71 Limit } & 200 & 200 & 200 \\
\hline & \multicolumn{3}{|c|}{ Accessible Package Surface b. } \\
\hline & Side & Top & Bottom \\
\hline \multicolumn{4}{|l|}{$\begin{array}{l}\text { Gamma } \\
\text { Neutron } \\
\text { Total }\end{array}$} \\
\hline \multirow[t]{3}{*}{10 CFR Part 71 Limit } & 1000 & 1000 & 1000 \\
\hline & \multicolumn{3}{|c|}{ Vehicle Outer Surface c. } \\
\hline & Side & Top & Bottom \\
\hline \multicolumn{4}{|l|}{$\begin{array}{l}\text { Gamma } \\
\text { Neutron } \\
\text { Total }\end{array}$} \\
\hline 10 CFR Part 71 Limit & $\mathbf{2 0 0}$ & 200 & 200 \\
\hline
\end{tabular}


Table 72

(Continued)

$2 \mathrm{~m}$ from Vehicle Outer Surface $\mathrm{d}$.

\begin{tabular}{llll}
\hline & Side & Top & Bottom \\
\hline $\begin{array}{l}\text { Gamma } \\
\text { Neutron } \\
\text { Total }\end{array}$ & & & \\
\hline 10 CFR Part 71 Limit & 10 & 10 & 10 \\
\hline & & Normally Occupied Positions \\
of Vehicle e.
\end{tabular}

a. Accessible external surface of package.

bd Accessible external surface of package where shipment is made in a closed transport. vehicle, provisions are made to secure the package so that its position within the vehicle remains fixed during transportation, and there are no loading or unloading operations between the beginning and end of transportation.

s. At any point on the outer surface of the vehicle, including the upper and lower surfaces, or in the case of an open vehicle, st any point on the vertical planes projected from the outer edges of the vehicle, on the upper surface of the load, and on the lower external surface of the vehicle.

d. At any point 2 meters from the vertical planes represented by the outer lateral surfaces of the vehicle, or, in the case of an open vehicie, at any point 2 meters from the vertical planes projected from the outer edges of the conveyance.

e. In any normally occupied positions of the vehicle, except that this provision does not apply to private motor carriers when persons occupying these positions are provided with special bealth supervision, personnel radiation exposure monitoring devices, and training in accordance with Paragraph 19.12 of 10 CFR Part 19. 
Table 73

Summary of Maximum Dose Rates (mrem/hr)

Hypothetical Accident Conditions

\begin{tabular}{|c|c|c|c|}
\hline & \multicolumn{3}{|c|}{$1 \mathrm{~m}$ from Package Surface } \\
\hline & Side & Top & Battom \\
\hline $\begin{array}{l}\text { Gamma } \\
\text { Neutron } \\
\text { Total }\end{array}$ & & & \\
\hline 10 CFR Part 71 limit & 1000 & 1000 & 1000 \\
\hline
\end{tabular}




\subsection{REVIEW OF CRITICALITY EVALUATION}

\subsection{General}

This section of the review confirms that the nuclear subcriticality design of a transport packaging submitted in a SARP for DOE certification uses acceptable analytical and/or test methods and complies with DOE 5480.3 and 10 CFR 71 regulations. 1,2,3 Discussed below are issues concerning the models used to represent the package for criticality, the material properties in these models, and convergence criteria for computational tools. Also discussed are issues concerning the benchmarking of computational tools, the calculation of a bias, and some operational concerns.

Figure 8-1 shows the types of information required from other sections of the SARP to perform the criticality review. General information is required on packaging dimensions, component materials, fissile contents, and neutron absorber materials. If the package undergoes any deformation under accident conditions, information from structures on the deformation is required. Thermal information is also required. Although most fissile material assemblies have negative coefficient's of reactivity, this condition should be checked in the calculation process. Reviewers should verify that this required information is adequate and usable.

It is often impractical to construct an exact representation of a package. SARP models are prepared to represent the criticality physics of the package for each of the fissile material loading conditions sought for the certificate. When such models are prepared as input to a computational tool, further simplifications are often made. The conservatism in these models concerning criticality issues must be reviewed.

Properties used to represent the materials in the models must be reviewed. These properties include the nuclear cross-sections for each material in the model and the number densities in each of the models. Neutron phenomena such as resonance absorption, self-shielding, and scattering must be adequately represented in the crosssections used.

K-effective results from the computational tools should be reviewed for adequate convergence. For Monte Carlo calculations, as the number of neutron histories increases, the mean value for $K$-effective should be seen to be slowly narrowing in to some fixed value; the standard deviation corresponding to each mean value should slowly decrease as the number of neutrons histories increase. 
Monte Carlo codes often present a $\mathrm{K}$-effective histogram for each set of neutron histories calculated. This histogram for the mean value should show a nearly normal statistical distribution. If the histogram is highly skewed, the calculation of more neutron histories for the problem is indicated.

For other computational tools, a convergence limit is often set; the selection of a proper convergence limit and the achievement of this limit should be reviewed.

Computational tools used in criticality calculations must be benchmarked against critical experiments. It is unlikely that a critical experiment will be found which matches the fissile material configuration and neutron poisoning configuration in a model for a package. More than one critical experiment should be calculated. For example, if a package includes water-moderated low-enriched-fuel rods held in a basket containing neutron poisons, and the fuel and basket are inside of a cask, then one set of critical experiments should be calculated for just the low-enriched-fuel rods in water at two different fuel rod pitches. Another set of critical experiments should be calculated for low-enriched-fuel rods in water with fixed poisons first placed very close to the fuel rod assembly and then farther away from the fuel rod assembly. From the results of such calculations, an appropriate bias for the computational tool may be determined.

K-effective results for a package should contain the biases determined from benchmark calculations of critical experiments. However, only negative biases are applied. For example, if a computed result for a critical experiment is always greater than 1.0, then the calculated $\mathrm{K}$-effective for the package is not corrected downward. Only corrections that increase $\mathrm{K}$-effective are made.

The overall operation of a package that includes loading, unloading, and storage over a long period of time must be reviewed for deterioration of materials. These issues are considered below.

Fissile material packages are often loaded or unloaded either in a hot cell under water or in a fuel pool because the fissile material has been irradiated. If a packaging is such that during unloading, a fuel bundle being pulled out of a hole in a basket could catch a protuberance on the basket and cause the basket to rise, leaving other fuel bundles in the packaging partially exposed to one another without neutron poison between them, then special jigs would be required for loading and unloading operations for that package. For example, a jig covering half of the top of the packaging may be required to be bolted to 
the packaging before fuel bundle loading and unloading operations can be conducted. These situations must be identified in the SARP, and the methods for dealing with them should be reviewed.

For packages that contain neutron poisons and involve the storage of fissile material over time spans of years, the methods used to ensure the presence of these poisons over the life of the package should be reviewed.

The discussions below present guidance for judging with the 10 CFR 71 sections in four areas: treatment of cross-sections in the models, construction of the physical models themselves, the modeling of critical experiments for benchmark calculations, and the interpretation of some K-effective results. These issues are in sections numbered to correspond with the format of the PRG.

\subsection{Areas of Review}

The following areas, identified in Regulatory Guide (R.G.) 7.9 are reviewed for compliance with regulations and DOE orders. 4

\subsubsection{Discussion and Results}

An application for a container may show compliance with regulatory requirements for several different fissile material loadings and/or basket configurations. Hence, a container may be Fissile Class 1 for one fissile material loading, and then be a Fissile Class II and/or Fissile Class III for other fissile material loadings. Table 8.1 presents a summary of the requirements in these sections.

\subsubsection{Package Fuel Loading}

This section should precisely state the fissile material loading permitted for each type of loading.

\subsubsection{Model Specification}

\subsubsection{Description of Calculational Models}

It is difficult to construct an exact physical model of a fuel assembly in a basket within a cask. Conservatism should be applied to any models that are constructed in a 
SARP. For example, in many fuel bundles small steel pins are used to separate the fuel rods from each other. In other bundles, grid plates are used. If the steel in these pins or plates cannot be modeled accurately, they should be ignored and replaced by water. In other components, manufacturing tolerances may be important. If there is a manufacturing tolerance associated with a component that is a neutron poison, the model should be on the conservative side and use the thinnest value that the manufacturing tolerances might provide for that neutron poison.

Often, preparing a model of a fuel pin-water-channel-basket assembly for each fuel pin in all of the fuel bundles inside of a cask, as input to a computational tool, is judged too difficult or exceeds the memory or computational capability of the computational tool. Then a homogenization process is used. The homogenization process usually involves the fuel pellets, fuel cladding, the gap between the pellets and cladding, and the water around the fuel pins only. In the homogenization process, a flux distribution is calculated for the components in the cell to be homogenized. Then a discrete ordinate code, such as XSDRNPM-S, is used to flux-and volume-weight each of the cross-sections for each of the materials in the cell, thus preparing a new cross-section set for the homogenized media. These new cross-section sets are then used in a criticality code, such as KENO.5 The homogenized media in a fuel bundle is then modeled geometrically as one element instead of 64 times two or three separate elements within a single fuel bundle.

Use of the homogenization technique in fuel assemblies may not result in $\mathrm{K}$-effective values that are conservative relative to $K$-effective values for discretely modeled fuel assemblies. Therefore, in a SARP, a comparison calculation for one cell (fuel bundle in a hole in a neutron poison basket) should be presented between a homogenized fuel cell and a discretely modeled fuel cell. This model should include the neutron poison basket modeled discretely. For each calculation, if the mean value of K-effective for the homogenized calculation is lower by more than one standard deviation than the mean value of $\mathrm{K}$-effective for the discrete calculation, then the bias may be increased for the mean value of $\mathrm{K}$-effective for those calculations in which homogenized modeling is used. The 1 sigma results for each calculation should be about equal. 


\subsubsection{Package Regional Densities}

Conservatism is often used for number densities in the modeling of fuel. Many applications model the fuel as unirradiated fuel. (Burnable poisons such as gadolinea are not included.) Further, conservative values of fissile mass (conservative enrichment) are also used. However, other applications include the number densities for depleted fissile material due to burn-up. Fuel rods do not burn evenly from top to bottom in a reactor, nor do they burn evenly across a fuel bundle.

Some applications may also include number densities of neutron poisons formed during irradiation in their fuel models. Neutron poisons formed during irradiation have different half-life values, and demonstration that $K$-effective results are safe after 20 years is difficult.

The SARP should provide a calculation for a worst case, showing the $K$-effective of the package modeled with unirradiated fuel. If the peak $\mathrm{K}$-effective for the model with the depleted fuel and/or the neutron poisons is about 0.95 , and the peak $K$-effective for the package for the unirradiated fuel is above 0.95 , the certificate should require additional evidence that the neutron poisons due to irradiation are really there, or the application should be denied. Providing this additional evidence is often difficult and expensive, requiring hot cell work.

\subsection{A Criticality Calculation}

A K-effective limit of 0.95 is often used in Special Nuclear Material licenses. Hand calculations may be used to show that the fisaile mass used to achieve K-effective of 0.95 would have to be increased by more than $40 \%$ to achieve criticality. From Table 8.2 , for example, if uranium oxide fuel rods enriched to 3 percent by weight and a fuel outside diameter of 0.4 inches were placed in water, about 1971 grams U-235 would be required to achieve a $F_{2}$-effective of 0.95 . This is for a fuel rod pitch of 0.86 inches and a fuel rod height of 13.9 inches, to 237 to 238 rods. About 2809 grams U-235 are necessary for a critical mass for this configuration.

In a SARP, K-effective results may be given for several different fuel loading conditions. From all of these calculations, some worst case conditions will emerge. Calculations to confirm the worst case conditions should be made. These calculations may be made by the reviewer, or may be specified by the reviewer and performed by 
someone else with the expertise in making criticality calculations. The model for these calculations should be made independently from the models for the SARP. If the Keffective for the worse case is not close to some limit, such as 0.95 or worse yet, criticality, then some assumptions may be possible. These assumptions permit simple models of the problem which result in very conservative $K$-effective values for the assemblies considered, and yet remain suitable for confirming calculations.

At least one confirming calculation should be made for a worst case in which the components in the package are modeled at temperatures determined from the thermal evaluation. The $\mathbf{K}$-effective results from this model should be lower than for those results obtained for models at room temperature. If this is not the case, more calculations are required to find the peak $K$-effective for all of the possible thermal conditions.

The reason for confirming calculations is that the criticality evaluation is very complex. Often, computational tools are used whose workings are not understood in great detail by either the applicant writing the SARP or the reviewer reviewing the SARP. If the applicant were to miss something in the preparation for the models, it would not be unusual for the reviewer to also miss the same important issue. A situation could arise in which a criticality accident could occur. The consequences of a criticality accident are severe in terms of dose rate outside of the cask.

A comparison of $K$-effective resulte for a confirming calculation with those in the SARP for a worst case should identify any trouble with modeling in the SARP. If there is trouble, a more detriled investigation is warranted.

\subsubsection{Calculational or Experimental Method}

The discussion below emphasizes Monte Carlo codes such as KENO- IV and KENO$\mathrm{Va}$ on the SCALE system.5-7 Although Monte Carlo codes aren't the only computational tools found in applications, they are often used. They permit modeling of very complex geometry with relative ease. The $\mathrm{K}$-effective values obtained are accurate. Monte Carlo codes are readily available, and their computational expense is moderate.

If an application contains fuel models that use cross-section sets which are collapsed from larger cross-sections sets (more energy groups), some explanation should be provided on how that collapsing was accomplished. Concerns about resonance 
absorption, self-shielding, some scattering effects, etc., should be discussed. However, the real test will come from the results of a confirming calculation for a worst case, discussed in Section 8.2.4.3 below.

\subsubsection{Fuel Loading or Other Contents Loading Optimization}

A SARP may give $K$-effective results for several different fuel loading conditions. From all of these calculations, some worst case condition will emerge that represents a loading under design conditions. Off-design conditions should also be evaluated in an application.

Most SARPs will evaluate K-effective for a model in which all of the fuel bundles are neatly centered in each hole in a basket and the basket is neatly centered in the cask. This model may not produce the highest $K$-effective. In some casks which have steel construction and lead shielding, the $K$-effective will increase when the poison basket is off-center and pushed over as close to the lead as it can get, and the fuel within the hcles in the basket are also pushed over next to the lead. In extreme cases, increases in $\mathrm{K}$ effective by as much as 0.04 have been calculated.

In some package array calculations in which the package contains undermoderated fuel, the highest $\mathrm{K}$-effective value may occur when a mist of water is between the packages. A mist may be defined as a water density in air that lies between about 8.8E-5 grams/ce (corresponding to saturated air at about $120 \mathrm{~F}$ at $14.7 \mathrm{psig}$ ) and $1 \mathrm{gram} / \mathrm{cc}$.

Each SARP should identify all the design conditions that are important and then should address these conditions for normal and off-normal operation.

\subsubsection{Criticality Results}

Section 8.2.5.3 discusses methods used to determine a bias for a computational tool from $K$-effective results of calculations that model critical experiments. The methods used to apply this bias to similar fuel assemblies, such as fuel rods held inside a basket inside of a cask, are discussed below.

It is assumed that the $K$-effective result from the cask calculation gave a mean value of 0.9094 and 1 standard deviation value of 0.0043 . A $2.11 \%$ bias is to be applied to the mean value and a 0,0045 bias to the 1 standard deviation value. The mean value with the bias 
applied then becomes $0.8094 \times 0.0211+0.9094$, or 0.9286 . The 1 standard deviation value with a bias applied becomes $0.0045 \times 0.9094+0.0043$, or 0.0084 . The upper limit is equal to the mean value plus 2 times the 1 standard deviation value ( 2 standard deviations) with bias applied: 0.9454 . The upper limit without the bias is 0.9180 . The difference is 0.0274 .

The value of the standard deviation is widely used in the nuclear industry. The value of the standard deviation appears in many Special Nuclear Materials licenses granted to licensees bandling nuclear fuels.

\subsubsection{Critical Benchmark Experiments}

Section 8.2.3.1 discusses the use of homogenized fuel-clad-water cross-sections. When KENO is used to calculate K-effective for a critical experiment (benchmarking), each fuel pin in the fuel assemblies should be modeled discretely in three dim nsions. Homogenized fuel-clad-water cross-sections should not be used. This is because the homogenization calculations are really done in two dimensions, and the l sakage of neutrons from the ends of the fuel assembly are not considered. This two- $r$.mensional technique could result in a calculation of $\mathrm{K}$-effective for the critical experiment that is tro high, meaning that the corresponding bias for the computational tool is too luw.

\subsubsection{Benchmark Experiments and Applieability}

A previous section discussed the use of more than one critice experiment for benchmarking a computational tool. An example of this process is giv .n below.

References 5 and 6 give a cros8-section set named 27GROUPNDF4 on the SCALE system for use with the KENO criticality codes. The 27GROUPNDF4 set is collapsed from a 218 group ENDF/B-IV cross-section set (Evaluated Nuclear Da ta File, version B-IV). More information on the ENDF/B-IV may be seen in Ref. 8-8. I' is the benchmarking of the 27GROUPNDF4 set with the KENO criticality code that is of zoncern here.

In this example, five critical experiments are selected. These experiments are to be used for benchmarking a computational tool for storing fuel 'sundles in a poison basket in a cask. Table 8.3 gives some information on these experiments. 
The first two experiments, TRX1 and TRX2, were run at the Bettis facility in the mid-1950's. These experiments used uranium metal fuel clad with aluminum and enriched to $1.3 \mathrm{w} / \mathrm{0} 235 \mathrm{U}$. The fuel rods were 48 inches long. The difference between the two TRX experiments involved fuel rod pitch: TRX1 has a triangular pitch of 0.711 inches and TRX2 has a triangular pitch of 0.356 inches.

Experiments 3, 4, and 5 in Table 8.3, PNL 2438-15, PNL 2438-20, and PNL 2438-32, involve $\mathrm{UO}_{2}$ fuel rods clad with aluminum and enriched to $2.35 \mathrm{w} / \mathrm{o} 235 \mathrm{U}$. The fuel rods are 36 inches long. These experiments were made at Pacific Northwest Laboratories in the mid-1970's. These experiments were run with a square pitch of 0.8 inches for the fuel rods and used a plate containing neutron poisons. The difforence between the PNL experiments which involve the composition of this plate, the thickness of this plate, and the spacing of this plate to the edge of the fuel rod array is discussed beiow.

The PNL experiments use three fuel rod arrays. From a plan view, each array has 20 rods in the $x$-direction and 17 rods in the $y$-direction. These rods are in a square lattice at a pitch of $0 . S$ inches. Two neutron poison plates are then placed near the center array; one poison plate is between the center array and the array just above it, and another poison plate is between the center array and the array just below it. The two outer fuel rod arrays are separated from the center array and the poison plates; these two outer arrays are adjusted toward the center array in a symmetrical fashion until criticality is achieved.

In PNL 2438-20, the neutron poison plates are constructed from 0.281 inches thick Boral. The plates are placed 0.254 inches away from the edge of the fuel rods in the center array. In PNL 2438-? , the neutron poison plices are constructed from 0.117-inch-thick 304L stainless steel containing 1.05 w/0 boron (borated stainless steel), and are placed 1.59 inches away from the edge of the fuel rods in the central array.

In PNL 2438-15, the neutron poison plates are removed.

\subsubsection{Details of Benchmark Cakculations}

Some results of these experiments may be seen in Table 8.3. An example of the PNL2438-15 results prepared as input to KENO-Va is shown in Table 8.4. 


\subsubsection{Realts of Benchmari Calculations}

Table 8.3 shows the results of these experiments in terms of the mean values and the 1 standard deviation values fo- both $K$-eflestive and the bias.

From these results, application of a bias of $1.7 \%$ to the mean value of $\mathrm{K}$-effective and $0.32 \%$ to the 1 standard deviation value of $\mathrm{K}$-effective for the KENO-Va code with the 27GROUPNDF4 cross-section set represents a conservative approach. If the fuel in the cask is stored such that some of the fuel rods are near poison plates on only one side of the fuel, or not near plates at all, application of this bias is justified. If the fuel rods in the cask are near poison plates on two or more sides of each fufil bundle, and do not move under normal operating conditions or accident conditions, use of a lower bias may be justified. This bias applies to fuel rod pitch-to-diameter ratios of about 1.8 , and to fuel rods with outside diameters between about 0.38 inches and 0.44 inches. Other critical experiments should also be modeled as input to the computational tool and K-effective results calculated.

\subsection{Acceptance Criteria}

The acceptance criteria for a criticality evaluation requires demonstration of compliance with 10 CFR 71.55, 71.57, 71.55, and 71.61.

\subsubsection{Diecurgion and Revalts}

An application for a container may show compliance with 10 CFR 71 for several different fissile material loadings and/or basket configurations. Hence, a container may be Fissile Class I for one fissile material loading, and then be a Fissile Class II and/or Fissile Class III for other fissile material loadings. Table 8.1 presents a summary of the requirements of these sections.

\subsection{Packape Fuel Loading}

This section should contain a statement giving precisely the fissile material loading permitted for each type of loading. 


\subsubsection{Model Specification}

\subsection{Description of Calculational Model}

The assumptions used in the fuel pin-clad-moderator modeling should be conservative. Fuel pin spacers or other structures that cannot be modeled accurately should be replaced by the moderator material. Fixed neutron poison material should be modeled to represent the thinnest credible value.

If fuel-cled-moderator homogenization was used in any of the models, give a set of comparison calculations for a fuel cell modeled discretely and for a fuel cell modeled homogeneously for the most reactive fuel loading. These results are needed to determine if a bias must be applied to the $K$-effective results for the entire package due to use of this modeling technique.

\subsubsection{Paclraye Regional Densities}

Information provided on the regional densities should be complete.

\subsubsection{Criticality Calculation}

\subsubsection{Calculational or Brperimental Method}

The discussion below emphasizes Monte Carlo codes such as KENO- IV and KENOVa on the SCALE system. Although Monte Carlo codes aren't the only computational tools found in applications, they are often rued. They periait modeling of very complex geometry with relative ease. The $K$-iffective values obtained are accurate. The Monte Carlo codes are readily available, and their computational expense is moderate.

The cross-sections used in the models should be appropriate. If an application contains fuel models that use cross-section sets which are collapsed from larger crosssections sets (more energy groups), some explanation should be provided on how that collapsing was accomplished. Concerns about resonance absorption, self-shielding, some scattering effects, etc., should be discussed.

\subsubsection{Fuel Loading or Other Contents Loading Optimization}

This section should contain calculations sufficient to identify the loading condition giving the highest $\mathbf{K}$-effective value for normal and accident conditions. Any off normal loading that can occur should also be discussed. 


\subsubsection{Criticality Reoults}

The K-effective results must contain a bias due to benchmarking of the computational tool and due to the use of homogenized cross-sections if these biases apply.

\subsubsection{Critical Benchmark E-periments}

The computer code and model should be benchmarked against appropriate criticality experiments.

\subsection{Procedure}

The section on criticality evaluation should identify, describe, discuss, and analyze the principal criticality engineering-physics design of the packaging, components, and systems important to safety and necessary to comply with the performance requirements specified in Paragraphs 71.55, 71.57, 71.59, and 71.61 of 10 CFR Part 71.

\subsubsection{Discaraion of Results}

Verify that the significant criticality design features of the package and the the criticality evaluation are adequately discussed at the beginning of the application.

Verify that the application describes the general size of the cask and the materials used in its construction. Verify that a discussion of the fissile material loadings for the cask along with the internal structure required by these fissile material loadings in order to meet the conditions of 10 CFR Part 71 are discussed. Several different fissile class designations may be sought for the same cask depending upon the fissile material loading coupled with the internal structure that would be required for that loading. See Table 8.1.

\subsubsection{Package Fuel Loading}

Verify that a statement of the package fuel loading is given. This is a legalistic statement of the fissile material loading. This statement should also appear in the cask certificate. 


\subsubsection{Model Specification}

Verify that the geometric model used in the calculation is given.

\subsubsection{Description of Calculational Models}

Dimensioned sketches to scale may be used. All materials used in all regions of the models should be presented. Differences between the actual package configuration and the models should be identified, and the models should be shown to be conservative. Verify that differences between the models for normal conditions of transport and for accident conditions of transport are clearly identified.

Some of the models are prepared as input to a computer code. Tables listing the inputs to the codes for each of the models may be presented here.

\subsubsection{Package Regiongl Densitie}

Verify that the material densities $(\mathrm{gm} / \mathrm{cm})$ and the atomic number densities (atoms/barn-cm) for the constituent nuclides of all materials used in all the calculational models for the normal conditions and accident conditions are given. Fissionable isotopes should be considered at their most nuclear reactive credible concentration. The atomic number densities for all of the isotopes should be checked to show that they are consistent with the masses and the volume occupied for the material specified for each of the regions. Any special constants used such as the molecular weights for $235 \mathrm{U}, 238 \mathrm{U}$, 238Pu, oxygen, density of $\mathrm{UO}_{2}$ and water, number density for oxygen etc, should be given in this section.

\subsection{A Criticality Calculation}

Verify that the criticality calculation is described. This section should describe the calculational or experimental methods used to determine the nuclear reactivity for the maximum fuel loading or other maximum contents loadings intended to be transported in the package. 


\section{BAA.1 Calculational or Experimental Method}

Verify that the SARP provides a general description of the basic calculational methods used to calculate the effective multiplication constant of the package under normal conditions of transport and accident conditions of transport to demonstrate compliance with the appropriate regulations. This should include a description of the computer program and neutron cross-sections used, along with the reference documentation for each. The basis for selecting the program and cross-sections should be discussed.

If experimental methods were used to determine the compliance of the package, verify that the SARP provides a complete description of the experiments and a discussion demonstrating that they conservatively take into account the normal and accident transport conditions for the package.

\subsubsection{Fuel Loading or Other Contents Loading Optimization}

Verify that the correct fuel loading or other contents loading for the maximum reactivity has been evaluated for both the single package and arrays of packages for both normal and accident conditions of transport. Verify that approximation, boundary conditions, calculational convergence criteria, and cross-section adjustments are itemized and discussed.

\subsubsection{Criticality Results}

Verify that the results of reactivity calculations establishing the most reactive configurations for both normal and accident conditions are displayed in tabular and graphic form. Verify that justification is provided for any interpolations and extrapolations. Verify that the validity and conservatiom of the analysis is included. The bias established with the benchmark calculations should be taken into ancount.

The requirements of $10 \mathrm{CFR} 71.55$ should be satisfied for a single package. The requirements of Articles 71.57, 71.59, or 71.61 of $10 \mathrm{CFR} 71$, as appropriate, should be satisfied for an array. 


\subsection{Critical Benchmark Experiments}

The critical benchmark experiment section shuuld provide justification for the validity of the calculational method and neutron cross-section values used in the analysis by presenting results of calculations for selected critical benchmark experiments.

\subsubsection{Benchmark Experiments and Applicability}

Verify that the SARP provides a general description of the selected critical benchmark experiments. These experiments must be analyzed using the same computational tool (catculational method and cross-sections) used to calculate the Keffective values for the package. The applicability of the benchmarks in relation to the package and its contents should be shown. All similarities and differences should be noted and resolved. Verify that references document these benchmark experiments.

\subsubsection{Results of Benchmark Calculationg}

Verify that the actual nuclear and geometric input parameters used for the benchmark calculations are provided. The results of the benchmark calculations should be provided. The calculational bias, if any, should be established and discussed.

\subsection{Finding}

The reviewer should determine that sufficient information has been provided to satisfy the review requirements of this review guide section and the regulatory requirements. The results of this determination should be expressed in a paragraph. These results often contain the legalistic statement of the permitted loading conditions for the package.

The confirmatory calculation should also be discussed. This discussion should include the model used for the confirmatory calculation, the computational tools used, the results of the confirmatory calculation, and the comparison of these results with those presented in the SARP. The bias applied to the results of the confirmatory calculation, if any, should be presented and discussed. 


\subsection{Refenences}

1. U.S. Department of Energy, DOE 1540.2: Hazardous Material Packaging for Transport_Administrative Procedures, U.S. Department of Energy, Washington, DC, September 30, 1986.

2. U.S. Department of Energy, DOE 5480.3: Safety Requirements for the Packaging and Transportation of Hazardous Materials. Hazardous Substance, and Hazardous Wasteg, U.S. Department of Energy, Wagkington, DC, August 9, 1985.

3. Office of the Federal Register, Title 10, Cade of Federal Regulations. Part 71, Office of the Federal Register, Washington, DC, 1984.

4. U.S. Nuclear Regulatory Commission, Regulatory Guide 7.9: Standard Format and Content of Part 71 Applications for Approval of Packaging of Troe B. Large Quantity and Fissile Radioactive Material, U.S Nuclear Regulatory Commission, Office of Standards Development, Washington, DC, January 1980, Rev. 1.

5. Petrie, L.M., and Cross, N.F., EENO-IV Improved Monte Carlo Criticality Brogram, Oak Ridge National Laboratory, Oak Ridge, TN, ORNL-4938, November 1975.

6. Petrie, L.M, and Landers, N.F., KENO.Va, An Improved Monte Carlo Criticality Brogram with Super_Grouping Oak Ridge National Laboratory, Oak Ridge, TN, NUREG/CR-0200, Vol. 2, Section F11, ORNL/NUREG/CSD 2/V1/R2, December 1984.

7. Bucholz, J.A. et al., SCALE. A Modular Code System For Performing Standardized Computer Analysis for Licensing_Evaluation, Oak Ridge National Laboratory, Oak Ridge, TN, NUREG/CR-0200, ORNL/NUREG/CSD/2, Vol. 1, Oak Ridge National Laboratory, July 1980.

8. Bohn, E.M. et al., Benchmark Testing of ENDF/B-IV, Brookhaven National Laboratory, Brookhaven, NY, BNL-NCS 21118 (ENDF-230) Vols. 1 \& II, March 1976. 
9. Hardy, J. Jr.; Klein, D.; and Volpe, J.J., A Study of Physics Parameters In Several Water-Moderated Iattices of Slightly Enriched and Natural Uranium, WAPD-M-931; March 1970.

10. Hardy, J. Jr.; Klein, D.; and Volpe, J.J., Nucl.Ssci.Eng, 40, 101 (1970).

11. Volpe, J.J.; Hardy, J. Jr.; and, Klein, D., Nucl.SSci.Eng, 40, 116 (1970).

12. Hardy, J. Jr.; Klein, D.; and, Dannels, R., Nucl. Sci. Enge, 26, 462 (1966).

13. Brown, J.R. et al., Kinetics and Buckling Measurement in Lattices of Slightly

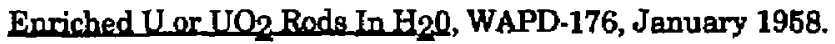

14. Sher, R., and Fiarman, S., Studies of Thermal Beactor Benchmark Data Interoretation: Experimental Corrections, EPRI NP-209, October 1976.

15. Bierman, S.R.; Clayton, E.D.; and, Durst, B.M., Critical Separation between SubCritical Clusters of 2.35 w/0 U235 Enriched U02 Rods in Water with Fixed Neutron Roisons, PNL-2438, October 1977. 


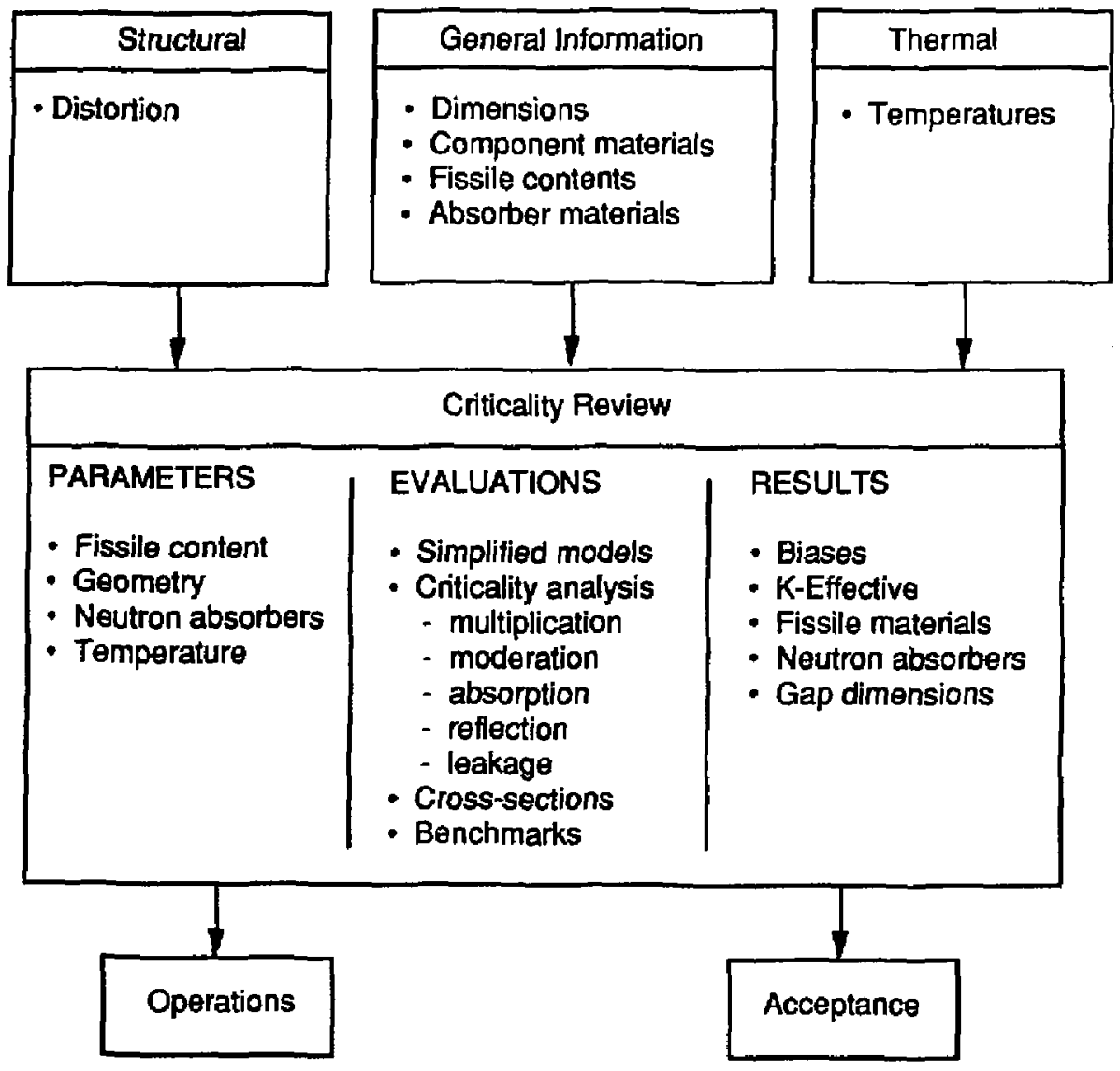

Figure 8-1 Input and output information for the criticality review process. 
Required Number of Packages to be Demonstrated as Subcritical Under Specific Moderation and Reflection Conditions as Per Section 71.55, 71.57, 71.59, and 71.61 of 10 CFR Part 71

\section{Couditions of Shipment}

FISSILE CLASS

No more than $5 \%$ reduction in the total effective volume of the packaging on which nuclear safety is assessed.)

I

Unlimited number of packages are to remain subcritical with optimum interspersed hydrogenous moderation No water reflection necessary.

II Five times the number of packages to be shipped are to remain subcritical in any arrangement when this array is closely reflected by water.

\section{ACCIDENT CONDITIONS}

\author{
(All packages damaged as per \\ hypothetical accident (HA) \\ specifications.)
}

250 packages are to remain subcritical in any arrangement under HA conditions with optimum interpersed hydrogenous moderation and close reflection by water on all sides of array.

Two times the number of packages to be shipped are to remain subcritical in any arrangement under IfA conditions with optimum interspersed hydrogenous moderation and close reflection by water on all sides of array.

Since the maximum value of the Transport Index (TI) for an individual package of Fissile Class II is 10 and the TI equals 50 divided by the allowable number of packages, 5 is the smallest value for the maximum allowable number of packages in a shipment. Therefore, the minimum number of packages in the array that must be considered in the criticality analysis is:

$5 \times 5$ or 25 packages for normal transport

III One shipment of packages is to remain subcritical when it is in contact with an identical shipment and the two-shipment array is reflected on all sides by water.
$2 \times 5$ or 10 packages for accident conditions

One shipment of packages is to remain subcritical under $\mathrm{HA}$ conditions with optimum hydrogenous moderation and close reflection by water. 
Table 82

Volume is Variable

$\mathrm{U}(3.0) \mathrm{O}_{2}-\mathrm{H}_{2} \mathrm{O}$ Cylindrically Shaped

Homogeneous Mixtures Length Varies

Diameter $=13.91^{\prime \prime}$ ID
Extrapolation Distance

Data From: Carter, R.D. et al., "Criticality Handbook," ARH-600, Vol. II, Figures III.B.10(3.0)

K-Infinite and Migration Area vs. Concentration Data from and full Water Extrapolation Distance Data from DP-1014 (Clumped, 0.4 in. OD)

\begin{tabular}{|c|c|c|c|c|c|c|}
\hline $\begin{array}{l}\text { U Density } \\
\text { (H/Fissile) }\end{array}$ & K-Infinite & $\begin{array}{c}\text { Migration } \\
\text { Area, SOCM }\end{array}$ & $\begin{array}{c}\text { Bara } \\
\text { Extrapolating } \\
\text { Distance,CM }\end{array}$ & $\begin{array}{c}1.0^{\mathrm{m}} \mathrm{H} 20 \\
\text { Extrapolating } \\
\text { Distance,CM }\end{array}$ & $\begin{array}{c}\text { Full H2O } \\
\text { Extrapolating } \\
\text { Distance,CM }\end{array}$ & $\begin{array}{c}\text { 2.0" } \mathrm{H} 20 \\
\text { Extrapolating } \\
\text { Distance,CM }\end{array}$ \\
\hline 1011.30 & 1.091541 & 32.67 & 2.26 & 4.25 & 6,26 & 5.25 \\
\hline 919.14 & 1.129870 & 32.29 & 2.22 & 4.24 & 6.23 & 5.24 \\
\hline 827.45 & 1.169367 & 31.95 & 2,21 & 4.22 & 6.21 & 5.22 \\
\hline 735.57 & 1207628 & 31.67 & 2.18 & 4.20 & 6.19 & 5.20 \\
\hline 643.73 & 1.249253 & 31.40 & 2.17 & 4.20 & 6.19 & 5.20 \\
\hline 551.74 & 1.291533 & 31.18 & 2.14 & 4.19 & 6.20 & 5.20 \\
\hline 505.94 & 1.312548 & 31.09 & 2.13 & 4.19 & 6.21 & 5.21 \\
\hline 459.91 & 1.333635 & 31.03 & 2.12 & 4.18 & 6.22 & 5.20 \\
\hline 414.06 & 1.353958 & 31.00 & 2.11 & 4.18 & 6.25 & 5.22 \\
\hline 368.07 & 1.373364 & 31,00 & 2.10 & 4.19 & 6.29 & 5.24 \\
\hline 322.14 & 1.390861 & 31.07 & 2.10 & 4.19 & 6.34 & 5.25 \\
\hline 27622 & 1405075 & 3121 & 209 & 4.19 & 641 & 5.27 \\
\hline 230.31 & 1.413390 & 31.47 & 2.08 & 4.20 & 6.51 & 5.31 \\
\hline 184.36 & 1.411386 & 31.93 & 2.08 & 4.22 & 6.65 & 5.36 \\
\hline 138.43 & 1.389508 & 32.74 & 2.07 & 4.25 & 6.88 & 5.44 \\
\hline 92.50 & 1.326772 & 3426 & 2.04 & 4.32 & 7.29 & 5.61 \\
\hline
\end{tabular}

$\begin{array}{crrcccc}\text { GMS U-235 } & \begin{array}{r}\text { U Density } \\ \text { (H/Fissile) }\end{array} & \begin{array}{c}\text { Cylinder } \\ \text { I.D. (in) }\end{array} & \text { keff (Bare) } & \text { keff (1.0) } & \text { keff (lull) } & \text { keft (2.0) } \\ 1970.81 & 1011.30 & 13.912 & .720 & .763 & .800 & .782 \\ 1970.81 & 919.14 & 13.912 & .744 & .789 & .827 & .809 \\ 1970.81 & \mathbf{8 2 7 . 4 5} & 13.912 & .768 & .814 & .854 & .835 \\ 3970.81 & 735.57 & 13.912 & .788 & .837 & .878 & .858 \\ 1970.81 & 643.73 & 13.912 & .809 & .860 & .903 & .882 \\ 1970.81 & 551.74 & 13.912 & .825 & .879 & .925 & .903 \\ 1970.81 & 505.94 & 13.912 & .831 & .887 & .934 & .911 \\ 1970.81 & 459.91 & 13.912 & .834 & .892 & .942 & .918 \\ 1970.81 & 414.06 & 13.912 & .834 & .895 & .947 & .922 \\ 1970.81 & \mathbf{3 6 8 . 0 7} & 13.912 & .830 & .894 & .950 & .923 \\ 1970.81 & \mathbf{3 2 2 . 1 4} & 13.912 & .820 & .838 & .948 & .919 \\ 1970.81 & \mathbf{2 7 6 . 2 2} & 13.912 & .800 & .874 & .940 & .908 \\ 1970.81 & 230.31 & 13.912 & .768 & .849 & .924 & .887 \\ 1970.81 & 184.36 & 13.912 & .718 & .809 & .895 & .851 \\ 1970.81 & 138.43 & 13.912 & .641 & .744 & .846 & .793 \\ 1970.81 & \mathbf{9 2 . 5 0} & 13.912 & .523 & .642 & .767 & .700\end{array}$


(Continued)

Table82

\begin{tabular}{|c|c|c|c|c|c|c|}
\hline GMS U-235 & $\begin{array}{l}\text { U Density } \\
\text { (H/Fissile) }\end{array}$ & $\begin{array}{l}\text { Cylinder } \\
\text { I.D. (in.) }\end{array}$ & keff (Bare) & keff (1.0) & keff (tull) & kefl (2.0) \\
\hline 2809.32 & 1011.30 & 15.657 & .770 & .806 & .837 & .822 \\
\hline 2809.32 & 919.14 & 15.657 & .796 & .834 & .865 & .850 \\
\hline 2809.32 & 827.45 & 15.657 & .822 & .861 & .894 & .878 \\
\hline 2809.32 & 735.57 & $\mathbf{1 5 . 6 5 7}$ & .844 & .885 & .919 & .903 \\
\hline 2809.32 & 643.73 & 15.657 & .867 & .910 & .946 & .929 \\
\hline 2809.32 & 551.74 & 15.657 & .886 & .932 & .970 & .952 \\
\hline 2809.32 & 505.94 & 15.657 & .894 & .941 & .981 & .962 \\
\hline 2809.32 & 459.91 & 15.657 & .899 & .948 & .989 & .969 \\
\hline 2809.32 & 414,06 & 15.657 & .901 & .952 & .996 & .975 \\
\hline 2809.32 & 368.07 & 15.657 & .898 & .953 & 1.000 & .977 \\
\hline 2809.32 & 322,14 & 15.657 & .889 & .948 & .999 & .974 \\
\hline 2809.32 & 276,22 & 15.657 & .872 & .935 & .992 & .964 \\
\hline 2803.32 & 230.31 & 15.657 & .841 & .911 & .976 & .944 \\
\hline 2809.32 & 184.36 & 15.657 & .790 & .871 & .947 & .908 \\
\hline 2809.32 & 138.43 & 15.657 & .711 & .804 & .896 & .848 \\
\hline 2809.32 & 92.50 & i5.657 & .586 & .697 & .812 & .751 \\
\hline
\end{tabular}

Note: $B$ are $(X=0),. X=1.0$ in. water and full water $(X=12$ in.) extrapolation distance (ED) values are used in the equation $\mathrm{ED}=\mathrm{C1}-\mathrm{C} 2 / \mathrm{EXP}\left(\mathrm{C} 3^{*} \mathrm{X}\right)$ to calculate $\mathrm{C1}, \mathrm{C2}$, and $\mathrm{C3}$. Then these calculated constants are used in the same equation to find the extrapolation distance for $\mathrm{X}=$ 2.0 inches water reflection. For fissile concentrations for which extrapolation distances are unavailable in ARH-600, 3.2 CM, 4.5 CM, or 6.7 CM are used for bare, 1 inch water and full water reflection respectively. 


\section{Table 89}

Critieal Experiment Results

Low Enrished Uranium/UO 2 Rods In Water

Aluminum Clad Around Rods

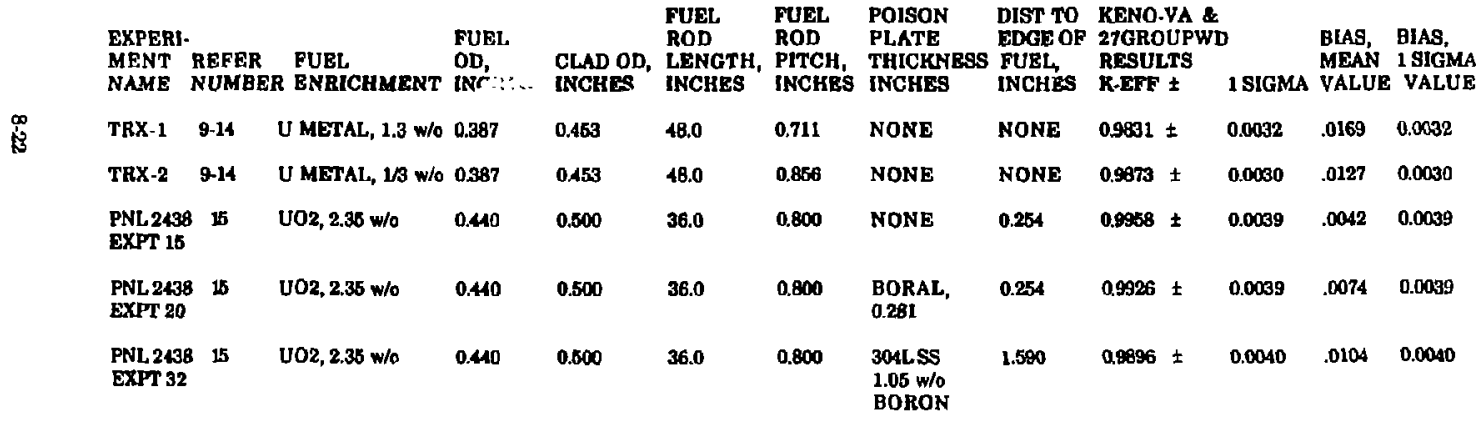


Trble84

Input For KENO-Va

KEFF PNL2438 2.35 W/O EXPERMMENT 015 CROSS-SECTION LATTICECELL U-235 1 0. 4.88892-4 END U-238 1 0. 2.00584-2 END 0 1 0. 4.10910-2 END

AL 2 0. 5.83752-2 END

SI $20.4 .73343-4$ END

FE 2 0. 2.38049-4 END

TI 2 0. 2.06465-4 END

CR 2 0. 6.54789-5 END

MN 2 0. 6.19794-5 END

CU $20.3 .06186-5 \mathrm{END}$

$S \quad 20.3 .03379 .5 \mathrm{END}$

H 3 0. 0.0667593 END

O 3 0. 0.0333797 END

CL 3 0. 5.13-7 END

B-10 4 0. 7.86700-3 END

B-11 4 0. 3.19328-2 END

C $40.9 .95061-3$ END

AL 4 0. 3.46756-2 END

SI 40 1.06786-4 END

FE $40.6 .86115-5$ END

MG 4 0. 3.08408-5 END

CU 40. 2.12408-5 END

CR $40.1 .4204-5$ END

$S$ 0. 1.40307-5 END

MN 40 . 1.36481-5 END

NA $40.130458-5$ END

NI 4 0. 5.10851-6 END

AL 5 1. END

AL 6 0. 5.85549-2 END

MG 60.1 .67141 .3 END

CR 6 0. 7.81508-5 END

CARBONSTEEL 7 1. END

END COMP

$\begin{array}{llllllll}\text { SQUAREPITCH } & 2.032 & 1.1176 & 1 & 3 & 1.27 & 2 & \text { END }\end{array}$

END
KEFF PNL2438 2.35 W/O EXPERIMENT 015

READ PARAM TME=60 PLT=NO END PARAM READ GEOM

UNIT 1

COM="GEOMETRY FOR FUEL PIN AND SPACING"

CYLINDER 110.55880 2P45.72

CYLINDER 210.63500 2P45.72

CYLINDER $610.63500 \quad 46.72-46.99$

CYLINDER $510.63500 \quad 50.80-46.99$

CUBOID 314 P1.016 $66.00-64.93$

UNIT 2

COM="GEOMETRY FOR BORAL POISON PLATE"

CUBOID 11 2P18.148 2P.2545 2P45.648

CUBOID 51 IP18.250 2P.3555 2P45.750

CUBOID $312 \mathrm{AP} 18.250$ 2P.3565 $66.00-64.93$

UNIT 3

COM="GEOMETRY FOR 17X20 FUEL BUNDLE"

$\begin{array}{llll}\text { ARRAY } 1 & -17.272 & -20.32 & -64.98\end{array}$

CUBOID 31 2P18.25 2P20.32 66.00 -64.93

GLOBAL

UNIT 4

COM="GEOMETRY FOR CRTTICAL ASSEMBLY"

CUBOID 31 2P9O. 2P150. 66.00 -64.93

HOLE 3 0. 0 . 0.

HOLE 3 0.62 .560 .

HOLE $30 . \quad-52.560$.

CUBOW 7 I 2P90.9525 2P150.9525 66.00-64.93

END GEOM

READ ARRAY

$A$ R=1 NUX=17 NUY=20 NUZ=1 FILL FI END FILL END ARRAY

END DATA 


\subsection{REVIEW OF OPERATING PROCEDURES}

\subsection{General}

The regulations governing operating procedures are contained in DOE order 1540.2, Chapter II, on Procedures; DOE order 5480.3, Section 10, on Operating Procedures; Subpart H of 10 CFR 71 on Quality Assurance; and Subpart G of 10 CFR 71, on Operating Controls and Procedures.1,2,3 In addition, regulations governing operations include Paragraph 20.205 of 10 CFR 20 on Procedures for Picking Up, Receiving, and Opening Packages;4 Paragraph 173.474 of 49 CFR 173 on Quality Contral Requirements Prior to Each Shipment of Radioactive Materials;5 10 CFR 71, Paragraph 71.47 on External Radiation Standards for All Packages; 10 CFR 173 Paragraphs 173.443 on Contanination Control, and 173.427 on Empty Radioactive Materials Packaging. ${ }^{6}$ Guidance is also given in Regulatory Guide (R.G.) 7.10 on what should be included in the operating procedures. 7 The applicant wishing to license a particular package will prepare a document, separate from the SARP, which provides detailed operating procedures to the package handlers and operators. This review guide does not address that seperate document. This review guide addreseses only the more limited operating procedures that are provided in the SARP. The procedures in the SARP are used to support the more detailed document, which is written at a later cate. The Review Procedures below vive recommendations as to what information should be provided in the SARP.

Figure 9-1 shows the types of information required from other sections of the SARP to perform the review. The objective of this review is to assure that the applicant has included in the Operating Procedures rection of the SARP all package specific information required by the regulations.

\section{Areas of Review}

The following general areas relate to operating procedures for transportation packages, and should be discussed in the SARP3:

\section{General}
a) planning
b) personnel qualifications
c) equipment
d) records
e) QA 
2. Summary of Operating Requirements and Restrictions

3. Package Loading

4. Shipment Preparation

5. Package Receipt

6. Package Unloading

\subsection{Acceptance Criteria}

The Operating Procedures section of the SARP is a supporting ducument to the final Operating Procedures document which is prepared by each user of the packaging. The SARF should contain all package-specific information related to operating procedures. The procedures should demonstrate that there is no unacceptable risk to the public or operating personnel during loading, unlaading, and handling operations of the package.

\section{Procedurea}

The reviewer will ensure that information discussed below is provided in the Operating Procedures section of the SARP. 8

\subsubsection{Ceneral}

\subsubsection{Plonning}

Verify that the operating procedures atress the importance of carefully planning each operation before any action is taken. Requirements in 10 CFR 71.105 stress the need for planning each operation, with respect to (i) using suitable equipment, (ii) ensuring that suitable environment conditions (auch as cleanliness) have been created and will be maintained, and (iii) ensuring that all prerequisites for the given activity have been satisfied.

\subsubsection{Perannel Qualification:}

Verify that operating procedures specifically list the qualifications of the personnel involved in the packaging operations. Requirements in $10 \mathrm{CFR} 71.105$ state that the licensee must provide for trining of personnel performing activities affecting quality. The operating procedures should specify appropriate training. 


\subsubsection{Equipment}

Verify that operating procedures list all equipment required for each aspect of packaging operations, with all pertinent details such as equipment specifications.

\subsubsection{A Records}

Verify that operating procedures give instructions on maintaining records. Verify that records for each shipment of licensed radioactive material are maintaine' for a period of two years, per the requirements of 10 CFR 71.91 and 49 CFR 173.47; The licensee must maintain, during the life of the packaging, quality assurance records to provide evidence of the quality of the packaging components that have safety sigaific nce, and of service affecting quality. These paragraphs also list what the records shculd include.

\subsubsection{Quality Assurance}

Verify that the operating procedures include appropriate quantitative and qualitativ acceptance criteria for determining that important activities have been satisfactorily accomplished, per the requirements of 10 CFR 71.111 .

In addition, the operating procedures should address the quality assurance requirements for identification, special proceses, inspection, testing, measuring and test equipment, handling non-conforming materials, records, and audits as required by 10 CFR 71.115 through 10 CFR 71.137.

\subsection{Summary of Operating Requirementu and Rectription}

This section of the Operating Procedures in the SARP should concisely summarize all requirements and restrictions for package operations as detailed in the other chapters of the SARP. This will include a list of drawing and revision numbers for all package components (as required for operations); a description of the form (solid, liquid, powder, etc.) and fissile load of the contents; any handling restrictions (such as lifting height limits, or dual load path requirements); any neutron poison, moderator, and gap requirements; expected gamma and neutron radiation levels, and locations of any streaming paths; and any closure (such as closure lid bolt torques necessary for containment) and component testing (such as pressure taps) requirements. 
The reviewer(s) must evaluate all other sections of the SARP (including General, Structural, Thermal, Criticality, Shielding, and Containment) to determine that all requirements and restrictions are properly accounted for in this summary. This summary should be brief; each individual item should be discussed in greater detail in the appropriate section of the operating procedures in the SARP (such as tie-down configurations in the ehjpment preparation section).

\subsubsection{Package Loading}

Verify that the operating procedures provide detailed instructions on package loading. Instructions on the following items should be included:

a. ensuring that all apprupriate documents have been reviewed by operating personnel;

b. verifying that the Certificate of Compliance permits the radioactive material to be shipped within the particular package used. If the licensee does not know the propertien of the material to be shipped, 10 CFR 71.83 states that the material must be packaged assuming credible values causing the maximum nuclear resctivity;

c. a list of any special equipment which may be needed;

d. ensuring that packaging sealing surfaces have been properly prepared and protected;

e. checking that all payload treatment processes performed subsequent to package loading are appropriate for the particular payload in question, and that process equipment operators are familiar with both processing procedures and the task operating procedures;

f. checking that packaging interior contamination levels are not so excessive that significant contamination could be imparted to the payload itself;

g. checking that all task components operate as designed, and have been tested if necessary;

i. detailed instructions on contents insertion;

i. detailed instructions on closure placement, packaging assembly and leaktesting;

j. instructions on package transfer from the loading site to the transportation vénicle; 
k. instructions on decontamination of exterior surfaces of the packaging and transport vehicle.

\section{A4 Shipment Preparation}

Verify that the operating procedures provide detailed instructions on shipment preparation. These instructions should include the following:

a. instructions on required package testing prior to release for transport;

b. instructions on radiation survey requirements;

c. instructions on securing package to vehicle;

d. instructions on rendering unused tie-down and lifting devices inoperable;

e. instructions on temperature survey requirements;

f. instructions on preparation of empty packaging for transport.

\section{9,45 Package Receipt}

Verify that the operating procedures give instructions to the package recipient on at least the following:

a. ensuring that appropriate paperwork is available for working on the packaging;

b. ensuring that radiological surveys and safety inspections of both the packaging and the transportation vehicle are made;

c. verifying that it is clear what the contents are, and in what form they are shipped.

\subsubsection{Package Unioading}

Verify that the operating procedures provide detailed instructiong for package unloading. Instructions on the following items should be included:

a. a list of any special equipment which may be needed;

b. closure removal;

c. contents removal;

d. inspection of interior of packaging after contents have been removed;

e. possible preparation of packaging for short- or long-term empty storage. 


\subsection{Frating}

Verify that sufficient and adequate information has been provided in the review plan for the package to satigfy the general regulatory requirements and that the evaluation supports the following conclusion, to be included in the safety evaluation report:

"This section of the applicant's SAR has been reviewed to determine that the operating procedures heve been designed in a manner that will assure compliance with the requirements of DOE Orders 5480.3 and 1540.2, Section 10, 10 CFR 71 Subparts $H$ and G, 10 CFR 20.205, 49 CFR 173.427, 49 CFR 173.443, 49 CFR 173.474, and 10 CFR 71.47."

"Basis for acceptance in the review has been conformance with established guidelines and criteria. The evaluation of the operating procedures provides reasonable assurance that, from the standpoint of general requirements on the packaging, it will be possible to transport radioactive material safely."

"The staff concludes that the protective features provided in the operating procedures conform to applicabie Regulations, Regulatory Guides, and industry standards ond are acceptable."

\subsection{References}

1. U.S. Department of Energy, DOE 1540.2: Hazardour_ Material Packariag for Transport=-Administrative Procedures, U.S. Department of Energy, Washington, DC, September 30, 1986.

2. U.S. Department of Energy, DOE 5480,3: Safuty Requirements for the Packaping and Trensportation of Hazardous Materials, Hazardous Substance. and Harardous Westes, U.S. Department of Energy, Washington, DC, August 9, 1985.

3. Office of the Federal Register, Title.10. Code of Federal Regulations, Part 71, Office of the Federal Register, Washington, DC, 1984.

4. Office of the Federal Register, Title 10.Code of Federal Repulations, Part 20, Office of the Ferteral Register, Washington, DC, 1984. 
5. Office of the Federal Register, Title 42. Code of Federal Requlations, Part 173, Office of the Federal Register, Washington, DC, January 1, 1985.

6. Office of the Federal Register, Title 10, Code of Federal Regulations, Part 73, Office of the Federal Register, Washington, DC, 1984.

7. U.S. Nuclear Regulatory Commission, Rerulatory Guide 7.10: Establishing Quality Assurance.Programs for Packagine Used in the Transport of Radieactive Material, U.S. Nuclear Regulatory Commission, Washington, DC, January 1983.

8. U.S. Nuclear Regulatory Commission, Regulatorr Guide 7.9: Standard Format and Content of Yart 71 Applications for Approval of Packarine of Tyze. B. Large Quantity and Fissile Radioactive Material, U.S. Nuclear Regulatory Commission, Office of Standards Development, Washington, DC, January 1980, Rev. 1. 


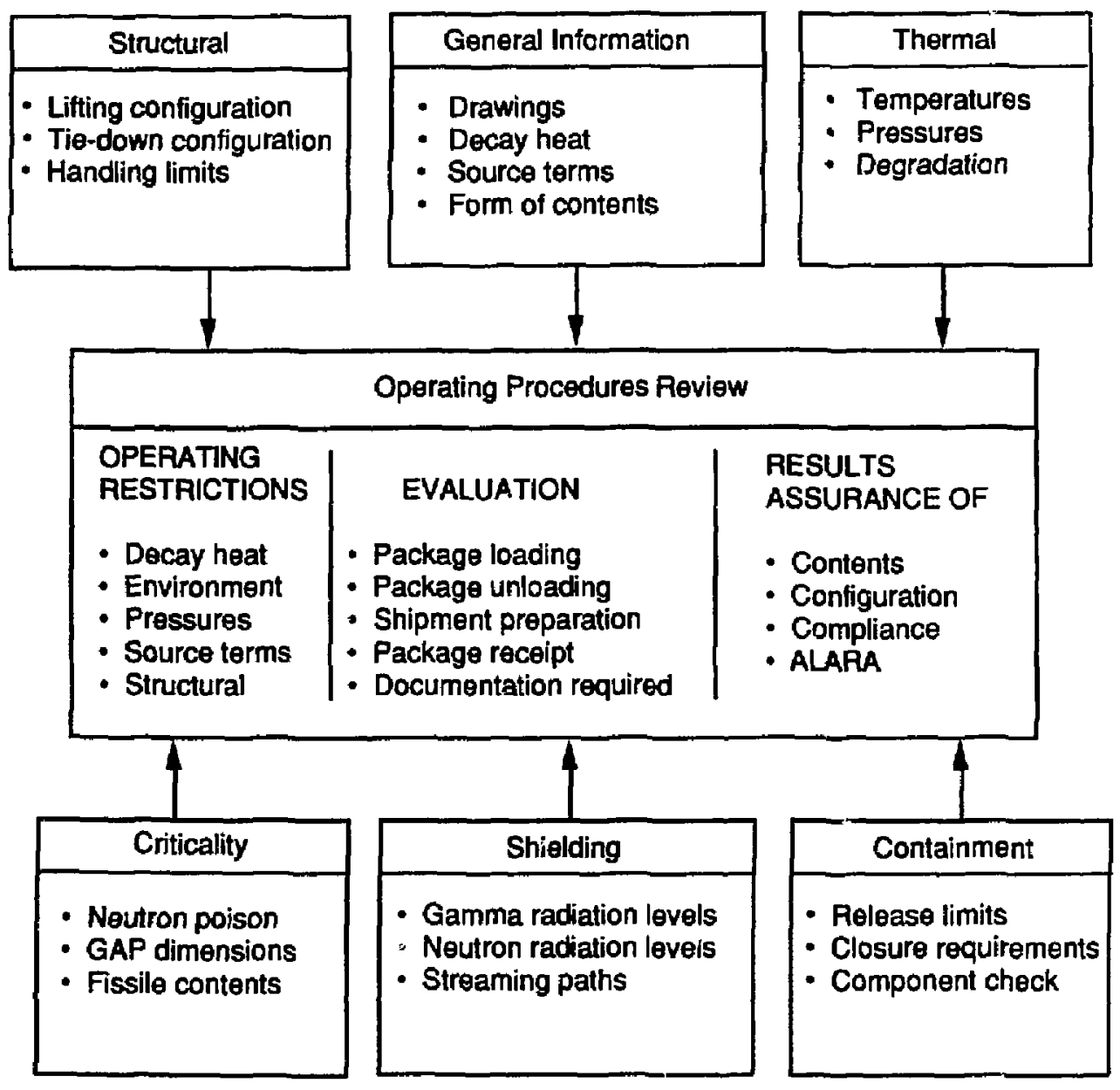

Figure 9-1 Input information for the review of operating procedures. 


\subsection{REVIEW OF ACCEPTANCE TESTS AND MAINTENANCE PROGRAM}

\subsection{General}

Thiq section of the review verifies that appropriate acceptance tests and a maintenance program have been defined in sufficient detail in the SARP that the fabrication and maintenance of the packaging can be ensured in compliance with DOE orders and regulatory requirements. $1,2,3,4$

Figure 10-1 shows the types of information required from other sections of the SARP to perform the review. Information is sequired from most of the sections and includes: pressure loads, heat loads, maximum temperatures for components, containment requirements, gamma and radiation shielding thickness and radiation limits, neutron poison components, and spacing requirements for any fissile materials. The loadings affecting the packaging acceptance teating and maintenance include temperature, pressure, source terms, and decay heat. The tests performed include visual, pressure, thermal, shielding, anc materials (lot testing). The resuits of the acceptance test and maintenance program assure the confinement of radioactive materials, subcriticality, the adequacy of shielding, the soundness of the fabrication, and the replacement of parts as required.

\subsection{Areas of Review}

The following areas, identified in Regulatory Guide (R.G.) 7.9, are reviewed for compliance with regulatory requirements. 5

\subsubsection{Acceptance Teats}

The acceptance test that must be performed prior to the first use of the packaging is reviewed. The acceptance test includes visual inspection, pressure tests, leak tests, component tests, shielding tests, thermal tests, and suberiticality tests.

\subsubsection{Maintenance Program}

The maintenance program used to ensure the continued safe performance of the packaging is reviewed. The maintenance program should describe all tests performed and their frequenciss. The replacement of parts such as seals and burst discs should be described and justified by the applicant. 


\section{Acoeptance Criteria}

The specific criteria for judging the acceptability of the acceptance tests and maintenance program in the SARP are proviried in the following subsections.

\subsubsection{Asceptance Teste}

The acceptance tests must address items listed in the following subsections.

\subsubsection{General}

Per 10 CFR 71.85, the applicant must define tests to ensure that:

a. there are no cracks, pinholes, uncontrolled voids, or other deiects which could reduce the effectiveness of the packaging;

b. the packaging is pressure-tested at least $50 \%$ higher than the maximum normal operating pressure when the maximum normal operation pressure exceeds 34.3 bilopascal (5 psi) gauge;

c. the packaging is conspicuously and durably marked with its model number, serial number, gross weight, and packaging identification number assigned by DOE.

\subsubsection{Containment Tests}

Per R.G. 7.4, the packaging must be leak tested per ANSI N14.5.6,7

\subsubsection{Gamma Shield}

Gamma scanning or probing may. be used to demonstrate the soundness of the gamma shielding. Alternativeiy, ultrasonic testing may he used. Whatever method is used, the following information should be provided in the acceptance test procedure:

1) Description of the measuring technique including the electronics.

2) The source type and strength used to measure the shield effectiveness.

3) The standards and methods used to calibrate the source, sensors, and other pertinent equipment.

4) The grid pattern used to check the shield.

5) The type of gamma sensor used to measure the shield effectiveness.

6) The specific test requirements and measurements.

7) The acceptance criteria. 


\subsubsection{Neutron Shield}

The neutron shield effectiveness should be verified by test using a neutron source of adequate strength to verify the shielding effectiveness. Information should be provided in the test procedure which is similar to that specified for the gamma shield testing in 10.3.1.3.

\subsubsection{Subcriticality Amurance}

Packagings designed to transport fissile material which contain neutron absorber material should be tested to demonstrate the presence of the neutron absorber material. The test description should include information similar to that requested for gamma shield testing 10.3.1.3. Fabrication records of the absorber material and its installation and testing should be maintained.

\subsubsection{Thermal}

Containers designed to transport radioactive material with decay heat should be tested to demonstrate their heat load capabilities unless otherwise justified. The test procedure should provide the following information:

1) Test requirements and acceptance criteria.

2) Heat load testing at various levels incluơiug rated capacity.

3) Temperature gradients acrose fll major materials and their interfaces.

4) Projected peak tewperatures of the simulated contents.

5) Method used to simulate the decay heat.

6) Ambient environment conditions during the conduct of the test.

7) The test configuration, instrumentation, and recording equipment.

\section{Maintenance Frogram}

A maintenance program must be described in the SARP and address the following.

\subsubsection{Testing}

The packaging must undergo periodic testing to ensure the proper functioning of the components important to safet $y$. Unless otherwise justified, periodic testing should be performed at least annually. In general, the acceptance criteria sperified in $\mathbf{1 0 . 3 . 1}$ should 
be used. When justified, lesser alternative testing and acceptanci criteria can be used for teating prior to each shipment of the packaging. For example, the requirements specified in ANSI N14.5 for the leak testing assembly prior to each shipment are less than those for periodic tests.

\subsection{Parte Replacement}

All components important to safety must be qualified for their useivl lifetiwe of service. The rep'acement scheduie for parts such as valves, closure seals, and closure bolts must be justified based on testing or experience. Testing per 10.3.i is :equircd following any parts replacement or repairs affecting the sefety of the packaging.

\section{A Procedures}

Verify that the appisant describes the acceptance tests and maintenance program to be used on the packaging, in compliance with Subpart G of 10 CFR 71.

\subsection{Acceptance Teats}

Verify that the SARP adequately describes tests to be performed prior to the first use of the package. As a minimum, the test descriptions should contain the following information.

\subsubsection{Vianal Ingpection}

Verify that sufficient visual inspections are performed and the intended purpose behind each inspection is discussed. Verify that the criteria for acceptance for each of these inspections are stated as well as the action to be taken if nowsompliance is encountered.

\subsubsection{Structural and Preasure Tests}

Verify that structural and pressure tests to be performed are irentified and describea. The acceptance criteria for the test should be stated as well as the action to be taken when the prescribed criteria are not met. The sensitivity of the tests should be provided in the SARP. 


\subsubsection{Leak Tests}

Review the leak tests to he performed. The leak tests should be perforned on the containment vessel as well as on auxiliary equipment such as shield tanks. The criteria for acceptance and the action to be taken if the criteria are not met should be stated. The sensitivity of the leak tests should be given in the SARP. Verify that the leak test criteria in 10.3.1.2 are met.

\subsubsection{Component Teats}

Verify that acceptance tests are addressed for all components. Acceptance criteria must be provided for each component. The action to be taken if the criteria are not met must also be stated.

\subsection{Valies, Rupture Disce, and Fluid Transport Devicew}

Verify that these components are 1 ,sted under the most severe service conditions for which the paskaging design assumes their acreptable performance. When the tests are presumed to adversely affect the continued performanc $c^{f}$ a component, the results of tests on components of the same model may be substit. ied. This information may be provided in the Thermal Evaluation section of the SARP.

\subsection{Gaskets}

Verify that all gaskets are tested under conditions simulating the most severe service conditions under which the gaskets are to perform. Since these acceptance tests may d:grade the performance of either the gasket under test or the packaing into which it is assembled or both, the tests are not necessarily performed on gaskets or packagings to be put into service. The simulation system must ensure adequate representation of thcse conditions that would prevail if the actual system were used in the test. Verify that the gaskets are procured under a quality assurance program adequate to ensure that acceptance testing of a given gasketing device is equivalent to acceptance testing of all gaskets supplied and identified by that manufacturer as that model gasket. 


\section{A.1A.9 Miscellaneous}

Verify that any other component whose failure would impair the packaging effectiveness is identified and tested under the most severe conditions for which it was designed. Since these acceptance tesis may degrade the performance of either the component under test or the system into which it is assembled or both, the tests are not necessarily performed on components or systems to be put into service. The simulation system should ensure adequate representation of those conditions that would prevail if the actual aystem were used in the test. Furthermore, verify that the components are procured under a quality assurance program adequate to ensure that acceptance testing of a given component device is equivalent to acceptance testing of all devices supplied and identified by that manufacturer as that model device.

\subsection{Tecte for Shielding Inteqrity}

Verify that tests to be performed to establish shielding for both gamma and neutron sources are identified and discussed. The discussion should include the dimensions of the grid pattern or a description of the scanning procedure that demonstrates the inspection of 100 percent of the packaging surface area. Verify that the acceptance criteria as well as the action to be taken if the criteria are not met are described.

\section{A.1.6 Thermal Acceptance Testo}

Verify that tests are identified for verifying that each package perfurms, within some defined variance, in accordance with the results of the thermal analyses or tests for normal conditions of transport.

\subsubsection{Ditcuesion of Text Setup}

Verify that the SARP adequately describes the tests. The description should include heat source, instrumentation, and schematic showing thermocouple and heat source locations as well as the placement of other test equipment. The test sensitivity based on instrumentation, test item, and euvironment variations should be provided and justified. 


\subsection{Test Procedureg}

Verify that the procedures used in testing and data recording are discussed. The frequency of data recording during the test should be reported. The criteria used to define the steady-state (thermal equilibrium) condition of the test item should also be reviewed.

\subsubsection{Acceptance Criteria}

Verify that the thermal acceptance criteria and the method employed to compare the acceptance test results with predicted thermal performance are discussed. Review the action to be taken if the thermal acceptance criteria are not met by a packaging unit.

\subsection{Maintenance Program}

Verify that the maintenance program used to ensure continued performance of the packaging is described. The program should include periodic testing, inspection, and replacement schedules as well as criteria for replacement and repair of components and subsystems on an as-needed basis.

\subsubsection{Structural and Preagure Teut}

Review the tests to be performed and the frequency of performance. Verify that the SARP adequately describes instrumentation and test sensitivity.

\subsubsection{Ieak Tests}

Review the tests to be performed and the frequency of performance. Verify that the sensitivity of these tests is stated. For most systems, this would include a test of each package before each shipment and an annual test of each packaging.

\subsubsection{Subsystem Maintenance}

Review the test and replacement schedule to be used for packaging subsystems (e.g., auxiliary cooling systems and neutron shield tanks) whose inadequate performance could impair the total package safety. Verify that the SARP justifies the schedules established, using verifiable test or manufacturer's data. 
10.4.2.4 Valves, Pupture Digcs, and Gaskets on Containment Veseel

Review the test and replacement schedule to be used for these components. Verify that the SARP justifies the schedules established, using verifiable test or manufacturer's data. For most systems, this would include as a minimum a visual inspection prior to each closure and an annual gasket and seal replacement.

\subsubsection{Shielding}

Review the test and inspection schedules as well as the corrective action to be used to ensure adequate shielding performance. Verify that the SARP considers both gamma and neutron sources.

\subsubsection{Thermal}

Review the tests proposed and the frequency of these tests that would be performed on the total system. Verify that the SARP justifies the frequency of the proposed tests that detect degradation in the thermal performance of the packaging prior to compromise of the package safety.

\subsubsection{Miscellaneous}

Revisw any additional test not considered previously that should be performed periodically on components and subsystems.

\subsection{Findings}

The reviewer verifies that sufficient and adequate information has been provided to satisfy the requirements of the regulatory requirements for the packaging acceptance tests and maintenance program and that the evaluation supports the following conclusion, to be included in the safety evaluation report.

"This section of the applicant's SARP has been reviewed to determine that the acceptance tests and maintenance program have been defined in a manner that will assure compliance with the requirements of 10 CFR Part 71, Paragraphs 71.85 and 71.87. The scope of the review covers package testing such as pressure, thermal and leakage, the replacement or repair of parts, and any supportive information or documentation." 
"Basis for acceptance in the review has been conformance with established guidelines and criteria. The evaluation of the containment design provides reasonable assurance that it will be possible to transport radioactive material safely."

"The staff concludes that the protective features provided in the design of the package conforra to applicable Regulations, Regulatory Guides, and industry standards, and are acceptable."

\subsection{Referenced}

1. U.S. Department of Energy, DOE 1540.2: Hazardous Material Packaging_for Trapsport-Administrative Procedures, U.S. Department of Energy, Washington, DC, September 30, 1986.

2. U.S. Department of Energy, DOE 5480.3: Safety Requirements for the Packariag and Transportation of Hazardaug Materiale, Hazardous Substance, and Hazardous Wasteg, U.S. Department of Energy, Washington, DC, August 9, 1985.

3. U.S. Department of Energy, DOE 5700.6B: Quglity Assurance, U.S. Department of Energy, Washington, DC, September 23, 1986.

4. Office of the Federal Register, Title 10, Code of Eederal Requlations. Pant 71, Office of the Federal Register, Washington, DC, 1984.

5. U.S. Nuclear Regulatory Commission, Regulatory Guide 7.9: Standard Format and Content of Part 71 Applications for Approval of Packagine of Type B. Large Ouantity and Fissile Radioactive Material, U.S. Nuclear Regulatory Commission, Dffice of Standards Development, Waghington, DC, January 1980, Rev. 1.

6. U.S. Nuclear Regulatory Commission, Repulatory Guide 7.4: Leakare Tests on Packages for Shipment of Radioactive Materials, June 1975.

7. ANSI N14.5-1977, Leakage Tests on Packages for Shioment of Radioactive Materials, American National Standands Institute, 1430 Broadway, New York, NY 10018. 


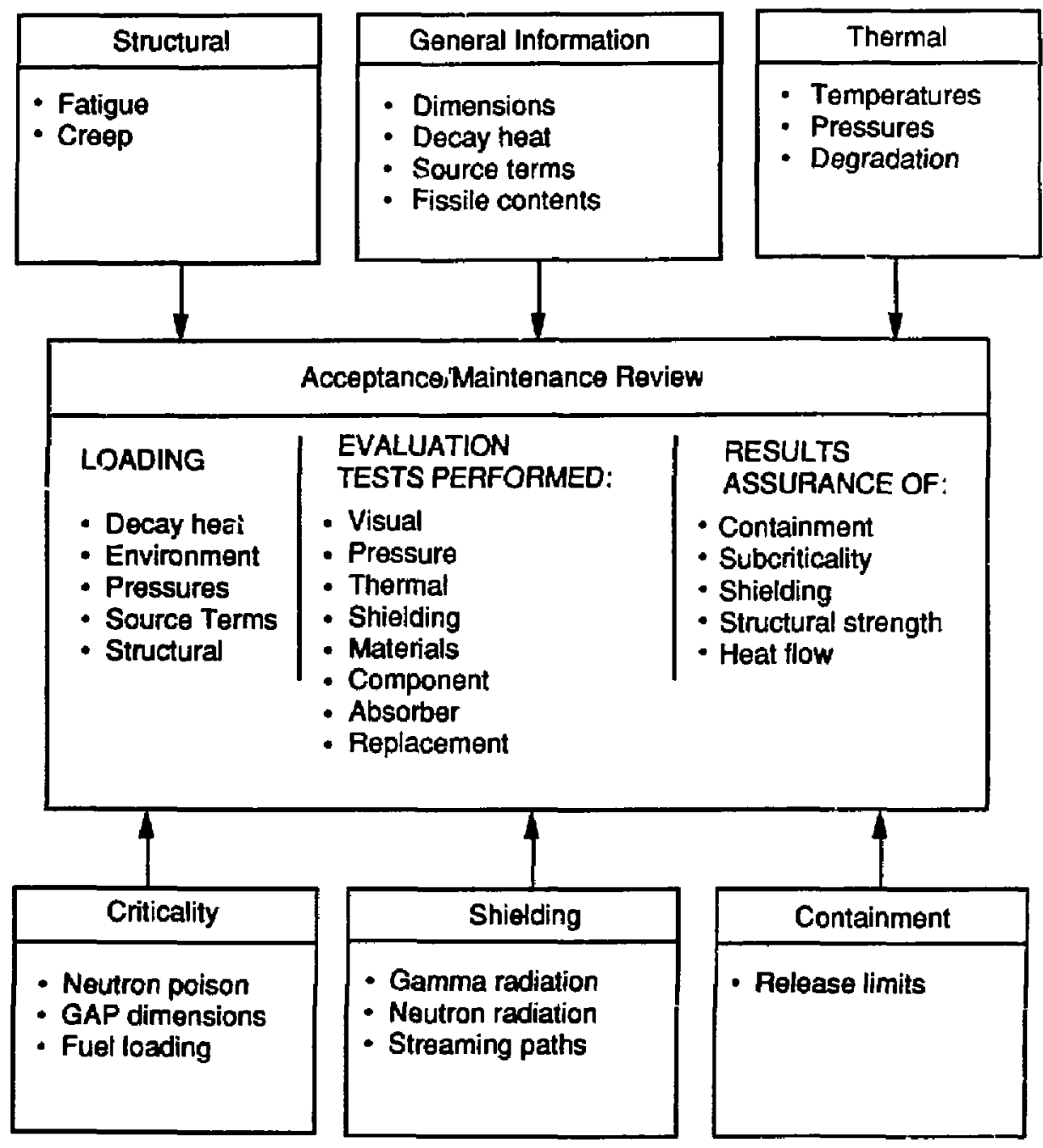

Figure 10-1 Input and output information for the review of the acceptance tests and maintenance program. 


\subsection{REVIEW OF QUALTTY ASSURANCE REQUIREMENTS}

\subsection{General}

This section of the review verifies that appropriate quality assurance requirements have been includsi in the Quality Assurance (QA) section of the Safety Analysis Report for Parliaging (SARP) to demonstrate compliance with Department of Energy (DOE) Orders and federal regulatory requirements. As indicated in Subsection 2.1.1 of this Packaging Review Guide (PRG), the reviewer must verify that the applicant's QA section in the SARP contains package-specific QA information required by DOE Orders and federal regulations that demonstrate compliance with the following documents for applicable QA requirements: DOE Order 1540.2, Chapter II; DOE Order 5480.3, Section 7 of aitachment to Order; DOE Order 6700.6B; Subpart H of 10 CFR Part 71; U.S. Nuclear Regulatory Commission (NRC) Regulatory Guide 7.10; and 49 CFR Part 173.1,2,3,4,5,6 The reviewer of the QA section of the SARP must be knowledgeable of the QA provisions in the relevant DOE Orders and federal regulations. Figure 11-1 indicates the interrelationship between DOE Orders, federal regulations, guidance documents, and the SARP.

The reviewer must assure that the QA section in the SARP is consistent with the quality standards specified in Section 2 of the SARP. As discussed in Subsection 2.1.1 of this PRG the quality standards are determined by the component safety group and packaging category. The QA requirements should be commensurate and accomplished by classifying each component, structure, or system as being important to safety or not being important to safety. The important-to-safety items should be grouped and classified into QA categories A, B, or C, with category A items containing the most important items relative to safety and with category $C$ itoms containing the least important items related to safety. The resultant list is known as a Q-List. The reviewer should utilize both NRC Regulatory Gujde 7.10 and ANSU/ASME NQA-1 90 guidnneg dacuments to verify the adequacy of the applicant's QA levels, 5,7

\subsubsection{Objectives and Authorization}

This review section describes QA requirements applying to designing, purchasing, fabricating, handling, shipping, storing, cleaning, assembling, inspecting, testing, operating, maintaining, repairing, and modifying components of packaging, which are important to safety. The design effort, operational plans, and QA requirements should be integrated to achieve a system in which the independent QA program is not overly stringent and the application of QA requirements is commensurate with safety significance. The reviewer must verify that the applicant's QA section in the SARP 
contains package-specific QA information required by DOE Orders and federal regulations that demonstrate compliance with the following documents for applicable QA requirements: DOE Order 1540.2, Chapter II; DOE Order 5480.3; DOE Order 5700.6B; Subpart H of 10 CFR Part 71; U.S. Nuclear Regulatory Commisaion (NDC) Regulatory Guide 7.10; and 49 CFR Part 173.

The reviewer must verify that the QA section of the SARP provides adequate confidence that three basic objectives are antisfied throughout the life cycle of the package. The basic objectives are:

1. Adequate containment of the radioactive material.

2. Assurance of subcriticality.

3. Adequate shielding of the radiation emitted by the radioactive contents.

This review must assure that the QA section of the SARP describes the controls to be used for the design, fabrication, assembly, testing, operations, maintenance, and repair of the package.

\subsection{Safety Focuo-Paclirafs Object}

The review Sections 3.0-10.0 of this guide cover the technical aspects for SARP acceptance and establish guidelines for the reviewer. This section on QA review is intended to assure that the QA activities described in the SARP provide control over all activities important to safety. The reviewer should focus on the three basic objectives that are fundamental to safe operations using this package. With the package as the central focus of the SARP, the reviewer should consider those activities dealing directly with design, fabrication, assembly, testing, operations, maintenance, and repair. A graded approach based on importance to safety should be reflected in the effort devoted in the $Q \dot{A}$ section of the SARP proposal.

\subsection{Q-List and QA Categories}

The reviewer should verify that an appropriate Q-List containing QA categories has been included in the SARP for each component.

One logical sequence leading to realistic QA requirements (see Figure 11.2) would be (1) classifying each feature of a component, structure, and system as important to safety (Q-List) or as not important to safety, (2) grouping items on the Q-List into QA categories (A, B, or C), and (3) specifying the level of QA effort applicable to each category. This 
approach assures that a sufficient number of QA activities is included to verify success in meeting goals. The QA categoires should be consistent with the quality standards (see Subsection 2.1.1) selected for each component.

\subsection{Areas of Review}

\subsubsection{Management Organization}

The structure of the organization and the assignuent of responsibility for each function should be clear.

\subsubsection{Quality Acourance Program}

The applicant must have a QA progran as required by NRC/DOE and 10 CFR 71.

\subsubsection{Q-List Preperation}

The SARP should include the entire list of components, structures, and systems which form the package. The rationale or methods used to classify each item or feature as important to safety (Q-List) or as not important to safety should be described.

\subsubsection{Quality Asurance Categories}

All items on the Q-List must be graded for their importance to safety. The grade levels are: Category A-critical to safety, Category B-maior impact_on safety, and Category $\mathrm{C}$-minor impact on safety. The methods used to determine the categories should be included.

\subsubsection{Control Activitie}

The QA section of the SARP must provide adequate controls for safety activities. As a minimum, the design, fabrication, agsembly, testing, operations, maintenance, and repair of the package must be included.

\subsubsection{Essential QA Elements}

The QA section in the SARP must address all 18 QA elements that are required by Subpart H of 10 CFR Part 71. The QA section of the SARP is to describe which QA elements apply to the package design, procurement, fabrication, handling, shipment, storage, cleaning, assembly, inspection, testing, operations, maintenance, repair, and 
modification of packaging items that are considered important to safaty. The reviewer verifies that the QA section in the SARP adequately describes the QA plan in sufficient detail with package-specific information.

\section{Documentation}

The QA program should ensure that activities important to safety and applicable to the design, fabrication, assembly, testing, operation, maintenance, and repair of packaging are described by written procedures and instructions. This documentation should be in place prior to engaging in these activities.

\section{Perwonnel Qualification.}

The proposed QA program should include measures for ensuring that perscnnel receive training commensurate with their responsibilities. Records must document specialized training for critical operations, QA indoctrination, and for current status of qualification.

\section{2 .9 Appropriate Efiort}

The QA section should contain QA requirements that are commensurate with the safety siguificance of a component, structure, or system. Furthermore, there must be consiatent application of the level of $Q A$ effort during the life cycle of the packaging design, fabrication, assembly, testing, operation, maintenance, and repair. It is the responsibility of the applicant to define or identify those items that must be checked by any potential user of the package to assure reliability and safety during operations.

\section{Acceptance Criteria}

\subsubsection{Management Organization}

The management structure should be such that quality standards are achieved by those assigned to do the work and conformance to the standards is verified by individuals not directly responsible for performing the work. The verifiers must have a reporting hierarchy with sufficient independence to control activities.

Formal organization charts should be sufficiently clear to the reviewer so that interface areas of responsibility have defined conflict resolution procedures. Responsible QA individuals must have authority to stop work for any safety related nonconformance. This authority should be in writing for those individuals so designated. 


\subsubsection{Quality Agrurance Program}

Measures should be established for (1) identifying the component, etructures, and systems to be covered by the QA program and (2) verifying that design objectives have been attained. Although 10 CFR 71 Subpart $H$ allows for a graded QA program, it does not preclude a maximum control effort on items critical to gafety.

\section{Q-Lit Preparation}

Each feature or element of a component, structure, system, and activity must be classified as important to safety (Q-List) or as not important to safety. The reviewer verifies that the applicant has evaluated the Q-List to determine that the function or physical characteristic of each part is essential to the gafety of the packaging. The reviewer of the QA section of the SARP and the personnel responsible for review of other packaging aspects should jointly evaluate the classification of each item in the packaging. The reviewer should continually interface with other review personnel during the entire period of the review. In order to implement an effective review of the QA section, a great deal of communication must exist between neview team members. The classificution of each item by the applicant should not have a lesser classification than that of the review team. However, the review team should consider the classification acceptable if the applicant has designated a higher classification of an item than the review team has determined.

An engineering evaluation of the potential for failure of each item and its effect on the safety of the package should be included in the SARP. A representative guideline, Figure 11-1, illustrates one approach to a logical determination of QA categories for the graded approach to QA planning.

\subsubsection{Quality Acourance Categorieo}

The reviewer should verify that quality categories are based on the relative safety significance of each item on the Q-List. The reviewer should determine that categories are established as follows:

Category A-Items that are critical to safety operation. Category A items could be structures, components, and systems whose failure or malfunction could result directly in a condition adversely affecting the public health and safety. 
Category B-Items that have a major impact on safety. Category B items could be structures, components, and systems whose failure or malfunction could indirectly result in a condition adversely affecting public health and safety. An unsafe condition involving category B type items could only occur if a primary failure occurs in conjunction with another failure.

Category C-Items that have a minor impact on safety. Category $C$ items could be components, structures, and systems whose failure would not significantly reduce packaging functional requirements and would not create a condition which would adversely affect public health and safety.

\subsubsection{Control Activities}

The reviever should focus on those control activities which deal directly with the package. Design, fabrication, assembly, testing, operation, mainteuance, and repair of packaging must be controlled and documented by written procedures and instructions. Furthermore, ang modification, maintenance, or repair to the packaging that affects important-to-safety items should have the same level of QA effort as prescribed for the original items. The same level of technical and QA requirements should be specified in the following activities as was specified for the packaging in its initial fabrication: procurement, fabrication, assembly, inspection, and testing. For example, the QA section of the SARP should require that any spare part replacements that are important to safety receive the same level of technical and $Q A$ requirement evaluations as the original items.

\subsection{Evential QA Fiementa}

All of the 18 QA elements of 10 CFR 71 Subpart $H$ must be considered applicable to each item on the Q-List. Using the graded approach based on importance to safety, the appropriate Level of Effort can be determined from Table 11.1. The QA section of the SARP should describe the logic used in the determination of QA categories.

Conservative design and low risk assumptions will usually result in Category B or C Quality Assurance designation. Categories $\mathbf{B}$ and $\mathbf{C}$ are desirable and require lower levels of effort. 


\subsubsection{Documentation}

The SARP should reflect that a documented QA program has been fully implemented by written procedures and is contained in QA/QC manuals. A master index of procedures, instruction, and directives related to activities important to safety should be established. The current status of QA program activities should be indicated as operational or planned.

\subsection{Personnel Qualifications}

Measures should be provided for ensuring that personnel performing special activities are qualified for their assigned responsibilities. The required qualification must be accomplished prior to starting an activity. On-the-job training will not be acceptable unless it is done under direct supervision by qualified instructors.

Qualification and documertation of personnei performing special activities should be accomplished and certified, based on guidelines established by ASME, ASNT, ANSI, or another recognized authority. Provisions for and records of retraining, refresher courses, and recertification shall be planned and documented.

\subsubsection{Appropriate Eniort}

The reviewer should verify that the QA section of the SARP addresses the 18 QA elements that are identified in Subpart $H$ of 10 CFR Part 71. NRC Regulatory Guide 7.10 provides an excellent guide for reviewing the QA section of the SARP using the graded approach to QA.

If the applicant has employed a national standard other than ANSI/ASME NQA-1 as his basic QA standard to address the 18 elements, the reviewer must ensure that the QA section of the SARP is in compliance with Subpart $H$ of 10 CFR Part 71. The reviewer should determine the level of QA effort for the important-to-safety items (Q-Liat), and then compare the level of QA effort applied by the applicant to the level of QA effort for important-to-safety items deemed necessary by the reviewer. The reviewer should consider an alternative method of review when sufficient information is not provided for the reviewer to determine acceptability of the $Q A$ requirements. In this manner, the reviewer can determine if an appropriate level of QA effort has been properly applied to the packaging. Consequently, acceptance of the QA section of the SARP as meeting federal regulations is based on both the QA section in the SARP and the implementing procedures that are presented. 


\section{A PAOCHDURES}

\subsubsection{Management Organization}

Verify that the first three elements in Table 11.1 are implemented. Firm evidence must be presented in the SARP that competent authority provides leadership and execution of QA throughout the organization.

\subsubsection{Quality Acurance Program}

Ensure that the QA requirements of the SARP contain sufficient controls to assure the safety requirements of (1) containment, (2) suber ticality, and (3) radiation shielding under the required conditions of 10 CFR 71.

Establishment of the Q-List and QA Categories as described in Section 11.3.3 and 11.3.4 will ensure that a logical engineering analysis has been accomplished for every item in the package. Pay special gttention to those activities described in Section 11.3.5, which focus on safety of the package.

The review should include all 18 elements of QA. The graded approach presented in Regulatory Guide 7.10 should be used in the SARP to cor serve resources and reduce unnecessary paperwork and duplications of effort.

\subsubsection{Quid Preparation}

Technical design and performance test requirements reviewed under Sections 3.0-10.0 of this guide provide a basis for ensuring the safety of the package. Verify that compliance with the Acceptance Criteria given is assured and documented by the QA section of the SARP.

Verify that each component, structure, and system used to form the package has been analyzed for its importance to safety. The engineering analysis for deciding to accept or reject the item for the Q-List will be reviewed by the technical reviewers of the appropriate section above. Clasification must be mutual between license applicant and reviewer in order for the appropriate level of QA to be included in the SARP and reviewed for QA compliance. 


\section{A.4 Quality Asourance Categorie:}

Review the methods used to establish QA categories: Ensure that the technical reviewer of the appropriate SARP gection concurs with the category chosen for inclusion in the QA section.

\subsection{Control Activitica}

Review the minimum set of activities to be controlled and managed for their importance to safety and inclusion in the SARP QA section. The minimum acceptance Citeria must conform with Section 11.3.5 above.

\subsubsection{Ementipl QA Elements}

Verify that all 18 elements of 10 CFR 71, Subpart $H$, have been included for each item on the Q-List. Coosider the adequacy of the SARP QA plan to cover all important to safety activities included in Section 11.2.6 above.

\subsubsection{Documentation}

Verify that each of the policies, procedures, instructions and controlled documents included in the QA program reflects the current status of each package. Authority and responsibility for these documents must be clearly understood by operations personuel as well as by top management. As a minimum, control should be exercised over the following:

1. Design documents (e.g., drawings, specification, codes).

2. Procurement documents.

3. QA and QC manuals.

4. Operating, maintenance, and modification procedures.

5. Inspection and test procedures.

6. Nonconformance reports.

7. Change requests and orders.

8. Corrective action reports.

Verify that measures have been established to ensure that all changes and modifications are reviewed and approved by the same organization that did the original work. The same QA ccntrols should be applied to all change orders and modifications to written documents and operations procedures. 


\subsection{Perwonnel Qualifications}

Verify that management plans are in place to assure qualified, trained personnel. Pay attention to special activities, such as welding and NDE inspection.

\subsection{Appropriate Fllort}

Verify that the whole life cycle of the packaging is controlled and documented in the QA Plan. Those activities to be reviewed include design, fabrication, assembly, testing, operation, maintenance, and repair.

The entire life cycle of packaging implies that packages or components will be reused. Verify that the QA section of the SARP includes measures for continuing inspection programs to ensure and document the continuing ability of the package to meet origingl specifications and performance requirements.

Ensure that specific items to be inspected or replaced and the frequency are planned and controlled. Rejected items must be isolated from reusable parts.

\subsection{Finding}

The reviewer verifies that sufficient and adequate information has been provided in the SARP for the packaging to satisfy the applicable DOE Orders and federal regulations and that the evaluation supports the following conclusion:

"The QA section of the applicant's SARP has been reviewed to determine that requirements have been selected and implemented in a manner that ensures compliance with DOE Orders 1540.2, Chapter II; 5480.3; and 5700.6B; and Subpart H of 10 CFR Part 71. Basis for acceptance in the review has been conformance with established guidelines and criteria. The evaluation of the QA requirements provides reasonable assurance that the package will be able to transport radioactive material safely." 


\subsection{References}

1. U.S. Department of Energy, DOE 1540.2: Harardous Material Packagine for Transport-Administrative Procedures, U.S. Department of Energy, Washington, DC, September 30, 1986.

2. U.S. Department of Energy, DOE 5480.3: Safetz Requirements for the Packaging and Transportation of Hazardous Materials, Hazardous Substance, and_Hazardoug Wasteg, U.S. Jepartment of Inergy, Washington, DC, July 9, 1985.

3. U.S. Department of Energy, DOE 5700.6B: Quality Assurance, U.S. Department of Energy, Washington, DC, September 23, 1986.

4. Office of the Federal Register, Title 10, Code of Federal Regulations. Part 71, Office of the Federal Register, Washington, DC, 1984.

5. U.S. Nuclear Regulatory Commiseion, Regulatory Guide 7.10: Establishing Quality Assurance Proxrams or Packaging Used in the Transport of Radionctive Material, U.S. Nuclear Regulatory Commission, Office of Standards, Development, Washington, DC, June 1986, Rev. 1.

6. Office of the Federal Register, Title 49, Code of Federal Rerulations, Part 173, Office of the Federal Register, Washington, DC, 1985.

7. The American Society of Mechanical Engineers, ANSUASME_NQA-1-1986 Edition: Quality Assurance Program Requirements for Nuclear Facilities, the American Society of Mechanical Engineens, United Engineering Center, 345 East 47th Street, New York, NY. 
Table 11.1

Level of QA Effort

Q-List Items

OA Element/Level of Effort

Cat. A

Cat. B

Cat. C

1. Approved QA Program

$\mathbf{X}$

$\mathbf{X}$

$X$

2. QA Organization

Responsibilities written.

Reporting levels clear.

Authority written.

$\begin{array}{lll}\mathbf{X} & \mathbf{X} & \mathbf{X} \\ \mathbf{X} & \mathbf{X} & \mathbf{X} \\ \mathbf{X} & \mathbf{X} & \mathbf{X}\end{array}$

3. QA Program

Procedures written.

Activities controlled

$\begin{array}{lll}\mathbf{X} & \mathbf{X} & \mathbf{X} \\ \mathbf{X} & \mathbf{X} & \mathbf{X}\end{array}$

4. Design

Most stringent codes.

$\mathbf{X}$

Prototype test required.

Formal review required.

$\mathrm{x}$

$\mathrm{X}$

Analysis (in lieu of test).

$\mathbf{X}$

Internal peer review.

$\mathbf{X}$

"Off-the-shelf" item."

$\mathbf{X}$

5. Procurement Document Control

Complete traceability.

X

Qualified vendor lists.

$\mathbf{x}$

Non-qualified vendors.

Traceability not required.

$\mathbf{X}$

$\mathbf{X}$

"Off-the-shelf" item."

6. Instructions, Procedures and Drawings

Must be written and documented.

$\mathbf{X}$

Qualitative or quantitative acceptance criteria.

$\mathbf{X}$

Routine procedures are acceptable.

$\mathrm{X}$

$\mathrm{X}$

*Items purchased from a catalog or "off the shelf" which, when received, are identified and visually checked for damage. 
7. Document Control

Issue must be controlled.

$\mathbf{X}$

Changes must be controlled.

$\mathbf{x}$

Only on safety items.

$\mathbf{X}$

Minor changes acceptable without

$\mathbf{X}$ formal trace.

Procurement documents only.

8. Control of Purchased Material, Equipment, and Services

Source evaluation and selection plans. $\quad \mathbf{X}$

Evidence of QA at contractor. $\quad X$

Inspections at contractors.

$\mathbf{x}$

Formal receiving inspection.

$\mathbf{X}$

Objective proof that all specifications $X$

$\mathbf{X}$

$\mathbf{X}$ are met.

Audits or surveillance at vendors plants. $\mathbf{X}$

Incoming inspection for damage only.

9. Identification and Control of Materials, Parts, and Components

Positive identification and traceability of each item.

$\mathbf{X}$

Identification and traceable to heats, lots, or other groupings.

$\mathbf{X}$

Identification to end use drawings, etc.

10. Control of Special Processes

All welding, heat treating, and
nondestructive testing done by
qualified personnel.

$\mathbf{x}$

Qualification records and training

$\mathbf{X}$ of personnel.

Only specified critical operations by qualified personnel.

$\mathbf{X}$

No special processes.

$\mathbf{X}$ 
11. Internal Inspection

Documented inspection of all $X$ specifications required.

Examination, measurement, or test of material or processed product to

assure quality.

Process monitoring if quality requires it.

Inspectors must be independent of those $X$ performing operations.

Qualified inspectors only.

$$
\mathbf{X}
$$

Visual receiving inspection only.
$\mathrm{X}$

$\mathbf{X}$

$\mathbf{X}$

$\mathrm{X}$

$X$

$\mathrm{X}$

12. Test Control

Written test program.

Written test procedures for all requirements in the package approval.

Documentation of all testing and evaluation.

Representative of buyer observes all supplier acceptance tests. $\mathbf{x}$

X

$X$

$\mathbf{X}$

No physical test needed.

13. Control of Measuring and Test Equipment

Tools, gauges, and instruments must be $\mathbf{X}$ in a formal calibration program.

Onily qualified inspectors.

$\mathbf{X}$

$\mathbf{X}$

No test required.

$\mathrm{X}$

14. Handling, Storage, and Shipping Control

Written plans and procedures required.

$\mathbf{X}$

$\mathbf{X}$

Routine handling.

$\mathbf{X}$

15. Inspection, Test, and Operating Status

Individual items identified as to status or condition.

Stamps, tags, labels, etc., must clearly show status.

$X$

$\mathbf{x}$

$\mathbf{X}$

$\mathrm{X}$

Visual Examination only. 
16. Nonconforming Materials, Parts, or Components

Written program to prevent $\mathbf{X} \mathbf{x}$ inadvertent use.

Nonconformance must be documented

$\mathbf{X}$

$\mathbf{X}$ and closed.

Disposal without records.

$\mathbf{X}$

17. Corrective Action

Written plar to correct all conditions adverse to quality.

X $\mathbf{X}$

No written documents.

18. Quality Assurance Records

Design and use records.

Results of reviews, inspections,

$\begin{array}{ll}\mathbf{X} & \mathbf{X} \\ \mathbf{X} & \mathbf{x}\end{array}$

test, audits, surveillance, and

$\mathbf{X}$ materials analysis.

Personnel Qualifications.

Records of fabrication retained

$\mathbf{X} \mathbf{X}$

throughout life of package.

$\mathbf{x} \quad \mathbf{X}$

Records of package use kept for 2 years after shipment.

$\mathbf{x} \quad \mathbf{x}$

All reconds managed by a written plan for retention and disposal.

$\mathbf{X}$

$\mathbf{X}$

Procurement records only.

19. Audits

Writen plan of periodic audits.

X

$\mathbf{X}$

$\mathbf{X}$

All certified auditors.

$\mathbf{x}$

Lead auditor certified.

$\mathbf{X}$

$\mathbf{X}$ 


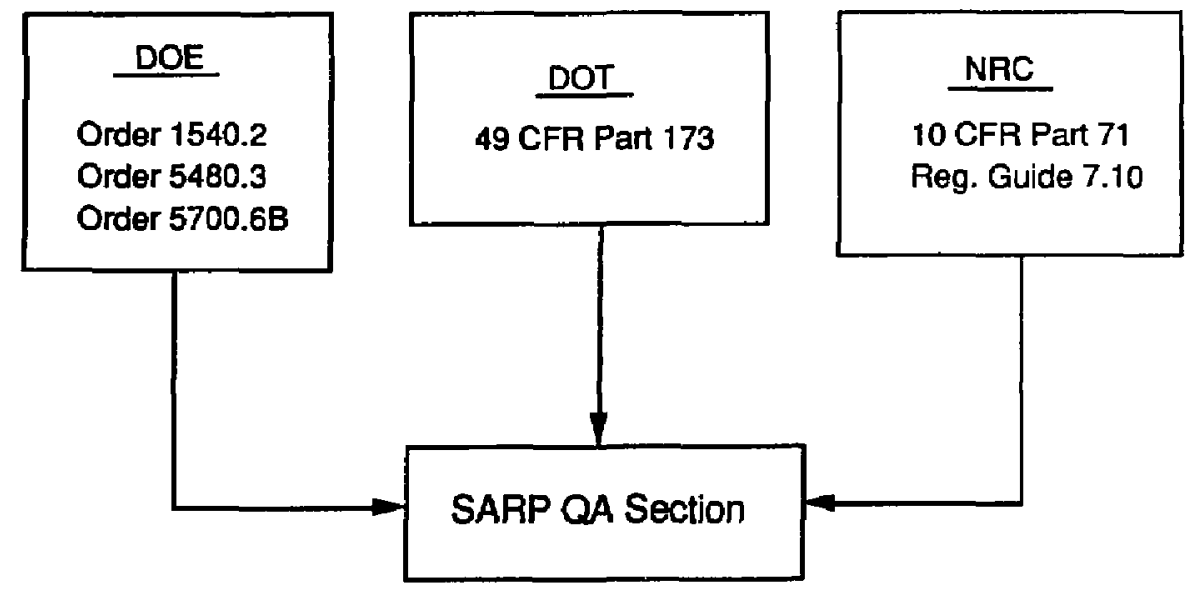

Figure 11-1 Regulatory documents with QA provisions. 


\section{Single component failure} causes consequence. No redundant system or automatic backup.

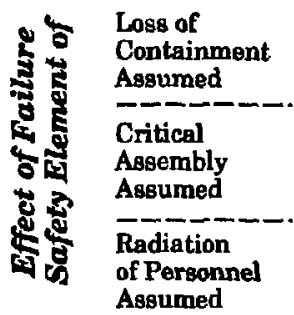

Lass of Containment Pransible

\section{Criticality} is Plausible

calit

Impossible

\section{Radiation of Personnel \\ Assumed}

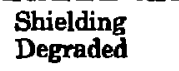

Two independent item

failures required to produce consequences. Redundancy provided.

Two independent detectable failures must occur simultaneously to produce consequences. Very conservative and proven design.

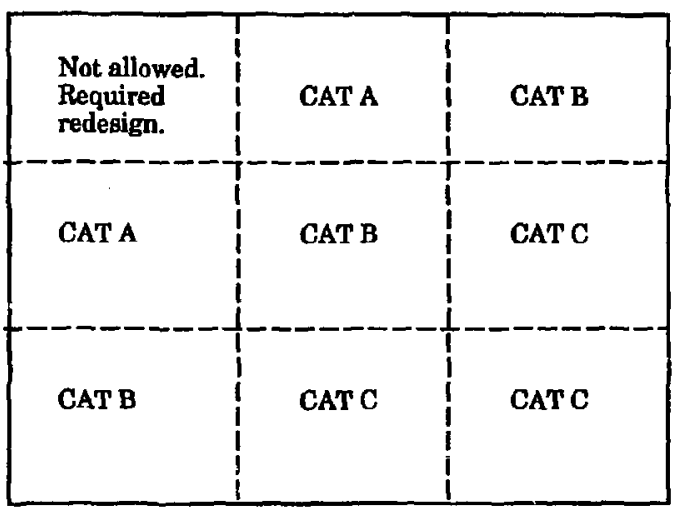




\section{APPENDIX A}

\section{Review of Special Form Radionctive Material}

\section{A.1.0 GENERAL}

The objective of this review is to confirm that radioactive material designated as special form for transport in a packaging complies with DOE 5480.3, 10 CFR 71,2 and 49 CFR 173.3 Per 49 CFR 173.476, each shipper of special form radioactive materials must have on file prior to shipment, a safety analysis report that demonstrates that the special form meets the requirements of 49 CFR 173.469. This report must be provided to the Research and Special Programs Administration in the Department of Transportation upon request. In addition, for DOE shipments per DOE $1540.2,4$ copies of all records for special form materials or encapsulations must be made available to the certifying official for review when requested. This Appendix is based on research performed at LLNL5 and provides guidance for reviewing records or safety analysis reports for radioactive materials designated as special form.

\section{A.1.1 Scope and Approach}

This review covers all types of special form radioactive materials. A special form radioactive material can be either a qualified solid material, such as irradiated hardware, or a qualified sealed capsule containing a radioactive material, such as an encapsulated radioactive source. General guidance is given for reviewing a candidate radioactive material for compliance with the regulations for designation as a special form radioactive material. General guidance is also given for evaluating special form radioactive material to determine that the material meets regulations throughout its useful life cycle from fabrication to final disposal.

A special form radioactive material is inert, insoluble, and indispersible so that even in an accident, radioactive material will not escape into the environment to adversely impact public health and safety. Special form radioactive materials have many uses, which include:

- Provide radiation sources for:

- calibration of radiation diagnostic equipment

- non-destructive tests of materials

- treatment of tumors (oncology). 
- Increase the quantity of a radioactive material that can be shipped in a Type A package.

- Provide part of the containment in Type B packages.

A qualified special form radioactive material will contain its radioactivity in normal or accident conditions. Thus, the containment issues are similar to those of the packaging of Type B radioactive materials for shipment. The review in this Appendix concentrates on evaluating the containment of radioactive material for special form characteristics especially when the materinl is subjected to the special form test conditions.

\section{A.1.2 Special Issues}

A special form radioactive material presents unique material and fabrication problems. If it is a simple, solid piece, the material will experience radiation damage in production, which will change its mechanical properties. In addition, because of the material's activity fabrication on or with the material must often be done remotely in a hot cell.

Radioactive materials are usually produced by bombarding a material composed of stable nuclei with neutrons (usually from a fission source) or with energetic ions. A radioactive material may have a chemical composition identical to an unirradiated material, but because of the radiation damage to the material during production, the rarioactive material may have substantially different mechanical properties than the unirradiated material. Since the mechanical properties of an irradiated material as a function of radiation does (or damage) are usually unknown, it is prudent to encapsulate a radioactive material with a well-characterized material to create a special form radioactive material.

Unencapoulated irradiated material may qualify as a special form radioactive material for shipment in Type B containers. To qualify as such, irradiated materials must demonstrably meet the special form test conditions because unirradiated material can have substantially different physical properties. Also, corrosion products or crude may be part of the irradiated material and must be evaluated in the testing. 
A special form radioactive material must withstand specified accident conditions without dispersing radionuclides into the environment. Since an accident can occur prior to or after long-term storage, the material's mechanical properties after a long exposure to the synergistic effects of the storage environment and ionizing radiation from the radioactive material, as well as in the "as-received" conditions, must be known .

\section{A.1,2,1 Fabrication}

Encapsulation of radioactive material to produce special form radioactive material may require special processes due to the activity of the muterial. Machining of a candidate special form radioactive material that emits short-ranged particles, such as alpha particles, is often performed in glove boxes to prevent the ingestion of radioactive particulates. For health and safety considerations, all machining, forming, joining, and inspecting processes on intense sources of penetrating radiation may be required to be performed remotely using master-slave manipulation.

Remote handling processes increase the risk of damage to a special form radioactive material. Remote fabrication processes increase the potential for the production of defective parts. Remote inspection processes increase the potential for failure to detect defective parts. Thus, the manufacturer of a special form radioactive material must be subjected to a comprehensive quality assurance program including, but not limited, to fabrication, handling, and inspection processes.

\section{A.122 Radioactive Decay}

Decay of the radionuclides in special form radioactive material will produce photons (x-rays and gamma rays) and particles (alphas, betas, and neutrons) that may damage the special form radioactive material.

The photons and beta particles will cause little damage to the special form radioactive material. However, they will increase the temperature of the material by exciting electrons, which lose energy to the collection of atoms that compose the material.

The alpha particles and neutrons may damage the special form radioactive material by producing Frenkel defects in the material. These Frenkel defects may cause an increase in the tensile strength of the material, but a decrease in the ductility of the material. The Frenkel defects will also cause an increase in the brittle-to-ductile transition temperature. 
Helium produced by the decay of alpha emitting radioisotopes or by the capture of neutrons by $(n, \alpha)$ reactions may also damage the special form radioactive material. The helium production in special form radioactive material may cause swelling and embrittlement of, and internal stresses in the material. In addition, neutron capture in the special form radiosctive material may cause the formation of new radionuclides in the material.

The production and decay of radionuclides in the special form radioactive material will result in a change in the chemical composition of the material. This change in the material chemical composition can cause a change of the physical and mechanical properties of the material, as a function of time. For example, ${ }^{137} \mathrm{CsCl}$ is frequently encapsulated and qualified as a special form radioactive material to be used as a gamma radiation source. The ${ }^{137} \mathrm{Cs}$, with a balf-life of 30 years, undergoes radioactive decay to ${ }^{137} \mathrm{Ba}$. Because of the radioactive decay of the ${ }^{137} \mathrm{Cs}$, the composition of the source will change as a function of time. The quantity of $\mathrm{CsCl}$ will decrease, while the quantity of $\mathrm{BaCl}_{2}$ will increase. As the source composition changes, the physical properties of the source material will change. For example, the melting point will decrease with a decrease in the percentage of $\mathrm{CsCl}$ of the source contents until a eutectic composition of the $\mathrm{Cs}, \mathrm{Ba}$, and $\mathrm{Cl}$ atoms is achieved. This change in the melting point can be substantial.

\section{A12.3 Storage}

Special form radioactive material may chemically and/or electro-chemically react with the storage environment and/or its radioactive contents. These reactions, over a period of time, may change the composition of the containment portion of the special form radioactive material, with resultant changes in the mechanical and physical properties of the material. Chemical processes include the formation of stable compounds and the selective leaching of constituent alloying materials from the special form radioactive material. Electro-chemical processes include the interaction of different materials, or different regions of the same material, coupled by an electrically conducting environment, causing pitting on the surface of a material. Examples of the types of corrosion include, but are not limited to, intergranular corrosion, such as the attack by liquid metals on austenitic stainless steels; stress corrosion; and hydrogen embrittlement. Corrosion often decreases a material's strength and ductility, as well as lifetime. Corrosion rates are not only a function of the materials and the environment, but also a function of the thermodynamic state system, such as the temperature, stress level, and heat treatment of the component materials. 
For example, ${ }^{137} \mathrm{CsCl}$ is frequently encapsulated in a stainless steel and qualified as special form radioactive material. When properly stored at room temperature, the corrasion rate of the $\mathrm{CsCl}$ contents on the stainless steel may be negligibly small. However, if the special form radioactive material is transported or operated so that the temperature increases several hundred degrees, the corrosion rate increases significantly, and in the extreme, may disqualify the special form radioactive material in a short period of time compared to storage at room temperature.

\section{A.1.3 Format}

A standard format has not been established for Safety Analysis Fieports for demonstrating that special form radioactive maverial meets regulatory requirements. Consequently, this review Appendix is formatted similarly to the main sections of this sview guide and covers those review areas necessary to verify compliance with reguintions. Safety Analysis Reports on special rorm radioactive material may not follow the format used here, but the information indicated should le provided to permit the verification of compliance.

During transport, special form radioactive materials are usually shielded by a Type B packaging. Also, each piece of specis' form radirstive material will be subcritical. Therefore, safety reviews for radiation shielding and nuclear subcriticality are not covered in this appendix and should be performed when evaluating the Type B packaging that is used to transport the designated specifl form radioactive material. The Quality Assurance Plan for special form radioactive material is reviewed by following the guidance in Section $\mathbf{1 1 . 0}$ of this review guide.

\section{A.2.0 REVIEW OF GENERAL INFORMATION}

\section{A.2.1 General}

The objective of this section of the review is to ensure that the applicant has included the general information required by 49 CFR $173.476(\mathrm{~b})$, for obtaining a Component Authority Certificate for exporting special form radioactive material from the United States. Additional information as required for packaging in 10 CFR 71, Subpart D, should be provided if the special form material is to be given credit towards the confainment requirements of $s:$ Type $B$ package. 


\section{A.2.2 Areas of Review}

The following areas are reviewed for general information on the special form radioactive material.

\section{A22.1 Une of Special Form Radicective Material}

The use of the special form radioactive material and identification number should be reviewed.

\section{A 222 Deacriftion of Special Form Radioactive Material}

A detailed description of the special form radioactive material, including drawings, should be reviewed.

\section{A223 Componition of Special Form Radioactive Material}

The composition of the special form radioactive material, including radioisotopes, should be reviewed.

\section{A2.4 Evahuation of Special Form Radioactive Materials}

Summaries of the special form evaluations should be reviewed for compliance with regulations.

\section{A.2.5 Quality Assurance}

The quality assurance requirements for the special form radioactive material should be reviewed.

\section{A226 Supplemental Information}

Supplemental information that may include drawings should be reviewed.

\section{A23 Acceptance Criteria}

\section{A23.1 Use of Special Form Radicactive Material}

The use for which the special form radioactive material was created must be presented. The environment for which the special form design use is allowed and/or prohibited must be presented. 


\section{A232 Description of Special Form Radioactive Material}

Per 49 CFR 173.476(b), and the relevant parts of 10 CFR 71.33, the description of the special form radioactive material must include:

1. Detailed statement of its design and dimensions, including complete engineering drawings.

2. Classification as Type $B$ or fissile material, with the appropriate category.

3. Gross weight.

4. Batch and serial identification number.

5. Specific material of construction, weight, dimensions, and general fabrication methods.

6. Surface dose rates, type, and spectrum of radiation.

\section{A.23.3 Composition of Special Form Radioective Material}

Per 49 CFR 173.476(b) and the relevant parts of 10 CFR 71.33, the description of the radioactive portion of the special form radioactive material must include:

1. Id entification and maximum activity of the radioisotopes.

2. Identification and maximum quantities of fissile isotopes.

3. Identification and concentration of the remaining chemical elements that make up the special form material.

4. Chemical and physical form.

5. Maximum weight.

6. Maximum amount of decay heat and percentage that is deposited within the special form material.

\section{A2.3.4 Evahuation of Special Form Radioactive Material}

Per 49 CFR 173.476(b), a statement must be made that the tests of 10 CFR 71.77 have been performed and that their results meet the requirements of $10 \mathrm{CFR} 71.75$. 
In addition, per 10 CFR 71.4, the candidate special form radioactive material must:

1. be a single solid piece, or contained in a sealed capsule that can be only opened by destroying the capsule; and

2. the piece or capsule must have at least one dimension not less than 5 millimeter (0.197 inch).

Evaluations made to demonstrate material compatibility, structural adequacy, radiation damage, containment, thermal behavior, and criticality must be summarized in sufficient detail to enable the reviewer to determine if the candidate special form radioactive material complies with regulations.

\section{A.2.5 Quality Asourance}

Per DOE Orders and $10 \mathrm{CFR}$ 71.37, the following quality assurance requirements must be met.

1. The applicant has provided a quality assurance program that conforms to the requirements of DOE Order 5700.6B5 6 and Subpart $H$ of 10 CFR 71.

2. The applicant identifies established codes and standards used in special form radioactive material design, fabrication, assembly, testing, maintenance, and use. In the absence of any codes or standards, the applicant must describe the basis and rationale used to formulate the package quality assurance program. When established codes and standards are not available, detailed guidance with respect to assessing compliance is provided in the main sections of this review guide dealing in specialized areas.

\section{A.2.3.6 Supplemental Information}

Supplemental information that supports this general information section, such as drawings and radionuclide listings, must be submitted. 


\section{A.4 Procedures}

\section{A.2.4.1 Use of Special Form Radioactive Material}

Verify that the following items are presented:

- the use for which the special form material was created,

- the environment for which the design use is allowed,

- the environment for which the design use is prohibited, if any, and

- the date on which the material must be requalified.

\section{A2.42 Description of the Special Form Aladioactive Material}

Verify that the description of the special form radioactive material is complete as follows.

\section{A.2.4.2.1 General}

Verify that the description of the special form radioactive material includes the external dimensions, gross weight, classification and category, and general fabrication methods with the weights and dimengion of each of the specific materials of construction. Verify that each piece of a batch of a special form radioactive material can be identified by the batch and serial number. Verify that the surface dose rate, type, and spectrum are appropriate to the composition of the radionuclides present in the material.

\section{A.2.4.2.2 Drawings}

Verify that drawings are included in the description of the special form radioactive material. Verify that all dimensions on the drawings are consistent and complete. Verify that material lists, fabrication techniques, and nondestructive examinations are pregented on the drawings.

\section{A.2.3 Composition of Special Form Radioactive Material}

Verify that the applicant has identified and given the maximum activity of the radioisotopes, including any fiesile isotopes. Verify that all the chemical elements that make up the special form radioactive material are identified and that their concentration is presented. Verify that the chemical form, physical form, and weight are presented. Verify that the maximum amount of decay heat for the special form radiaactive material is given, and confirm its value. 


\section{A2.4.4 Evaluation of Special Form Radioactive Material}

Verify that the summaries of the evaluations are correctly taken from the various sections of the SAR. Evaluate the summary results to determine if the special form radioactive material complies with regulations.

\section{A.2.4.5 Quality Agsura .}

Verify that appro ..... quality assurance requirements are applied during the design, manufacture, shipwent, and use of the special form radioactive material.

\section{A2A6 Supplemental Information}

Verify that all supplemental information, such as drawings and radionuclide listings, are consistent with the description of the special form radioactive material.

\section{A.3.0 REVIEW OF MATERIAL AND FABRICATION SPECIFICATIONS}

\section{A.3.1 General}

The review of material and fabrication specifications for special form radioactive material follows the applicable portions of Section $\mathbf{3 . 0}$ of this review guide. The review should specifically address the special issues identified in Subsection A.1.2 of this appendix for reviewing special form materials.

\section{A.3.2 Areas of Review}

The areas of review follow Subsection 3.2 of this review guide. The review should specifically include evaluations of the potential effects of remote fabrication, transportation, use, storage, and radioactive decay on the special form radioactive material.

\section{A.3.3 Acceptance Criteria}

The acceptance criteria are those provided in Subsection 3.3 of this review guide, specifically those relating to containment components. 


\section{A.3.4 Procedures}

The review procedures follow those in Subsection 3.4 of this review guide. Verify that the special issues in Subsection A.1.2 of this appendix have been adequately evaluated for qualifying the special form radioactive material.

\section{A.4.0 REVIEW OF STRUCTURAL EVALUATION}

\section{A.4.1 General}

A candidate special form radioactive material must pass several structural tests before qualifying as a special form radioactive material. These tests include an impact test, a percussion test, and for certain geometric configurations of a candidate material, a bending test. These structural tests will cause stress on the candidate material in addition to the existing stresses caused by, for example, thermal gradients in the material. The general approach and methods used in Section 4.0 of this review guide can be used in performing the review. The review should specifically address the special issues identified in Subsection A.1.2 of this appendix for reviewing special form radioactive materials.

\section{A.4.2 Areas of Review}

The areas of review required to evaluate structural adequacy for providing containment of radioactive material are described below. Information from the General Information Materials and Thermal Sections of the Safety Analygis Report is required to perform the review. Reviewers responsible for these other sections should assist in verifying that the information required for the structural review is adequate.

\section{A.4.2.1 Structural Design}

The significant structural design features of the special form radioactive material are identified and reviewed for their adequacy to provide their intended containment function. Structural design (both analysis and test) criteria are reviewed.

\section{A.4.2.2 Weights and Centers of Gravity}

The special form radioactive material weights and centers of gravity are reviewed for each major part or subassembly. 


\section{A4.23 Material Properties}

The physical and structural properties of the materials used in the special form radioactive materials are reviewed for completeness and adequacy for the special form application and the related structural evaluation. This review is coordinated with the materials review given in Section A.3.0 of this appendix.

\section{A42,4 Special Form Structural Tests}

The structural evaluation of the special form is reviewed to determine if the standards in 10 CFR 71.75 and 10 CFR 71.77 are met. This review is primarily concerned with the structural evaluation but is coordinated with the materials, thermal, containment, operations, and acceptance/maintenance testing. This reviey must cover the special form radioactive material throughout its life cycle.

\section{A4.2.5 Appendix}

Supplemental information, which may include test data and analytical procedures, is reviewed.

\section{A.43 Acceptance Criteria}

The special form radioactive material must meet the standards in 10 CFR 71.75 and 71.77 throughout its life cycle. The applicable testing and analysis techniques used in Section 4.0 of this review guide provide acceptable methods and approaches for the evaluations. A statistical sampling plan for the tests of 10 CFR 71.77 must be presented and justified. When properly justified, analysis may be used to reduce sample size.

\section{A.4A Procechures}

The review areas in Subsection $\mathbf{A . 4 . 2}$ are reviewed for completeness and compliance with the acceptance criteria in A.4.3. The applicable review procedures in Section 4.0 of this review guide provide guidance in several areas. Verify that the special issues in Subsection A.1.2 of this appendix have been adequately evaluated for qualifying the special form radioactive material throughout its life cycle. 


\section{A.5.0 REVIEW OF THERMAL FVALUATION}

\section{A.5.1 General}

A candidate special form radioactive material must pass a heat test before qualifying as a special form radioactive material. The thermal load from the heat test will be added to the thermal load from the absorption of the energy released by the decay of the radionuclides in the candidate material. The general approach and methods used in Section 5.0 of this review guide can be used in performing the review. The review should specifically address the special issues identified in Subsection A.1.2 of this appendix for reviewing special form radioactive materials.

\section{A.5.2 Areas of Review}

The areas of review required to evaluate the thermal response of the special form radioactive material to specified thermal loads are described below. Information from the General Information Materials and Structural Sections of the Safety Analysis Report is required to perform the review. Reviewers responsible for these other sections should assist in verifying that the information required for the thermal review is adequate.

\section{A.5.2.1 Thermal Design}

The significant thermal design features of the special form radioactive material are identified and reviewed for their adequacy to provide their intended containment function. Thermal design (both analysis and test) criteria are reviewed.

\section{A.5.2.2 Material Propertice}

The physical and thermal properties of the materials used in the special form radioactive materials are reviewed for completeness and adequacy for the special form application and the related thermal evaluation. This review is coordinated with the materials review given in Section A.3.0 of this appendix. 


\section{A5.23 Special Form Thermal Tests}

The thermal evaluation of the special form is reviewed to determine if the standards in 10 CFR 71.75 and 10 CFR 71.77 are met. This review is primarily concerned with the thermal evaluation but is coordinated with the materials, structural, containment, operations, and acceptance/maintenance testing. This review must cover the special form radioactive material throughout its life cycle.

\section{A.5.2.4 Appendix}

Supplemental information, which may include test data and analytical procedures, is reviewed.

\section{A5.3 Acceptance Criteria}

The special form radioactive material must meet the standards in $10 \mathrm{CFR} 71.75$ and 71.77 throughout its life cycle. The applicable testing and analysis techniques used in Section $\mathbf{5 . 0}$ of this review guide provide acceptable methods and approaches for the evaluations. A statistical sampling plan for the tests of 10 CFR 71.77 must be presented and justified. When properly justified, analysis may be used to reduce sample size.

\section{A.5.4 Procedures}

The review areas in Subsection A.5.2 are reviewed for completeness and compliance with the acceptance criteria in A.5.3. The applicable review procedures in Section 5.0 of this review guide provide guidance in several areas. Verify that the special issues in Subsection A.1.2 of this appendix have been adequately evaluated for qualifying the special form radioactive material throughout its life cycle.

\section{A.6.0 REVIEW OF CONTAINMENT EVALUATION}

\section{A.6.1 General}

Qualified special form radioactive material will contain its radioactivity under all transport conditions. Thus, the containment issues are similar to those of the pacliaging of Type B radioactive materials for shipment, particularly when the special form radioactive material consists of a radioactive material encapsulated by an unirradiated material. The containment requirements must be met throughout the useful life of the 
special form radioactive material from its fabrication to its final disposal. The special issues in Subsection A.1.2 must be addressed when the containment evaluation of special form radioactive material is being reviewed.

\section{A.6.2 Areas of Review}

The areas required to review the containment evaluation for special form raujioactive materials are described below. Information from the General Information, Materials, Structural, and Thermal Sections of the Safety Analysis Report is required to perform the review. Reviewers for these other sections should assist in verifying that the information for the containment evaluation review is adequate.

\section{A.6.2.1 Containment Design}

The containment design features, boundaries, and evaluations are reviewed for the special form radioactive material.

\section{A6.2.2 Leakage Test}

The leakage tests of the special form radioactive material are reviewed.

\section{A.6.2.3 Immersion Test}

The immersion and leach tests of the special form radioactive material are reviewed.

\section{A.6.2.4 Appendices}

Supplemental information, which includes test data and analytical procedures, is reviewed.

\section{A.6.3 Acceptance Criteria}

The acceptance criteria for each area of review are given below.

\section{A.6.3.1 Containment Design}

The containment boundary must be clearly identified, especially all welds and areas where leakage might uccur under extreme conditions. 


\section{A.6.3.2 Lealcage Test}

Following each structural and heat test performed in accordance with 10 CFR 71.77, the special form radioactive material sample must be leakage tested in accordance with 10 CFR 71.75. The tests must demonstrate that the material will function as special form radioactive material during transport, under all conditions. A different sample can be used for each structural and heat test. The test procedures must be described, standards must be identified, and implementation of the tests must be assured. As a minimum, leakage testing per ANSI N14.5 ${ }^{7}$ must be performed. Testing procedures present in ISO/TR4826-1979(E) ${ }^{8}$ may also be used, but must be performed in accordance with ANSI N14.5 test requirements and $10 \mathrm{CFR} 71.75$.

\section{A.6.3.3 Immersion Test}

Following the leakage test, each sample must be subjected to the immersion test specified in 10 CFR 71.75 .

\section{A.6.3.4 Appendices}

Supplemental information, such as test data that support the containment evaluation, must be submitted.

\section{A6.4 Proceduree}

The review areas in Subsection A.6.2 are reviewed for completeness and compliance with the acceptance criteria in A.6.3. The applicable review procedures in Section 6.0 of this review guide provides guidance in several areas. Verify that the special issues in Subsection A.1.2 of this appendix have been adequately evaluated for qualifying the special form radioactive material throughout its life cycle.

\section{A7 REVIEW OF OPERATING PROCEDURES}

\section{A.7.1 General}

A special form radioactive material may be subjected to many different handling and transport operations as well as different storage cunditions during the life cycle of the material. During its life cycle, each piece from a batch of special form radioactive material may have a different history than the other pieces from the same batch. 
Therefore, each piece of special form radioactive material should be identified by a batch number and a serial number. All operations, including but not limited to handling, transporting, storing, and using, which involve a given piece of special form radioactive material, should be recorded under the batch number and serial number of the piece. Procedures should be written for all operations and should include record forms for tracking each form piece. Records should accompany each piece of material and be stored in an information center so that they can be accessed readily for quality assurance or for periodic verification of the piece as a special form radioactive material.

\section{A.2. Areas of Review}

The areas of review for operations involving special form radioactive material include the following areas.

\section{A 7.2.1 Identification and Tracloing}

Each piece of special form radioactive material should be identifiable and able to track throughout its lifetime.

\section{A.7.22 Operation and Records}

Procedures, including record keeping, should be presented for all anticipated operations.

\section{A.7.3 Acceptance Criteria for Operations}

The Operating Procedures section of the Safety Analysis Report (SAR) is a supporting document to the final Operating Procedures document that is prepared by each user of the special form radioactive material. The SAR should contain all specific information related to operating procedures for the special form radioactive material. ine procedures should demonstrate that there is no unacceptable risk to the public or operating personnel during all operations involving the special form radioactive material.

\section{A.7.3.1 Identification and Tracking}

Each piece of special form radioactive material must be marked with a batch and serial identification number that is easily readable throughout the life cycle of the material. 


\section{A7.22 Operating Procedures and Records}

Procedures must be presented for all anticipated operations, including but not limited to handling, transporting, storing, and using the special form radioactive material. Where applicable, procedures must include clear statements of both the permissible and prohibited operations. A procedure must be included and implemented for recording operations, maintenance, conditions of storage, and abnormal incidents for each piece of special form radioactive material. In addition, the location of each piece of special form radioactive material must be recorded. The records must be maintained in a central, accessible lucation for the life of we material.

\section{A.7.4 Procedures}

The review areas in Subsection A.7.2 are reviewed for completeness and compliance with the acceptance criteria in A.7.3. Verify that the special issues in Subsection A.1.2 of this appendix have been adequately addressed for operating the special form radioactive material throughout its life cycle.

\section{A9.0 REVIWW OF ACCEPTANCE TESTS AND MAINTENANCE PROGRAM}

\section{A.B.1 General}

A special form radioactive material may be used and stored for long time periods between shipments. The operations environment may cause degradation of the containment function, resulting in a compromise of the ability of the special form radioactive material to resist dispersion of radionuclides into the environment under normal or accident conditions. Therefore, acceptance tests should be performed on the special form radioactive material prior to its first shipment and all shipments following long-term storage, extended operation, or abnormal incidents. Likewise, a maintenance program should be defined to periodically ensure that no significant degradation of the containment function occurs.

\section{A8.2 Areas of Review for Acceptance Tests and Maintenance}

The areas of review required for acceptunce tests and maintenance of special form radioactive material include the following. 


\section{A.8,2.1 Acceptance Testa}

Acceptance tests should be reviewed to ensure that the special form radioactive material functions as a special form radioactive material, especially prior to shipment.

\section{A.8.2.2 Maintenance}

The maintenance program should be reviewed to ensure its adequacy over the life cycle of the special form radioac'ive material.

\section{Ads Acceptance Criteria for Acceptance Teuts and Maintenance}

The acceptance criteria for acceptance tests and maintenance of special form radioactive material are given $\mathbf{l}$ low.

\section{A.8.3.1 Acceptance Tests}

The applicent must specify acceptance tests to be performed prior to the shipment of special form radioactive material. The tests must demonstrate that the material will function as special form radiaac ive material during transport, under all conditions. The test procedures must be describəd, standards must be identified, and implementation of the tests must be assured. AB a minimum, leakage testing per ANSI N14.57 must be performed. Testing procedures present in ISO/TRA826-1979(E) ${ }^{8}$ may also be used, but must be performed in accordance with ANSI N14.5 test requirements and 10 CFR 71.75.

\section{A.8.3.2 Maintenance}

The applicant must describe maintenance tests and procedures to ensure that the special form radioactive material remains qualified over its life cycle. A maintenance sche Jule for the special forr radioactive material consistent with the expected degradation of the material properties with time must be specified. The special issues in Subsection A.1.2 must be addressed in the maintenance program and schedule. A statistiral sampling plan for the maintenance tests must be presented. The number of sample. required to represent the batch from which the samples are drawn must be determined. The prescribed maintenance schedule, including completion dates, must be entered into the records specifie in Section 7.3.2. 


\section{A.4.4 Procedures}

The review areas in Subsection A.8.2 are reviewed for completeness and compliance with the acceptance criteria in A.8.3. Verify that the special issues in Subsection A.1.3 of this appendix have been adequately addressed for maintaining the special form radioactive material throughout its life cycle.

\section{A.0 REIFERENCES}

1. U.S. Department of Energy, DOE 5480.3: Safety Requirements for the Packaring and Transportation of Hazardous Materials, Hazardous Substances, and Hazardous Wastes, U.S. Department of Energy, Washington, DC, August 9, 1985.

2. Office of the Federal Register, Title 10. Code of Eederal Regulations, Part 71, Office of the Federal Register, Washington, DC, 1985.

3. Office of the Federal Register, Title 49. Code of Federal Repulations, Part 173, Office of the Federal Register, Washington, DC, 1985.

4. U.S. Department of Energy, DOE 1540.2: Hazardous Material Packacing for Transport-Administrative Procedures, U.S. Department of Energy, Washington, DC. September 30, 1986.

5. Hovingh, J., Review Guide for Certification of a Syecial Form Radioactive Material, UCID Draft, Lawrence Livermore National Laboratory, Livermore, CA, Draft 1989.

6. U.S. Department of Energy, DOE 5700.6B: Quality Assurance, U.S. Department of Energy, Washington, DC, September 23, 1986.

7. ANSI N14.5-1987, American National Standard for Radioactive Materials-Leakage Tests on Packages for Shipment, American National Standards Institute, Inc., 1430 Broadway, New York, NY 10018, January 16, 1987.

8. ISO/TR4826-1979(E), Sealed Radioactive Sources-Leak Test Methods, available from American National Standards Institute, Inc., 1430 Broadway, New York, NY, 10018, February 15, 1979. 